\title{
MOVING 'OUT,' MOVING ON:
}

\section{GAY MEN'S MIGRATIONS THROUGH THE LIFE COURSE}

\author{
By
}

\author{
Nathaniel M. Lewis
}

A thesis submitted to the Graduate Program in the Department of Geography

in conformity with the requirements for the

Degree of Doctor of Philosophy

Queen's University

Kingston, Ontario, Canada

March, 2012

(C) Nathaniel McAllister Lewis, 2012 


\section{Abstract}

This thesis explores how gay men make migration decisions through the life course. Recent studies of queer migration fall into two categories: (1) the role of the state and its heteronormative policies (e.g., family reunification-based immigration policy or criminalized homosexuality) and (2) queer migrations within countries, which employ narrative approaches but often presume a linear, usually rural-to-urban trajectory of migration among young queer people fleeing one place and emancipating themselves elsewhere. This study nuances the dynamics of migration decision-making among gay men, adopting a life course approach that examines how historical and social contexts, institutions, and individual circumstances and subjectivities convene to shape migration trajectories.

For this research, I use the migration narratives gay men living in two citiesOttawa, Ontario, Canada, and Washington, D.C., U.S.A.- to capture the dynamics of migration decision-making in two different locational contexts. 48 interviews with Selfidentified gay men (24 in each city) ground this study. Respondents were asked about their reasons for migrating, the community, home, and family environments in sending and receiving places, changes in aspects of health, well-being, and relationships before and after migrating, and aspects of everyday life after moving to Ottawa or Washington, D.C. The focus on two capital cities was adopted not only to examine places that draw internal migrants from a variety of places, but also to elaborate on the dynamics of gay life in two mid-sized cities overlooked in sexuality and space literature, and on the ways in which the institutions of these two "government towns" have simultaneously attracted and regulated gay men and other sexual minorities. 
I advance several findings in this study. First, coming-out migrations are both much less linear than traditionally conceived and are influenced more by the internal social dynamics of places than flat characterizations of places as homophobic or backward. Second, the dynamics of the places that gay men leave and come to are often quite literally embodied in terms of health and well-being. Third, the government town is a paradoxical place that has been queered by the emergence of gay rights-seeking and advocacy regimes, yet continues to regulate gay men's lives in diffuse ways. 


\section{Acknowledgements}

I would like to thank my advisor, Dr. Audrey Kobayashi, for her support of this research and my development as a scholar. She not only helped me to conceive this project, but has provided guidance on applications, publications, and numerous other aspects of my career.

The faculty and staff at the Department of Geography at Queen's University have been exceptionally helpful to me during the past four years. In particular, I would like to thank Dr. Betsy Donald and Dr. Mark Rosenberg for their assistance with this thesis and with the preparation of other articles, as well as Dr. Kathleen Lahey (Faculty of Law), Dr. Mary-Louise Adams (Kinesiology, Cultural Studies) and Dr. Benjamin Forest (Department of Geography, McGill University), for serving on my thesis committee. I would also like to thank my mentors in the sexuality and space community, including Dr. Michael Brown, Dr. Larry Knopp, Dr. Robert Vanderbeck, and especially Dr. Andrew Gorman-Murray. Their insights have been especially helpful in the development of this project and other areas of my work. Thanks are also due to Sheila MacDonald, Joan Knox, Kathy Hoover, and Sharon Mohammed for their assistance with multiple teaching duties and grant and conference applications.

I gratefully acknowledge the support of Queen's University, the Association of American Geographers, and especially the Social Sciences and Humanities Research Council of Canada for supporting my research through the Vanier Canada Graduate Scholarship. I am particularly indebted to the 48 men and the various members of the gay service and advocacy communities in Ottawa and Washington, D.C., for their participation in my research, without which the project would not have been possible. 
Thanks also to editors and reviewers at Social \& Cultural Geography and Gender, Place and Culture, where portions of this research (versions of Chapters 6 and 9, respectively) have been published.

Friends inside and outside of academic geography have been especially supportive during the Ph.D. process, particularly Catherine Fraser, Drew Bednasek, Yolande Pottie-Sherman, Gentry Hanks, Candice Christmas, Nicholas Brown, Kirsten Greer, Steven Everhardus, Giselle Valarezo, Adam Sleeter, Marc Silverman, Madeleine Wilcox, Brian Harman, Nickolas Tzoulas and Chad Foreman. My parents, Judy McAllister-Lewis and Deane Lewis, along with my sister, Emma Lewis, are the most important sources of love and support in my life and career. 


\section{Table of Contents}

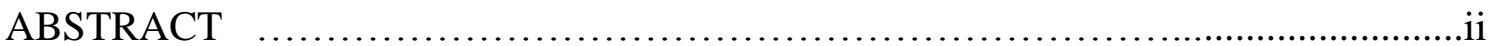

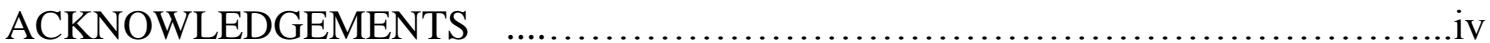

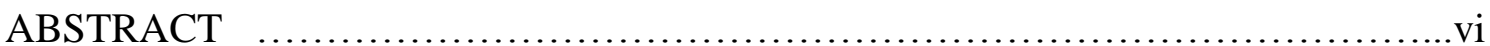

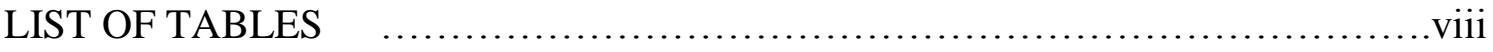

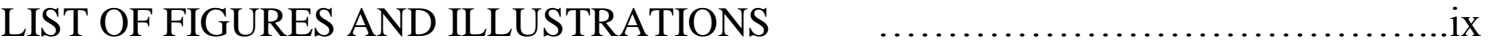

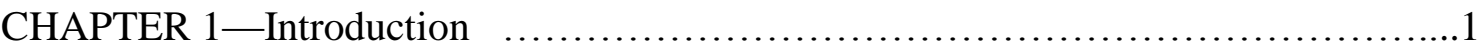

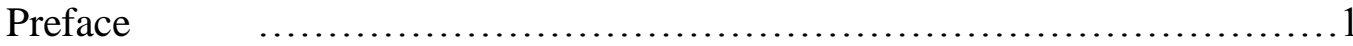

1.1 Queer Migration in the North American Imaginary $\quad \ldots \ldots \ldots \ldots \ldots \ldots \ldots \ldots \ldots . .2$

1.2 - Complicating Queer Migrations: An Empirical Approach ………….....4

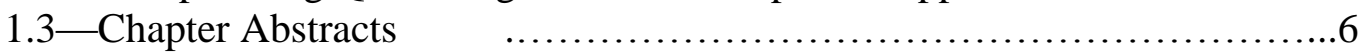

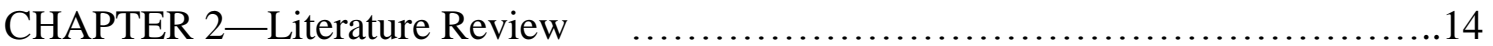

2.1-Migration Theory and Sexuality $\quad$..................................14

2.2-Medicalizing Migration: Gay Men and the Diffusion of HIV/AIDS …16

2.3-Queer Consumers: Viewing Gay Migration through an Economic

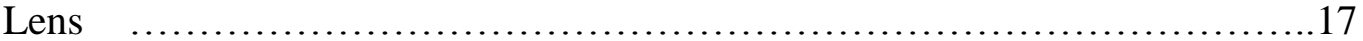

2.4-Sexuality and Space or Sexuality and the City? $\quad$....................19

2.5-De-Centering Sexualities $\quad$.......................................24

2.6-From Places to Flows: New and Emerging Studies of Queer

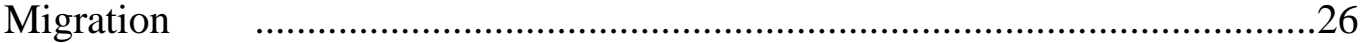

2.7-Between Body and State: Gaps in the Study of Queer Migration _...29

2.8 - Toward a Life Course Approach in Queer Migration Studies ..............32

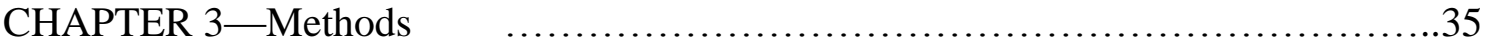

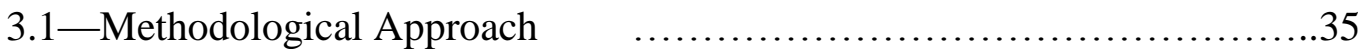

3.2 - Queering the Capital: Selection of Study Sites …......................36

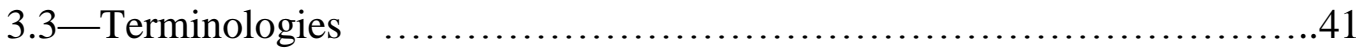

3.5-Interview Design $\quad$............................................... 44

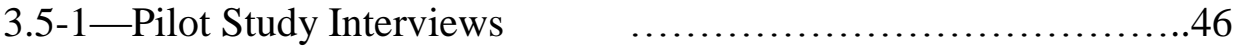

3.5-2-Revised Interviews $\quad$......................................47

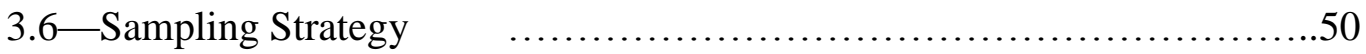

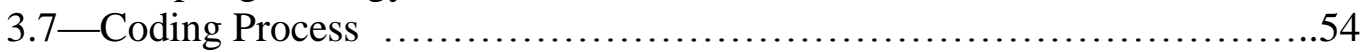

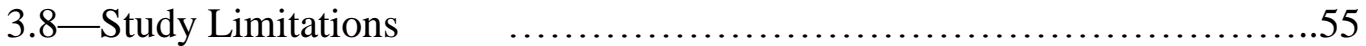

CHAPTER 4-Gay Men's Migrations from a Life Course Perspective ...............58

4.1-The Life Course as a New Approach to Human Development ..............58

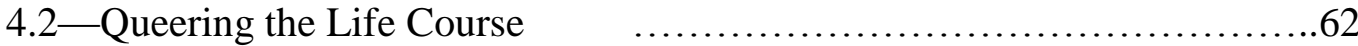

4.3-Integrating Mobility into the Queer Life Course $\quad . . . \ldots \ldots \ldots \ldots \ldots \ldots . . . .64$

4.4-Maturation, Identity Formation, and Mobility among Gay Men $\quad$.....70

4.5—Placelessness to Permanence: Migration, Networks, and Social

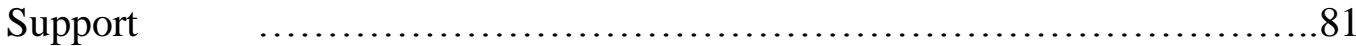

4.6. - Institutional Infrastructure and Community Identities ....................86

4.7-Changing Historical Contigencies $\quad$................................. 91

4.8 - The Myth of the Homeland and 'New' Complexities of Queer

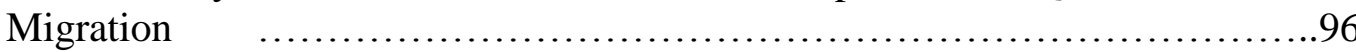


CHAPTER 5-Beyond Binary Places: Everyday Geographies of Moving Out as

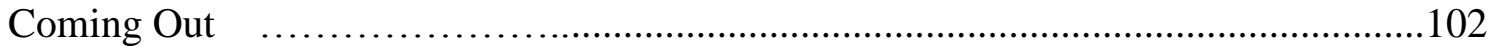

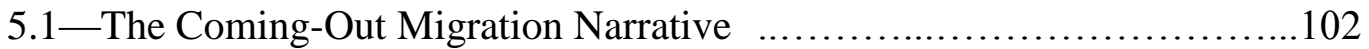

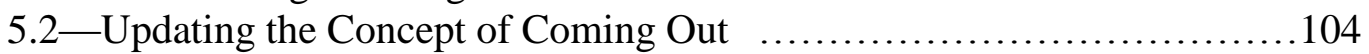

5.3 - Complicating the Role of Place in Coming-Out Migrations ...........106

5.4 - There was probably a Little Voice in me: Recognizing Difference,

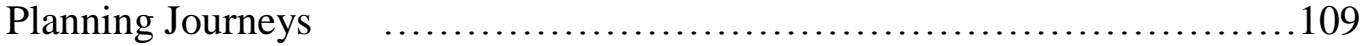

5.5-'Waiting for things to Happen:' Moving Out to Move Forward ‥112

5.6 - 'There is that Fear ...:' Moving due to Possible Rejection ...........117

5.7— 'New City, Nobody Knew Me:' Moving Out to Seek Anonymity _..119

5.8 - 'So I really do it for my Mother:' Moving Out to Mitigate Social and

Familial Burdens $\quad$................................................ 123

5.9- The Importance of the Everyday: Seeing the Grey Zones of Queer

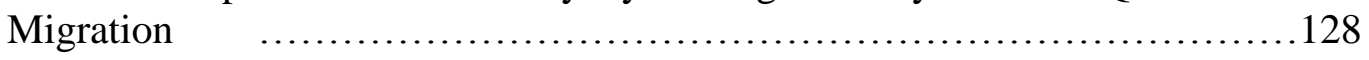

CHAPTER 6-Segmented Journeys of Moving Out as Coming Out _.........133

6.1-One-Way Journeys: Linearity in the Coming-Out Migration

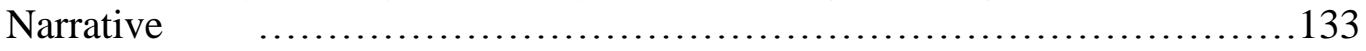

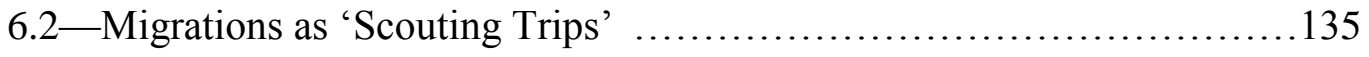

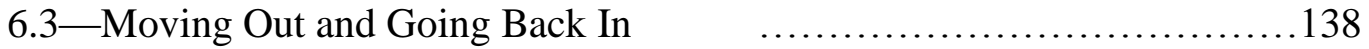

6.4-Migrations as Coming-Out Tests and Triggers .........................141

6.5-Journeys in the City: Encountering the Imagined 'Community' _..144

6.6-Journeys 'Back Home' ............................................ 147

6.7-Conclusion: Rethinking Moving Out as Coming Out ................150

CHAPTER 7-Embodied Emigrations: Health Experiences and Migration

Decision-making $\quad$................................................... 154

7.1 - Connecting Queer Migration and Health $\quad \ldots \ldots \ldots \ldots \ldots \ldots \ldots \ldots . \ldots . \ldots . \ldots 154$

7.2 —Embodied Emigration: Emotional Experiences of 'Out-of-Placeness' ...159

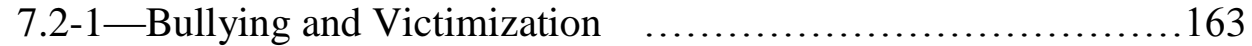

7.2-2 - Concealing Sexuality ...................................165

7.2-3 - Embodying Stress: Anxiety, Depression, and Suicide

Ideation $\quad$...............................................169

7.3 - Health After Migration: Encountering 'The Scene,' Encountering

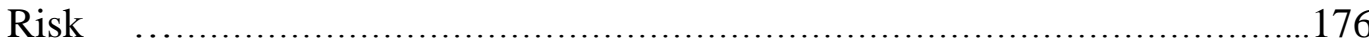

7.4-Minority Stress and Migration: The Qualitative Perspective $\quad . . \ldots . . . .183$

CHAPTER 8-Migration as Security: Capital Cities as New Homelands? ...........189

8.1. Introduction $\quad$................................................. 189

8.2. Precarious Positions: Migration as a Negotiation of Uneven

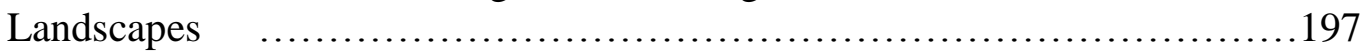

8.3. Precarious Positions, Part Two: Conceiving Risk at Work .........205

8.4. Seeking Security: Discursive Constructions of the Capital City ...........209

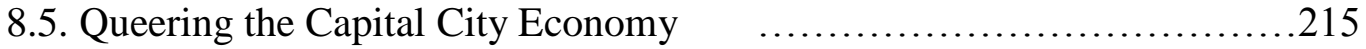

8.5-1. Legislative and Policy Changes ...........................213

8.5-2. The Emergence of Gay Workplace Organizations $\quad$..........215 
8.5-3. Synergies between the Government and Advocacy Sectors ..217 8.5-4. The Network Effect: Social Dynamics of the Capital-City Gay Economy

8.6. New Migrations, New Homelands $\quad$..............................222

CHAPTER 9-Gay in a Government Town: Experiences of Relocation and

Regulation .227

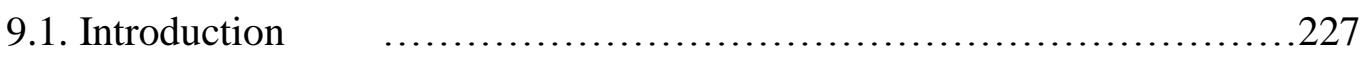

9.2. Situating and Contextualizing Ottawa and Washington, D.C. .............231

9.3. Historic Governmentalities in Ottawa and Washington, D.C. ..........2234

9.4. Ottawa and Washington, D.C. in National Struggles for LGBT

Advancement ...................................................................239

9.5. Government Cultures and the Fragmentation of Gay Communities _..247

9.6. The Continued Entrenchment of Government in Gay Men's Everyday

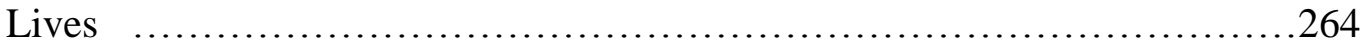

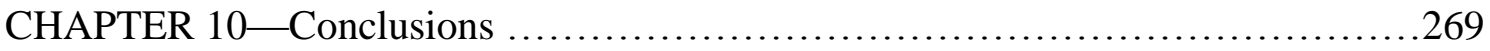

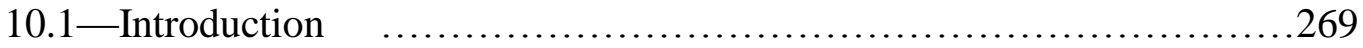

10.2 - Revisiting the Literature $\quad$.......................................269

10.3 - The Value of a Life Course Approach $\quad$..........................2.273

10.4 - Limitations: Those Who Cannot Migrate and Those Who Must _..279

10.5-The Role of Scale and Hierarchy in Gay Men's Migrations ..........283

10.6 - Between Body and Place: The Relational Nature of Queer

Migration $\quad$...........................................................28 287

10.7- Ongoing Experiences: Coming Out and the Regulation of Sexuality ...289

10.8 - Questioning 'the New Homonormativity' .........................290

10.9 - Toward Holistic and Contingent Concepts of Queer Migration _...292

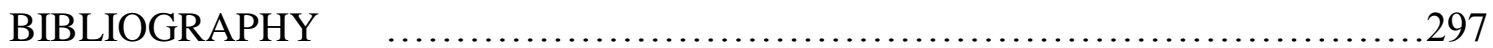

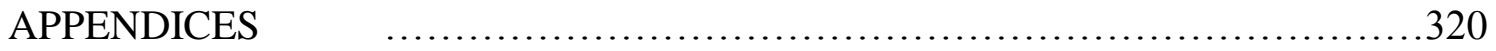




\section{List of Tables}

Table 3.1-Proportions of Same-Sex Partnered Households among All Partnered Househoulds, Canada, Ottawa-Gatineau, Toronto, Vancouver, and Montreal CMAs, 2006

Table 3.2-Proportions of Same-Sex Coupled Households among

All Coupled Households, United States and MSAs with Highest

Concentrations of Same-Sex Couples, 2000

Table 3.3-Demographic Characteristics, Sample of Self-identified Gay Men (N=24), Ottawa, Ontario, Canada

Table 3.4-Demographic Characteristics, Sample of Self-identified Gay Men (N=24), Washington, D.C., U.S.A.

Table 4.1-Life Course Events Occurring at Time of Migration, Sample of

Self-identified Gay Men (N=24), Ottawa, Ontario, Canada

Table 4.2-Life Course Events Occurring at Time of Migration, Sample of Self-identified Gay Men (N=24), Washington, D.C., U.S.A.

Table 4.3 - Gay Rights Advancements, Canada and the United States, 1968-Present

Table 5.1 - Sub-themes Related to Coming Out, Sample of Self-identified Gay Men (N=48), Ottawa, Ontario, Canada, and Washington, D.C., U.S.A

Table 7.1-Sub-themes Related to Health Experiences, Sample of SelfIdentified Gay Men (N=48), Ottawa, Ontario, Canada, and Washington, D.C., U.S.A.

Table 8.1-Sub-themes Related to Economic Migration, Sample of SelfIdentified Gay Men (N=48), Ottawa, Ontario, Canada, and Washington, D.C., U.S.A.

Table 8.2 - Most Important Reasons for Moving, Occupations, and Incomes Sample of Self-identified Gay Men (N=24), Ottawa, Ontario, Canada

Table 8.3-Most Important Reasons for Moving, Occupations, and Incomes, Sample of Self-identified Gay Men (N=48), Washington, D.C., U.S.A.

Table 9.1. Sub-themes related to Rights and Regulations, Sample of SelfIdentified Gay Men (N=48), Ottawa, Ontario, Canada, and Washington, D.C., U.S.A. 


\section{List of Figures and Illustrations}

Map 3.1-Place Moved From, Sample of Self-identified Gay Men (N=48), Ottawa, Ontario, Canada and Washington, D.C., U.S.A.

Figure 4.1-Factors Driving Migration across the Gay Life Course

Figure 4.2-Migration to Ottawa by City Type of Origin and Age at Time of Migration, Sample of Self-identified Gay Men (N=24), Ottawa, Ontario,

Canada

Figure 4.3-Migration to Washington, D.C., by City Type of Origin and Age at Time of Migration, Sample of Self-identified Gay Men $(\mathrm{N}=24)$,

Washington, D.C., U.S.A.

Figure 4.4-Migration to Ottawa and Washington, D.C., by Place of Origin and Age at Time of Migration, Full Two-City Sample of SelfIdentified Gay Men (N=48)

Figure 4.5-Next Anticipated Migration, by City Type of Destination and Age at Time of Interview, Sample of Self-identified Gay Men (N=24), Ottawa, Ontario, Canada

Figure 4.6-Next Anticipated Migration, by City Type of Destination and Age at Time of Interview, Sample of Self-identified Gay Men (N=24), Washington, D.C., U.S.A.

Figure 4.7-Next Anticipated Migration, by City Type of Destination and Age at Time of Interview, Sample of Self-identified Gay Men (N=48), Ottawa, Ontario, Canada, and Washington, D.C., U.S.A. .76

Figure 7.1.-Place-Based Determinants of Minority Stress and Health Outcomes among Gay Men and Other Sexual Minorities 


\section{CHAPTER 1}

\section{Introduction}

\section{Preface}

When I began this Ph.D. thesis project, I immediately began looking for a phrase that would answer the inevitable question, "So, what are you studying?" Gay migration, I decided, was a term that adequately described what I was studying without burdening those who were being polite but not really interested. The inevitable follow-up from most, however, was not a prompt to explain more about the project, but an assertion of their implicit understanding of the topic: "Oh, so you study how gay people move to cities." The first few times this happened, I tacked back and forth between trying to engage and affirm ("Well, that's definitely part of it.") and the need to show the complexity of the project ("It's much more than that."). After all, I had chosen to study gay men's migrations to two cities - Ottawa, Ontario, and Washington, D.C., U.S.A.seemingly validating the claims that individuals with non-normative sexual identities (i.e., queer people $)^{1}$ tend to move to cities.

Yet, I also wanted to show what contributes to the centrality of migration in the lives of gay men and perhaps queer people, how migration decisions are made, how these decisions are contingent upon age, class, and background, and how the processes and

\footnotetext{
${ }^{1}$ Here, the term "queer" is used to signify those whose sexual identities diverge from heterosexual norms, including gay men. Despite its presumed ability to capture the diversity and fluidity of sexualities, the term "queer" has been critiqued as an inappropriately universalizing term. Some presumably queer people may not identify as such. Others view it as Western construction that only applies to places that experienced the advent of "gay" as an identifier for sexual non-normativity (itself a response to the emergence of "homosexual" as category in the $20^{\text {th }}$ century), followed by a subsequent shift to "queer" as a more critical and fluid signifier (see Jackson 2001; Green 2002). Since the respondents in this study self-identify as "gay," this term is used when discussing their experiences or those of other gay men. Queer, while employed by some to purposefully transgress the rigidity of categories such as "gay," is used here to denote the broader idea of sexual non-normativity and highlight portions of this study where the findings are potentially applicable to people whose identities might be perceived as sexually non-normative.
} 
pathways of queer migration change depending on the migrant's origins and destinations — especially those beyond the rural hinterlands and metropolitan homelands between which queer migrants are thought to travel. I began to respond to those who understood my project through a rural-urban framework with a "yes, but ..." type of response. Yes, gay men may move to cities, but it's more often from another city than from a rural area. Yes, they may leave due to experiences of stress or perceived homophobia, but not always because a place is inherently homophobic. Yes, migration is often central in the lives of gay men, but the role and trajectory of migration may change at different points in the life course. The following thesis is therefore about the various contingencies and subjectivities that shape gay men's migration narratives. The objective of the project is to see queer intra-national migrations beyond the linear, unidirectional, and often emancipatory frameworks through which they have traditional been viewed.

\subsection{Queer Migration in the North American Imaginary}

During the past decade, discourses of exclusion, discrimination, and flight have appeared in various forms in the mainstream North American media. In a scene from Milk, the 2008 film portraying the life of openly gay San Francisco city councilman Harvey Milk, the would-be mayor gives the following advice to a teenager calling his campaign headquarters from Minnesota: "There's nothing wrong with you, listen to me. You just get on a bus, to the nearest big city, to Los Angeles or New York or San Francisco, it doesn't matter, you just leave. You are not sick, and you are not wrong and God does not hate you. Just leave" (IMDB 2011). The recent It Gets Better media campaign, sponsored by The Trevor Project (a U.S. LGBTQ youth suicide hotline) and 
the Gay, Lesbian and Straight Education Network (GLSEN), employs celebrities to tell gay teenagers that anti-gay discrimination dissipates as they gain the opportunity toamong other things - move out. A collection of these narratives, It Gets Better: Overcoming Bullying, Coming Out, and Creating a Life worth Living (Savage and Miller 2010), offers a similar message of passive encouragement, delivered by people in positions of privilege and critiqued by activists (see Puar 2010) as a problematic directive to turn blame and guilt into all-American success without really resisting its root causes.

Another problem with these portrayals, and with the imaginary of queer migration more broadly, is the narrow treatment of mobility. Media-based and even scholarly portrayals of queer migration (see Plummer 1995; Weston 1995; Cant 1997; Parker 1999; Maddison 2002) have tended to rely on the construction of binaries such as conservative/liberal, rural/urban, and developed/developing. In an intra-national context (the focus of this thesis), migration for queer people emerges as a linear, often final process in which one place - assumed to be incompatible with one's sexuality —is exchanged for another, usually urban, place more conducive to the development of a gay identity. Even work that gives a more nuanced treatment to issues of global and transnational circuits of sexual practice and identity still conceive of queer flows within countries as rural-to-urban (see Binnie 2004). Conceiving queer migration in this way not only ignores the mutual constitution of place and identity, but flattens the notion of place itself. Places are cast as inherently safe, accepting, dangerous, or homophobic, while the ways in which subjectivities such as age, race, and class inform experiences of those places are secondary. Moving to New York or San Francisco therefore becomes a narrow, linear trope used to signify what is actually the negotiation of multiple landscapes 
(including homes, neighbourhoods, and countries) rendered uneven by the continued construction of homosexuality as a deviant category of the population in need of regulation (Halperin 2000; Olund 2010).

The conception of queer migration as rural-to-urban flight is partially historical in its origins. Chauncey (1994), for example, elaborates how the migration of single workers to cities such as New York during the Industrial Revolution gave rise to queer subjectivities and communities that disrupted the perceived norms of heterosexuality and the nuclear family structure. In her own portrayal of queer migration in the United States about 50 years later, Kath Weston (1995) frames cities such as New York and San Francisco as homelands to which rural and small-town gay men and lesbians moved as they sought out queer compatriots and a stake in the United States' emergent gay rights

movement. Interestingly, framings of queer migration as a phenomenon based on national and regional oppositions have persisted despite an increasingly connected world (Munt et al. 2002; Bryson et al. 2006) and more inclusive (yet still uneven) regimes of queer rights in North America (Lind 2004; Smith 2005a).

\subsection{Complicating Queer Migrations: An Empirical Approach}

Many have suggested that further empirical studies are the key to challenging oversimplified understandings of queer intra-national migrations (Knopp and Brown 2003; Knopp 2004; Gorman-Murray 2007, 2009). While much empirical work has been done to "de-center" the assumed urbanity of sexual non-normativity (Osborne and Spurlin 1996; Fellows 1998; Phillips et al. 2000; Knopp and Brown 2003; G. Brown 2008) and the ways in which queer migrants are regulated at the borders of nations with 
heteronormative immigration policies (Manalansan 2006; Lubhéid 2008), relatively little has been done to complicate the origins and trajectories of intra-national queer migration flows themselves. Much of the existing work in this area is conceptual, reframing these journeys as personal, peripatetic searches for identity emerging from within queer individuals (Fortier 2001; Knopp 2004). Although this work has been extended in productive ways, such as conceiving of queer migrations as embodied journeys (GormanMurray 2007), focusing on the body does not always acknowledge the social contexts in which queer migrations originate. They emerge not simply from the emotions and desires contained within the body or from place attributes such as laws, politics, and practices, but from a dialectical interaction of individual queer lives and the social contexts (e.g., cultures, families, and social networks) in which they are embedded. These contexts are not only geographically fluid but also temporally fluid over the course of queer lives. Finally, I seek to fill a geographic gap in the study of intra-national queer migration by focusing on Canada and the United States. Among the major studies conducted thus far, few have focused on North America (Weston 1995 being a notable exception), with the remainder conducted in the United Kingdom (Cant 1997), Brazil (Parker 1999), and Australia (Gorman-Murray 2009).

This thesis therefore seeks to contribute to the ongoing project of exploring queer migration journeys, namely by: (1) challenging the linearity and finality of those journeys; (2) highlighting the importance of micro-level factors such as age, life stage, health status, ethno-racial identity, career trajectories, and familial and social networks in these journeys, and (3) filling a geographic gap in this area of study. More specifically, this thesis demonstrates that the challenges of sexual non-normativity arise continually 
throughout the queer life course, and that migration is both a means of negotiating these challenges and a vehicle through which individual life courses are continuously redirected. In making this argument, I also seek to answer the following questions:

(1) How is the ongoing process of coming out—including coming out in a variety of environments or "scales" (e.g., the family home, the university, the work force, the neighbourhood)—mediated by migration?

(2) How are gay men's experiences of place embodied in terms of emotion, behavior, and health, and how do these embodiments influence their migration decisions, or conversely, become influenced by moving elsewhere?

(3) How do the uneven landscapes of stigma, social acceptance and human rights that gay men encounter at multiple scales (e.g., home, family, community, country) mediate their migration decisions?

(4) What are some of the variations in queer migration journeys and are particular variations associated with particular life events or life stages?

\subsection{Chapter Abstracts}

I answer these questions over the course of nine remaining chapters. Although each of the chapters has been written to stand on its own, they follow both a scalar and temporal progression. After a literature review on queer migration, a synopsis of a life course approach to queer migration, and a brief discussion of methods (particular variations in coding or theme selection are discussed within chapters), the next three chapters (5-7) address the micro-scale of intra-national queer migrations. These chapters focus on narratives of coming-out journeys, embodied health experiences associated with 
migration, and the social, familial, and community contexts associated with coming out and pre- and post-migration health experiences. In contrast, the last two chapters preceding the conclusion (8-9) are more concerned with the macro-structures mediating queer migrations and livelihoods, particularly the political economies and regulatory bodies found in the capital cities that serve as the case studies for this thesis. Every chapter, to some extent, addresses the interaction of macro-structures (e.g., laws and institutions) with the circumstances and subjectivities of the 48 men whose stories form the basis of this thesis. At the same time, over the course of the thesis there is a general scaling outward from the individual men's bodies to the structures of the cities, regions, and nations they inhabit and traverse.

The remaining chapters also roughly correspond to stages in the life course. Although this thesis aims to avoid abstract, developmental understandings of the queer life course and acknowledges that stages such as coming out and entering the labour market may happen simultaneously or in unexpected orders, it also strives to explore in a structured manner how gay men use migration to negotiate particular progressions of life events. Chapters 5 and 6 , which focus on coming out and migration, tend to employ early-in-life narratives. Chapter 7, which discusses the relationships between health, migration, and minority stress (i.e., stress associated with anti-gay stigma), also focuses on the experiences of younger men, particularly those who encountered homophobia in school and community environments prior to moving. Chapters 8 and 9, in contrast, address the experiences of men later in life, particularly as they seek to enter the labour market and establish identities based on community and political engagement, and sometimes marriage or adoption. Finally there is a gradual transition from migration 
pushes to pulls, although both are depicted here in a manner less deterministic than that found in earlier migration theories. Each chapter devotes attention to both pushes and pulls, but Chapters 5-7 focus more on experiences giving rise to gay men's out-migration while Chapters 8-9 discuss the particular factors that attracted gay men to Ottawa and Washington, D.C., and the ways that their lives changed following migration.

Chapter 2, the literature review, places this study in the context of an "unruly" literature on queer migrations and livelihoods (Lubhéid 2008). I explain here that while literature on queer places and spaces (e.g., homes, neighbourhoods, and ephemeral spaces such as parades and protests) has become more geographically nuanced (see Phillips et al. 2000; Markwell 2002; Binnie and Skeggs 2004; Johnston 2007; Waitt and GormanMurray 2007), much of the literature on queer migration has relied on essentialized understandings of the relationships between non-normative sexuality and mobility. Many studies are predicated on assumed geographic binaries between tolerant cities and conservative countrysides or between the enlightened West and a backward developing world. Still others draw implicit links between gay men's bodies and illness, often pointing to HIV/AIDS as a force of return migration (Cohn et al. 1994; Ellis and Muschkin 1996). While there is value in these discourses - the migration of gay men very much can be the product of concerns about health or the policies and practices of places - they need to be placed in the context of men's circumstances, subjectivities, and the networks and institutions within which they are embedded.

The methods for this project are discussed in Chapter 3, where I outline the semistructured interview as a research tool and my particular positionality as a gay man studying gay men's migrations. I discuss a pilot study conducted in Ottawa in September 
2009 and the change in approach (i.e., from ranking exercises to simpler, open-ended questions) as well as a shift from the specific lens of mental and emotional health to the more general lens of the life course. Finally, I address some of the limitations of the study, particularly the challenges of having respondents look back to experiences such as coming out and its relationship to moving away.

Chapter 4 offers the life course as a lens through which variations or modes of gay migration can be revisited. Building on life course theory and brief portions of interview material, this chapter offers a framework for thinking about how the distinctive life courses of gay men might give rise to migration. Each of the key factors thought to influence the life course (e.g., age, historical contingencies, and institutions)—along with interactions among those factors - might also contribute to the migration decisions of gay men. Using a life course framework provides an alternative to explanations of queer intra-national migration that rely too heavily either on place binaries or highly individualized, wandering identity quests. The objective of this chapter is not to establish stage-sequential typologies of gay migration, but to consider the possibilities of how age and life circumstances, mediated by the historical, social, and cultural particularities of places, might inform the migration decisions of gay men.

The substantive empirical portion of the thesis begins in Chapter 5, which highlights the centrality of moving out to come out in the lives of gay men. Here, I explain that coming-out migrations, while for some men more mundane and everyday in nature than those described in narratives of displacement and emancipation (Plummer 1995; Puar et al. 2003; Knopp 2004), are still driven by the ongoing construction of homosexuality as a deviant, problematic identity. Yet the stigmatization of being gay 
does not always manifest in obvious ways such as familial disownment; instead it emerges in more diffuse ways, including expectations of rejection, management of expected familial and social burdens, and the recognition of an uneven landscape of social acceptance. The majority of coming-out migrations, then, are less attributable to the characteristics of places (e.g., political and religious leanings, urban or rural proximity) than they are to the social dynamics encountered by queer individuals in places. In other words, the desire to move — sometimes several times_during a comingout process emerges from the contingencies of families, social networks, relationships, careers, and other circumstances embedded in places but not always aligned with dominant understandings of those places.

In Chapter 6, I shift from the role of places - and the social contexts embedded within them — to the actual trajectories, or flows, of men's migrations during coming out. Here, I challenge the ontological and teleological finality of coming-out migrations as they have been conceived thus far; i.e., as the disclosure of a fully-formed gay identity before or after moving to and resettling in a singular location. I reframe coming out migrations as ongoing journeys that, while often occurring earlier in life, may traverse many locations and last several years. I also offer some variations on the theme of moving out as coming out, including: scouting trips to assess the gay life potentials of different destinations, moving out and going back in (the closet), migrations used as tests of one's sexuality, and journeys within the city, and journeys home to places previously lived - often to disclose changed or changing sexual identities to friends or family. This chapter, in conjunction with Chapter 5, also establishes that coming out is not an 
individual journey but an intricately social and relational process that occurs in the context of place-embedded networks of friends, families, colleagues, and communities.

Chapter 7 argues that queer migrations are not only ongoing and highly individualized, but often quite literally embodied processes that affect—and are affected by—aspects of mental, emotional, and physical health. Here, I use the semi-structured portions of interviews to assess and discuss how health factors such as anxiety, depression, alcohol and drug use mediated men's most recent migrations to Ottawa or Washington, D.C. Building on both the minority stress literature from psychology and qualitative geographic work on the body and embodiment (particularly that which examines queer migration at the scale of the body), I introduce the concept of migration as a mode of self-care in the lives of queer people. This chapter not only provides qualitative accounts of stress in gay men's lives, but connects them to decisions about migration. I also discuss some of the health risks (e.g., alcohol abuse, low self-esteem, and social isolation) that men experience upon moving to new and unfamiliar cities and particularly as they seek acceptance into the communities and scenes they encounter.

In Chapter 8, I address gay men's motivators for migration later in life, particularly as they enter into the labour market, negotiate long-term partnerships, and establish community identities. Here, I challenge literature that frames queer migration as the product of sexual desire or consumption practices, as well as econometric literature that frames the locational choices of same-sex couples as no different than those of their heterosexual counterparts (i.e., they are based on economic rationality). Evidence from the interviews reveals that the rationales for migration, particularly later in the life course, lie somewhere between the negotiation of sexual identity and economic rationality. The 
narratives highlight intersections of men's sexual identities with the political economies of capital cities, especially the emergence of civil service sectors, the transformation of those sectors to promote the inclusion of gay men and lesbians, the concomitant emergence of capital cities as centers for gay rights-seeking, and the synergies between the civil service and advocacy sectors. These factors not only act as powerful attractors for gay men, but have led to the emergence of alternative gay economies that extend beyond often-studied configurations of bars, clubs, and social services.

Chapter 9 serves as a rejoinder to Chapter 8 by assessing how the unique political and economic configurations of the capital city affect the daily lived lives of the gay men who move there. Employing governmentality theory and building on an earlier paper on the ongoing legacies of historic gay repression in Ottawa (see N. Lewis 2011), I assess how the entrenchment of government institutions in gay men's lives - while offering a sense of political and economic security — has also created gay communities in which modes of activism, community-building, and social life are decidedly more disciplined and (hetero-) normalized than those in commonly studied cities, such as Manchester, Sydney, San Francisco, and New York. This normalization manifests in several ways, including: (1) the force of a gay federal rights-seeking agenda in Ottawa and a similar dominance of the national gay agenda in Washington, D.C.; (2) the self-disciplining of gay men in workplaces and public spaces; (3) social valuation systems based on income and government ranking; and (4) the limited visibility of gay and queer spaces. I also assert that the case studies of these two cities that for gay men, the forces of governmentality — especially as mediated by government institutions — are felt most strongly at the "center" of the state where those institutions are thickest or densest. 
Chapter 10, the concluding chapter, summarizes the ways in which the thesis has complicated intra-national queer migrations beyond the generalizations of intolerant places, flight, and emplacement in metropolitan queer homelands. I assert that queer migrations are circuitous, ongoing, and segmented, although not necessarily peripatetic, as has been indicated in past research (see Knopp 2004). In fact, they are purposeful and embodied responses to the challenges of negotiating various life course events including coming out, experiences of ill health, and entering the work force. I also suggest that the networks, linkages, and communities embedded in the places that gay men traverse are as influential in their migration trajectories (and daily lives) as perceived characterizations of places as metropolitan, liberal, or accepting. Finally, I make a complementary argument that queer lives are shaped fundamentally by the individual city-ness of the places in which they are located. 


\section{CHAPTER 2}

\section{Literature Review}

\subsection{Migration Theory and Sexuality}

Migration is an established area of study within human geography that cuts across the sub-disciplines of population, political, social, economic, and urban geography. Although the study of human migration continues to rely on the familiar concepts of push and pull factors, sending and receiving areas, and settlement and resettlement, the groups studied and the spatial rubrics through which they are studied have expanded. The oncedominant emphasis on ethnic and national immigrant groups has been replaced by a more polycentric study of migrant groups ranging from women to workers to gay men and lesbians (Silvey 2004; Nawyn 2010). The country-to-country focus, too, has been broadened to include inter-city and inter-regional movement, daily home-to-work migrations, and moves across and between neighbourhoods. The recent emergence of theoretical and empirical work on queer migrants — the focus of this project — provides an opportunity to observe the ways in which work on queer mobilities has enriched studies of both migration and sexuality in geography.

I seek here to summarize the varied and "unruly" (Lubhéid 2008) discourses in queer migration and highlight the areas that the literature has not addressed. First, I discuss the various ways in which the study of migration, over time, has begun to address some of the patterns, flows, and decision-making processes among gay men and other queer people. Second, I address the differences between deterministic economic and medical models of gay migration and more nuanced (albeit slowly emerging) understandings of queer mobilities. Third, I outline how the shifts in both the approach to 
research on migration and settlement (i.e., from quantitatively to qualitatively informed) and the scales at which they are studied (from nation to city, home, and body) have contributed to fruitful studies of gay and queer migrations and communities. Finally, I evaluate the openings left by these incisive yet disparate studies, particularly the lack of attention to how the social and cultural contexts of places-beyond simple liberal/conservative or urban/rural binaries — might drive queer migrations.

Migration theory, while becoming more nuanced over time, has historically sorted into neoclassical, structural, or systems-based frameworks. The strict neoclassical approach developed by Ravenstein (1885) and nuanced by scholars like Portes (1997) and Rumbaut (1997) explains migration as an individual decision based on selfmaximization and mediated by pushes and pulls, such as poverty in one place and job opportunities in another. A second approach, coinciding with the Marxist turn in geography, theorized that migration generally has resulted from the purposeful maintenance and exploitation of place-based inequalities by developed countries. Migration to countries such as the United States and Canada was consequently recast as a byproduct of a global struggle for equality based on race and class (Jadotte 1977; Wachter 1980). A more nuanced migration systems theory, based on the interaction of macro-factors, such as legal and economics regimes, and micro-factors such as individual desires and subjectivities, did not emerge until the late 1980s (Fawcett 1989; Castles and Miller 1998). Although this model provided ample opportunity for understanding the particularities and contingencies of queer migrations, most studies of queer migration that emerged in the 1990s and early 2000s were connected to HIV/AIDS, global gay tourism, 
the pink dollar, and the creative class. Put differently, queer mobilities were studied less for their own interest than for their relevance to broader medical and economic agendas.

\subsection{Medicalizing Migration: Gay Men and the Diffusion of HIV/AIDS}

Much of the initial attention to the movement of gay men in the 1980s and 1990s was due to the panic over a growing HIV/AIDS epidemic and the consequent medicalization of gay men (Turner et al. 1993; M. Brown 1995). Cohn et al. (1994), for example, observed that the growing number of HIV-positive gay men in rural areas of North Carolina was the product of poor HIV/AIDS education in those areas, the likely contraction of the disease in AIDS "epicenters" and the return migration of ill men to be cared for by their families. Ellis and Muschkin (1996) similarly found that coming home to seek the support of one's parents figured prominently into the migration decisions of AIDS patients relocating to rural areas of Florida. Although these studies usefully highlighted that home and family relationships were perhaps more important to AIDS patients than metropolitan care facilities and services, they also portrayed the gay male migrants as a universally ill population that rural areas were poorly equipped to assist.

More recent studies, while conducted with a less disease-centered approach, still link queer migration with disease transmission. In a study of Dominican, Brazilian, and Colombian men living in New York City, Bianchi et al. (2007) find that the combination of sexual freedom and social pressures that queer newcomers experience in cities like New York can lead to sexually risky behavior and a period of increased vulnerability to HIV. Although many geographers (see, for example, Wilton 1996, 1999; M. Brown 2006; N. Lewis 2009) have since turned their attention to other types of health 
experiences among gay men — a trend bolstered by advancements in HIV/AIDS treatments and the realization that it was also a heterosexual disease- - this work has rarely been used to theorize the role of health and well-being in gay men's migration decision-making processes.

\subsection{Queer Consumers: Viewing Gay Migration through an Economic Lens}

The so-called "de-gaying" of HIV/AIDS and the increasing cultural awareness of gay and lesbian lives and identities opened new opportunities for geographic research on sexuality and place in the 1990 s and early 2000s. For example, new data on same-sex couple households in 2000 were used to create tools such as Gates and Ost's Gay and Lesbian Atlas (2004). Much of the emerging geographic research on gay men, however, has also focused on the relationships between gay and lesbian mobilities and economic projects such as gay tourism and creative city development strategies. As both queer and mainstream media outlets recast gay men and lesbians as "normal" participants in society, advertisers and marketers saw the "pink dollar" as the optimal target for travel, real estate, and many luxury products (Puar 2002,124). A small group of studies in economics and business, for example, focused on gay market segments (Kates 2000) and brand relationships (Branchik 2002), suggesting that certain economic sectors could be developed and supported based on the presence of a large gay community. Others (see Florida 2002, 2005), saw "gays" as part of the cultural diversity and buzz that cities would need to attract talent and become competitive in a new economy based on knowledge, diversity, and creativity. 
Interestingly, many of the economic studies that have attempted a more systematic analysis of migration and resettlement among gay people maintain stereotypes of wealth and consumption among gay men by methodologically privileging economic rationality over individual experiences. Seeking to provide a practical counter-argument to qualitative studies that explain gay population distribution as the product of social and political acceptance, these studies posit that the locational decisions of gay male couples are based largely on financial decision-making (see Black et al. 2002; Walther and Poston 2004; Black et al. 2007; Cooke and Rapino 2007). They argue not only that the locational decisions of male same-sex couples are only marginally different from those of childless heterosexual couples, but also that they are the product of cost-benefit analyses favoring places with expensive housing and more natural, cultural, and "non-child" amenities.

These studies are problematic for several reasons. First, they are based on samesex couple data — generally considered a poor proxy for the gay population at large — and typically focus on metropolitan areas meeting a certain population threshold (e.g., $500,000)$ for purposes of statistical reliability. Second, they reinforce the stereotype of gay men as an upwardly mobile group even though they have been shown to earn less than heterosexual men (Carpenter 2007; Carpenter and Gates 2008). Finally, they treat places as static containers for gay residents, with little attention to the circumstances under which decisions to migrate there might be made. Their cumulative effect, therefore, has been more of a reinforcement of the wealthy gay urbanite stereotype than a practical counterargument to the socially constructed nature of gay men's locational choices. 


\subsection{Sexuality and Space or Sexuality and the City?}

Alongside the narrower understandings of queer identities and mobilities

produced in the medical and economic fields, queer scholars in geography and other disciplines began to produce their own brand of "sexuality and space" studies in the $1990 \mathrm{~s}^{2}$. Employing feminist epistemologies of lived experience, intersectionality, and contingency, these scholars explored the ways in which sexualities and places were mutually constituted (Rose 1993; Sparke 1996; Wilton 1996; Pratt 1999). Strongly influenced by queer theory, these scholars also sought to undo the categorical conceptions of sexuality mentioned above and re-introduce sexual identities as socially and spatially fluid (Sullivan 2003; Giffney 2004). One body of work, influenced by the concept of diaspora and typically rooted in gender and cultural studies, has examined the construction and mobility of sexual identity across national borders (Manalansan 1995; Eng 1997; Gopinath 1997). This work examined how queerness might complicate national and cultural belonging, as well as western notions of sexual non-normativity rooted in the construction of "homosexuality" as a unified category. Meanwhile, a second body of work more strongly rooted in geography has examined both how sexuality might be constructed, performed, negotiated, and regulated through space (Bell 1991; Bell et al. 1994; Bell and Valentine 1995; Valentine 2000; Valentine and Skelton 2003). This work

\footnotetext{
${ }^{2}$ The discipline of geography has devoted considerable attention to defining the concepts of space and place. In general, space has been described as a vector that mediates or diffuses discursive and material practices. Place, in contrast, is usually defined as somewhere anchored or defined by particular sets of social relations, historical events, and cultural meanings (i.e., place is space filled with meaning). Recent interventions, however, have noted that spaces, too, are socially and culturally constructed sets of flows or places. Sexuality and space, the generally accepted moniker for geographies of sexualities, also suggests that there is a particular importance to the less easily defined sets of flows and relations through which sexuality and place/space are mutually constituted. For ease of explanation, this thesis typically uses the term space when referencing where relational flows (e.g., migration) occur, and place to describe the specific, meaning-filled locations that are traversed or encountered.
} 
has given considerable attention to the relationship between places (usually cities) and sexual identities, as well as the politicization and regulation of sexuality.

First, the growth of sexuality and space studies has spawned a number of analyses that highlight the relationship between the city and gay and lesbian lives. Much of this work has been historical, foregrounding the advent of the "gay community" in the particularities of the Industrial Revolution, urbanization, and the migration of single men and women to cities such as London and New York (Laqueur 1993; Chauncey 1994; Aldrich 2004). While these studies frame (in-) migration as a precondition for the emergence of non-heterosexual identities and communities, most contemporary analyses of urban sexualities focus on the city itself, and particularly the "gay ghettos" within them. Interestingly, the first studies of these neighbourhoods focused not on sexuality itself, but on gay gentrification as a political-economic process with which one category of sexual identity was intertwined (Lauria and Knopp 1985; Knopp 1990, 1992).

Later studies, however, focused on cities as places where sexual identities and subcultures were produced, and sometimes performed in ephemeral spaces such as cruising grounds, parades, and protests (Bell et al. 1994; Markwell 2002; Johnston 2007; Brown and Knopp 2008). Gay villages such as West Hollywood (Los Angeles), Darlinghurst (Sydney) and Church Street (Toronto) thus emerged as compassionate, supportive communities in which queer people could come out of the closet and negotiate or celebrate their identities (Forest 1995; Markwell 2002; Law 2003; Nash 2005, 2006). At the same time, the village scene has been described as a paradoxical space in which certain queer people also encounter physical and emotional risk as well as various modes of regulation (Markwell 2002; Valentine and Skelton 2003; Nash and Bain 2007). While 
some might fit neatly into the commercialized, increasingly cosmopolitan identities that gay villages are thought to produce (Bell and Binnie 2004; Binnie and Skeggs 2004), others may be excluded or surveilled (Podmore 2001; Ray 2004; Waitt 2006). Sexuality and space studies have also animated the politics of sexuality, again using a city-centered approach. Some studies provide accounts of how queer homelands such as New York, San Francisco, and Toronto became sites from which gay rights struggles were waged (D’Emilio 1983, 1989; Nash 2005). Again, migration appears as an ancillary event, with urban in-migration contributing to or accompanying the development of a Stonewall-era ${ }^{3}$ mode or urban queer politics (Weston 1995). Other studies, usually in political science, have examined gay and lesbian politics at the national scale by tracking rights-seeking agendas and legislative accomplishments (Smith 2004; Smith 2005a; Weeks 2007).

Building on the notion of sexual citizenship — in which sexuality is neither a private matter nor a regulatory category, but a facet of the everyday relationship between citizens and the state - geographers have begun to address the complex spatialities of queer politics beyond the scale of the city or the nation (Bell and Binnie 2004). Many scholars use a Foucauldian framework to show how the production of "homosexual" as a definable population category (Foucault 1978; Halperin 2000) has led to the selective regulation of queer identities and practices in particular times and places, and through mechanisms such as public health campaigns, bath house raids, and the Census (Legg 2005; Cooper 2006; Nash and Bain 2007; M. Brown 2009; Oswin 2010; Olund 2010). Others have attributed the regulation of sexuality, and particularly the decline of a radical

\footnotetext{
${ }^{3}$ The identifier "Stonewall" refers to the 1969 Stonewall Rebellion, a three-day protest in New York City's Greenwich Village sparked by a police raid at the Stonewall Pub. Stonewall is now commonly thought to have initiated the gay rights movement, and is sometimes used to refer to the era of early gay liberation politics in the 1960s and 1970s.
} 
queer politics, as a product of neoliberal economic regimes and practices that value sameness and efficiency over transgression (Duggan 2002; Smith 2005b; Cooper 2006).

Critics of queer normalization claim that gay activist and social service organizations lost federal funding in the 1980s and 1990s due to increasing conservatism and downsizing. In addition, work aimed at enfranchising queer people was recast as controversial, unpopular, and risky, unless it could be connected with agendas such as youth education or HIV prevention. At the same time, seeking rights through court cases, lobbying, and bureaucratic organizations such as Human Rights Campaign and Egale Canada began to outpace more transgressive modes of queer politics such as genderbending and pro-sex rhetoric (Warner 1995; Duggan 2002; Nash 2005). These changes too, have been spatially contingent. Smith (2005b) observes that while gay organizations in Toronto, for example, have been able to pursue more localized grassroots agendas, those in the more thoroughly state-suffused city of Ottawa have often been subsumed into formalized and distinctly national processes of lobbying and rights-seeking.

Many scholars have claimed that the neoliberal turn in queer politics has flattened the diversity of sexual identities almost as soon as they began to be studied within the social sciences. They argue that the ongoing regulation of sexuality, the production of a cosmopolitan gay identity, and the granting of rights such as marriage have created a complicit, "homonormative" group of gay, middle-class, and usually white citizens while other identities are obscured (Duggan 2002; Nast 2002; Richardson 2005).

Homonormative citizens are observed not only to avoid "a more challenging sexual politics" (Cooper 2006, 922), but to create a new type of patriarchy (Nast 2002) that presumes to speak for the broader spectrum of queer people. By ostensibly colluding with 
both the market economy and with more conservative government agendas, this group is thought to be central in an emergent "homonationalism" that dismisses developing countries as anti-gay and delegitimizes queer people who do not fit into white, western paradigms of sexuality (Puar 2007). Despite calls to examine the nuances of queer lives that may appear normative on the surface (Sothern 2004; Oswin 2005), homonormativity has become yet another spatially reified concept: it emerges in one set of (western) countries, is typified by white, middle-class urbanites, and marginalizes queer people in rural, peripheral areas and the developing world.

This brief overview of sexuality and space studies highlights some of the ways in which queer identities and politics - and the mutual constitution of the two - are animated through space. The partial (though not intended) effect of this work, however, has been the spatial containment of queerness. While queer theorists have introduced the idea that sexualities themselves are fluid, scholars of sexuality and space scholars have only sometimes examined the spatial fluidity of sexualities. Queer people's lives, experiences, and identities have been most frequently studied through the lens of the city, and particularly the gay village or ghetto. Meanwhile, the politicization and regulation of sexuality has typically been studied at the scale of the city or the nation, often with the former animating the latter. Consequently, much of the work on sexuality and space has positioned the city as the origin of sexual non-normativity. Cities are highlighted as the places where queer identities and politics develop — or even where queer lives beginwith only limited attention given to sexualities in non-urban contexts or across spatial contexts. The following section explains that sexuality and space studies, while 
increasingly providing accounts of queer lives in non-urban contexts, has not yet produced sufficient work to overturn the impression that queer lives are spatially static.

\subsection{De-Centering Sexualities}

In an effort to overcome the preponderance of metropolitan-based studies of queer space, geographers have increasingly turned their attention to "de-centering" sexualities (see Phillips et al. 2000) by examining the lives and experiences of queer people outside the largest metropolitan centers (Waitt and Gorman-Murray 2007; Visser 2008; G. Brown 2008, 2009). These studies have investigated rural areas (Bell and Valentine 1995; Osborne and Spurlin 1996), mid-sized cities (Visser 2008), country towns (GormanMurray et al. 2008), government towns (N. Lewis 2011), and increasingly, the Global South (G. Brown et al. 2010). They have also examined everyday spaces such as the home, the workplace, and the daycare center (Waitt and Gorman-Murray 2007; Luzia 2008, 2010). By extending the range of environments examined, geographers have countered the once-totalizing binaries of heterosexual and queer space (Knopp and Brown 2003). Rural areas once fixed as conservative or homophobic, are now observed to be temporarily and sometimes permanently made into "gay capitals" by ephemeral events such as film festivals (Gorman-Murray and Waitt 2008).

Such studies also blur the script of homonormativity, in which gay men and lesbians are observed to imitate heterosexual lifestyles anchored in domesticity and consumption (Duggan 2002; Nast 2002). In fact, suburban and rural queer couples could be seen not only as providing a counterpoint to the single, affluent, and urban global gay, but also as transgressing the heterosexual norms thought to dominate those settings. 
Gorman-Murray et al. (2008) find that even in a small town where queer people are few in number, gay men often use their private homes as community social and organizational centers, and often actively mark their homes as queer space with rainbow flags and other symbols. Visser (2008) notes that such cases prompt us to think of normalization as reflexive: even as queer people lead lives that appear to embrace heterosexual norms, they also tend to queer presumably heterosexual spaces through a process of homonormalization. Several studies additional studies demonstrate that queer peoples' life-worlds are generally complex and frequently adapt to and resist heteronormative environments. For example, gay men leading ostensibly homonormative lives may travel elsewhere for a "gay fix" in a place where they can be more open, or perform their sexuality differently in private, public, and professional environments (Waitt and Gorman-Murray 2007; N. Lewis 2011).

While this new generation of sexuality and space studies productively de-centers the assumed metronormativity of queer lives (G. Brown 2008), few consider how the complexity of queer space might inform migrations that — until recently — have been framed largely as linear, rural-to-urban migrations or as the by-products of medical and economic phenomena. On one hand, much of the theory on sexuality and space suggests linkages between place, sexuality, and mobility. Queer people might move to gay villages (or other, more dispersed queer spaces) to come out, even if the "great gay [urban] migration" of the 1960s and 1970s is less universal than it once was (Weston 1995). Queer people might also move in order to negotiate a spatially uneven landscape of rights and regulation - not just between countries, but within them. Given the ongoing nature of the gay rights movement itself, especially in the United States, it could also be possible 
that queer people might still move to participate in the political activities centered in particular communities (Forest 1995; Law 2003). Since these potential linkages are rarely examined, the spatialities of individual queer lives — as opposed to those of queer "communities" or queer culture at large_-remain somewhat hidden. Consequently, understandings of queer migration within countries have advanced only marginally compared with those of sexuality and space more broadly. Queer places have been decentered and nuanced, yet queer flows have not been complicated in the same way.

\subsection{From Places to Flows: New and Emerging Studies on Queer Migration}

During the past decade, cultural and social geographers have initiated a more critical study of queer migration focused on two main areas. One body of work considers the ways in which the movements of queer migrants are restricted by national borders, usually through the enforcement of immigration policies that privilege the heteronormative family (Manalansan 2006; Lubhéid 2008; Mountz 2010). Although this work reveals important relationships between sexuality, mobility, and regulation, it tends to privilege the nation as the primary container of forces moderating queer migration. Most of the work on migration within countries, the focus of this thesis, has been conceptual. Some of this work is based on familiar narratives of exclusion and displacement, implicitly inviting assumptions that most queer migrations are between homophobic, rural places, and accepting, urban ones. In other words, queer people may "move out" because they experience social isolation and disconnection when they fail to fit in —what Cresswell (1996) and others have called being "out of place"—or perceive themselves to not fit in (Fortier 2001, Gorman-Murray and Waitt 2008). They may also 
move in search of protection against stigma, prejudice, violence and other stressors that manifest themselves as unevenly distributed "forces of geography" at a variety of spatial scales (Bryson et al. 2006, 803-804; Gorman-Murray 2007; Knopp 2007).

A second body of work on queer migrations inside countries employs a less structural approach. In a number of thought pieces, queer journeys are linked to both identity formation (i.e., finding oneself through place) and to pursuit of physical and emotional security, particularly during coming-out processes (Fortier 2001; Knopp 2004, 2007; Gorman-Murray 2009). These migrations are frequently described as wandering or "peripatetic" searches in which queer individuals shape and accrue identities through place. These may involve trading in a childhood home (though not always an intolerant, conservative, or rural one) for a new "queer home," or leaving one city to experience living differently in another (Fortier 2001; Knopp and Brown 2003; Knopp 2004). Knopp (2004, 2007) has also argued that queer people, whose relationships with place are perhaps more likely to shift or rupture than those of heterosexual people, are at home in movement itself. Building on work in emotional geography (Davidson and Milligan 2004; Bondi et al. 2005) and providing a counterpoint to work that describes queer journeys as flights or escapes, Gorman-Murray $(2007,2009)$ notes that queer migrations emerge not just from feelings of fear, but also searches for comfort and love.

Even these more nuanced conceptions of queer migration are limited in their own way. First, they frequently invoke the same spatial binaries that characterized early queer migration research and the study of sexuality and space more generally. Both Fortier (2001) and Knopp (2004) invoke the idea "emancipating” oneself from the closet by moving out to come out, suggesting not only the existence of a fully formed gay identity 
that can be freed from the closet, but the existence of a place that is accepting in a way that would allow full emancipation to occur. In a similar vein, Fortier $(2001,410)$ suggests that some queer migrations emerge in search of a "queer cultural homeland" into which one can easily insert oneself "without ever having set foot there before." While acknowledging that queer people may move between many different homes, these accounts still invite assumptions that certain, uniform types of places facilitate or encourage particular types of movement. Since the subjectivities and circumstances of individual migrants are obscured, it is difficult to consider how the social dynamics created in various places might inform the dialectic journeys of queer people.

Few scholars have undertaken empirical studies that examine individual mobilities and trajectories of queer people within countries. In what is generally considered the first such study, Weston (1995) uses retrospective interviews with queer migrants to explain the mass movement of American gay men and lesbians to New York, San Francisco and other "gay meccas" in the 1970s and 1980s. This great gay migration, she argues, originated in the rural areas and suburbs of the United States as young queer people sought affirmation and community in the cities where grassroots gay rights movements were emerging. Similar themes are elaborated in studies by Cant (1997) and Parker (1999), which also focus on rural-to-urban migration. More recent empirical studies - mostly in Australia - have focused less on urban-rural differentiation than on bodily experienced emotions, desires, and relationships, changing the scale of analysis from nation or the city to the body itself (Gorman-Murray 2007, 2009; Waitt and Gorman-Murray 2010, 2011). Critically reworking Knopp's (2004) idea of the peripatetic identity quest, Gorman-Murray $(2007,2009)$ finds that much of the queer migration 
occurring within Australia can be linked to searches for comfort and love provided by both people and places. By focusing on individual migration narratives rather than metanarratives of coming out, oppression, or rural-to-urban flight, these most recent studies challenge the implied linearity and finality of queer migrations by highlighting the multiplicity and diversity of queer migrations, including urban-to-rural movement and return migrations (Waitt and Gorman-Murray 2008, 2010, 2011; N. Lewis 2012).

\subsection{Between Body and State: Gaps in the Study of Queer Migration}

The recent work on de-centered queer spaces such as the country town and the family home has complicated binary frameworks of queer intra-national migration. It also frames queer migrations as inherently emotional journeys that emerge from desire and love, and not just fear and displacement. This most recent emotional turn, however, tends to posit the body — and the emotions and desires located within — as the primary driver of migration. While a focus on emotion and embodiment provides a way of overcoming assumptions about queer intra-national migration (i.e., that they are linear flights from flatly homophobic places), it sometimes elides the social networks, institutions, and policies and practices of places that contribute to queer migrations and inform processes of settlement and regulation thereafter. Health outcomes and economic issues make little appearance in the queer migration literature, while political motivations remain largely relegated to studies of transnational queer migrations and the immigration policies that mediate them. These gaps omissions might be reactive. In an effort to avoid further reifying queer migration flows as the products of illness or pink-dollar consumerism, health-related and economic aspects of queer migration have been avoided entirely. In 
addition, the quantitative techniques often employed in those areas of geography are considered at odds with the cultural turn under which sexuality and space studies emerged. Yet with increasingly nuanced understanding of the individual subjectivities and circumstances in queer lives, however, there is perhaps once again room to consider the role of health, economics, and politics, in shaping intra-national migrations.

The current work on queer migration and embodiment provides an opportunity to reinvestigate the relationship between relocation and a wide range of health issues beyond the realm of HIV/AIDS. In an effort to identify alternative emotions influencing queer migrations, scholars have emphasized the role of comfort, love, and security, as opposed to fear and stress - the emotions traditionally discussed in displacement-based narratives and the ones most likely to have an effect on health. There is now an opportunity to re-assess, in a more nuanced way, how discomfort, isolation, and exclusion — and the related health outcomes of anxiety, depression, panic, suicide ideation - may contribute to migration decisions. Bridging this gap requires re-integrating health into the study of queer migration, though in a different format from the epidemiological, medicalized studies of the 1990s and early 2000s. The next logical step is to reconceive health, particularly mental and emotional health, as a fundamental element of many queer migrations and not just as a particularism of refugee flows (Momartin et al. 2003) or ill populations with limited mobility (Cohn et al. 1994). Psychosocial relationships between environmental factors and health or well-being in queer people are now typically explained through "minority stress," or the unique, chronic, and socially induced stressors that one experiences due to their status as a member of sexual or other minority group (Meyer 1995, 2003; Cochran 2001). Studying 
queer migration, then, might include "taking seriously peoples' feelings of health and illhealth as bound up with diverse sites, spaces, and places where health is challenged and treated" (Philo 1996, 38).

As with health, there is also an opportunity to consider the role of economic concerns in queer migration, included those related to the particular issues of coming out in the workplace and to career trajectories more generally. Since the economic lives of gay men, lesbians, and other queer people extend well beyond the familiar discourses of tourism, the pink dollar, and gentrification (see Badgett 1996), their migration decisions are likely to involve more mundane concerns such as career advancement and everyday spending decisions. The parameters, however, may be different. As Gavin Brown (2009) has observed, gay men and lesbians have a vested interest in supporting and participating in diverse economies that extend beyond mainstream, capitalist enterprises that perpetuate heteronormativity. It is therefore useful to think about how gay men's migrations might be influenced by desires to work in inclusive and non-discriminatory workplaces or interests in supporting gay-owned businesses and other alternative enterprises outside the realm of nightlife, bars, and social services often thought to the gay economy. Migration decisions among gay men, then, might emerge not only from economic rationality (Black et al. 2002, 2007; Walther and Poston 2004; Cooke and Rapino 2007), but from the everyday ways in which sexuality and economic decisionmaking intersect (G. Brown 2009).

Finally, there is an opportunity to revisit the regulation of queer migration beyond the laws governing international migration. Queer migration has only occasionally been studied in conjunction with the politics of places, usually in the context of how 
immigration legislation affects bi-national same-sex couples (Manalansan 2006; Howe 2007). Yet given that the landscapes through which queer people move are uneven in terms of both rights and everyday inclusion (and not just immigration policies), intranational migrations are also regulated - though perhaps in more subtle and diffuse ways than those between countries. As Ray $(2004,3)$ observes, the social inclusion of queer people "does not just happen organically" and is contingent on policies and practices that "mitigate practices of inclusion and exclusion." Queer people are therefore likely to move within countries based on discursive understandings of how queer lives and communities are shaped and regulated in particular destinations. Lewis (2011), for example, finds that in the government-dominated city of Ottawa, both the reasons that gay men settle there (e.g., career opportunity, the perception of protection against discrimination) and their modes of conduct after moving are much different from what might be found in cities such as Toronto and Montreal.

\subsection{Toward a Life Course Approach in Queer Migration Studies}

A meaningful and well-rounded study of queer migration, then, involves addressing not only the highly individualized processes of identity formation, relationship-building, and self-discovery, but also the ways in which places-and the networks and institutions embedded in them — contribute to health and well-being, political enfranchisement, and economic security. Although this study builds on existing accounts of queer migration, such as those focusing on coming out and migration, it also purposefully seeks to interrogate the role of structural factors (e.g., health, economics, and politics of place) in the migration decisions of gay men. At the same time, it aims to 
avoid the abstract understandings of these factors that have been presented in the past. Accomplishing both of these objectives requires an approach that neither reinforces queer mobilities as a series of disjointed, structural "types," such as tourism-based or HIV/AIDS-related, nor exclusively privileges emotion and embodiment. Instead, this thesis focuses on the interaction of structural factors driving queer migrations in North America and the ways that these factors interact with individual subjectivities of sexuality, age, race, and cultural background. Studying queer migration through the life course also offers an opportunity to examine the multiplicity of migrations that emerge throughout queer lives, rather than instances of "moving out to come out"-which, itself, can be life-long processes of "becoming" mediated by several journeys (Worth 2009).

The life course approach acknowledges both the distinctive networks and landscapes encountered by queer people throughout their lives. In the upcoming chapter, I explain that - according to life course theory and the relatively scant work on queer life courses - intra-national migrations among gay men are related to an individual's networks, the institutions he encounters, his individual subjectivities, and the historical contexts in which his migration decisions are made. These highly variegated factors complicate the ostensible attributes or characteristics of place conceived in the media and the broader discursive imaginary of North America. I use evidence from my interviews to show the centrality of these life course considerations in gay men's lives and their migration decisions.

Following this brief positioning chapter, I summarize the methods used and data collected before moving onto several thematic discussions. Chapters 5 and 6 expand on the useful work initiated by scholars like Fortier (2001), Knopp (2004), and Gorman- 
Murray $(2007,2009)$ by further exploring the role of coming out in decisions to move to Ottawa and Washington, D.C. Chapter 7 examines some of the very literally embodied health outcomes that gay men have experienced in certain places and how these have contributed to decisions to move. Chapters 8 and 9 discuss the specific role of the capital city as a destination for mobile gay men. The narratives describe Ottawa and Washington, D.C., as both places where gay men perceive the protection of the state and an opportunity to negotiate identities and rights. They also highlight the two cities as places where gay men are exposed to everyday apparatuses of governmentality, particularly in the form of workplace practices, class stratification, and the management of urban space. 


\section{CHAPTER 3}

\section{Methods}

\subsection{Methodological Approach}

As established by a rich tradition in social and cultural geography, this project employs an ethnographic case study approach, adopting qualitative techniques such as interviews to understand how one group (self-identified gay men) experiences a particular phenomenon or practice (migration). A case study approach offers several research benefits. First, it allows for the inclusion of the processes and mechanisms that lead to a particular set of findings, ultimately resulting in a less wasteful research process (Cornwell 1988). Given that this project aims to move past binary and linear understandings of queer migration, it is necessary to adopt an ethnographic approach that demonstrates the complexity of behaviors, experiences, and circumstances within a population group — gay men, in this case (McKendrick 1999). This study therefore answers McHugh's (2000) call for ethnographic approaches to migration studies that avoid simple linear conceptions of migration and resettlement. Employing individual narratives also avoids the implied "groupness" of gay men by adopting the individual as the unit of analysis (Mitchell 1983). In accordance with a case study framework, I also allow for some flexibility in my approach (e.g., revising interview questions according to the circumstances of the individual) rather than requiring a controlled or closed experimental format (Mitchell 1983; Forrester 1996).

The approach employed here might be more correctly called a reflexive ethnographic approach. I moved to, and lived in, both case study cities as an openly gay man. I moved to Washington, D.C., shortly after university, came out during my first year 
there, and lived there for five years (2003-2007). I moved to Ottawa specifically to conduct the first portion of this field research and stayed for about two years (20092011). Consequently, my insights as a participant-observer and autoethnographer bolster and contextualize the accounts of the men interviewed (Chang 2008). While my own experiences — including moving to a larger city while coming out — follow those of many respondents, the particularities of my experience as a white, middle-class, educated man also contrast significantly with respondents of different ethno-racial and class backgrounds. My personal counter-perspective often clarified the role of place-based experiences (e.g., growing up in a rural area) or intersectional subjectivities (e.g., cultural identities among African-Canadian and African-American men) in determining migration experiences and trajectories.

\subsection{Queering the Capital: Selection of Study Sites}

Most sexuality and space research to date has focused on large metropolitan areas such as New York and Toronto (Chauncey 1994; Nash 2005, 2006) and occasionally on rural areas (Osborne and Spurlin 1996; Fellows 1998; Phillips et al. 2000; Waitt and Gorman-Murray 2007). The choice to study Ottawa and Washington, D.C. - two midsized cities (albeit with large surrounding metropolitan areas) — was therefore part of the ongoing project in sexuality and space research to de-center queer lives (Phillips et al. 2000) and shift the focus to non-metropolitan cities that might not carry status as a "queer homelands" (Fortier 2001; G. Brown 2008). At the same, time, capital cities present distinct sets of factors that are equally likely to influence the migration decisions and everyday lives of queer people. As national capitals, both places act as sites of 
governmental power and influence as well as contestation and negotiation: households in a nation's capital are likely to hold more political sway (and are often the first to be appeased), while riots and protests are likely to have greater political impact than in other similarly-sized cities (Hall 1986; Dascher 2000). Residents of Washington, D.C., although they do not representation in the U.S. Congress, may be attracted by the city's role as a "policy making gateway" that provides an institutional framework for those seeking to "peddle influence" (Stough 2000). Consequently, capital cities may also attract queer people seeking to influence their own inclusion or associate and interact with others who have similar objectives. Washington, D.C. and Ottawa, then, have become destinations not because of their amenities or cultural status but because of a particular configuration of networks and institutions_-overcoming the idea that sexual nonnormativity follows a size-based urban hierarchy (Knopp and Brown 2003).

Each city also represents a type of "paradoxical" place (Rose 1993, Valentine and Skelton 2003; Ray 2004) in which sexual non-normativity is alternately accepted, excluded, and regulated, depending on the individual and circumstances concerned. Consequently, these study sites offers an opportunity to examine how individual subjectivities such as age, ethno-racial identity, and class influence decisions to migrate and the resultant changes in everyday life. Ottawa, the site of the first major Canadian gay rights demonstration in 1971 (see Smith 1998), is ostensibly a place that "fosters diversity" and provides "strengths to build on" for the gay community (Wright 2003). Both national gay rights agencies such as Egale Canada and local service agencies such as Pink Triangle Services, Bruce House, and Centretown Community Health Center, offer opportunities for self-care and political engagement and foster an atmosphere of 
inclusion (Wright 2003; Smith 2005b). At the same time, Ottawa is noted for its limited connectivity with other cities, conservatism, and the "closeting" of gay men —in health care and other sectors — and generally poor wellness of gay men with unstable housing and less education (Lena et al. 2002; Wright 2003). In addition, engagement with the city's political and social networks tends to be limited to particular groups. The city's "gay business district," while acknowledged as a "revitalizing force" in the city was not given any kind of official recognition as a "gay village" by the city until November 2011, an issue attributed to both the dispersed — even hidden—nature of the city's gay population and the prevalence of socially conservative attitudes (Social Planning Council of Ottawa 2003; Le/The Village 2011). Political activism in the city, too, has historically been dominated by middle-class gay men, particularly lawyers, trade unionists, and businessmen (Smith 2005b).

Washington, D.C., poses a similar paradox. The city has one of the largest gay populations (including $4.4 \%$ of all U.S. gay male couples) despite its position outside of the country's industrial core and lack of any significant history of international or internal migration - excepting African-American northward migration in the early $20^{\text {th }}$ century (McChesney 2005, Price et al. 2005). At the same time, the city has begun to attract gay men from many regions through an increasingly visible gay scene, diverse neighbourhoods and subcultural communities (e.g., leather, drag) and the continued occupational stability of the government sector (Patterson 2002; Paris and Anderson 2007). But concurrent with its ascendance from "sleepy southern town" to "sophisticated world capital," D.C., like Ottawa, appears to be a place where gay residents are both (nominally) included and regulated on a day-to-day basis. Despite the emergence of 
several neighbourhoods "where being gay is okay," its most well-known gay areas (e.g.,

Dupont Circle) are collections of high-rent townhouses and a few bars, contributing to a

wealthy, professional, conservative vision of the community (Lauria and Knopp 1985;

Icard 1986; Paris and Anderson 2007).

For a life course approach to queer migration - that is, one focused on the role of both structures and subjectivities in shaping gay men's migration decisions throughout life - these two capital cities are ideal study sites. First, the high recorded numbers of same-sex couples indicates suggests the presence of gay men, and that the density and particular combinations of institutions in these cities (civil service, government, and advocacy agencies) are likely related to their settlement there (see Tables 3.1 and 3.2).

Table 3.1. Proportions of Same-Sex Partnered Households among All Partnered Households, Canada, Ottawa, Toronto, Vancouver, and Montreal CMAs, 2006

\begin{tabular}{|l|l|l|l|l|l|}
\hline & Canada & $\begin{array}{l}\text { Ottawa- } \\
\text { Gatineau }\end{array}$ & Toronto & Vancouver & Montreal \\
\hline Total Married & 6105910 & 211590 & 1059125 & 433180 & 562055 \\
\hline Opposite-sex & 6098445 & 211215 & 1056740 & 432295 & 561180 \\
\hline Same-sex & 7465 & 380 & 2390 & 885 & 880 \\
\hline Same-sex \% of Total & $\mathbf{. 1 2}$ & $\mathbf{. 1 8}$ &. $\mathbf{2 3}$ &. $\mathbf{2 0}$ &. $\mathbf{1 6}$ \\
\hline Total Common-Law & 1376865 & 51105 & 109290 & 58830 & 252685 \\
\hline Opposite-sex & 1338985 & 49070 & 102055 & 55025 & 245200 \\
\hline Same-sex & 37885 & 2035 & 7230 & 3800 & 7485 \\
\hline Same-sex \% of Total & $\mathbf{2 . 7 5}$ & $\mathbf{3 . 9 8}$ & $\mathbf{6 . 6 2}$ & $\mathbf{6 . 4 6}$ & $\mathbf{2 . 9 6}$ \\
\hline
\end{tabular}

Source: Statistics Canada 2006, special tabulation, courtesy of Brian Ray, University of Ottawa.

Table 3.2. Proportions of Same-Sex Coupled Households among All Coupled Households, MSAs with Highest Concentrations of Same-Sex Couples, 2000

\begin{tabular}{|l|l|l|l|l|l|l|l|l|}
\hline & $\begin{array}{l}\text { United } \\
\text { States }\end{array}$ & $\begin{array}{l}\text { D.C.- } \\
\text { Baltimore }\end{array}$ & $\begin{array}{l}\text { San } \\
\text { Francisco }\end{array}$ & Miami & Atlanta & $\begin{array}{l}\text { Seattle } \\
\text { Los } \\
\text { Angeles }\end{array}$ & $\begin{array}{l}\text { New } \\
\text { York }\end{array}$ \\
\hline Total Coupled & 105480101 & 1565048 & 1414216 & 759021 & 849509 & 791044 & 3047459 & 4118921 \\
\hline $\begin{array}{l}\text { Opposite-sex } \\
\text { (married/unmarried) }\end{array}$ & 54493232 & 1545309 & 1385330 & 747162 & 837638 & 779424 & 3008250 & 4066255 \\
\hline $\begin{array}{l}\text { Same-sex } \\
\text { (unmarried) }\end{array}$ & 594391 & 19739 & 28886 & 11859 & 11871 & 11620 & 39209 & 52666 \\
\hline Same-sex \% of Total & $\mathbf{. 5 6}$ & $\mathbf{1 . 2 6}$ & $\mathbf{2 . 0 4}$ & $\mathbf{1 . 5 6}$ & $\mathbf{1 . 4 0}$ & $\mathbf{1 . 4 7}$ & $\mathbf{1 . 2 9}$ & $\mathbf{1 . 2 8}$ \\
\hline
\end{tabular}


Studying the experiences of men living in these two cities, then, offers an opportunity to explore how these institutions might animate both the migration decisions and day-to-day lives of gay men who have moved there. How might the Canadian and U.S. governments - long considered disciplining and regulatory forces in the lives of gay men - eventually become significant attractors as places to work? To what extent is migration to these political, rather than cultural, gay centers the product of men's desires for political self-actualization? In answering these questions, I move beyond the discourse of gay men's locational choices as the product of consumption decisions or the organic emergence of a few specific cultural and political gay homelands. Second, given the interest in men's individual experiences and circumstances, it was important to create a sample in which the respondents had diverse origins and migration trajectories. Focusing on national capitals, where the migration pathways of gay men are as likely to be national or international in scale as they are regional, provides a strong foundation for capturing a variety of migration experiences and circumstances.

Selecting two study sites, as opposed to one, also provides several research benefits. By focusing on both Ottawa and Washington, D.C., I am able to ask questionsand make some conclusions - about the relocation of gay men to national capitals, rather than just one particular destination. In other words, what is unique about this type of city as a destination for gay men and other queer migrants? Using study sites in two different countries, each with its own political, historic, and geographical context, also provides an opportunity to examine how distinctive sets of networks and institutions - and differing landscapes of human rights and social acceptance—have influenced men's migration 
decisions. Throughout the thesis, especially in the later chapters, I seek to highlight patterns and narratives of migration that differ across the two countries.

\subsection{Terminologies}

As a footnote in the introduction explained, gay and queer are neither categorical nor unproblematic terms. Although queer has been used to this point to refer to individuals with non-normative sexual identities - and to sexual non-normativity in general—it should not be taken as a signifier of universality or uniformity among the experiences of gay men, lesbians, bisexuals, or other queer people. The term "queer" is intended to capture the fluidity and diversity of sexual identities not captured by categorical terms such as gay and lesbian. It is also a historically and politically significant term, emerging as a form of resistance to the totalizing, regulatory category of "homosexual" that was popularized at the turn of the century (Foucault 1979; Halperin 2000). In addition to being used alongside the terminologies of gay and lesbian during the gay liberation movements of the late twentieth century, queer also became the central concept of queer theory developed in the 1990s (Sullivan 2003; Giffney 2004). In this body of theory, queer is employed as rhetorical and conceptual device that emphasizes the dynamism and fluidity of human sexuality and its implications for the study of politics, health, economies, and any number of other social phenomena.

Gay, in contrast, is a term emerging from the late nineteenth-century construction of "homosexual" a category used to capture individuals (especially men) whose sexual and sometimes social practices extended beyond the confines of "normal" heterosexual society (Foucault 1979; Halperin 2000). Over time, however, it has become the dominant 
signifier of sexual identity for men oriented toward same-sex sexual relationships, while the term lesbian has typically been employed for females. Gay, however, has often taken precedence in descriptions of social phenomena such as the gay rights movement and gay tourism, even though it is mostly men who employ it as a personal identifier. Despite its more limited scope, regulatory origins, and misleading reification as the main signifier of sexual non-normativity in North America, gay is used in this thesis to refer to the interviewees — who self-identify with this term — and their experiences. While queer is a popular term in social science literature, and arguably becoming more popular in North America and Europe, men who identify as gay do not necessarily identify as queer (see Jackson 2001; Green 2002).

This discussion also combines the sexual signifier, gay, with the gender signifier, "man" or "men." The terminology of "gay man," however, was not one imposed upon the respondents. As the notice, letter of information, and letter of consent show, all correspondence and descriptions related to the research project employ the term "selfidentified gay men" (see Appendices A and B). This sample of narratives therefore reflects the self-selection of respondents who identify themselves as gay men.

Consequently, their narratives may not reflect the experiences of men living in other parts of the world where same-sex relationships are unlikely to be described as either gay or queer (Ferguson 2004; Arora 2006; Haritaworn 2008; Jivraj and de Jong 2011). In addition, they reflect a distinctly North American version of gayness, rooted not only in the establishment of a homosexual category of the population, but a historical, usually urban-centered narrative of repression, liberation, and increasingly, normalization (see D’Emilio 1983, 1989; Kinsman 1996). The following section discusses, however, that 
part of the motivation for studying gay men is to uncover some of the social and spatial nuance of this seemingly dominant narrative.

\subsection{Justification for Studying Gay Men}

The reasoning for my focus on gay men is two-fold. First, the majority of academic and journalistic representations of gay urban life have focused on men living in very large metropolitan areas, and accordingly, have devoted a great deal of attention to the villages, entertainment venues, and sexualized spaces marked as gay space that have flourished in those areas (Knopp and Brown 2003; G. Brown 2008, 2009). This project therefore contributes to the ongoing project of de-centering-both geographically and epistemologically — the proliferation of work on gay men, which has frequently reinforced stereotypical understandings of mobility based on spending power, consumption in metropolitan areas, and sometimes HIV status. This study acts as a counterpoint by keeping self-identified gay men as the study group, but changing the research site to the "government town" and expanding the examination of lived gay spaces to include homes, schools, and especially workplaces in both "sending" and “receiving” places (see also Waitt and Gorman-Murray 2007; Luzia 2008, 2010).

Second, in acknowledging that fieldwork is personal (England 1994) and that my own subjectivity as a gay man having lived in both Ottawa and Washington, D.C., was likely to influence — and could indeed bolster — my research process, I chose to focus on gay men in order (1) access resources more easily, (2) to conduct my interviews in a productively conversational, exchange-based manner and (3) to add a dimension of experiential authority (see Clifford 1988; Brown and Knopp 2008) to the study. Having 
lived in both study sites and gained tacit knowledge of gay men's mobilities (having relocated several times as an openly gay man) helped to shape the interviews and create productive dialogues between respondent and researcher, rather than a unilateral collection of information.

\subsection{Interview Design}

Given the complexity of the research topic, semi-structured interviews were the optimal tool for understanding gay men's migration decisions and experiences through the life course (Valentine 2005). This method was chosen for several reasons. First, the quantitative techniques typically used in migration studies and elsewhere in population geography are insufficient for this project. While U.S. and Canadian Censuses can provide limited baseline data on the socioeconomic attributes of male same-sex couples) in those they tend to underestimate the same-sex household population, and in general they are a poor proxy for the attributes of gay men in general (Cochran 2001; Balsam et al. 2005; Knopp and Brown 2006). In addition, quantification is generally a poor technique for capturing empirically experienced marginalization, discrimination, or regulation in minority groups since it obfuscates the social and political dynamics of cities, neighbourhoods, and the other types of highly localized settings that might influence those experiences (Daniel 1997; Hannah 2005). Other national-level surveys attempting to capture the attributes of gay men offer more focused data on topics such as health and mental health, but their use of small sample sizes in large geographic catchments makes it more difficult to determine the impact of place on gay men's livelihoods and mobilities (Cochran 2001; N. Lewis 2009). 
As noted by Gibson and Argent $(2008,136)$, shedding light on the complexity of migration processes themselves, including the motives for moving and personal experiences of moving, involves a commitment to more qualitative methods and techniques. The semi-structured interview, which follows the same general progression of questioning for each respondent while allowing for rephrased or follow-up questions, is therefore an ideal vehicle for understanding the role of migration in gay men's lives through the life course. For this project, interviewing was preferable to a more general survey since it allowed interviewees' responses to be understood in the context of their broad migration narratives and even broader biographies or life stories that might "illuminate the space between shared understandings and subjective experience" (Cohler and Hostetler 2003, 559; see also Silvey and Lawson 1999).

The 48 main interviews were designed to capture how gay men in two different national and urban contexts (Ottawa, Ontario, Canada and Washington, D.C., U.S.A.) had used migration to negotiate various life events, and to assess the effects of these moves and sometimes past moves on their daily lives. An additional six key-informant interviews with social service providers, representatives of gay advocacy and community groups, and the gay and queer media were conducted to glean third-party perspectives on the mobilities of gay men at the scale of the community as opposed to that of the individual. These perspectives therefore incorporate an additional way of knowing and a converging line of inquiry. (Yin 2003; Gattrell and Flowerdew 2005) The design of the interviews with gay men, however, changed considerably between a small pilot studyconducted between September and October 2009—and the bulk of the interviews, conducted between October 2009 and May 2010. 


\section{5-1. Pilot Study Interviews}

Between September and October 2009, I interviewed four self-identified gay men and two key informants (a sexual health educator and a minister at a gay-positive church) using the design developed at the time of my qualifying exam (April 2009). Ethics approval for the project was gained in June 2009 (see Appendix A). Respondents were provided with a recruitment notice (Appendix B), a letter of information, and letter of consent to sign either at the interview or prior to the interview (see Appendices C and D). The first part of the pilot interview for self-identified gay men (see Appendix E), usually lasting about 20 minutes, gauged changes in self-assessed mental and emotional health status (before and after migration) as the point of departure for interrogating men's migration decisions (i.e., determining the extent to which health concerns were related to the move). These changes were captured through a rubric adapted from the Duke University Health and Wellness Self-Assessment Profile (Duke University Medical Center 2005). Respondents were asked to apply the statements, "describes me completely," "somewhat describes me," and "doesn't describe me" to a variety of health indicators (e.g., nervousness, feeling depressed or sad) to both their pre-migration and post-migration circumstances. Following the completion of this rubric, respondents were asked to rank their reasons for moving from a pre-given set of factors, including employment opportunities and desire to improve one's social life, before moving on to a battery of open-ended questions (usually lasting about 40 minutes), such as "What caused you to leave your previous place of residence?" and "To what extent did concerns about mental health influence your decision to move?" 
After each interview, the key themes and findings were summarized and each respondent was asked for his feedback on the usefulness and appropriateness of the questions for understanding his migration decisions and experiences. In this exercise, respondents raised several issues with the methodological assumptions, the structure and approach of the interview, and the overall research focus. The first concern was that the quantitative mental and emotional health self-assessment in the first part of the interview did not match the overall objectives of the project. The research goal was to examine stories of migration decision-making across gay men's life courses rather than establishing rules about the factors involved - health-related or otherwise. In addition, there was a question as to whether a quantitative mode of analysis was useful for a snowball sample of gay men in two cities. Any patterns of data derived would only describe the sample — and not necessarily all gay men — rendering the explanatory power of any quantitative measurement relatively limited. Second, the ranking exercise of migration motivations proved confusing for most respondents. Many thought that they were assigning a Likert-style power value to each factor rather than the intended ordinal ranking (1-7) for each of the seven factors. In addition, the ranking exercise pre-selected seven factors ostensibly associated with relocation rather than letting the respondents narrate their own reasons for moving.

Respondents also raised concerns related to the overall approach of the interview. The reliance on quantitative indicators in the first part of the interview, as well as the use of relatively close-ended questions in the second portion, changed the mood of the interview and impeded the collection of potentially useful information. As observed by some of the respondents, beginning the interviews with a battery of indicators diminished 
trust between the interviewer and interviewee and confused the real point of the studyto obtain the respondent's migration narrative. In fact, some respondents felt that the point of the exercise was to test their responses to the open-ended questions against the previous battery of ranking-based responses, leading to more controlled and cautious responses. Second, the structure of the interviews tended to "dead-end" the conversation. Too many questions could be answered yes or no, while others presumed linkages — for example, between coming out and migration - that may not have existed for some.

The pilot study also prompted switching the theoretical orientation of the study from mental health/minority stress to the life course. As the pilot interviews transpired, it became clear that the defining factors in men's migration decisions were not mental health concerns (e.g., anxiety, depression) per se, but the individual circumstances at various points in the life course that created particular states of mind and often precipitated migration. Among the men interviewed in the pilot study, it appeared that migration was more about the management of life events more generally, with changes in health as correlates rather than causes. With this new orientation, it was more productive to adopt an open-ended approach that allowed respondents to offer the most important and personally relevant factors in their migrations to Ottawa and Washington, D.C.

\section{5-2. Revised Interviews}

Interviews for key informants (Appendix F) were not revised. In the interviews with self-identified gay men devised for the remainder of the study, the quantitative rubric of health indicators assessed before and after migration was exchanged for a simpler rubric that asked respondents to think about how particular aspects of life had 
changed before and after migration (see Appendix G). These included health factors (e.g., drug use, anxiety, depression, sleeping habits, social support) as well as more general aspects of life, such as relationships with family, and participation in organized activities. Respondents were asked to discuss if and why these aspects of life changed due to migration and given an opportunity to discuss how each had informed or resulted from migration decisions. In this way, they became prompts for discussion of the life events and changes mediated by migration, rather than a way to collect data. The four gay men interviewed in the pilot were later administered this revised rubric.

The open-ended questions, in contrast, asked respondents to consider directly how they made their decisions to come to Ottawa or Washington, D.C., with particular attention to their life circumstances prior to moving, the communities and infrastructures they sought to (or expected to) access after moving, stigma based on their sexuality or other subjectivities in both origins and destinations, and future migration plans. In this portion of the interview, careful attention was paid to the wording of the questions, allowing them to be as general as possible (e.g., why did you decide to come to Ottawa?) rather than presumptive (e.g., how did mental or emotional health play into your decision?). This line of questioning was intended to help respondents weave together a migration narrative that focused on their most recent migrations - that is, those to Ottawa or Washington, D.C.- - while also taking into account previous migrations and life events, such as coming out or changing careers. 


\subsection{Sampling Strategy}

Between October 2009 and May 2010, 44 semi-structured interviews (48

including the initial four pilot interviews with revised addenda) were conducted with selfidentified gay men (ages 24-59) in Ottawa (October 2009-February 2010) and Washington, D.C. (April-May 2010). The men were recruited through respondent-driven snowball sampling, a process in which respondents can both provide information about themselves and refer the researcher to other respondents. This approach is ideal for researching small or hidden populations that are poorly captured through traditional sampling methods (Frank and Snijders 1994). In addition to obtaining respondents more quickly, snowball sampling can better highlight the diverse circumstances under which gay men migrate by allowing the researcher to create a demographically diverse cohort with a varied age, occupational, and ethno-racial distribution (Meyer 2003).

The snowball began with the personal contacts and key informants in both cities, with each initial respondent referring one to five additional respondents, usually by sending them the notice and researcher contact information. This process continued until 24 respondents had been obtained in each city, and additional parameters for age and ethno-racial diversity (20\% men of colour) were satisfied (see Tables 3.3 and 3.4). While these parameters do not necessarily allow for generalizations about any one group (e.g., men of colour, middle-aged men), it allows for a fuller examination of how various intersectional subjectivities might influence gay men's migrations. Respondents were 2459 years old and had moved to either of the two cities between 6 months and 29 years prior to the interview. In Ottawa respondents had moved from (in order of frequency): the Atlantic Provinces (Newfoundland, New Brunswick, Nova Scotia, and Prince Edward 
Island), Ontario (outside Ottawa), Europe ${ }^{4}$, Quebec, the Prairie Provinces (Manitoba, Saskatchewan, and Alberta), British Columbia, and Africa. In Washington, D.C., respondents had come from (in order of frequency): the Northeast, the Southeast, the Midwest, the San Francisco Bay Area, the Pacific Northwest, and Asia and Oceania (see Map 3.1). Men reported many ethno-racial identities, including Anglo-Canadian, FrenchCanadian, African-American, African-Canadian, Hispanic, and Aboriginal. Interviews were conducted mostly in neutral locations such as cafes and lasted 50-70 minutes.

Map 3.1. Place Moved From, Sample of Self-identified Gay Men ( $N=48$, Ottawa, Ontario, Canada and Washington, D.C., U.S.A.

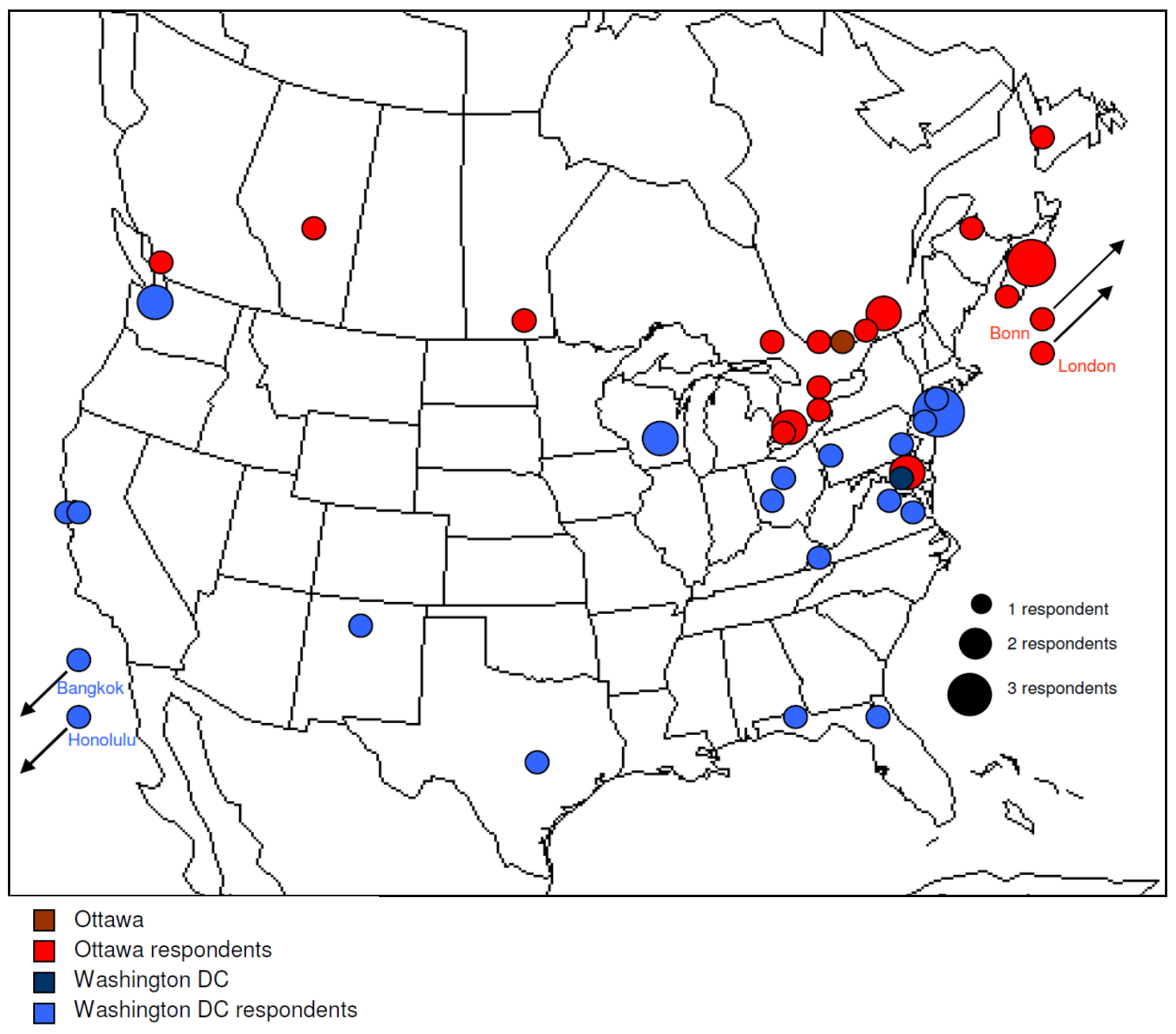

${ }^{4}$ All respondents were Canadian or U.S. residents, but a few had moved after living abroad. 
Table 3.3. Demographic Characteristics, Sample of Self-identified Gay Men (N=24), Ottawa, Ontario, Canada

\begin{tabular}{|c|c|c|c|c|c|c|}
\hline Pseudonym & Age & Race & Ethnicity & $\begin{array}{l}\text { Years } \\
\text { in } \\
\text { Ottawa }\end{array}$ & $\begin{array}{l}\text { Previous Place } \\
\text { Lived }\end{array}$ & Place of Birth \\
\hline Shawn & 42 & White & French-Canadian & 22 & Alfred (ON) & Sudbury (ON) \\
\hline Daniel & 28 & White & $\begin{array}{l}\text { French, English, } \\
\text { Canadian }\end{array}$ & 9 & Arnprior (ON) & $\begin{array}{l}\text { Kapuskasing } \\
\text { (ON) }\end{array}$ \\
\hline Jerry & 59 & White & $\begin{array}{l}\text { English, Irish, } \\
\text { Scottish, Anglo }\end{array}$ & 14 & Bonn (GER) & Victoria (BC) \\
\hline Mark & 49 & White & $\begin{array}{l}\text { English, Irish, } \\
\text { Anglo-Canadian }\end{array}$ & 26 & $\begin{array}{l}\text { Corner Brook } \\
\text { (NL) }\end{array}$ & St. John's (NL) \\
\hline Chad & 35 & White & Anglo-Canadian & 8 & Edmonton $(\mathrm{AB})$ & Halifax (NS) \\
\hline Wally & 43 & White & Anglo-Canadian & 12 & Halifax (NS) & Halifax (NS) \\
\hline Randall & 45 & $\begin{array}{l}\text { Black, } \\
\text { Aboriginal }\end{array}$ & $\begin{array}{l}\text { African-Canadian, } \\
\text { Mik'maq }\end{array}$ & 17 & Halifax (NS) & Digby (NS) \\
\hline Adrian & 56 & Black & $\begin{array}{l}\text { African-Canadian, } \\
\text { Mik'maq }\end{array}$ & 29 & Halifax (NS) & Glasgow (NS) \\
\hline Rick & 27 & White & $\begin{array}{l}\text { Anglo-Saxon, } \\
\text { Canadian }\end{array}$ & 2 & London $(\mathrm{ON})$ & $\begin{array}{l}\text { Thunder Bay } \\
(\mathrm{ON})\end{array}$ \\
\hline Ashton & 47 & White & $\begin{array}{l}\text { British, Anglo- } \\
\text { Canadian }\end{array}$ & 19 & London $(\mathrm{ON})$ & $\begin{array}{l}\text { Corner Brook } \\
\text { (NL) }\end{array}$ \\
\hline Derek & 31 & White & $\begin{array}{l}\text { French, French- } \\
\text { Canadian }\end{array}$ & 4 & Winnipeg (MB) & Winnipeg (MB) \\
\hline David & 55 & White & Anglo-Saxon & 29 & London (UK) & Ottawa (ON) \\
\hline Raymond & 41 & White & French-Canadian & 13 & $\begin{array}{l}\text { Montebello } \\
(\mathrm{QC})\end{array}$ & $\begin{array}{l}\text { St. Francois- } \\
\text { Xavier-de- } \\
\text { Brampton (QC) }\end{array}$ \\
\hline Kent & 27 & Black & Southern African & 2 & Montreal (QC) & $\begin{array}{l}\text { Bujumbura } \\
\text { (BUR) }\end{array}$ \\
\hline Sebastian & 42 & Métis & $\begin{array}{l}\text { French-Canadian, } \\
\text { Mik'maq }\end{array}$ & 19 & Montreal (QC) & Yarmouth (NS) \\
\hline Sam & 44 & White & European-Canadian & 9 & Montreal (QC) & Toronto $(\mathrm{ON})$ \\
\hline Terry & 40 & White & Flemish, Canadian & 13 & $\begin{array}{l}\text { Pointe-Aux } \\
\text { Roches (ON) }\end{array}$ & $\begin{array}{l}\text { Pointe-Aux- } \\
\text { Roches (ON) }\end{array}$ \\
\hline Anthony & 28 & White & Polish-Canadian & 1 & Saskatoon (SK) & Anola (MB) \\
\hline Raymond & 31 & Black & Jamaican, Canadian & 8 & Toronto $(\mathrm{ON})$ & $\begin{array}{l}\text { Scarborough } \\
(\mathrm{ON})\end{array}$ \\
\hline Luke & 24 & White & French-Canadian & 7 & Welland (ON) & Welland (ON) \\
\hline Francis & 30 & White & French-Canadian & 13 & Tracadie (NB) & Tracadie (NB) \\
\hline James & 40 & White & Canadian, Anglo & 9 & Vancouver (BC) & $\begin{array}{l}\text { Port Coquitlam } \\
\text { (BC) }\end{array}$ \\
\hline Smith & 41 & White & Western European & 6 & $\begin{array}{l}\text { Washington } \\
\text { (DC) }\end{array}$ & Standish (MI) \\
\hline Steve & 47 & White & British, Canadian & 6 & $\begin{array}{l}\text { Washington } \\
\text { (DC) }\end{array}$ & $\begin{array}{l}\text { Ottawa Valley } \\
(\mathrm{ON})\end{array}$ \\
\hline
\end{tabular}


Figure 3.4. Demographic Characteristics, Sample of Self-identified Gay Men (N=24), Washington, D.C., U.S.A.

\begin{tabular}{|c|c|c|c|c|c|c|}
\hline Pseudonym & Age & Race & Ethnicity & $\begin{array}{l}\text { Years } \\
\text { in D.C. }\end{array}$ & $\begin{array}{l}\text { Previous Place } \\
\text { Lived }\end{array}$ & Place of Birth \\
\hline Phillip & 43 & Black & $\begin{array}{l}\text { African- } \\
\text { American }\end{array}$ & 7 & Philadelphia (PA) & Eagle (PA) \\
\hline Shane & 27 & Black & $\begin{array}{l}\text { African- } \\
\text { American }\end{array}$ & 6 & Richmond (VA) & Hinsdale (IL) \\
\hline Jeffrey & 42 & Asian & Chinese & 11 & $\begin{array}{l}\text { Slippery Rock } \\
\text { (PA) }\end{array}$ & Hong Kong (CHN) \\
\hline Brian & 27 & White & Jewish & 5 & Middletown (CT) & Pittsburgh (PA) \\
\hline Owen & 32 & White & Jewish & 9 & $\begin{array}{l}\text { Williamsburg } \\
\text { (VA) }\end{array}$ & King George (VA) \\
\hline Doug & 26 & White & German & 9 & Longmont (CO) & Grand Junction (CO) \\
\hline Peter & 39 & Black & $\begin{array}{l}\text { African- } \\
\text { American }\end{array}$ & 15 & Austin (TX) & Austin (TX) \\
\hline Jake & 35 & White & Jewish & 9 & New York (NY) & Brooklyn (NY) \\
\hline Jack & 24 & White & $\begin{array}{l}\text { European- } \\
\text { American }\end{array}$ & 1 & Seattle (WA) & $\begin{array}{l}\text { Colorado Springs } \\
\text { (CO) }\end{array}$ \\
\hline Jordan & 26 & Asian & Chinese & 3 & Berkeley (CA) & Manila (PHI) \\
\hline George & 39 & White & Jewish & 4 & New York (NY) & Chicago (IL) \\
\hline Marshall & 29 & White & Italian & 1 & New York (NY) & St. Louis (MO) \\
\hline Martin & 46 & White & $\begin{array}{l}\text { European- } \\
\text { American }\end{array}$ & 4 & Madison (WI) & Gladstone (NJ) \\
\hline Max & 31 & White & $\begin{array}{l}\text { European- } \\
\text { American }\end{array}$ & 6 & Honolulu (HI) & Manassas (VA) \\
\hline Ian & 31 & Hispanic & Nicaraguan & 6 & Seattle (WA) & Managua (NIC) \\
\hline Nick & 26 & White & $\begin{array}{l}\text { European- } \\
\text { American }\end{array}$ & 0.5 & Columbus $(\mathrm{OH})$ & Wellesley (MA) \\
\hline Jesse & 42 & Asian & Chinese & 21 & Santa Fe (NM) & Carmel (CA) \\
\hline Michael & 44 & Hispanic & Paraguayan & 4 & Madison (WI) & Asuncion (PAR) \\
\hline Jason & 25 & Asian & Thai & 3 & Bangkok (THD) & Bangkok (THD) \\
\hline Arthur & 31 & White & $\begin{array}{l}\text { European- } \\
\text { American }\end{array}$ & 2 & Emory (VA) & Huntsville (AL) \\
\hline John & 33 & White & $\begin{array}{l}\text { Italian- } \\
\text { American }\end{array}$ & 16 & Kenilworth (NJ) & Brooklyn (NY) \\
\hline Adam & 34 & White & German & 6 & Dayton $(\mathrm{OH})$ & Worthington (MN) \\
\hline Joseph & 38 & White & European & 11 & Tallahassee (FL) & Milwaukee (WI) \\
\hline Tim & 27 & White & $\begin{array}{l}\text { Italian- } \\
\text { American }\end{array}$ & 6 & Gainesville (FL) & Bradenton (FL) \\
\hline
\end{tabular}




\subsection{Coding Process}

Interviews were coded in a two-step process based on the terminology used by respondents during the interviews. This process is commonly referred to as content analysis or categorical analysis (Cohler and Hostetler 2003). While computer programs such as NVIVO (see Richards 2002) are often used to conduct this type of analysis, their reliance on automated searches of pre-given codes gives primacy to the frequency with which categorically assigned information appears. Other details, such as the context in which a theme appears, may be obscured. In light of this a more open coding process (Strauss 1990), using a series of compiled word documents, was employed. All transcripts were read to determine the main themes in respondents' migration narratives and four themes emerged: coming out and migration, embodied health experiences preceding and following migration, economically and professionally motivated migrations, and the role of institutions in the relocation and everyday lives of gay men. Passages, defined here as one exchange between interviewer and respondent or a series of related, successive exchanges, were labeled with a symbol (e.g., \# for coming out, for economic migration) and placed in corresponding documents (see Appendix $\mathrm{H}$ ).

Each of the four documents was then re-coded for sub-themes. Passages were assigned alpha-numeric codes to indicate both the overall theme and the specific subtheme. Moving to seek greater anonymity while coming out, for example, was coded $\mathrm{CO} 2$, with CO signifying coming out (see Appendix I). The frequency of passages for each sub-theme and the number and percentage of respondents mentioning each subtheme are discussed in the corresponding chapters. In line with a qualitative approach, these brief discussions within chapters address how quotations are selected and how 
information is ordered (Baxter and Eyles 1997). Although the chapters were originally planned to correspond to the four main themes established in the interviews, slight alterations to the structure of the thesis were made after coding for sub-themes.

The first theme, coming-out migration, was really two themes: (1) the everyday ways in the social dynamics of places mediate the coming-out journey; and (2) the trajectories or flows of coming-out journeys themselves. The second theme of embodied health experiences is discussed in its own chapter. The final two themes, economic migration and the institutional mediation of migration, were reconfigured into two differently constructed chapters. During the coding process, it became clear that the economic and political factors mediating gay men's migrations to Ottawa and Washington, D.C., were double-edged in nature. While the presence of the civil service, public sector jobs, and visible advocacy institutions have attracted gay men to those cities, they have also regulated the daily lives of gay men in particular ways. It was more logical, then, to create one chapter about the political-economic pulls of Ottawa and Washington, D.C., and second on the historic and present-day governmentalities of capital cities and their influence on the lives of gay men.

\subsection{Study Limitations}

The findings of the study must be considered in light of several methodological limitations. First, the particular sample of men selected for the study is both (1) too small to define dominant or typical migration trajectories among gay men and (2) reflects the experiences of a mobile, educated group of men. Given that the sample comprises only 48 men, it does not provide a direct alternative to national-level studies on the locational 
choices of same-sex couples (Black et al. 2002, 2007; Gates and Ost 2004; Walther and Poston 2004; Cooke and Rapino 2007). Instead, it uses the lens of individual experience to understand the intersection of sexuality with migration throughout the life course. Most of the men interviewed, however, were highly educated (usually with a bachelor's degree or higher), and therefore had a greater ability to move and a higher likelihood of having positive experiences after moving, such as gainful employment (see Finney 2011). Studying migration, in and of itself, may imply researching a group of men with the financial and educational means to move away from places where they encounter discrimination, stigma, or difficulty coming out to friends and family. Consequently, there is an inherent class bias in the study despite setting parameters for age, ethno-racial, and geographic diversity.

The second limitation comes from the temporal constraints of the respondents. Since respondents are asked to look back on their migration experiences, they may recount their experiences more cohesively or logically than they actually transpired. They may also struggle to explain the distinct motivators or combination of motivators involved in their moves. In migrations associated with coming out, for example, respondents discussed instinctive or subconscious desires to move as often as they described moving after disclosing a gay identity. Similarly, respondents sometimes had difficulty separating the roles of sexuality and maturation in migration decisions and the life changes they experienced after they migrated, reflecting that "homosexuality may be inextricable from other lines of identity development" (Kertzner 2001, 86). Interviews asked respondents to clarify or qualify these distinctions whenever possible, rather than simply reading in causal progressions of events, such as choosing to leave a place 
because it was perceived to be homophobic. The adoption of a semi-structured interview format, along with the disclosure of coding processes, helps to address the complexities and challenges of using retrospective accounts. 


\section{CHAPTER 4}

\section{Gay Men's Migrations from a Life Course Perspective}

\subsection{The Life Course as a New Approach to Human Development}

Understandings of life events and life changes have long been grounded in human development or life cycle models from psychology and psychiatry (see, for example, Erikson 1963; Levinson 1978). These stage-sequential models typically employed pregiven phases, such as early socialization, identity formation, and partnership, to describe the transitions that individuals were expected to undergo at particular ages. Biological notions of human development, however, failed to acknowledge how differences among institutions such as schools and workplaces, or historical factors such as legally sanctioned homophobia and discrimination, might affect the realization of individual potentials and life goals, such as career advancement, marriage, and child rearing (Kertzner 2001; Barker et al. 2006; Bailey 2009). Consequently, developmental and lifecycle models have presumed a smooth linearity in life transitions that is unrealistic in the context of the historically and spatially variegated contingencies in gay men's inclusion, social support, and human rights (Kimmel and Sang 1995; Barker et al. 2006). Even the work on human development that does acknowledge sexual difference still employs taken-for-granted conceptions of transition. Coming out, for example, has problematically been framed as a sequential-stage event where initial same-sex attraction is followed by identity confusion and same-sex experimentation, identity assumption, and finally self-identification as gay or lesbian (Cass 1979, 1996; Troiden 1989).

The life course model, which views life events through a longitudinal lens incorporating historical factors, individual subjectivities, and social contexts, provides a 
more realistic framework for understanding the lives of gay men and other queer people. In some ways a reaction to more fixed and static developmental or life cycle approaches, the life course is typically defined as a series of individual transitions that are culturally and institutionally framed. A life course approach therefore examines the interplay of institutional factors (e.g., labour markets and government regulations), individual characteristics (e.g., age, ethnicity, and sexuality), interpersonal relationships (e.g., social networks), and historical factors in the mediation of life events (Heinz and Krüger 2001; Floyd and Bakeman 2006; Kobayashi and Preston 2007).

Although the life course approach has mostly been employed in the fields of sociology and demography, it has also has a long tradition of application to geographic phenomena such as migration. Often considered the first application of the life course concept in geography, Thomas and Znaniecki's (1918) research on Polish immigrants to the Midwestern United States employed biographical accounts of individual immigrants' lives to understand both Polish culture itself and its transformation across both places (e.g., Poland, Chicago) and life course. Since then, geographers have begun to consider how migration might mediate life course events and trajectories, suggesting that movement is not just a response to economic and political forces (Ravenstein 1885), but a means of actively forming identities and negotiating life events (Vanderbeck 2007; Kobayashi and Preston 2007; Bailey 2009).

Despite offering a more nuanced approach to life trajectories than a stagesequential approach, the life course is still limited in some ways. First, life course research, especially in highly quantitative fields such as demography, still frequently presumes ordered sequences of events, such as education, employment, marriage, 
childbearing, and retirement. In addition, quantitative, nomothetic research on the life course (e.g., measuring for age effects and cohort or generational effects on the timing of various stages) has both depended on and reified these sequences (see, for example, Palmore 1978; Elder 1985). Second, these frameworks are often heteronormative, assuming that events such as marriage and becoming parents are equally applicable to all individuals. Although more recent research has acknowledged destandardized variations in the life course (see, for example, Widmer and Ritschard 2009 for an analysis of how changing constructions of gender roles impact the life course), it is still often conceived through frameworks that render sexuality an omission or afterthought.

For gay men, the institutions and social networks that typically shape life course events are especially complex. Not only are levels of social acceptance for sexual nonnormativity highly variable across space, but the rights and regulations that dictate particular life course events such as marriage may exclude gay men. Since gay men's life courses are highly affected by spatial contingencies, they are perhaps more likely to use migration as a means of navigating these contingencies during life events. More specifically, communities - the place-based collections of individuals and practices that steer the life course and shape its various turns and trajectories — are conceived differently among queer people than they are among heterosexuals. In contrast to social capital theory (Putnam 1993; McKenzie and Whitley 2002), which paints formations such as nuclear families and parent-teacher associations as "bonding" forces in the development of individuals and the places they inhabit, community for queer people is a more contingent and geographically variable construct. While there is certainly no single type of queer community (or heterosexual community, for that matter), the particular 
factors that might comprise it (e.g., a large and visible queer population, advocacy organizations, and social venues) are disproportionately located in particular places, usually cities. This does not discount the existence of rural queer communities (see Osborne and Spurlin 1996; Phillips et al. 2000), but acknowledges that the ones that become familiar, visible, or known to the outside are located in relatively few places.

In addition, the building blocks of queer communities - and the particular blocks that are leveraged at various points in queer life courses - have changed over time. Political and social mobilizations, which have been historically central to queer communities, have alternately focused on liberation (1970s), HIV/AIDS (1980s and 1990s), and more recently, marriage rights (see Lind 2004; Smith 2005a). The institutions most relevant to these various mobilizations have also changed, rendering the lobbying firms of Washington, D.C., just as relevant as the streets of San Francisco in the formation of a localized queer activist community. The types of communities sought out by gay men may also change across the life course, with attraction to a more concretized set of social venues, sports and activity groups, and even branded neighbourhoods eventually replaced with more subtle forms of kinship organized around extended “families of choice” (Weston 1991; Cohler and Hostetler 1997; Weeks et al. 2001).

In the following brief positioning chapter, I explain the ways in which the life course model is complicated by considerations of sexuality and mobility, and highlight some of the distinctive ways in which gay men observed their life courses to be influenced by social networks, institutions, and historical contingencies and contexts. In this approach, transitions such as coming out, for example, might be framed as complex, cultural, socially, and geographically influenced processes of "becoming" (Worth 2009) 
rather than taken-for-granted steps or stages. Recent research applying the life course model to gay men and other queer people provides some useful ways for thinking about how non-normative sexual identities may direct, interrupt, or alter the life course (Kimmel and Sang 1995; Cohler and Galatzer-Levy 2000; Kertzner 2001).

\subsection{Integrating Sexuality into the Life Course}

The first key theme in recent research on gay men's life courses is the construction of homosexuality as both a deviant category of identity and an illegal practice - until 1969 in Canada and until 2003 in many states in the United States (Halperin 2000; Olund 2010). Under these constructions of sexual non-normativity, many gay men have been exposed to stigma and discrimination early in life. These experiences not only lead to the concealment or repression of a gay identity, but a subsequent delay in the formation of romantic relationships (Kertzner 2001; Meyer 2003; Barker et al. 2006). Later in life, gay men may feel off schedule relative to their heterosexual peers who have married and started families or established community-based identities as fathers, mentors, coaches, or elected officials (Simon and Gagnon 1986). In addition, the major life changes that gay men may make, such as permanent partnership, may not be legally validated by marriage and partner-benefit rights, or informally validated through the acknowledgement of anniversaries and other milestones.

Perceived social stigma and the ongoing discourse of heterosexuality also forces gay men to negotiate coming out at various points in the life course. Disclosure is not just a singular event that occurs during a "transition" to homosexuality during adolescence or young adulthood; it is an ongoing process involving family members, friends, colleagues, 
and institutional settings encountered throughout life. Gay men may and other queer people may feel pressure to come out (or alternately, conceal or manage their identity) when beginning a new job (Badgett 1996; Humphrey 1999; Griffith and Hebl 2002) or accessing health care (van Damme 2004; Cant 2005), for example.

A second key theme is the relationship between place, sexuality, and health and well-being. Kertzner $(2001,87)$ observes that the mental and emotional health problems that gay men may encounter as a result of minority stress and stigma may "disrupt developmental milestones including the formation of sexual and social identity in adults." In particular, the "minority stress" that gay men experience as a result of social stigma and prejudice put them at higher risk for anxiety, depression, suicide ideation, and other potentially disruptive health outcomes (Meyer 1995, 2003; Cochran 2001). The ongoing experience of rights denial among gay men and other queer people has also been observed to negatively affect their mental and emotional health (Herdt and Kertzner 2006). There is therefore an increasing need to not just prove that many poor health outcomes among gay men are socially influenced (as opposed to products of poor health behaviors or non-normative sexualities themselves), but to show how variations in landscapes of rights and acceptance, along with individual experiences and subjectivities, might influence gay men's health (N. Lewis 2009).

The third key theme is the role of historical events and place-based social histories in the life courses of gay men. Gay men, at least those living in western countries, have witnessed a change in cultural attitudes toward non-normative sexualities, particularly the transition from homosexuality as individual pathology—classified as a disorder by the American Psychiatric Association until 1973 - to a sexual identity shared by a large 
proportion of the population ${ }^{5}$ (Barker et al. 2006). Gay life courses, however, are shaped not only by social stigma and prejudice, but by acts of resisting and transforming these conditions through protests, parades, court petitions, and other forms of public organizing (Kertzner 2001; Smith 2005a). The HIV/AIDS pandemic also figures prominently in the life courses of many gay men as a source of societal and self-regulation, political mobilization, and personal grief or trauma. The pandemic, while causing many gay men to conflate sexual desire with illness or to avoid same-sex sexual contact, also provided opportunities for community-building and for individual men to develop communitybased identities as activists (M. Brown 1997; Kertzner 1997, 2001; Epstein 2003).

\subsection{Integrating Mobility into the Gay Life Course}

Despite increasing attention to the role of sexuality in the life course, few studies consider the roles of mobility and migration in shaping the life trajectories of gay men and other queer people. Given extensive documentation of the unevenness in rights and social acceptance for queer people, especially between rural and urban areas (Weston 1995; Binnie 2004; Barton 2010) but also across regions and countries (Smith 2005a; Lubhéid 2008; N. Lewis 2009), it seems reasonable that gay men might employ relocation as a means of negotiating various life course events. Often, migration itself has been framed as a life course event (Dykstra and van Wissen 1999). More frequently, however, migration has described as tool through which events such as labour market entry, retirement, and the initiation of childhood education are negotiated (Cooke 2003; Kobayashi and Preston 2007).

\footnotetext{
${ }^{5}$ As mentioned earlier, the category of homosexuality itself emerged from the assumed pathology of sexual non-normativity and the consequent interest in grouping sexually non-normative individuals into a single, regulate-able population (see Foucault 1978; Halperin 2000).
} 
Queer people are likely to employ migration in a similar fashion, but in the context of distinctive spatialities and temporalities in the rhythms and sequences of queer lives (Halberstam 2005; Barker et al. 2006; Vanderbeck 2007; Bailey 2009). Some processes, such as coming out, are unique to queer people and therefore unlikely to be addressed in the usual streams of life course research. Meanwhile, job searches and marriage are undertaken by both heterosexual and queer people, but queer people are likely to encounter a different landscape of institutional rights and protections (e.g., marriage laws and workplace anti-discrimination policies) that mediate these events. By the same token, people of colour and immigrants have also been observed to experience the life course differently from others (see Kobayashi and Preston 2007; Finney 2011), suggesting that marginalization in general has a profound impact on life trajectories. As forthcoming chapters show, some men's moves were informed by the intersection of their race or class with sexual identity (Valentine 2007). While the forthcoming discussion does not foreclose the role of other marginalized subjectivities in men's migration narratives, it gives analytic primacy—by virtue of interview design and theoretical context - to the influence of sexuality. As queer of colour scholars and other geographer studying intersectionality have suggested, the impact of race cannot be separated from other subjectivities (Valentine 2007; Haritaworn 2008). Consequently, this study aims to highlight how race and sexuality interact in certain individuals' narratives; for example, the ways in which men perceived the accumulation of multiple signifiers of difference.

Based on analysis of gay men's migration narratives and the broader literature on life course, it seems that several factors coalesce to shape migrations across gay life courses (see Figure 4.1). In general, this thesis frames transitions, or what might better be 
termed "life events," as the catalysts for migration among gay men. While many of these life events may be similar to those experienced by heterosexual men (e.g., career and relationship changes), they may also be rendered different or more complicated by the ongoing processes of disclosure or coming out that intersects them. In addition, the specifics of migration - including when, from where, and to where—are influenced by some combination of social and familial contexts (e.g., home life, especially during childhood or adolescence), historical events and contexts (e.g., changes in laws), and institutional contexts (e.g., schools and, later in life, workplaces). All of these contexts are, in turn, influenced by the places in which migrations begin and terminate; this type of place context might include size, community infrastructure, and social attitudes.

Migrations decisions are also influenced by individual subjectivities, some of which are likely to stay constant over time (e.g., ethno-racial identity), but others (e.g., sexual identity) that will change with time and age.

\section{Figure 4.1. Factors Driving Migration across the Gay Life Course}

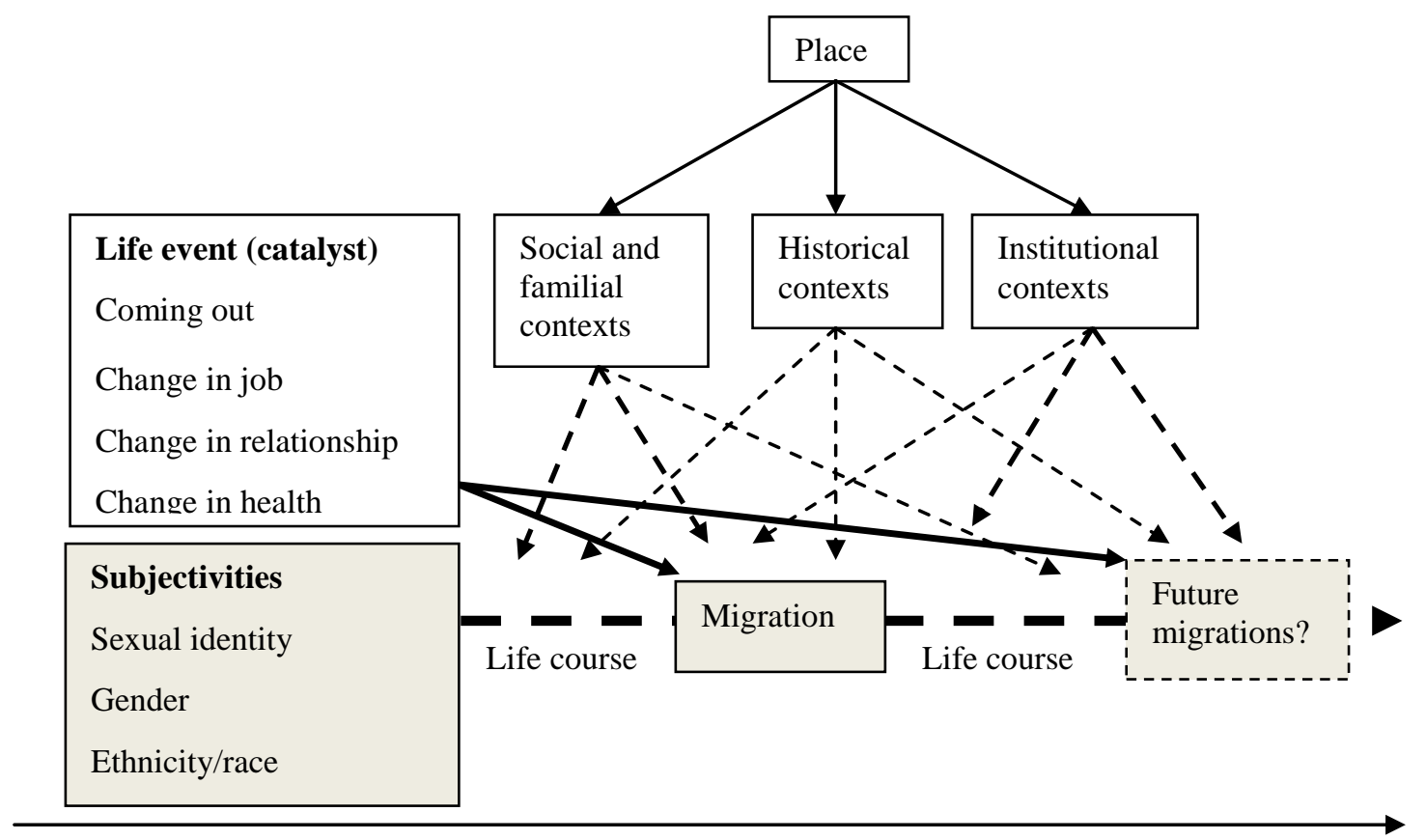

Time and Age 
The individual narratives of the 48 men in this study confirm that place-and particularly movement between places - is central in the negotiation of life course events for queer people (Knopp 2004). Although the respondents had diverse backgrounds and had moved to Ottawa or Washington, D.C., at different points in life, they almost universally moved during life transitions such as beginning university, looking for a first or new job, or initiating a process of coming out (see Tables 4.1 and 4.2). Building on existing research life course research that considers the interplay of the personal, interpersonal, historical, and institutional, the following discussion considers some of the ways in which gay men's lives shape and are shaped by migration decisions. I consider four distinct aspects of gay life courses and their relationships to migration: (1) the relationship between maturation, gay identity, and mobility; (2) access to and cementation of social networks; (3) historical contexts; and (4) institutional considerations and constraints. 
Table 4.1. Life Course Events Occurring at Time of Migration, Sample of Selfidentified Gay Men (N=24), Ottawa, Ontario, Canada

\begin{tabular}{|c|c|c|c|c|}
\hline Pseudonym & City & $\begin{array}{l}\text { Age at time } \\
\text { of migration }\end{array}$ & Previous place lived & $\begin{array}{l}\text { Life course event(s) } \\
\text { occurring }\end{array}$ \\
\hline Steve & Ottawa & 41 & Washington (DC) & $\begin{array}{l}\text { Career change, aging } \\
\text { parents }\end{array}$ \\
\hline Raymond & Ottawa & 23 & Toronto $(\mathrm{ON})$ & Entering graduate school \\
\hline Pete & Ottawa & 23 & Montebello (QC) & Career change \\
\hline Anthony & Ottawa & 27 & Saskatoon (SK) & Sought job transfer \\
\hline Sebastian & Ottawa & 23 & Montreal (QC) & Career change \\
\hline Luke & Ottawa & 21 & Welland (ON) & Family relocation \\
\hline Derek & Ottawa & 25 & Winnipeg (MB) & Entering labour market \\
\hline David & Ottawa & 26 & London (UK) & $\begin{array}{l}\text { Entering labour market, } \\
\text { coming out }\end{array}$ \\
\hline Terry & Ottawa & 27 & Point-aux-Roches (ON) & $\begin{array}{l}\text { Entering labour market, } \\
\text { coming out }\end{array}$ \\
\hline Chad & Ottawa & 27 & Edmonton $(\mathrm{AB})$ & Sought job transfer \\
\hline Johnson & Ottawa & 27 & Halifax (NS) & Partner's career change \\
\hline Ashton & Ottawa & 28 & London (ON) & Entering labour market \\
\hline Jerry & Ottawa & 45 & Bonn (GER) & $\begin{array}{l}\text { End of career assignment, } \\
\text { end of a relationship }\end{array}$ \\
\hline Shawn & Ottawa & 26 & Alfred $(\mathrm{ON})$ & $\begin{array}{l}\text { Entering labour market, } \\
\text { coming out }\end{array}$ \\
\hline Kent & Ottawa & 25 & Montreal (QC) & Career change \\
\hline Randall & Ottawa & 32 & Halifax (NS) & $\begin{array}{l}\text { Entering graduate school, } \\
\text { end of a relationship }\end{array}$ \\
\hline Wally & Ottawa & 31 & Halifax (NS) & Career change \\
\hline Rick & Ottawa & 25 & London $(\mathrm{ON})$ & Career change \\
\hline James & Ottawa & 31 & Vancouver (BC) & Career change \\
\hline Mark & Ottawa & 23 & Corner Brook (NL) & Career change, coming out \\
\hline Steve & Ottawa & 35 & Washington (DC) & Partner's career change \\
\hline Francis & Ottawa & 17 & Tracadie (NB) & Beginning education \\
\hline Sam & Ottawa & 35 & Montreal (QC) & Re-entering labour market \\
\hline Daniel & Ottawa & 18 & Arnpior (ON) & Entering university \\
\hline
\end{tabular}




\section{Table 4.2. Life Course Events Occurring at time of Migration, Sample of Self- identified Gay Men (N=48), Washington, D.C., U.S.A.}

\begin{tabular}{|c|c|c|c|c|}
\hline Pseudonym & $\begin{array}{l}\text { Current } \\
\text { city }\end{array}$ & $\begin{array}{l}\text { Age at time } \\
\text { of migration }\end{array}$ & Previous place lived & Life course event(s) occurring \\
\hline Marshall & DC & 17 & Kenilworth (NJ) & Entering university, coming out \\
\hline Jesse & $\mathrm{DC}$ & 21 & Santa Fe (NM) & Entering labour market \\
\hline Ian & $\mathrm{DC}$ & 25 & Seattle (WA) & Career change \\
\hline Max & $\mathrm{DC}$ & 25 & Honolulu (HI) & $\begin{array}{l}\text { Overcoming health problems, } \\
\text { moving closer to home }\end{array}$ \\
\hline Jason & $\mathrm{DC}$ & 22 & Bangkok (THD) & $\begin{array}{l}\text { Entering graduate school, } \\
\text { coming out }\end{array}$ \\
\hline Tim & DC & 21 & Gainesville (FL) & Entering graduate school \\
\hline Nick & $\mathrm{DC}$ & 26 & Columbus $(\mathrm{OH})$ & Entering labour market \\
\hline Michael & $\mathrm{DC}$ & 40 & Madison (WI) & $\begin{array}{l}\text { Re-entering labour market, } \\
\text { career change }\end{array}$ \\
\hline Joseph & $\mathrm{DC}$ & 27 & Tallahassee (FL) & Career change, coming out \\
\hline Doug & $\mathrm{DC}$ & 18 & Longmont $(\mathrm{CO})$ & Entering university, coming out \\
\hline Adam & $\mathrm{DC}$ & 28 & Dayton $(\mathrm{OH})$ & Career change \\
\hline Arthur & $\mathrm{DC}$ & 21 & Emory (VA) & $\begin{array}{l}\text { Entering labour market, coming } \\
\text { out }\end{array}$ \\
\hline Marshall & DC & 28 & New York (NY) & $\begin{array}{l}\text { Leaving graduate school, career } \\
\text { change }\end{array}$ \\
\hline Phillip & $\mathrm{DC}$ & 36 & Philadelphia (PA) & $\begin{array}{l}\text { Career change, end of a } \\
\text { relationship }\end{array}$ \\
\hline Martin & $\mathrm{DC}$ & 42 & Madison (WI) & Partner's career change \\
\hline George & $\mathrm{DC}$ & 35 & New York (NY) & Entering graduate school \\
\hline Jordan & $\mathrm{DC}$ & 23 & Berkeley (CA) & Entering graduate school \\
\hline Jake & $\mathrm{DC}$ & 26 & New York (NY) & Career change \\
\hline Jack & $\mathrm{DC}$ & 21 & Seattle (WA) & $\begin{array}{l}\text { Entering graduate school, } \\
\text { coming out }\end{array}$ \\
\hline Peter & $\mathrm{DC}$ & 24 & Austin (TX) & Career change, coming out \\
\hline Owen & $\mathrm{DC}$ & 23 & Williamsburg (VA) & Entering labour market \\
\hline Brian & $\mathrm{DC}$ & 22 & Middletown (CT) & Entering graduate school \\
\hline Jeffrey & DC & 31 & Slippery Rock (PA) & Entering labour market \\
\hline Shane & $\mathrm{DC}$ & 21 & Richmond (VA) & Entering labour market \\
\hline
\end{tabular}




\subsection{Maturation, Identity Formation, and Mobility among Gay Men}

As most life course research indicates, age and individual maturation are central in determining the time in life at which particular events occur. Yet as mentioned above, strict time-clock, stage-based conceptions of maturation elide the contingent and relational nature of individual development (Schwanen 2006; Bailey 2009). For gay men in particular, shifts in identity_particularly in the importance of a gay identity in relation to age - may shape their migration decisions over the life course. The age of coming out, for example, might influence the chosen destination (e.g., a university or an urban gay village), the length of time over which a spatially defined gay community remains central to identity, and the timing of future life events, such as relationships and career decisions (Kertzner 2001; Barker et al. 2006). Although respondents were not asked directly about how age and individual development affected their migration decisions, many men indicated that improvements, declines, or changes in certain aspects of life were mediated by aging as much as they were by changes in location. The following narratives demonstrate not just the dual roles of age and relocation in the life courses of gay men, but also the ways in which both informed their migration decisions in a dialectic fashion.

Only three out of 48 men (about 6\%) identified coming out as their most important reason for moving (all of these men lived in Ottawa), but many alluded to a strong relationship between the formation of a gay identity and their choices about where to live at various points in life. Many discussed their interest in locating themselves in a known gay center — or even a specific gay village — as they began to come out, usually in their late teens or early twenties. Gay men's interests in defining a gay identity vis-à-vis a symbolically constructed or "ethnic" community of other gay men, while not universal to 
all coming-out narratives, are well documented (Weston 1995; Forest 1995; M. Brown 2000; Valentine and Skelton 2003). Men that moved to Ottawa or Washington, D.C., from smaller communities, usually in their teens or twenties, felt that moving to larger cities (albeit smaller than the ostensible homelands of New York or Toronto) provided some of the freedom needed to define changing sexual and social identities. This was borne out in the analysis of men's moves across the life course and up and down the urban hierarchy. Modeled after Plane et al.'s (2005) analysis of the U.S. general population, Figures 4.2 (Ottawa sample), 4.3 (Washington, D.C.), and 4.4 (both cities), show that the men who moved earlier in life tended to move from a smaller city. In contrast, men who moved later in life showed no distinct pattern of movement up or down the urban hierarchy.

Figure 4.2. Migration to Ottawa by City Type of Origin and Age of Migration, Sample of Self-identified Gay Men (N=24), Ottawa, Ontario, Canada

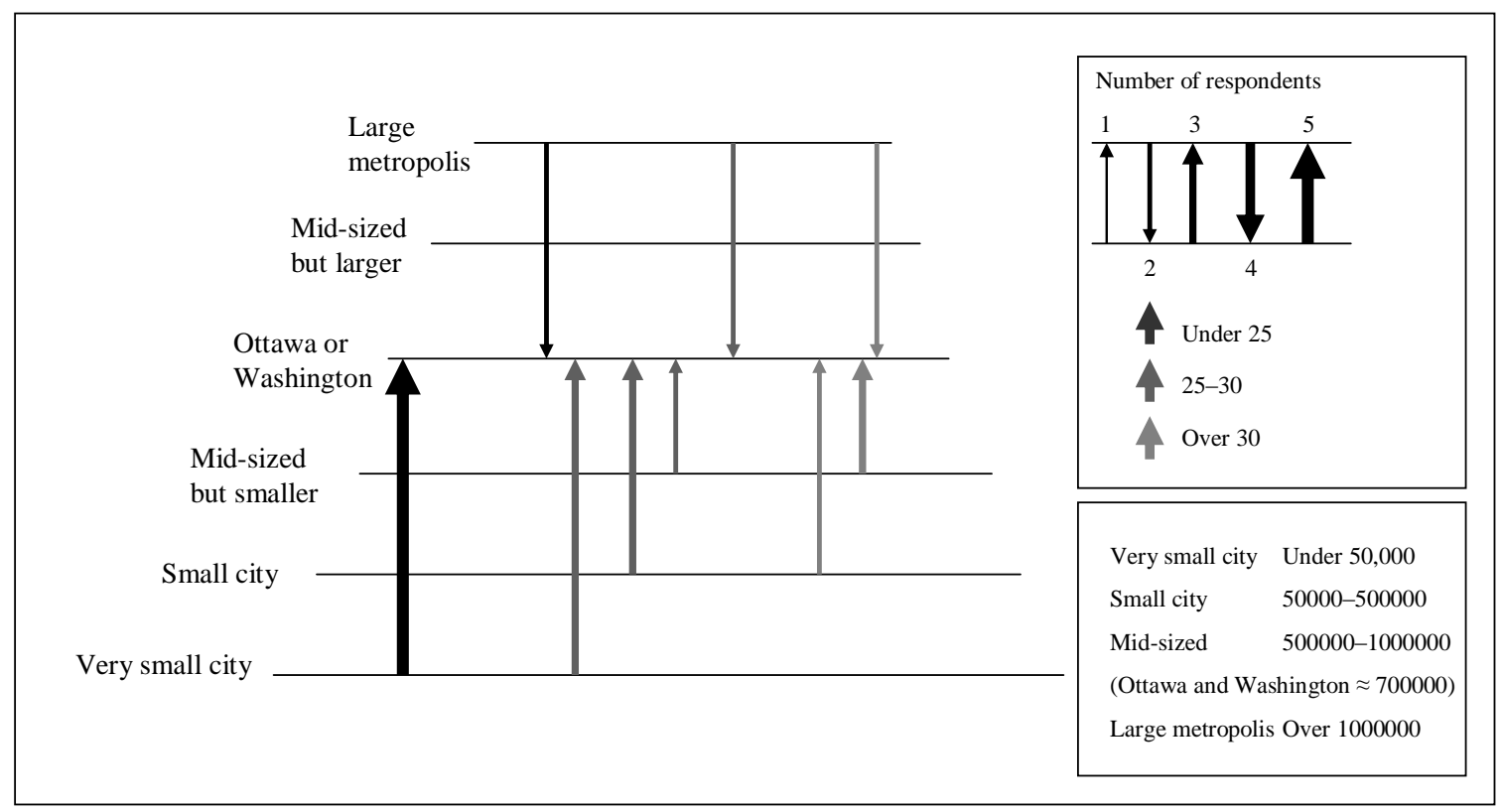


Figure 4.3. Migration to Washington, D.C., by City Type of Origin and Age of Migration, Sample of Self-identified Gay Men (N=24), Washington, D.C., U.S.A.

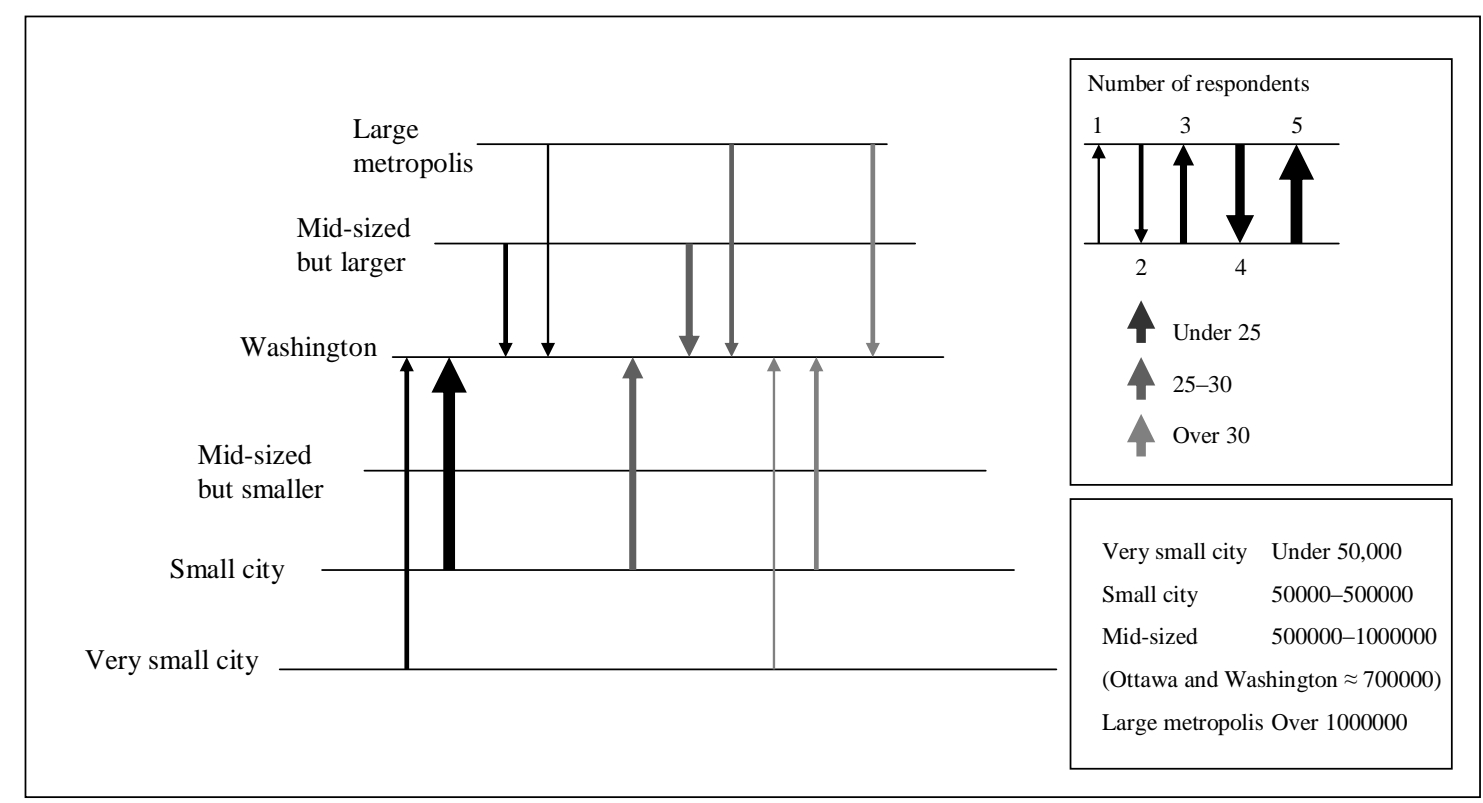

Figure 4.4. Migration to Ottawa and Washington, D.C., by Place of Origin and Age at Time of Migration, Sample of Self-identified Gay Men ( $=48)$, Ottawa, Ontario, Canada, and Washington, D.C., U.S.A.

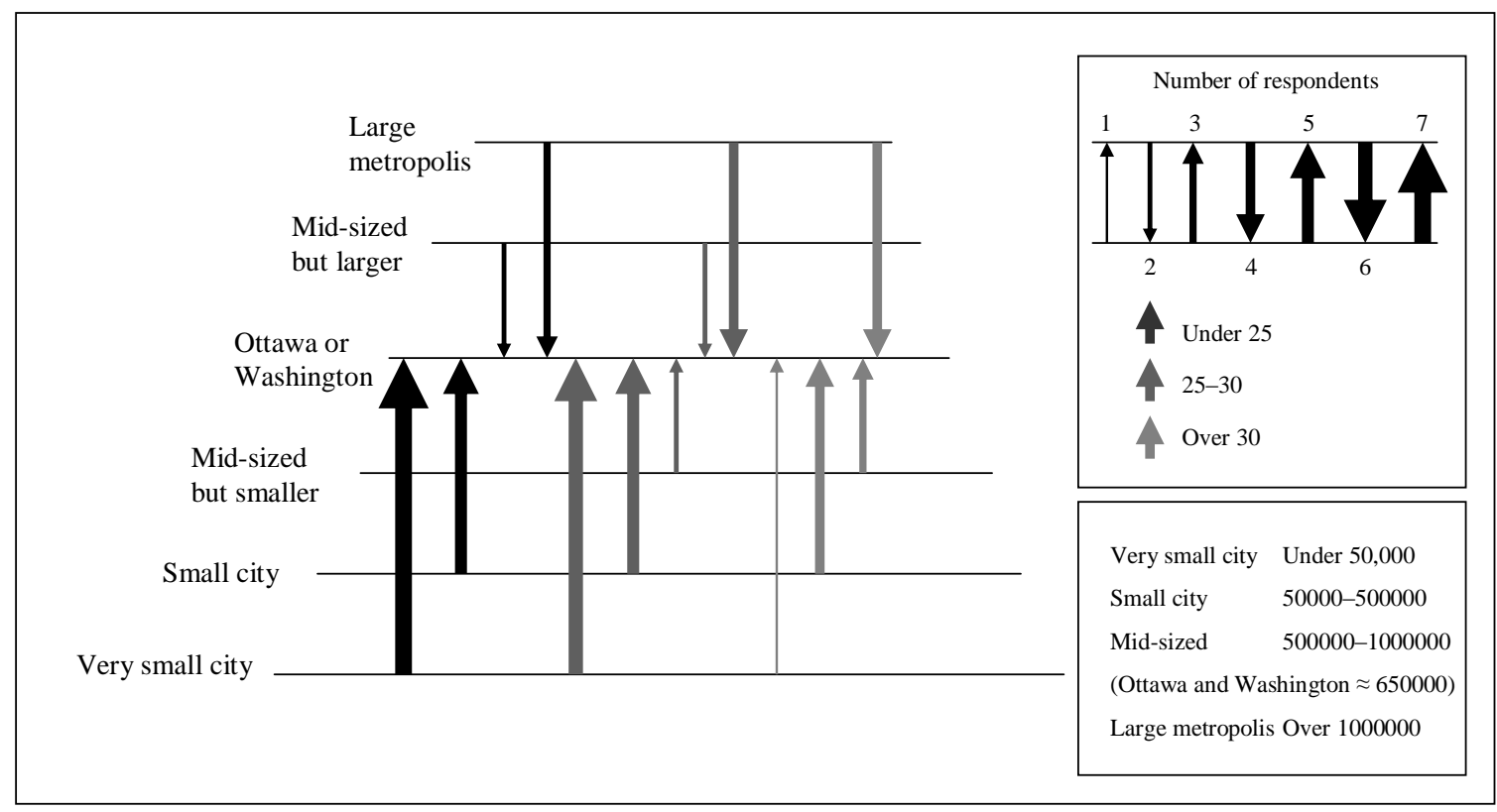


Men invoked ideas of comfort and safety in reference to moving to a larger city relatively early in life (see Gorman-Murray 2009). Sebastian, who moved from rural Nova Scotia to Ottawa in his late teens, described coming to Ottawa for university as "the freedom to be able to come out and be who [he] was" (Sebastian, 42, Métis, Mik'maq, French-Canadian) ${ }^{6}$. Nick, who moved from suburban Massachusetts to Washington, D.C., at roughly the same age, felt it was not just attending university itself, but moving to a university in a large city, would provide the right environment to come out in his late teens. "[Probably] any university I went to would have been a big improvement. It's just sort of if you get toward [the coming-out] stage and discover who you, who you are ... and yeah, maybe I wanted to live in a city like D.C." (Nick, 26, white, Eastern EuropeanAmerican). Also invoking the idea of comfort, Shawn, who moved to Ottawa from northern Ontario in his early twenties found that "there was a certain comfort in ... being on my own and being able to live my life without the constant scrutiny of others" (Shawn, 42, white, French-Canadian).

For others, comfort came not just from being in a larger place that offered greater anonymity, but from the opportunity to define oneself in relation to a specific gay community. Raymond described his hesitation about moving to Ottawa from Toronto in his mid-twenties after having used the city's Church Street village as a "place to come out in." "I was very scared about moving," he said. "I was very scared of leaving that sort of safety of that village" (Raymond, 31, black, Jamaican-Canadian). These accounts reflect

\footnotetext{
${ }^{6}$ Randomly assigned pseudonyms are used to protect the identities of the respondents. Basic age and ethnoracial data is provided with each pseudonym to provide an idea of each respondent's unique positionalities. In a few cases, multiple identifiers (e.g., British, Canadian, Anglo) are imputed to single ones (e.g., AngloCanadian). While demographic details are not always pertinent to the particular aspect of migration being discussed, they are retained with each quote for purposes of consistency. Other details of each respondent's migration narrative (e.g., place of origin and historic context of the migration) are provided in the text.
} 
both (1) the centrality of "moving out to come out" (M. Brown 2000) in the identity formation of gay men, usually early in life, and (2) the tendency for this to manifest in moves from smaller places to larger ones.

Men in the older age cohorts, however, observed that living in a city, and accessing the gay communities within it, became decreasingly important as they aged. As several studies in psychology and human development have noted, gay men tend to define their identities less in relation to the gay community later in the life course, and their social supports tend to be drawn from a more diverse array of sources (Kertzner 2001; Barker et al. 2006). In line with this research, men's narratives of anticipated migrations also alluded to a decreasing interest in the gay community as it is typically imagined, describing a willingness to move down the urban hierarchy that increased with age (see Figures 4.4, 4.5, and 4.6). When sorted by their current age, men under 30 typically anticipated moving to a similarly sized or larger city-especially in the Ottawa case-while those who were over 40 showed a more mixed response. Not only were these men most likely to "stay put," but those who anticipated moving were as likely to move to a smaller city as they were a larger one. 
Figure 4.5. Next Anticipated Migration, by Destination and Age at Time of Interview, Sample of Self-identified Gay Men (N=24), Ottawa, Ontario, Canada

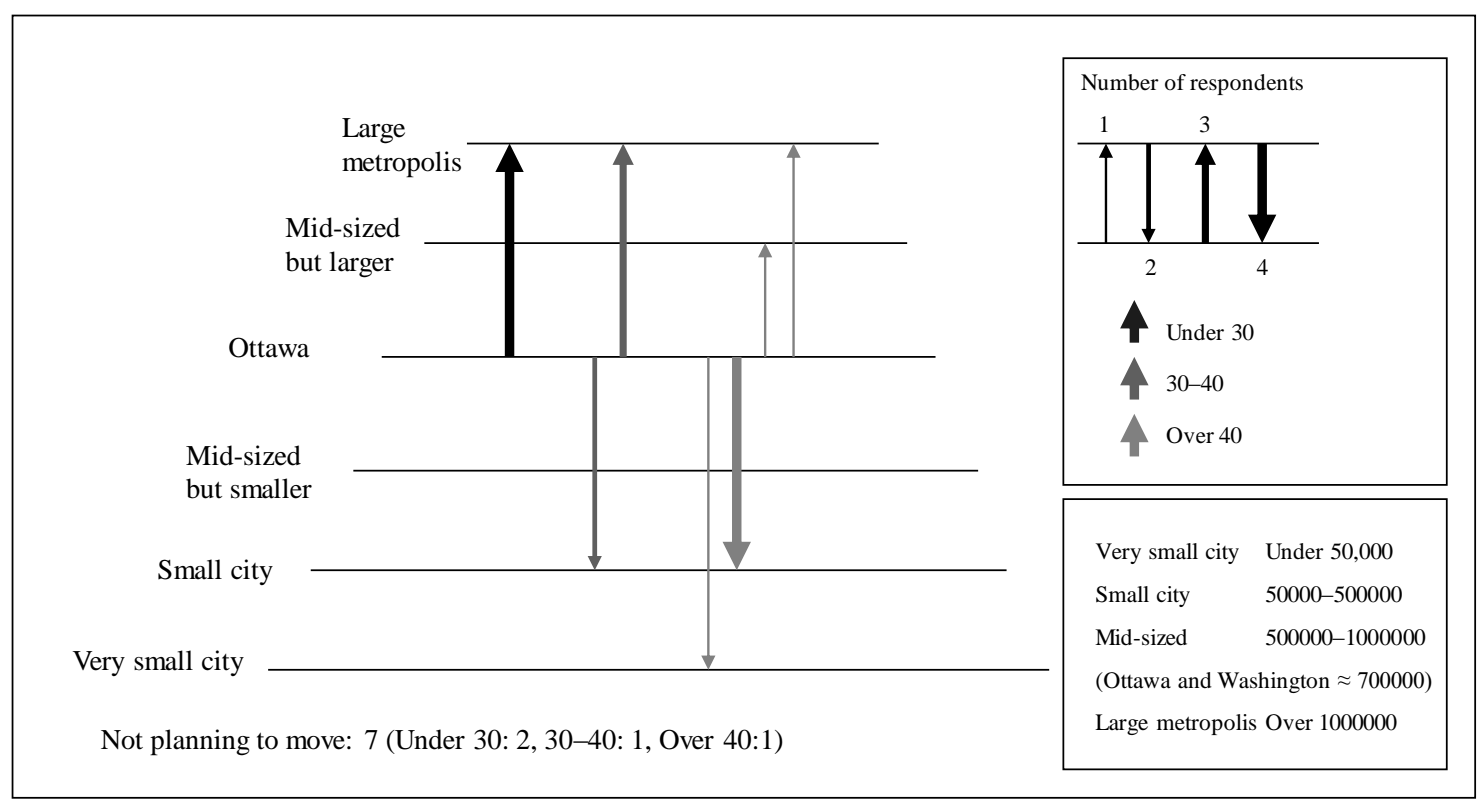

Figure 4.6. Next Anticipated Migration, by Destination and Age at Time of Interview, Sample of Self-identified Gay Men (N=24), Washington, D.C., U.S.A.

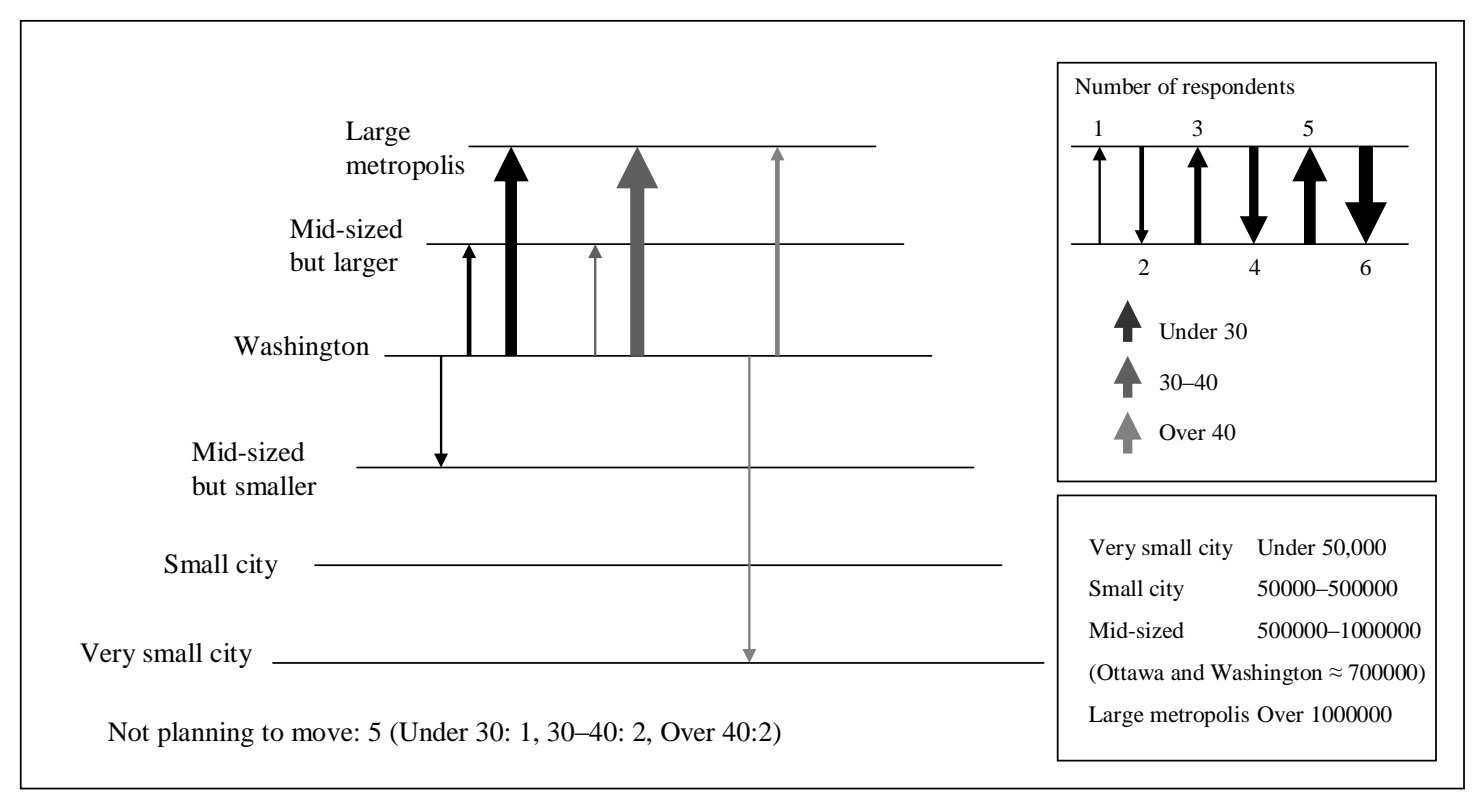


Figure 4.7. Next Anticipated Migration, by Destination and Age at Time of Interview, Sample of Self-identified Gay Men (N=48), Ottawa, Ontario, Canada, and Washington, D.C., U.S.A.

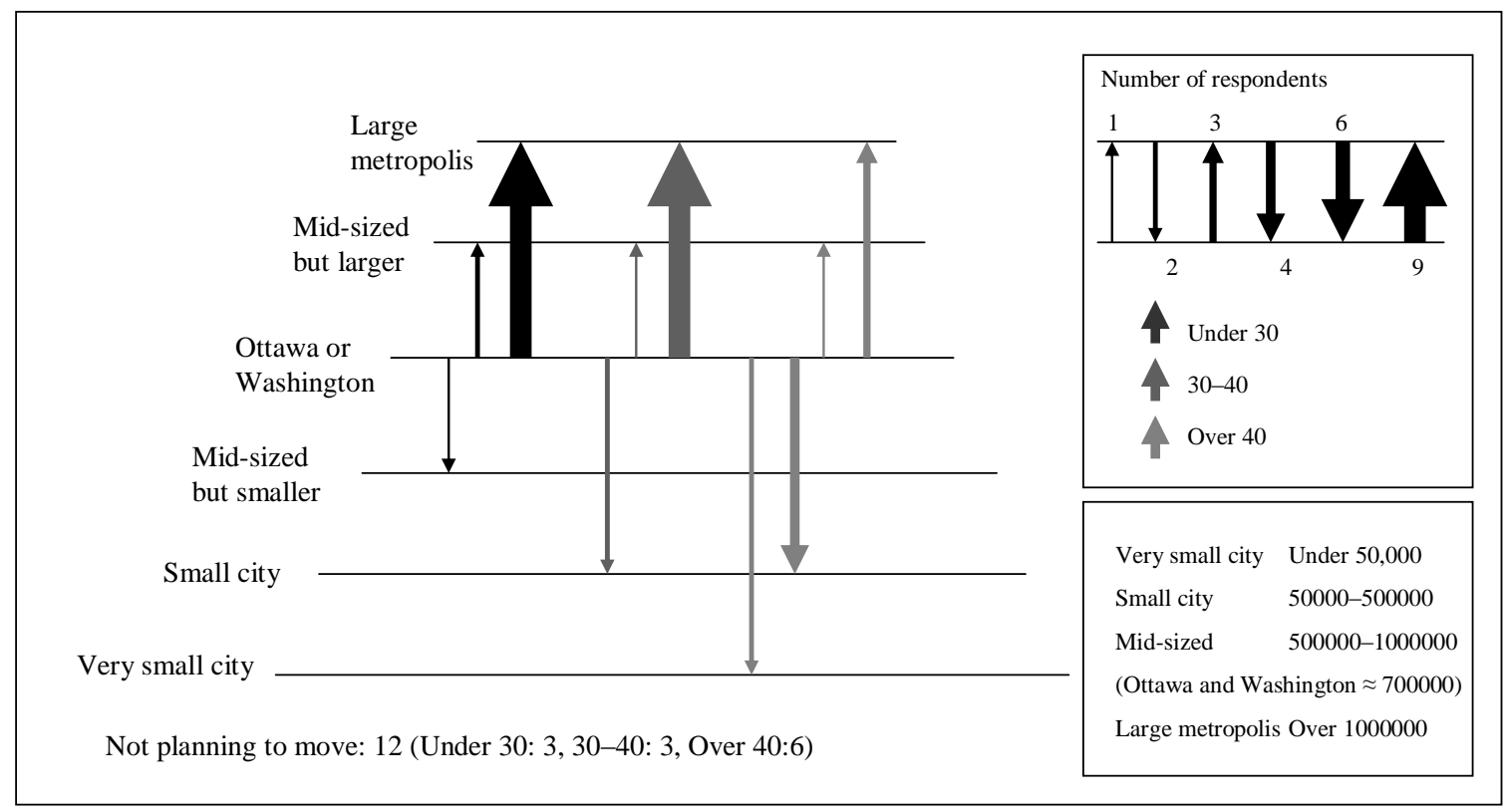

The decreasing likelihood of moving to a large metropolitan area later in life reflects just one aspect of how gay men's perceptions of community change as they get older. In general, the older cohorts of men interviewed felt less reliant on the gay community — at least in the highly visible, mortar-and-bricks sense of the term — but continued to rely highly individualized communities of friends and colleagues. As David (55, white, Anglo-Canadian) said, "I think now, at this stage in life, it's the comfort of friends, associates, former colleagues from the work force, current colleagues ... it's that free will association of like-minded guys and the pleasure of their company." For other men, pulling away from the community was related to becoming partnered and engaging in domestic practices no different than those of heterosexual couples. Marshall, a 29year-old in Washington, D.C., felt that all of his friends of a similar age had begun to focus on long-term relationships. "Maybe everybody's wanted a boyfriend all along," he 
said, "but it seems like people are focusing more on long-term rather than a couple dates" (Marshall, 29, white, Italian-American). Michael, who came out later in life and had lived in smaller cities such as Madison, Wisconsin, for most of his life, felt little need to live in distinctively gay areas, especially after he was partnered: “.... as I get older and [my partner and I] get older, that distinction between the gay community and the mainstream community, uh, doesn’t really matter much” (Michael, 44, Hispanic, Paraguayan).

For others, weaning oneself from the community was related to the security of individual identities. Terry, who lived in Ottawa, explained that by 30 , he felt secure enough in his (gay) identity that he no longer needed the social venues or interactions of the community. Sam, who moved from Montreal to Ottawa in his early thirties, explained that with age, his identity was no longer based on the institutional components of the community, especially participating in specifically gay organizations:

I think it's becoming less prominent, I would say, than my Montreal days, just because I wasn't in that coming out phase, I wasn't in the activist phase and I think I'm sensing that ... I could be in a book club that isn't gay, or I could be in a swimming club-I've looked at swimming clubs that aren't explicitly gay—and that would be okay. So I think it's sort of a natural life cycle, I guess, in sort of the coming-out process that you, um, start to wean yourself away from the community. (Sam, 44, white, European-Canadian)

For Pete, who grew up in southeastern Quebec, his choice at age 30 to move to Ottawa instead of Montreal aligned with what he imagined as a general progression toward "[living] a more 'straight' life, eventually." For Pete, this more straight life was not a heterosexual one, but one in which participation in the gay community—and the social restrictions that he felt were imposed by it—were ultimately reduced. "Being in like a big city like Montreal," he said, "you always like some people [but] you're kind of like forced to hang out with [others] and that kind of stuff. But also like being in Ottawa 
where I have great friends and a great partner as well, so you're more like, not necessarily more exclusive, but having like more friends that are suitable to your lifestyle" (Pete, 41, white, French-Canadian).

In conjunction with their changing perceptions of community, older men also looked for stable environments, characterized by a secure labour market, a highly educated population, and proximate, accessible, and sometimes suburban neighbourhoods. Their narratives reveal that the urban gay community, historically positioned as the central space in gay men's lives (Knopp and Brown 2003) often plays a temporally limited role and is later exchanged for a more mundane, "everyday" environments (G. Brown 2008; Gorman-Murray et al. 2008). Ashton, a 47-year-old from Newfoundland who moved from London, Ontario, to Ottawa at age 30, said, "It's not necessarily related to the gay element," he said. "It's as you get older, and you settle down with someone ... I guess you notice more that the neighbourhood has great coffee shops and good restaurants" (Ashton, 47, white, Anglo-Canadian). Raymond, who had initially been unwilling to leave the safety of Toronto's gay village, ultimately appreciated the more diffuse community he encountered in Ottawa—as opposed to a dominant "scene" - as he entered his thirties.

[It's through] the diffuseness of the community that you can sort of be who you want, you can sort of engage in the community in the way that you want to on your own terms ... Also I sort of liked Ottawa's sort of non-village scene that was happening here ... you know, Montreal's fun to go to once in a while, but I sort of afraid that I'd get sucked back into that life that I had in Toronto where it was very sort of village-based, and $\ldots$ and I didn't necessarily want that again. I liked the sort of diversification that I found. (Raymond, 31, black, Jamaican-Canadian)

These men's preferences for more stable, more diverse, or even so-called "straight" environments do not, however, imply uniform gravitation toward more 
heteronormative spaces and lifestyles later in life. Although scholars such as Duggan (2002) and Nast (2002) observe a growing adoption of lifestyles rooted in domesticity and consumption among queer people, and especially gay men, those who do not meet (or choose not to meet) the implicit class and social criteria for these lifestyles may feel more comfortable in places where other queer people have clustered. Some men, even later in life, draw a clear line between the "child-focused" environments of the heterosexual world and places where one can live a gay life. Joseph, a 38-year old living in Washington, D.C., observed that the importance placed on children among some middle-age heterosexual couples - and the ongoing restrictions placed on gay adoptioncreates a significant disjuncture between gay and heterosexual life courses and locational preferences. His brief trips to the Midwest to visit family members both highlighted this disjuncture and affirmed his decision to stay in downtown Washington, D.C. "When I leave D.C., when I go to Indiana to see my brother in Wisconsin, [the disjuncture] becomes very apparent, and it becomes very apparent that I live a completely different life than they live. Well, just, I mean that children are the focus of the straight world, it's all about kids ... um, parents are completely, absolutely dedicated to their children (Joseph, 38, white, European-American).

In contrast, when single men encountered places where partnered, domestic lifestyles appeared dominant among gay men their own age, they felt out of place (Cresswell 1996). In Ottawa and Washington, D.C., where there is a stable (and often highly paid) labour force and an overarching emphasis on professionalism and conservatism (see N. Lewis 2011), the dominance of normative lifestyles can be isolating for men who fail to "fit the mold." James, who moved to Ottawa in his early thirties 
described this tension: “Well, 'cause I wasn't government, wasn't making the money, wasn't, you know, didn't buy a house at 25 with my government salary and my boyfriend ... [I] didn't fit the, the mold of the, you know, the upper kind of, government-bureaucrat kind of double-income, live in the suburbs and drive my car ... (James, 40, white, AngloCanadian). Sebastian, a 42-year old who moved to Ottawa from Montreal, felt that Ottawa had lost some of its initial attraction when he became single after ending a longterm relationship.

I find [Ottawa has] more people 35 and older, maybe the people who have good-paying, stable jobs ... this is a city that has a good infrastructure to support a long-term relationship lifestyle ... but if you're single in this city ... after 5 years of being single in this city, you've, you know, the infrastructure to support going out isn't there. (Sebastian, 42, Métis, French-Canadian, Mik'maq)

The narratives here reveal some of the ways in which age, identity formation, and other subjectivities such as class, occupation, and relationship status might influence decisions about mobility. The process of young queer people "moving out to come out" is well documented (Weston 1995; Fortier 2001; Valentine and Skelton 2003), and some younger men's narratives fit into the discourse of rural and suburban isolation, migration, and the creation of a gay identity in the city. As upcoming chapters will show, however, coming out is often an extended, segmented process mediated by multiple moves and the ethno-racial and class subjectivities of individual men. Gay men later in life may face equally complicated mobility decisions. They are not only considering the implications of moving for careers and relationships, but sometimes balancing their ongoing connection to the gay community with a perceived need to dissociate from it. Ottawa and Washington, D.C., frequently became paradoxical places for men that moved there earlier in life - sometimes as part of a coming-out process — but later found themselves unable to 
fit into the normalized lifestyle that they felt was expected in those cities. As with coming out, it is also useful to think about the devaluation or decentralization of gay identity as a contingent, sometimes difficult process bound up with places and movement—rather than something that just happens. Movement between cities, or even within them, is thus a way of defining and managing a gay identity throughout the life course.

\subsection{Placelessness to Permanence: Migration, Networks, and Social Support}

The decisions that gay men make about where to live, and where to move to are not just the product of personal characteristics such as age or maturity, but also the particular networks in which they seek to embed themselves at various points in the life course. This calls for a somewhat different, looser definition of gay community, compared to how it has typically been framed. Social networks were central in many of the migration narratives, echoing Weston's (1991) argument that the networks of friends that queer people create in places are "families of choice." As Chapter 7 notes, gay men - including more than one-fifth of the men interviewed (nine respondents) experience significant loneliness or isolation during the life course, often as they dissociate themselves from relationships or networks perceived as unsupportive and seek out networks in which a new identity can be formed. Several men, in fact, highlighted the establishment of a gay social network as both a reason for moving and one of their highest priorities after moving to a new place. They described social networks as "the way that you get introduced to other things" (Henry), "the people you choose," (Adrian), and a set of friendships that are "compatible" with an individual's personality and circumstances (Anthony). Social networks are therefore not just coming-out tools or 
points of entry into the community, but support systems that-particularly in the absence of heteronormative family structures_-gay men rely on throughout life (Weston 1991; Weeks et al. 2001; Barker et al. 2006).

Many men saw their social networks as integral to their quality of life and valued those more than romantic relationships or the presence of a community in the sense of gay village or set of gay establishments. Chad, a Nova Scotian who moved from Edmonton, Alberta, to Ottawa, said, “I wouldn’t say [the community] plays a huge part [in my life], but my gay friends and network make up a big part" (Chad, 35, white, Anglo-Canadian). John, who moved from New Jersey to D.C. for a Foreign Service job, said, "The key for me is [to] build up a support network of friends first, which I have ... and then, you know, see what you can do on the relationship side of things" (John, 33, white, Italian-American). Several men also saw their social network as the factor that kept them in a particular place even if a job or something else had attracted them at first. For Rick, who- before coming to Ottawa - had moved from northern Ontario to London, Ontario, for a job in HIV/AIDS activism, establishing a social network had been challenging. He recalled, "not meeting people despite doing this job that was quite sort of quite connected to the gay community ... it was a little, certainly, a little depressing and ... a deterrent to wanting to stay, to wanting to stay longer" (Rick, 27, white, AngloCanadian).

Social networks took on different types of significance for gay men at various points in the life course. Men who had moved to Ottawa or Washington, D.C., around the time that they came out saw their migrations as a temporary "trading off" of networksusually between families and friends in hometowns or at school - to distinctly "gay" 
networks. For a few men, the exchange of networks was stark. As Shawn described moving away from northern Ontario and coming out in Ottawa, "you dissociate from everything that has come before, and you get to define yourself as you would define yourself" (Shawn, 42, white, French-Canadian). Daniel, who moved only miles away from family in eastern Ontario when he came to Ottawa, observed, “... there's definitely a transition when you cut off your established connections to a community and then moving to a new one where you have to rebuild it and it's even harder depending on your own behavior ..." (Daniel, 28, white, French-Canadian).

For some men, this exchange involved an explicit disinvestment in one set of social networks in anticipation of establishing new ones elsewhere. "I was not developing relationships," said Anthony, “... and part of it was that I chose not to develop relationships" (Anthony, 28, white, Polish-Canadian). In some cases, withdrawing socially was related to fear of being "found out." Doug, who moved from Colorado to D.C. for university said, "I didn't have a lot of friends in [Colorado] ... I think mainly 'cause I was terrified of being found out as gay so there was definitely that freedom when you moved to D.C., you know that, you know that it's accepted here and that once I found a group of friends in college that I knew would accept me, that's when I came out" (Doug, 26, white, German-American). For men who had essentially discarded one network for another, the contrasts between old and new homes were unambiguous. John, for example, felt that "home" in New Jersey, in contrast to Washington, D.C., "is like more of a memory, melancholy ... like I don't have a lot of friends there, so it's more like going home and thinking about growing up" (John, 33, white, Italian-American). 
For most men, however, the process of accruing and molding networks throughout the life course was a more nuanced process involving multiple sets of networks and conceptions of home. Social networks were often evaluated and negotiated, without necessarily being ruptured or discarded. For Luke, leaving southwestern Ontario for Ottawa involved a social network that had been rendered uncomfortable by his disclosure of a gay identity. "[It wasn't] a flat out negative reaction," he said, "it's just things changed ... in our friendship, and none of the changes were really changes that made me comfortable" (Luke, 24, white, French-Canadian). Jack, who moved from Colorado to Washington, D.C., after a temporary stay at his childhood home, realized that the networks he had established as a teenager no longer seemed sufficient for a recently out young adult.

I really say first and foremost like, when I moved back [to Colorado] like after - since like a lot of my friends had graduated and moved out of the state-I kind of went back there after school and tried to like make new friends and like really branch out and it was just like impossible ... that was really the main reason I left was like I just didn't have a social life going on there. (Jack, 24, white, European-American)

Many men specifically referenced the density of networks as an important reason for leaving one place and settling in another. Typically, they explained this density in terms of the "critical mass" of gay men they expected to find in a large city. As Chapter 5 notes, this was one of the most common themes in the project, mentioned by $25 \%$ of the men interviewed (12 respondents). About one-fifth of men interviewed (10 respondents) also referenced the importance of socializing and networking in professional settings, while half (24 respondents) acknowledged the role of queer organizations or economies in their migration decisions (see Chapter 8). "You feel limited when there's only one place to go, and one option for meeting people," said Pete, who moved from southern 
Quebec to Ottawa (Pete, 41, white, French-Canadian). Anthony, who moved from Saskatoon to Ottawa at age 27 explained, "I didn’t enjoy ... the personalities, the individuals ... there wasn't a large enough base for me [in Saskatoon] to build a large social network" (Anthony, 28, white, Polish-Canadian). "I think I probably have, I would gauge, ten to twenty times more friends [in D.C.] than I did in Ohio," said Adam. "I think the way it works is, you have more opportunities to meet people than you do, uh, in a lower-density area" (Adam, 34, white, German-American). For these men, moving was partially based on a desire to be part of a gay community, without being forced to repeatedly encounter the same places, events, and "personalities." Put differently, they sought the freedom to create their own support system from the ground up, rather than simply "inserting" themselves into a ready-made community (Fortier 2001).

Later in life, however, men were more concerned with the stability of social networks rather than the establishment of new ones. Many described the changing valuation of networks as the result of shifting priorities, rather than a simple "weaning away" from the gay community, as one respondent (Sam) put it. Priorities for men later in life included long-term partnership (instead of relationship experience), permanent employment, and the opportunity to become community leaders. Max, who moved from Honolulu to Washington, D.C., in his mid-twenties, began seeking stable networksrather than dense or highly visible ones—as he began "[valuing] life ... on more adult terms" (Max, 31, European-American). Sam, who moved from Montreal to Ottawa in his early thirties, suggested that a city like Ottawa was more likely to foster these types of networks than a recognizable queer homeland like Montreal. "A lot of the friendship networks - thrive off of ... a very stable employment nature compared to the rest of 
Canada," he said, "so, um, to put down roots, definitely this is a place to do that. It has a culture of stability because of the public service" (Sam, 44, white, European-Canadian). As Sam seems to indicate, gay men later in life focus on concretizing support networks rather than building new ones. Ashton, who had originally moved to Ottawa intending to move back "home" to the Atlantic Provinces, said his plan changed around age 40:

We all have that discussion, "so when you retire, are you going to stay in Ottawa or are you gonna move on?" And a lot of people were like, 'well, you know, I thought I'd be going somewhere else but I look around and I think, well I have all my network of friends here, I've been here 20 years, if I move away and I've gotta [sic] build it all from scratch. (Ashton, 47, white, Anglo-Canadian)

These perspectives demonstrate that while migration may be central to queer people's lives, an affinity for liminal space or "placelesseness" itself (Fortier 2001; Knopp 2004) is contingent on age and life stage. As Knopp (2001) discusses in his retrospective account of his personal and geographic journey into academia, queer journeys may eventually become more geared to building communities and rooting oneself in places, rather than wandering between them. As the next section reveals, men's decisions to move (or not move) were frequently related to their desires to build identities based on community, and not just sexuality.

\subsection{Institutional Infrastructure and Community Identities}

As previous life course research has suggested, the social and spatial trajectories of individual lives are shaped not only by shifts in priorities and desires, but also by the institutions they encounter (Heinz and Krüger 2001; Bailey 2009). Among gay men negotiating an institutional landscape in which support and acceptance of non-normative sexualities are highly variable, migration decisions may be shaped by the presence of 
institutional constraints in one place and the availability of opportunities in another. Men often moved in order to access the institutions (e.g., universities) that they felt would foster the development of a gay identity. As noted in Chapter 8, the most common references to institutions were specific to the study sites of Ottawa and Washington, D.C. Over one-fourth of the men interviewed (13 respondents) were drawn to the discursive and career-based significance of both gay and mainstream political and advocacy institutions in those cities. Several, however, also referenced the universities, social services, and other potentially gay-positive institutions that might be found in a variety of places. For Nick, who moved from suburban Massachusetts to Washington, D.C., for university (before leaving for graduate school and returning a second time), both the act of moving away for university and the school's specific location played a role in his personal development.

I think the first move [to D.C.] is different because it was undergrad and it involved-I mean I was just coming to terms with my sexuality at that point - so I think there was tremendous growth ... it probably was a big improvement from, from that, but I mean any probably university I went to would have been a big improvement. It's just sort of if you get toward that stage ... and discover who you, who you are and yeah, maybe I wanted to live in a city like D.C. (Nick, 26, white, Eastern European-American)

For others, moving provided access to otherwise unavailable social service institutions that served as points of entry to new networks. Two men living in Ottawa discussed the importance of resources for young adults in their coming-out journeys.

One of the first things I did when I came to Ottawa was go to Pink Triangle Youth meetings and just kind of met some people, and some of whom are actually still my friends now ... and I guess they were kind of structured, kind of weekly, kind of, you know, under-25 meetings. (Derek, 31, white, French-Canadian)

After my first year at university, I went back to New Brunswick for the summer, and it's when I was that I was like enough is enough, when I 
go back to Ottawa; I gotta [come out] ... so when I came back, in September I went to the Pride Center. (Francis, 30, white, FrenchCanadian)

As men became older, however, they were increasingly interested in accessing institutions through which they could establish community identities, as opposed to purely individual ones. The family- and child-oriented institutions through which these identities are typically established may be less accessible for gay men and the alternatives (e.g., gay sports leagues or political groups) may only be located in very specific places. As Kertzner $(2001,88)$ notes, “whereas heterosexual identity remains socially and culturally articulated throughout the life course, the social and existential meaning of homosexual identity becomes less clear with regard to questions concerning the legacy of individual lives for future generations and the role of the self in the world." With less frequency of becoming parents than their heterosexual counterparts, gay men are less likely to be part of parent-teacher associations, scouting troops, and other venues in which men tend to cement their community identities later in life. They may also feel out of place in heteronormative sports leagues or professional organizations. Accessing institutions that build experience, confidence, and self-esteem throughout the life course, then, may require moving to places where there are organizations aimed at building the gay community, such as advocacy groups and gay media, or sectors known to be inclusive of gay men, such as the civil service.

Gay communities, then, are not just concretized, spatially concentrated, one-stop shops for coming out or casual socializing, but also the broader sets of networks and institutions in which both personal and professional development occur. Shane, who moved from Richmond, Virginia, to Washington, D.C. after university, described the 
leadership experience and confidence from working — both as a volunteer and paid employee - in many of the city's gay advocacy organizations. "I think that having more access ... a larger gay community, experience-wise, you know, you just grow and I think I've had a lot of opportunities here — as a leadership position partially—really help my confidence (Shane, 27, black, African-American). Several more men felt that it was chiefly through institutions - rather than more casual participation or consumption-that the gay community contributed to their everyday lives:

There's a community umbrella group called "Time Out" in Ottawa ... and the golf [team] was one that I've been coordinating for about eleven years now. Um, it's my primary connection with the community and my primary means, I'd have to say, of ... of building friendships although there's [sic] many other outlets. (Wally, 43, white, Anglo-Canadian)

I started [volunteering for Ottawa service agency] Bruce House and at the same time I was writing with [gay newspaper] Cap X. You suddenly become an instant sort of celebrity. (James, 40, white, Anglo-Canadian)

What I sought [in moving to Ottawa], of course, was, you know, acceptance and a community ... but at that time when I moved here ... it was starting to grow. So I grew with it, and the things that I probably expected or sought were the things that I was creating or helping to create. (Adrian 56, black, African-Canadian).

Terry, a 40-year-old living in Ottawa, observed that the opportunity to participate in both gay and mainstream organizations was important for gay men who might not be expending their energy in the process of raising children.

I mean all I have to do is look around here in [the Ottawa neighbourhood of] Sandy Hill," he said. "... our community association, and the president is a gay man, um, a number of people on the executive are gay ... I think it's because gay people have this energy, they have the time, they have the interest, um, so, you know, they become involved in that and they become interested in that ... whereas straight people, you know, you're raising kids, life is hectic because of that, less time to spare. (Terry, 40, white, Flemish-Canadian) 
Gay men's identities later in life are not only established by access to institutions, but by the degree to which the gay community is institutionalized within places more broadly. Integrating non-normative sexualities into economic projects such as place marketing and job recruitment has been criticized as a strategy for assimilating and normalizing queer people (see Duggan 2002; Nast 2002). In addition, the emergence of high-profile national gay rights organizations, such as Egale Canada and Human Rights Campaign, have been criticized as neoliberal, assimilative counterparts to the localized, grassroots organizations that dominated the movement in the 1970s and 1980s (Smith 2005b). Many men, however, saw the recognition of their sexuality in the workplaces and other institutions of Ottawa and Washington, D.C., as evidence of the potential to establish meaningful community identities.

Almost half of the men interviewed (19 respondents) saw government work as a sources of professional and social security, though $6 \%$ (3 respondents) saw the culture of the "government town" as a detractor from the types of social and cultural amenities that might typically be associated with the gay community. Citing his experience in a D.C. government agency with a culture of "outness," Nick said, "I think the workplace ... I have some gay friends [there and] that sort of institution's good, 'cause ... I've been going out with them ... planning trips and $10 \mathrm{~K}$ races together ... and you can just socialize at work, which just makes it way more enjoyable (Nick, 26, white, Eastern European-American). Max observed that he was likely to stay in D.C. because the visible, highly public integration of gay men into the city's institutions offered extensive opportunities for both paid work and volunteering. "[Washington, D.C.] is a political town and the gay community here is a political entity as much as it is a social entity. I 
think that's one of the big differences between like the, the community here and the community in most other towns is that, you know, it sees itself in those terms" (Shane, 27, black, African-American).

\subsection{Changing Historical Contingencies}

As previous life course research has suggested, individual lives are shaped by both individual decisions (i.e., agency) and the structural and historical contexts in which they are lived (Elder 1985, 1998; Hostetler and Cohler 1997; Cohler and Hostetler 2003). For gay men in North America, these contexts have shifted rapidly in the past few decades. While the landscape of rights and inclusion is still uneven, both Canada and the United States have decriminalized homosexuality, overturned its categorization as a psychiatric disorder, and in some cases granted marriage and adoption rights (Lind 2004; Smith 2005a). Yet important differences remain. As Chapter 9 discusses more fully, Canada's gay rights are upheld constitutionally (i.e., by the Charter of Rights and Freedoms), while the U.S. government levied a baseline of rights denial through the Defense of Marriage Act in 1996. Although several states have since chosen to redefine marriage to include partnerships between two men or two women, each state also retains the right to overturn such redefinitions through referendum (Lind 2004; Smith 2005a). 
Table 4.3. Gay Rights Advancements, Canada and the United States, 1968-present

\begin{tabular}{|c|c|c|c|c|}
\hline & \multicolumn{2}{|c|}{ Canada } & \multicolumn{2}{|c|}{ United States } \\
\hline & Year & Action & Year & Action \\
\hline Decriminalization & 1968 & $\begin{array}{l}\text { Criminal Law Amendment } \\
\text { Act decriminalizes same- } \\
\text { sex intercourse, but } \\
\text { mandates higher age of } \\
\text { consent (21) than for } \\
\text { heterosexuals (18). }\end{array}$ & 2003 & $\begin{array}{l}\text { U.S. Supreme Court decision on } \\
\text { Lawrence v. Texas repeals } \\
\text { sodomy laws still existing in } 14 \text { of } \\
50 \text { states. }\end{array}$ \\
\hline Marriage & 2005 & $\begin{array}{l}\text { Civil Marriage Act } \\
\text { recognizes same-sex } \\
\text { marriage at the federal } \\
\text { level, enforcing marriage } \\
\text { rights in the four provinces } \\
\text { or territories that had not } \\
\text { yet legalized same-sex } \\
\text { marriage; Alberta, Prince } \\
\text { Edward Island, Nunavut } \\
\text { Territory and Northwest } \\
\text { Territories. }\end{array}$ & -- & $\begin{array}{l}\text { Defense of Marriage Act (1996) } \\
\text { defines marriage as a union } \\
\text { between a man and a woman, but } \\
\text { six states, one district, and two } \\
\text { autonomous American Indian } \\
\text { tribes recognize same-sex } \\
\text { marriage: Connecticut, Iowa, New } \\
\text { York, Massachusetts, New } \\
\text { Hampshire, and Vermont, along } \\
\text { with Washington, D.C., and the } \\
\text { Coquille and Suquamish tribes } \\
\text { (Oregon and Washington, } \\
\text { respectively). }\end{array}$ \\
\hline Adoption & -- & $\begin{array}{l}\text { Adoption is a } \\
\text { provincial/territorial } \\
\text { consideration, but same- } \\
\text { sex adoption has been } \\
\text { legalized in every } \\
\text { Canadian province and } \\
\text { territory. }\end{array}$ & -- & $\begin{array}{l}\text { Adoption is a state consideration. } \\
\text { States with adoption rights for } \\
\text { same-sex couples are: Maine, } \\
\text { New Hampshire, Vermont, } \\
\text { Massachusetts, Connecticut, } \\
\text { Rhode Island, New Jersey, } \\
\text { Florida, Ohio, Indiana, Illinois, } \\
\text { Iowa, Arkansas, New Mexico, } \\
\text { Colorado, California, Nevada, } \\
\text { Oregon, Washington. } \\
\text { States with legislation specifically } \\
\text { outlawing same-sex adoption are: } \\
\text { Utah, Michigan, Mississippi, and } \\
\text { Oklahoma. }\end{array}$ \\
\hline Immigration & 2001 & $\begin{array}{l}\text { Under the Immigration and } \\
\text { Refugee Protection Act, } \\
\text { Canadian citizens can } \\
\text { sponsor a same-sex partner } \\
\text { of a different nationality. } \\
\text { Couples in which neither } \\
\text { partner is Canadian must } \\
\text { choose one partner to be } \\
\text { the principal applicant and } \\
\text { sponsor of the second. }\end{array}$ & 1996 & $\begin{array}{l}\text { Defense of Marriage Act (Section } \\
\text { 3) renders it illegal for the foreign } \\
\text { same-sex partner of a U.S. citizen } \\
\text { to be issued a green card. }\end{array}$ \\
\hline
\end{tabular}

Sources: Egan v. Canada 1995; Rosenberg v. Canada 1998; Smith 1998, 2005a, 2008; Hurewitz 2002;

Halpern et al. v. Canada 2003; Lind 2004; HRC 2011a, 2011 b. 
While many of the men whose lives are discussed in this research have migrated in the context of an improving but still variegated legal and institutional landscape, others relocated to Ottawa and Washington, D.C., fifteen or twenty years prior to being interviewed. For these men, migration occurred in the context of the HIV/AIDS crisis and a visible, highly charged struggle for both medical care and political inclusion. Historically, the migrations of gay men and the subsequent formation of recognizable, visible gay communities had strong underpinnings of displacement, flight, and finding safe haven—what Plummer $(1995,15)$ called "suffering, surviving, and surpassing." For example, $23 \%$ of men interviewed (11 respondents) mentioned experiences of discrimination or feeling out of place (see Chapter 5), while another $21 \%$ specifically referenced negative experiences in particular sectors of employment (see Chapter 8).

Men who moved in the 1980s and 1990s, however, also frequently placed their individual struggles in the context of "community" battles; that is, advocacy was both an antidote to discrimination and a point of entry into the community. As the HIV/AIDS crisis unfolded, some men sensed a need to mobilize, both politically—by engaging in advocacy — and geographically, by locating themselves in places where the battle was being waged. Reflecting on their past migrations, some men suggested that volunteering and advocacy had once been dominant modes of both identifying oneself as gay and engaging with the community. While moving out was thus more of an imperative for young gay men in the 1980s, the advent of the internet and a decline in advocacy in the 1990s and later rendered relocation perhaps a less obvious—but still common—life choice (see also Munt et al. 2002; Bryson et al. 2006). 
As past work on the medical aspects of queer migration have suggested, the HIV/AIDS crisis emerged as a focal point of queer mobilities and communities in the 1980s and 1990s (Cohn et al. 1994; M. Brown 1997; Raimondo 2003). Some moved after losing friends and partners to the disease, while others who had contracted AIDS themselves sometimes moved home to seek care or be with family near the ends of their lives (Ellis and Muschkin 1996; M. Brown 1997; Raimondo 2003). Yet the HIV/AIDS crisis also influenced queer migrations in less obvious (and less medicalized) ways. As a point of political and social mobilization, it further attracted gay men to the cities that decades earlier had emerged as centers of the gay liberation movement (Weston 1995). HIV/AIDS-related volunteerism and advocacy, as much as the disease itself, became a new call to arms that drew gay men to particular cities and further concretized them as gay homelands. Adrian, who moved from Nova Scotia to Ottawa in the early 1980s — and among all the respondents, had moved the longest ago-saw HIV/AIDS as central to both the gay migrations of that era and to his own development of a community-based identity.

So, bang, I became involved with Gays of Ottawa, which was the hub and the forefather of every other organization we have here now ... when I moved here in '81, that was the very first inklings of the gay plague, that's what it was called ... So that was just surfacing, the gay community was just starting to mobilize because nobody else was, and between '81, '85, when they identified the virus, a whole lot happened in the communitynot just here, but every gay community ... we were instrumental in educating the rest of community about this disease, literally, you know? And then, of course, the waves of deaths, deaths, started after, so then even more support was required, you know, people supporting people who were kicked out of their homes from a double whammy-a, coming out, and coming out and telling them that they had an incurable disease. (Adrian, 56, black, African-Canadian, Mik'maq)

In contrast, many men saw the "de-gaying” of AIDS (M. Brown 1995, 1997) and the increasing normalization of queer politics occurring at the end of the 1990s (Duggan 
2002; Oswin 2005; Cooper 2006) as the decline of a catalyst that had once generated many queer migrations and mobilizations. "I think the whole gay movement has changed dramatically," said Wally. "[After Stonewall and the decades that followed] there was something definitely to fight for. We've achieved that and ... now the movement I think, is stepping back and saying, 'You know, what are we fighting for?'” (Wally, 43, white, Anglo-Canadian). Ashton suggested that these changes have animated the geography of the gay community:

The gay life, I think it's probably a little less active. A lot of people are older, they don't go to bars so much; younger people - um, you know the whole issue of being gay is less of an issue-with, with their straight friends. They hang out with them in whatever bar, doesn't have to be gay. So I think that because of that, the market's sort of drying up for gay bars. And, um, so, the gay community's not as vibrant or as visible. (Ashton, 47, white, Anglo-Canadian)

The internet has further de-centered the geography of gay North America, reducing the centrality of historic homelands such as the Castro (San Francisco) and Greenwich Village (New York), and uprooting coming out and other "intimate" processes from place (Munt et al. 2002; Bryson et al. 2006; Valentine 2008). Reflecting on his earlier moves as a young adult, Sam said, "I have to keep in mind I'm talking 2010 versus 1995 ... you know, the advent of the internet changed [coming out], even for rural America, you know ... now, even though there are other people out there like you, and you can find them — there might, there might be some distance between you — but you can find them” (Sam, 44, white, European-Canadian). James agreed, “... As a general, we don't need to go to clubs as much to meet people; there's the internet, there's those kinds of things" (James, 40, white, Anglo-Canadian). 


\subsection{The Myth of the Homeland and 'New' Complexities of Queer Migration}

The intricacies of gay men's life courses suggest the need for more nuanced understandings of the role of migration in queer lives. A life course approach reveals some of the factors, such as age and career trajectories, that are likely to shift the reasons for migration throughout individual gay lives. It also points to some of the historic and institutional developments that have changed the nature of gay men's migration decisions and processes over time. Both aspects of the life course approach usefully complicate narratives that position queer migrations as one-time events that involve fleeing to the city. On one hand, queer migrations have always been influenced by intersecting subjectivities as age, making them more complex than most narratives have suggested. On the other, a changing landscape of rights and acceptance, along with technological developments such as the internet, have made the simple "get thee to a big city" narrative (Weston 1995) less applicable then it once was.

In the context of a wider range of places where gay rights and identities might be supported and fewer places where being openly gay is potentially dangerous, linear conceptions of queer migration may be decreasingly relevant. In North America, gay men's migrations now seem to now involve multiple segments, return and routine trips, and hedging between places instead of merely exchanging one for another. In addition, access to online information and ease of transportation might allow for migrations that are planned, methodical, and undertaken explicitly because of the gay life potentials that a place is thought to provide. At the same time, some of the forces thought to drive individual queer migrations and the broader imaginary of queer migration have perhaps diminished in recent years. While there are now many places in North America where 
being gay is legally and socially acceptable, the idea of a traditional gay "homeland" is arguably less relevant. Events such as the early gay liberation movement and the HIV/AIDS crisis - events that once mobilized and concretized urban gay communitieshave faded. In addition, many suggest that the solid boundaries of "gay" identity—and concomitant borders of gay ghettos—are increasingly challenged by men's and women's desires for "queer" lives with fuzzier borders (Oswin 2005; Browne 2006; Nash 2010). Consequently, gay men's migrations are now perhaps less a matter of inserting themselves into already-formed gay communities than they were in the past. Instead of looking for a monolithic community into which they would ostensibly fit, most men interviewed were concerned with accessing a network or set of networks that suited their individual circumstances.

Marshall, who moved from Missouri to San Francisco in his early twenties (and later moved to Washington, D.C., after graduate school), saw his imagined picture of the gay homeland disintegrate after moving. Although he had not moved to San Francisco explicitly because of its imagined relevance to gay men- he simply wanted to take off a year after university to see the West coast- -he was surprised to find that it was "not a good place to be coming out as a 22-year old:"

I didn't have a lot of gay friends in San Francisco ... you know, I never felt a part of it and everybody was 40 and everybody who was younger had, you know, well half the city had died of AIDS and it was just like it was such a depressing place to live. And D.C. was vibrant and young and everyone was in their 20 s and it was fun and everyone was out on Tuesdays and I was 22 , and you know, I was able to really integrate ... so I think a lot of it was that I was 22 and it just was not a good place to be coming out as a 22-year-old ... I think that they were all just you know, far above, you know the coming-out phase. (Marshall, 29, white, ItalianAmerican) 
Marshall's experience emphasizes the fluidity of gay places and lives, and its implications for migration. For Marshall, San Francisco had been rendered an antique sort of place by both the history and demographics of the gay community. For a 22-yearold, the city's status as a sort of gay homeland was less important than the distinct sets of networks and institutions he was able to access there.

In contrast, some of the older respondents saw themselves as decreasingly able to adjust to new places as they became older. In particular, they saw a tension between an expectation that "gay identity" should become less important later in life and the continued reliance on gay networks and institutions (i.e., the community), especially among men who were not partnered. The increased emphasis on partnering around age 30 noted by Marshall and several other respondents seems to stems from a perception that being single—and the involvement with the "community" that it might entail—is inappropriate for gay men later in life. Places thus become characterized by the binaries of "good for single men" versus "good for partnered men." Echoing Sebastian's observation that Ottawa was a good place for partnered men but "lacked the infrastructure" for single men, Max, a 31-year-old, said that D.C. was "a very good place to live if you're like partnered, but it's really not so good to live if you're single." (Max, 31, white, European-American)

As these narratives suggest, gay men's migrations are rarely driven by the concept of a one-size-fits-all homeland. Instead, moving to new places often involved the negotiation of networks that were relatively "submerged" or "closed" at first glance. As Marshall mentioned in his description of San Francisco, gay communities experience generational gaps, class and occupational divisions, and the same exclusions found 
elsewhere in society. Consequently, gay men moving to a new place might not encounter the automatic welcome mythologized by the concept of the historic gay homeland.

I think most people come [to D.C.] from undergrad, they have a lot of friends from undergrad ... or, you know, people through work, you know, especially if you work for the government, you work for [the] State [department], you work for whatever, you know - there are a lot of other homos there- and I think you know, you just hang out with your friends from work. (George, 39, white, Jewish-American)

... Who are the leaders within the gay and lesbian community here in Ottawa? The population is fairly old, and it's been doing it for a very, very, very long time, so, it's a very difficult gang of people to break into ... it, it tends to be, um, not a gang of people that is ... is extremely enthusiastic about new people or new ideas, or bring them in ... that's not something that's particularly sought after. (Steve, 47, white, AngloCanadian)

Several men also suggested that increasing transience in gay communities, perhaps another product of the changes in transportation and communication affecting most migrations, has also complicated the processes of entry into communities. The routine inflows and outflows of gay men in Ottawa and Washington, D.C., many observed, had caused disinvestment in once-stable communities and reduced opportunities for newcomers to access social supports. While few cities are characterized by static, permanent gay communities, transience might be particularly in these capital cities, and especially in Washington, D.C.

I think that level of investment ... I think in general there's sort of this idea that, well, I mean you know I'm not gonna [sic] be here that long anyways ... there's this idea that ... the people in D.C. are interested in what they can get out of you ... and while I, I didn't really find this to be the case exactly ... it's a very strong myth that perpetuates strongly in this city. (Ian, 31, Hispanic, Nicaraguan)

I mean, D.C's extremely transient, so if you leave for 4 months, you come back to a different city. I think the things that are difficult here are that, um, because people come and go ... you always have to meet new people and you always have to make new friends, and, um, and those 
friends are going to leave or you're going to leave, um, or both. People come back, which is a nice thing about D.C.- - you don't really get to experience that until your late twenties but, there's always a sense that you have to, um, you have to constantly refresh your social life and you always sort of have to reinvent it and re-establish it. Um, it becomes a lot easier once you're established because it's easier to meet new people. You meet people through networks; people come and go. (Brian, 27, white, Jewish-American)

These accounts not only demonstrate the importance of networks and institutions in gay men's lives, but that leaving one set of geographically embedded networks to create a home in another is a complex and difficult process. Migration for gay men thus rarely constitutes a simple process of displacement from one locale and emplacement in another. Instead, it involves navigating a variety of networks and institutions - and the subjectivities excluded or privileged within them - as they move through the life course.

I now turn to several thematic discussions that address the particular points at which migration intersected most frequently with respondents' life courses. Chapters 5 and 6 address the process of coming out, particularly "moving out as coming out" and the places and journeys involved in that process. These chapters show that coming-out migrations, far from simple journeys of emancipation, are embodied, contingent, relational, non-linear journeys that permeate the life course. In Chapter 7, I discuss how gay men's migrations and the experiences that precede and follow them are quite literally embodied in terms of health behaviors and outcomes. The last two chapters emphasize role of institutions, and specifically institutional unevenness, in gay men's migrations throughout the life course. As gay men seek entry into the labour market and approach life events such as partnership or adoption, their migrations are increasingly animated by the uneven landscape of human rights and inclusion in North America. While Chapter 8 highlights the capital city as a cluster of institutions promoting the security and inclusion 
of gay men - specifically through legislation and alternative gay economies at the nexus of the civil service and advocacy sectors-Chapter 9 shows how these same institutions have created everyday lives that are arguably more restricted and disciplined than the other destinations to which gay men move. This final chapter therefore re-asserts that gay men's lives, while changed through migration, are subject to the institutions geared toward regulating a non-normative sub-population. 


\section{CHAPTER 5}

\section{Beyond Binary Places: Everyday Geographies of Moving Out and Coming Out}

\subsection{The Coming-Out Migration Narrative}

Migration as a form of "coming out" among queer people has gained increasing attention in both sexuality and space studies and the popular media. In the past decade, coming out has been framed as a typology of queer migration, one in which the subject and their identity are entwined with movement (M. Brown 2000; Fortier 2001; Knopp 2004; Gorman-Murray 2007, 2009). In coming out, queer people are thought leave both a particular geographic space and the "spatial metaphor" of the closet (Sedgwick 1990; M. Brown 2000; Brown and Knopp 2006). The idea of moving out as coming out, however, is not a new one. Geographers and other social scientists have documented the way in which places, particularly cities, have historically drawn men and women seeking liberation in a geographically uneven landscape of acceptance and inclusion for nonnormative sexualities (Chauncey 1994; Weston 1995). Historians, for example, have noted that European and North American cities during the Industrial Revolution became sites where economic opportunity, a critical mass of single men and women, and changing notions of home and family, offered opportunities for the sexual exploration and the creation of non-heterosexual identities (Laqueur 1993; Aldrich 2004).

Working in a U.S. context, Chauncey (1994) explains how New York City in the late 1800 s and early 1900 s became a magnet for gay men hoping to participate in emerging gay neighbourhoods, a vibrant street culture, and a social scene that frequently mixed heterosexual and gay New Yorkers. Kath Weston's (1995) more recent portrayal of queer migration to San Francisco and New York in the post-Stonewall 1970s posits 
moving to the metropolis as an imperative, claiming that gay men and lesbians following the imagined command to "get thee to a big city" were largely escaping rural, closeted environments and identities for new lives in on the east and west coasts. New York, San Francisco, and — to a lesser extent—cities such as Chicago and Toronto, were thus framed as queer homelands in which gay men, lesbians, and other queer people could escape rural isolation and define themselves through an urban community of like-minded others (Castells 1983; Forest 1995; Munt 1998).

These portrayals usefully integrate sexuality in the historical imaginary of migration within North America and Europe and illustrate that the social inclusion of queer people is not a post-1960s invention. The binaries of tolerant/intolerant and rural/urban migration that dominate these studies, however, also position the migrations of queer men and women as symbolic journeys intended to escape monolithically intolerant places and emancipate themselves in the safe havens of urban centers (Gorman-Murray 2007). As Forest (1995), Miller (2005), and others have pointed out, these discourses are often perpetuated by gay media interlocutors (e.g., particular reporters at gay and alternative newspapers) who, depending on their positionalities as activists or business owners, might seek to concretize the urban gay village as the central space in gay communities otherwise exposed to exclusion and intolerance. As Yue (2008) notes, queer migration has typically been characterized as coming out and leaving a heteronormative childhood and a homophobic family home. The dominant discourse thus elides the variety of paths, patterns, and scales of relocation among queer people (Gorman-Murray 2007, 106). 
It also obscures the sometimes divergent trajectories of social acceptance toward non-normative sexualities at various scales during the past two decades (Seidman et al. 1999; Weeks 2007). Canada, for example, legalized same-sex marriage in 2005 and each of its provinces has legalized joint adoption. The United States military has, as of 2011, repealed its "Don't Ask, Don't Tell" (DADT) policy on the disclosure of sexual nonnormativity and New York has joined the ranks of five other states granting marriage rights for same-sex couples. Despite these types of legal protections, gay men might continue to experience informal prejudice (Cochran 2001; Meyer 2003) in a variety of "everyday" locales such as the school and the street (Bontempo and D'Augelli 2002; Walton 2004; Eisenberg and Resnick 2006). Coming-out migration, then, is certainly more complicated than moving from a flatly homophobic place to one considered gaypositive in terms of formal rights or social acceptance. Updating the coming-out migration narrative therefore requires a more nuanced interpretation of both coming out itself and the places involved in that process.

\subsection{Updating the Concept of Coming Out}

While the concept of coming out has become more nuanced than the stage-based, path-dependent conceptions popularized during 1980s and 1990s (see, for example, Troiden 1989), it is now less frequently seen as a once-and-for-all emergence from the closet than it is a gradual, accretive process (Sinfield 2000; Valentine et al. 2003; Knopp 2004; Barker et al. 2006; Floyd and Bakeman 2006; Gorman-Murray 2007). In addition, it has become understood less as a purely personal process anchored in sexual relationships (Weeks 1977) to one that - depending on the contexts in which it occurs- 
can be a political statement or even an economic risk (Bell and Binnie 2004; Binnie 2007). Coming out, then, is not just the fulfillment of "a short-term appetite for selfdeclaration" but rather "a dialectical journey" of "becoming" in which someone comes to know themselves as gay (Browning 1998; M. Brown 2000; Knopp 2004; Worth 2009). Intersectional subjectivities such as class and race figure prominently in the coming-out process. Men who have grown up in middle-class home environments or have high-income jobs, for example, may have had greater means to "move out to come out" or manage the coming-out process from afar. As many of the forthcoming narratives will show, men of colour often face particular difficulty negotiating or disclosing a changing sexual identity in the context of racial discrimination and informal prejudice from home and community environments. Scholars leveraging a queer of colour critique have further problematized notions of coming out as a series of "quintessentially progressive" disclosures that leads to the formation of a complete, affirmed gay identity (Ferguson 2004; Arora 2006). Many queer of colour scholars also find that the emphasis on disclosure — itself the product of a manufactured, oppositional, and "disclose-able" category of "homosexuality" - is problematic because it suppresses the fluidity of sexuality and the various intersectional subjectivities (e.g., age, race, family histories and circumstances) that might also be disclosed (Ferguson 2004; Haritaworn 2008; Jivraj and de Jong 2011). Others find that the prevalence of the coming-out motif itself is problematic; in many non-Western contexts, same-sex intimacy is rooted in "alternative formations" based on religion, family, and kinship rather than overarching ideas of nonnormativity and deviance (Arora 2006; Olund 2010). 
Given the multiplicity of individual circumstances that might influence a comingout process - and the generally flexible, contingent nature of coming out itself-it is more useful to think of coming out as a process that is highly personal but socially and geographically influenced. Place, then, is also central to men's coming-out experiences, but perhaps in more nuanced ways than extended by studies on the formalized oppression of national immigration regimes (Lubhéid and Cantù 2005; Manalansan 2006; Lubhéid 2008) or historic mass migrations from the rural countryside to metropolitan areas (Laqueur 1993; Chauncey 1994; Plummer 1995; Weston 1995; Cant 1997; Parker 1999; Maddison 2002; Binnie 2004).

\subsection{Complicating the Role of Place in Coming-Out Migrations}

Gay men continue to move in order to form identities, navigate social and familial relationships, and find opportunities to create the particular type life they are seeking. These journeys are, however, as often urban-to-urban, or between two ostensibly accepting places, as they are rural-to-urban or away from a place assumed to be homophobic. Coming-out migrations, then, does not always occur under threats of homophobia, suppression or physical violence ${ }^{7}$, but the product of decisions and processes occurring in the ostensibly supportive spaces of the college campus, the family home, the suburb, and the city itself. As Gavin Brown $(2008,1223)$ observes, processes such as coming out, relocating, and living an openly gay life are perhaps now less acts of transgression than they are mundane, everyday events. The growing "everydayness" of

\footnotetext{
${ }^{7}$ This is not intended to elide or underplay the very real threat of violence that many queer people experience. Several countries, for example, have policies that illegalize and punish sexual non-normativity. Queer people occupying various class, ethnic, racial, or religious subjectivities, may experience prejudice or abuse in more informal ways or at different geographic scales (e.g., home, workplace, street). They might also have little or no opportunity to migrate.
} 
queer migration, however, does not negate the gravity of decisions to relocate, but it does require a somewhat different understanding of place that moves beyond binaries such as tolerant/intolerant and liberal/conservative.

Examining everyday migrations not explained through oppositional differences in the characteristics of places requires scaling inward to uncover the complexities of individual decisions and trajectories. Other geographers have begun the project of complicating the imagined rural/urban and tolerant/intolerant binaries of queer migration, noting that rural areas, homes, and workplaces have been "queered" as lesbian, gay, and other queer people move to or come out in areas beyond the city (Knopp and Brown 2003; Waitt and Gorman-Murray 2007; Visser 2008; Luzia 2008, 2010). Several have also noted that queer people frequently embrace multiple ideas of "home" and feel comfortable enough in placelessness to continue migrating throughout their lives (Fortier, 2001; Knopp, 2004). In addition, the internet and digital communications have allowed queer people to come out in virtual places, sometimes prior to or simultaneous with coming out in a physical place (Munt et al. 2002; Bryson et al. 2006).

One approach used to capture the complexity of queer coming-out journeys is analysis through the lens or "scale" of the body (Fortier 2001; Knopp 2004; GormanMurray 2007). In this approach, migrations of queer people emerge at the intersection of individuals' identity formation, concepts of home, and embodied desires for emplacement or romantic relationships. Although this scaling in usefully uncovers the diversity of migration decisions and trajectories among queer people, it tends to reify the body — and the embodied emotions within it — as the primary driver of the coming-out journey. Consequently, the role of place seems to disappear, and the coming-out journey is 
reframed as a wandering or "peripatetic" exercise driven mostly by individual desires, whims, or "identity quests" (Knopp 2004). I advocate in this chapter for a somewhat different approach that reasserts the role of place in queer coming-out migrations, but avoids binary and essentialized characterizations of the places involved.

In an increasingly complex and uneven landscape of rights, inclusion, and social acceptance for queer people, it is more useful to think of places as complex, dynamic sets of networks and institutions in which the queer migrant-subject is embedded. The places that queer people engaged in coming out move to and from are regulated not just by policies and practices, but also by families, relationships, schools, workplaces, and other elements of life influenced by_-but not necessarily dominated by_uneven geographic contours of social acceptance and inclusion. Processes of disclosure are thus profoundly informed by place, but not always in straightforward ways. For example, a young man coming out might live in a diverse, politically liberal city, but choose to move away because he suspects that relatives or work colleagues will understand his homosexuality as a "deviant" category of identity (Olund 2010; N. Lewis 2011).

Rather than risking the rupture of their existing networks without having established an alternate network elsewhere, he might move both to manage the comingout process from afar. Even when a place does not pose imminent harm or exclusion, coming-out migrations are routinely employed to both form identities and manage relationships. I therefore propose a lens of analysis based on the social dynamics of place (e.g., the networks and institutions embedded in places and encountered by queer individuals), rather than characteristics of place. The objective here is not to eradicate or nullify place, but to reconceive places as sets of networks, institutions, and social 
relations located in particular geographic areas that—over time — accrue a discursive and emotional significance for each migrant. I focus here on four key sub-themes that emerged under the main theme of coming out in the interview material (see Table 5.1): (1) moving to galvanize a course of personal development perceived as stunted; (2) moving away preemptively to emplace oneself elsewhere because they fear or anticipate rejection from people around them, (3) moving to seek the anonymity or social space needed to develop an identity on one's own terms, and (4) moving to mitigate the perceived burden of coming out for families and friends.

\section{Table 5.1 Sub-themes related to coming out among 48 Self-identified gay male respondents, Ottawa, Ontario, Canada and Washington, D.C., U.S.A.}

\begin{tabular}{|l|l|l|l|}
\hline Sub-theme & $\begin{array}{l}\text { No. of } \\
\text { passages }\end{array}$ & $\begin{array}{l}\text { No. of } \\
\text { respondents }\end{array}$ & $\begin{array}{l}\text { \% of } \\
\text { respondents }\end{array}$ \\
\hline Critical mass and gravitational pull of a larger city & 15 & 12 & 25 \\
\hline Feeling out of place or discriminated against & 14 & 11 & 23 \\
\hline Adjustment and transition after coming out & 14 & 9 & 19 \\
\hline Distance from family & 12 & 9 & 19 \\
\hline Role of parents in coming out and migration processes & 11 & 9 & 19 \\
\hline Anonymity and distance from previous identity & 11 & 6 & 13 \\
\hline Use of brief trips for clarity and self-discovery & 7 & 6 & 13 \\
\hline Feelings of stasis and inability to advance & 6 & 6 & 13 \\
\hline Moving out to avoid burdening others & 4 & 4 & 8 \\
\hline Fear of rejection & 4 & 4 & 8 \\
\hline Undertaking research in advance of migration & 3 & 3 & 6 \\
\hline 'Subconscious' awareness of sexual difference & 3 & 2 & 4 \\
\hline Integration into a new city following coming out & 1 & 1 & 2 \\
\hline Delaying migration until coming out & 1 & 1 & 2 \\
\hline
\end{tabular}

\section{4. 'There was probably a Little Voice in me': Recognizing Difference, Planning Journeys}

The discourse of displacement, flight, emancipation, and survival that has characterized much of the queer migration literature aptly portrays the challenge and strain of disclosing one's non-normative sexuality in societies where acceptance and 
inclusion are socially and spatially uneven (Plummer 1995; Puar et al. 2003). Yet it also overlooks both the frequency of coming-out migrations undertaken with relatively little emotional trauma and the nuances of migrations that are actually more gradual and carefully planned journeys rather than urgent, once-and-for-all flights. Most of the respondents who discussed migration as part of a coming-out process noted two common experiences: a gradual awareness of their sexuality — usually described as "subconscious" - and conducting research to assess the suitability or "gay life potentials" of potential destinations (Gorman-Murray 2007; Waitt and Gorman-Murray 2010).

Most of the men who undertook some version of a coming-out journey described an "inkling," "feeling" or "voice" that made them aware of their sexual difference. While about one-fourth of the men interviewed (11 respondents) had purposely migrated shortly after coming out to leave an unsupportive environment (e.g., "I moved to get away from my parents") — and one even intentionally delayed migration until coming out — most men were less definitive about the link between their sexuality and their migration decisions. Many indicated that while they had not self-disclosed a gay identity to others or even themselves, they knew instinctively that moving away would be helpful in managing the process of coming out. Four percent of the men interviewed (two respondents) described this instinct as "subconscious." Francis, who had moved from northern New Brunswick to Ottawa for university, remembered: “There was probably a little voice in me that was saying, 'It's time for you to go' ... as I said, I probably didn't know it was that voice [i.e., one related to his sexuality] at the time" (Francis, 31, white, French-Canadian). Jerry, who left Ottawa for law school in London, England, in the late 1970s before returning several years later agreed that "[coming out] would have been 
harder [in Ottawa]. ... It probably would have happened ... but, yeah, [moving away] helped ... not consciously, but in hindsight" (Jerry, 59, white, Anglo-Canadian). Joseph (38, white, German-American), while not acknowledging any kind of subconscious intuition or prescience about his sexuality, felt that his experience of moving to Washington, D.C., reflected an archetypal discourse of "moving out as coming out": “I’ve actually_I don't even know if I should reference this - but I know that I've heard, um, that a lot of times gay men will move subconsciously ... to get, to just, to get away ... to, to be able to be their own person ... not even thinking that, you know."

Among men who decided to leave prior to defining or disclosing a gay identity, they were frequently deliberate - as opposed to peripatetic - in their choices about where to move. Gorman-Murray (2009) ascribes this process of going somewhere (i.e., moving to a specific destination rather than just "getting out") to the "gravitational" pull of a real or imagined gay community located elsewhere. Rather than simply assuming the city to be a site of liberation, men often conducted research to make a decision about where to come out. Six percent of the men interviewed (three respondents) discussed this process explicitly. For Mark, who came out in the pre-Internet age, his research was based mostly on informal conversations and the tacit knowledge of friends. When he decided to move from Newfoundland to Ottawa in the early 1990s, Mark relied on the experience of a friend who had made the same move: "It was more of a gut thing; but okay, he went there and maybe this will work out for me" (Mark, 49, white, Anglo-Canadian).

For Nick and Daniel, who were younger and had come out more recently, moving out and coming out involved deliberate, almost mathematical online research processes. Both men were about to begin university at the same time they anticipated coming out- 
and in Nick's case, had explicitly decided to not come out until university — and both considered the qualities of potential universities and the cities they were located in. Nick (26, white, Eastern European-American), who moved to D.C. after high school said, "I ... read through the schools and like if they're accepting of like alternative lifestyles and if there are gay people.” Similarly, Daniel (28, white, French-Canadian), who moved to Ottawa from an Ontario town about an hour away, said, "I was looking not just at the schools but the cities around them." In addition to finding a Canadian Studies program in a (partially) French-speaking city, he "wanted to go where there were other gay people." He tested Ottawa as a potential destination by researching online whether his proposed university had a queer student group, whether there gay organizations and bars in Ottawa, and whether networking sites such as gay.com listed a high number of profiles for the city. Even the most ordinary of queer migrations thus involve moments of recognition in which the emergence of sexual difference becomes something to be negotiated, managed, and planned for. For most men, however, self-recognition of difference alone did not result in assumptions about being out of place and needing to leave. Instead, their decisions to move were intimately linked with the ways in which they viewed their personal development and relationships in the social and institutional contexts of the places they moved from.

\section{5. 'Waiting for things to Happen': Moving Out to Move Forward}

In perhaps the most everyday of the coming-out migration themes discussed here, many men discussed moving out to overcome the feeling of stasis associated with a stillubiquitous “closet." Most respondents who moved as part of a coming-out journey felt 
that the place they lived in — regardless of its size or other characteristics—could not provide the "new life potentials" they would find elsewhere (Knopp 2004; Waitt and Gorman-Murray 2010). Again, the primary motivator for men to move elsewhere while coming out was the perceived lack of social space or identity space available in the networks in which they were embedded. Consequently, $13 \%$ of the men interviewed (six respondents) felt that their lives were in some ways contracting or becoming stunted in the places they left. Many discussed a feeling of stasis, specifically the notions of "treading water," "waiting for things to happen" or "missing out" on the type of social life and personal development that they expected to have in a different place. Many interviewees experienced a narrowing of social connections when they began coming out or planning to come out, often because they weren't "comfortable being close to people" or felt "guarded and distant" from the people they had been friends with to that point. Many men also felt that their romantic lives would not progress if they never moved, either because they feared they would never come out or because opportunities for relationships would be limited. Sebastian (42, Métis, French-Canadian, Mik’maq), stressed the difficulty in "learning to date in your twenties rather than in your teens" and the challenge of "doing things that are age-appropriate at an age-appropriate time." Such experiences reinforce the centrality of migration in gay men's life courses, demonstrating that location might render gay men not only out of place (Cresswell 1996), but also temporally out of synch with their heterosexual peers (Kertzner 2001; Barker et al. 2006). Changing locations, then, can serve as a way for men to reset or resynchronize a life course that feels stalled or stunted. 
Migrating to Ottawa or Washington, D.C., for most men, was not a decision based solely on the push of a limiting or constraining environment, but also on a variety of carefully reasoned pulls within other places. On one hand, the dominant trope of size (of both the city and the imagined gay community) was an important factor in decisions about where to come out. One-fourth of the men interviewed (12 respondents) named the gravitational pull of a larger city as one of their reasons for moving during a coming-out process. For many, the attraction of a larger city was the relative density of social connectivity compared to the (usually smaller) places they moved from-being "bound to run into [other gay] people" or "be in contact" with gay men. It was here, some said, that they felt they could build a group of friends through work, socializing, organizations, or other pathways, with less selectivity about the disclosure of their sexual identity. For a few, the presence of a commercial gay village — something disproportionately available in the largest cities - was an important precondition for coming out. Raymond (31, black, Jamaican-Canadian) who purposefully stayed in his hometown of Toronto during university, said that it was important for him to have the city's Church Street village as “a place to come out in." But despite the power of the "big city" trope, few men automatically assumed that a bigger city was the panacea for coming out. Many men specifically chose Ottawa or Washington, D.C., for their particular combination of size and social accessibility, rather than Toronto, New York, or other cities that might be seen as more likely destinations in the hierarchy of "queer diffusion" (Knopp and Brown 2003; G. Brown 2008). Rick, who moved from northern Ontario to London, Ontario, and later to Ottawa, said:

I think [Ottawa's] appealing to Canadian, particularly rurally situated gay men, because it's a large center but it's also a stepping stone between a 
city the size of Calgary or obviously Toronto or Montreal or Vancouver. So ... I think that for men that are looking for a step ... there's a lot of transition and Ottawa's seen as a transition city for a lot of gay men. (Rick, 27, white, Anglo-Canadian)

For many men, perceptions of the gay space in the communities they moved from informed their decisions to leave. In several cases, the marginal gay spaces (e.g., unmarked bars, church basement youth group meetings) in the rural, small-town, and even metropolitan communities they came from were understood to be signifiers of peripheral social status and a lack of safety (Visser 2008; Gorman-Murray 2010). In contrast, the perceived centrality and visibility of gay space in Ottawa and Washington, D.C. - as opposed to the simple existence of it — was an attractive attribute. Relocating for many was as means of accessing gay space beyond the places they deemed to be "fringe," "trashy," "sleazy" or "over-sexualized" (Weston 1995; Visser 2008; Waitt and Gorman-Murray 2010). Mark, who had moved from Newfoundland in his late twenties remembered, “... there was a bar in St. John's when I was coming out, so I would go there a few times, but it was kind of a seedy, you know, back-door kind of place at the time" (Mark 49, white, Anglo-Canadian).

In contrast, Ottawa and Washington, while not having the expansive commercial gay villages of cities like Toronto and New York, were seen as providing reasonably central and visible gay establishments. Luke (24, white, French-Canadian) compared the availability and visibility of gay organizations throughout Ottawa with the marginal spaces they occupied in his hometown in the Niagara region of Ontario: “... they are a lot more nurturing; they're a lot more kind of spread out throughout the city, so you don't have to go scoping out some little basement room in a church." Interestingly, many men were also attracted to the "mainstream" feel of places that have been characterized 
elsewhere as commercial, complicit, and normalized (Nast 2002; Duggan 2002). Joseph, who had from the Florida panhandle observed that D.C.'s gay bars were places that, to him, felt less on the "fringe": "I think finally being someplace and looking around in [a D.C. bar] ... was kind of like, you know, these guys look like guys who could be in Tallahassee at some frat bar somewhere" (Joseph, 38, white, German-American).

Respondents were especially attracted to the status of Ottawa and Washington, D.C., as national capitals and "government towns," despite a history of hostility toward gay men and reputations for promoting conservative and disciplined identities (Smith 2005; Cooper 2006; N. Lewis 2011). As Chapter 8 discusses more fully, almost half of the men interviewed (20 respondents) indicated that their migration decisions were influenced by the relatively secure nature of government work. This influence is partially attributable to the perceived feasibility of being out in professional settings. Many respondents commented on the presence of openly gay men in the civil service, in prominent political positions, and organizations such as the World Bank (Washington, D.C.) and Canadian Red Cross (Ottawa). Adrian (56, black), who moved to Ottawa from Nova Scotia over 25 years earlier, said "You can probably be as out as you want to be in Ottawa, because of the structure of Ottawa ... the environment, that political structure. Regardless of ... what type of government we have in, we, as a community, are everywhere in this city."

For several of the respondents, the visibility of gay identities within particular occupational sectors (e.g., advocacy) and among individual public figures (e.g., openly gay politicians) indicated that these cities were safe spaces to come out. Moreover, it prompts us to think about the role of gay space beyond the pubs and clubs in queer 
coming-out migrations. To realistically consider the potential of disclosure and a "gay life" in a given place, men look for the visibility of queer people in public, economic, and professional spaces as well as social ones (see also Gorman-Murray and Waitt 2010; Catungal and McCann 2010). The narratives discussed thus far also show that coming-out migrations are not just on a knee-jerk flight to large cities, but moves predicated on carefully reasoned assessments of gay spaces and visibilities within particular cities.

\section{6. 'There is that Fear': Moving due to Possible Rejection}

Since the stigma associated with sexual non-normativity is geographically uneven (N. Lewis 2009), many men struggle with balancing or managing the temporal, locational, and social contexts of coming out. While fear is central to traditional narratives of coming out and migration, it is usually addressed in the context of empirically experienced discrimination and the threat of bodily harm (Valentine 1993; Gorman-Murray 2009). Yet as Owen (32, white, Jewish-American) observed, the fears driving coming-out migrations may emerge from within families and homes: "You can plop someone down in the middle of New York City ... but it really depends on what their family background is like and most people have difficulty coming out, usually, because of that." Aligning with Owen's observation, eight percent of the men interviewed (four respondents) directly referenced fears or expectations of rejection in the home environments they moved from. In most cases, they collected cues from the people around them to discern whether they could safely disclose their sexuality. In cases where they perceived prejudice from those around them or felt that they would end up being excluded from the networks they had established, men moved in order secure a network 
elsewhere before risking losing the one in which they were already embedded. Terry, a 40-year old who moved to Ottawa from southwestern Ontario ten years earlier, explained that his fears of rejection were less informed by the place where he grew up than by the cultural and social particularities of his family, and the geographic and historical contexts in which his parents migrated from Europe:

But, um, my parents and certainly my dad when they left [Belgium] in the ' $60 \mathrm{~s}$, kind of maintained the social mores of that time and, and so, you know, you do see that whereas the country moved on but, you know, [my parents] didn't ... but you know [I was] always fearful that they would reject you, which didn't happen in my case but there is that fear ... and so that ... that's a factor. (Terry, 40, white, Flemish-Canadian)

Migrating to a new place, then, facilitates the coming out process by allowing for the development of new social networks, and provides some assurance of fitting in somewhere, even if not in the place left behind. But like Terry, very few respondents found that their fears of rejection were realized. Randall reflected on his decision to leave Nova Scotia and then finding out several years later that his mother was accepting —or at least indifferent- to his sexuality. "I was worried that I was being deceitful, because, you know, an omission is as bad as, you know, a contrivance, isn't it? But um, you know ... [if I moved away] I wouldn't have to confront that" (Randall, 45, black/Aboriginal, African-Canadian, Mik'maq). For Randall, it was anxiety over the rupture of his support system (i.e., confronting the possibility of changed relationships) and the pressure and guilt he associated with day-to-day "deceit" that caused him to move out before coming out. In some cases, however, moving away to build an identity and secure a network provided the confidence to disclose one's sexuality. As Mark, who moved to Ottawa from Newfoundland in his twenties, explained: 
I think being away actually helped, that I felt able to [come out to family] eventually. Um it took, took a while, I would, you know, I told sisters first and then, and then ... but feeling grounded, more grounded that I was confident enough to have that - those conversations, and knew they wouldn't be devastating to me. But ... I did ... get an identity that I was comfortable with and that felt confident in, and then felt empowered to be strong enough to tell my parents when I knew it was going to be a difficult conversation. (Mark, 49, white, Anglo-Canadian)

In yet other cases, moving away provided family members with time and space to accept or acclimate to a relative's recently disclosed sexual identity. Max, who transferred from a Washington, D.C., university to one in Arizona before moving back many years later said:

The reason I transferred out was to get away from my family or my parents ... time was a big issue ... I think it took them a while to sort of sort through all of those issues and ... finally what ended up happening is that they, um, sort of have always been-since that time-deeply apologetic about how they handled my coming-out period. (Max, 31, white, European-American)

Fears about divulging sexual identity were thus a key factor in men's decisions to move away from family homes classifiable neither as blatantly homophobic nor unequivocally accepting. Although their fears of outright rejection were not always well-founded, moving away allowed many men to create a to gain the confidence to come out, to create a social safety net in anticipation of a negative coming-out experience, or to allow for the mutual readjustment of themselves and their family members following one.

\section{7. 'New City, Nobody Knew Me': Moving Out to Seek Anonymity}

Anonymity, or the state of being unknown, has long been central to discourses of moving out and coming out. As noted by Weston $(1995,268)$, "Relocation, especially of the sort that puts miles between relatives and the person coming out, could itself be the 
prerequisite for acquiring that desired sense of anonymity." Men engaged in a process of coming out thus often seek distance from one set of home communities and identities both to simplify the coming-out process and to establish a new (though not completely separate) communities and identities elsewhere (Fortier 2001). Coming out therefore sometimes requires a spatial break with families, friends, and places to - as one respondent said-“do what they want" and "be what they want" (Sebastian, 42, Métis, French-Canadian, Mik'maq). Among the men interviewed, 13\% (six respondents) indicated that achieving some degree of anonymity while coming out informed their migration decisions.

For some, anonymity was achieved by acquiring the personal space to explore how their sexual and social identities might be intertwined. Marshall (29, white, ItalianAmerican), who moved from St. Louis, Missouri, to Washington, D.C. in his early twenties said, "it was a very easy time to self-explore, you know, coming out, all of that, but, but just with like society, not with myself ... new city, nobody knew me." More frequently, however, men observed that moving away was a means of disentangling themselves from the familial and social networks established in the places left behind. Mark, who moved from Newfoundland in his late 20s, explained that both the geographic and emotional closeness of his family and community contributed to his "suffocation."

Um, I think it was the whole thing of I was closeted, living a closeted existence. My family was there, I had a, you know, a large extended family. I didn't feel I could be out, um, and that was probably the greatest difficulty. I mean I liked it, you know people are warm generally, but I wasn't feeling empowered enough to be, to be out ... I needed that distance and that break, uh, so yeah it was a little ... a little suffocating (Mark, 49, white, Anglo-Canadian). 
Later in the same interview, he discussed why his professional position as a teacher at a Catholic school, coupled with the social and spatial dynamics of a town in a province that had just experienced a major sexual abuse scandal at a Catholic orphanage, resulted in what Griffith and Hebl (2002) call a "disclosure dilemma" in their study of coming out in the workplace. Since the networks of the town were so interconnected, Mark found it too risky to explore his sexuality in a personal context and remain closeted professionally.

Moving to Ottawa for government work became a more logical choice.

Um, well as a teacher, uh, I felt a little bit exposed. I met people from time to time and I would have people visit my apartment-I was actually living in a small town outside of Corner Brook, um, for a while, and you know I was feeling, that oh okay, this could blow up in my face at some point ... I couldn't be, couldn't have been out at work, and you know, socially there was a real stigma, I think. And I mean in Newfoundland, of course, the whole scandal with the Mount Cashel orphanage and the Catholic Church and everything did have a chill over, I think, gay issues generally. People, you know, made the connections and ... the unfortunate connections.

In other cases, men moved away to escape the perceived scrutiny of a peer group. Frequently, they referred to feelings of exposure and vulnerability among their peers and unable to move forward with coming out. Shawn (42, white, French-Canadian), who had moved to Ottawa from northern Ontario in his early twenties, said, “... there was a certain comfort in ... being on my own and being able to live my life without the constant scrutiny of others." The decision to move, however, was not always based on an expectation of judgment from a peer group. Many men also believed that maintaining the relationships they had established at home might slow down or impede the coming-out process. Jack explained why staying at home in Colorado instead of moving to Washington, D.C., would have created a more lengthy, complicated coming-out process in which existing friendships would need to be "reshaped." 
I think it might have happened a little bit differently just in that I would have been around like groups of friends that I'd known since the beginning of college who thought I was straight, and would have had to, I don't know, kind of like reshape everything. I think it would have been tough, so I don't think it would have happened like quite as rapidly or easily as here. (Jack, 24, white, European-American)

For others, moving out to come out required not just moving away, but moving far away. The point of a coming-out journey was not simply to flee a small town, but to put significant geographic distance between themselves and the social networks in which they had been embedded. Francis, who moved to Ottawa from eastern New Brunswick, observed, “... just rumors of somebody being gay there, like the whole city knew, and they were gossiping about it. There's no way I would have lived there ... like I'm, I don't have a thick skin enough to handle that" (Francis, 30, white, French-Canadian). Almost employing a principle of distance decay in their coming-out migrations, some men were interested in moving to places with the fewest linkages to their friends and families from home. Consequently, many moved to entirely different regions rather than the closest big city. Sebastian, for example, discussed his reasons for leaving not just his hometown but also the entire province of Nova Scotia:

For moving [to Ottawa], it would have been the freedom to be able to come out and be who I was. I had a scholarship at Dalhousie [University], I could have gone there for free-I had to work for the same amount of money here-all of my friends who were ... who were going to university were going to Halifax ... from the year before me, uh, somebody who was in university was seen going in or out of the one gay bar there was in Halifax, then everyone back home knew about it a week later. (Sebastian, 42, Métis, French-Canadian, Mik'maq)

Similarly, Doug (26, white, German-American), who moved from a town in Colorado to Washington, D.C. for university, said, “Boulder didn't really seem like an option for me just 'cause it was so close to [my hometown] and it was just like, that's where everybody 
was going." In these cases, moving to an ostensibly accepting environment like a

university or a nearby city with a visible gay population (e.g., Halifax) was not sufficient;

it was more important to have the social space needed to form a gay identity and the ability to manage disclosure unilaterally and from a distance-without threat of gossip or rumor. As these narratives demonstrate, anonymity does not require a city as much as it requires freedom from the entanglements of families, friends, and places themselves.

\section{8. 'So I really do it for my Mother': Moving Out to Mitigate Social and Familial Burdens}

Narratives of coming-out migration often assume that moving away from one's current home - particularly the homes of parents and families - is simply a response to a supposedly intolerant or unhealthy home environment (Weston, 1995; Binnie, 2004; Barton 2010), sometimes "triggering" migration a new place (M. Brown 2000). Some men's stories align with this discourse of disapproval, disappointment and the temporary or permanent rupture of families. Max, for example, said that he moved because his family relationships "denigrated" after coming out:

Coming out wasn't so difficult for me ... like I mean I felt really strongly that I was doing the right thing ... and, um, certainly like it didn't make me happy that my relationship with my parents sort of denigrated, but I don't think there was ever a time when I thought that they were right, like in terms of like, you know, their prejudice against gay people. I was always pretty sure that it was unreasonable. And the reason I transferred out [from James Madison University to the University of Arizona] was to get away from my family, or my parents. (Max, 31, white, EuropeanAmerican)

A more common story, however, was one in which men actively chose to move away after coming out — or in anticipation of coming out — in order to mitigate the burden that they believed it would impose on their family and friends. These respondents felt that 
while their sexual difference would not constitute grounds for the familial disownment or societal exclusion that it once did—thus requiring self-displacement—it would still require that their loved ones also disclose something still often conceived as abnormal or deviant (Halperin 2000; Olund, 2010). In other words, parents, families and friends would also need to come out of the closet. As Kertzner $(2001,85)$ notes in his study of gay men in midlife, homosexual identity was often perceived as a "burden that disrupted life history." Interestingly, many of the respondents saw their identity as a burden to others more than themselves, expecting that the disclosure of being gay would be understood as the "betrayal or trust of a relationship" or as an emotional encumbrance (Flowers and Buston 2001, 59). Many men therefore moved away to avoid tasking family or friends with admitting that they had a son, grandson, nephew, cousin, or friend who was gay. While $8 \%$ of men interviewed (four respondents) referenced the concept of burden directly, others among the 19\% (nine respondents) discussing the role of parents in migration decisions alluded to subtler notions of creating inconvenience or difficulty by coming out.

Two men discussed the particular difficulties of coming out in black communities that were internally influenced by Christian doctrine and externally marginalized by racism and discrimination. Peter attributed his move from Austin, Texas, to Washington, D.C., largely to his unwillingness to burden his grandmother with the reality of his sexuality. "Because my grandmother raised me and [she was] very, very old-fashioned, um, and I wouldn't want to put any undue burden on her" (Peter, 39, black, AfricanAmerican). Randall, in contrast, framed his move in terms of structural racism, as opposed to internal, familial expectations about living in accordance with what might be 
termed African-American (or African-Canadian), Christian values. Randall lived in Halifax, Nova Scotia—a city that he described as having a long history of racism—before moving to Ottawa in the 1990s. He had felt that coming out would not only exacerbate his own "double whammy" of being black and Aboriginal, but would inconvenience his friends, many of whom were racialized and dealing with their own issues of poverty or unemployment: "[My friends] had their own shit to deal with, so there wasn't any way I was going to, you know, shovel more on to them. So, you know, what we could sort of provide for each other was kind of limited" (Randall, 45, black/Aboriginal, AfricanCanadian, Mik'maq). Before coming out, Peter and Randall had not only considered not only the networks and communities in which they were embedded, but also the circumstances and subjectivities of their friends and families. Their strategies reiterate that coming-out migration is not just about identity formation, but the management of the particular networks in which the migrant is embedded.

Often, men reacted to cues from family members that suggested their coming out would be excessively burdensome. In some cases, they took their family's silence on the issue of sexuality as evidence that they did not want to discuss it. Michael, who had moved from South America to Wisconsin, and later to Washington, D.C. said, "Uh, the [other family members] probably suspect, and my mother probably is the one who really knows, but we don't talk about that" (Larry, 44, Hispanic, Paraguayan). In other cases, however, the message from families was more overt:

It's just an issue of why, why bother [coming out to my parents] at this point. I mean they know I've never had any girlfriend. So I'm kind of going, uh ... but, and they always have to say, "I like things just the way they are." So they give me signals they don't really want to know. But bottom line is I don't ... honestly if they asked me I would tell them in a minute. It's they don't really ever ... they don't ... I get signals from 
them they don't want to know, so I kind of respect that. (Chad, 35, white, Anglo-Canadian)

Even without any indication from family members that their sexuality would be better left undisclosed, some men moved away to prevent an imagined strain on relationships between family members. Jack, for example, explained that coming out in close proximity to his family would have "messed things up" between his immediate and extended family:

You know, I have like some of my relatives-like my grandparents and some aunts and uncles - that are very, very conservative Christians, and like, I just don't know how it would change the family dynamics, 'cause we have this very, very tight-knit family ... I don't know, I wouldn't want to have like ... um, mess anything up in that way, so ... (Jack, 24, white, European-American)

Although Jack's extended family was ultimately supportive of his sexual identity and his decision to come out, he felt that moving away would allow him to test this from a distance, by telling his parents after moving away and allowing them choose to share the information with other family members as they thought appropriate. This, he felt was preferable to being faced with an extended family in which some members knew about his sexuality and others—-whom he was too scared to tell—did not. Other men worried that family members who were displeased with their disclosure would blame or punish other family members who continued to live in close proximity. Chad, who had discussed his family's intimations that they did not want to discuss his sexuality later added, "My father's a bit of an ass, so it would make my life—-my mother's life—very miserable. So I really do it for my mother more than my ... I know what his reaction would be and her living with him would be." 
The most common familial burden perceived by respondents, however, was their parent's fear about the safety and well-being of their children during the coming-out process. In particular, many felt that they needed to physically put themselves in a place that would mitigate their parents' fears about the bullying, exclusion, or physical safety. According to Doug, who had moved from Colorado to Washington, D.C., for university:

My mother took it very well when I came out in college ... but I feel if I came out in high school, she wouldn't have taken it well as much, and I think that's because she probably would have worried about me more, just being in that environment ... than like in D.C. in college, where she knew here I already had a lot of friends who knew I was gay and didn't really give a shit. (Doug, 26, white, German-American)

Other parents were concerned about "someone taking advantage" of their son or that their sons would contract HIV after coming out and encountering the scene for the first time (see Valentine and Skelton 2003). Consequently, many of the respondents' parents prevented them from utilizing tools, such as online social networks and local gay youth organizations that would have helped them in the coming out process. While they were aware that some of their parents' concerns may have been unfounded, a few men felt it would be easier to both avoid and allay their parents' fears and avoid their protective behaviors by moving:

It wasn't kind of out of, I think, gratuitous homophobia or willful homophobia, but I guess I think part of it may be that but just a part of it was kind of the parent reflex to protect their kids in whatever situations they may be. Um, and so, in that sense and so they kind of restricted the amount of gay stuff I could do and I think that helped contribute to feeling a sense of sadness and kind of maybe also the desire to move, yeah. (Derek, 29, white, French-Canadian)

Doug's and Derek's accounts reinforce that some of the most pressing difficulties for many of the men who moved out to come out were less related to inherently 
discriminatory or homophobic places than they were to the particularities of the familial and social networks in which they were located.

\subsection{The Importance of the Everyday: Seeing the Grey Zones of Queer Migration}

On one level, the narratives discussed here are mundane: they rarely involve the instances of outright abuse, harassment, and intolerance so evident in the North American imaginary of queer migration. Instead, they are largely everyday journeys motivated by personal development, desires for anonymity, fears of rejection, and the management of burdens - factors often glossed over as commonsense. At the same time, these narratives offer a powerful opportunity to re-examine the role of place in queer coming-out journeys. In most of the scenarios discussed, men's migrations were motivated less by monolithic conceptions of places as intolerant, homophobic or otherwise "at odds" with their identity, and more by the complex grey zones of familial and social networks and educational and professional institutions embedded within those places. Often, the places that men moved from (e.g., Seattle, Austin, Winnipeg), were not small, rural, or known to be particularly homophobic, but were rendered incompatible with coming out by the networks and relationships embedded there.

The importance of complex place dynamics was revealed in each of the four elements of coming-out migration discussed. Men who sought to move forward in their personal development searched not just for big cities with recognizable gay commercial spaces, but to places where gay spaces and identities were central and visible in a diverse set of economic and professional sectors (G. Brown 2009). Men who had moved because they feared rejection were not so much fleeing as they were setting up an alternate or 
backup social support network elsewhere. Men seeking anonymity were not simply going to a place where they could be unknown or start from scratch, but were purposefully disentangling themselves — often through long-distance moves - through which secondary information about their sexuality might reach family members or friends. The complexity of gay men's coming-out origin's and destinations is perhaps most aptly demonstrated by those migrations intended to mitigate or defer familial burdens. In these cases, coming-out migration was not a reaction to place at all, but rather a use of space to manage relationships. Men's destinations, too, reflected the complexity of place dynamics in queer migration. Respondents from Canada's Atlantic Provinces, for example, purposefully did not go to the Halifax — the regional gay center that might have been considered the first line of defense under the city-centered thesis of gay coming-out migration. Knowing that regional communication networks were dense and that they would likely encounter people from home, they instead chose to live in a city (Ottawa) where they would have more room to come out and less likelihood of their sexuality being discussed in their hometown.

These cases suggest that place, space and distance are all central to queer comingout migrations. While some coming-out migrations might be driven by the need to leave a place perceived to be homophobic or repressive, many moves are driven by more general desires to create space around oneself while coming out, usually at a distance from existing sites of existing social entanglements. Getting out is perhaps not as important, then, as going to a specific "somewhere" that affords significant space around the migrant-subject and a sufficient amount of distance between himself and the networks embedded in a previous home (Gorman-Murray 2009; Gorman-Murray and Waitt 2010). 
As Knopp (2004) suggests, coming out might involve a search for liminal space — or even "placelessness" itself — rather than the simple exchange of a homophobic place for one imagined as gay- or queer-friendly.

The narratives put forth here also offer an opportunity to revisit the role of the body in queer migration. Offered by scholars like Silvey (2004), Knopp (2004), and Gorman-Murray $(2007,2009)$ as a counterpart to studies of binary origins and destinations for queer people (urban/rural and Global South/Global North), the "embodied migration" concept places the queer individual at the center of the migration process. Migration is thus driven by identity quests, searches for emplacement, and emotions such as love and comfort. In many ways this study affirms the centrality of the body in coming-out migrations: many men's journeys were partially driven by the desire to form an individual sexual identity, and many men's coming-out migrations were driven by emotions such as fear. At the same time, this study challenges the potential reification of the body as the primary driver of queer migration. In these everyday migrations, it is more apt to describe the coming-out journey as one motivated by the body's position within and relationship to the various networks embedded in a variety of complex, dynamic places. The importance of these embedded or emplaced social dynamics was demonstrated in men's decisions to not just flee, but to choose specific places and trajectories that that they felt would help them manage the coming-out process and the various relationships it might affect.

Finally, this chapter signals a related need to reassert the role of stigma in comingout migration, not just in migrations originating in countries and locales with blatantly homophobic policies and practices (i.e., formalized stigma) but also in journeys between 
seemingly unremarkable places (G. Brown 2008). Instances of legalized or formal discrimination in the form of job loss or restricted mobility rarely entered into the narratives discussed here. The reasons for this absence are partially related to policy. On a global scale, Canada and the United States are two countries that now have relatively progressive policies concerning the rights of queer people (see Table 4.3 in Chapter 4). In Canada, the marriage, adoption, and immigration rights protected under the Charter of Rights and Freedoms are consistent across provincial borders, rendering Ottawa legally indistinct from the places that most men moved from. In the United States, these same rights and protections are geographically inconsistent, yet many of the respondents had moved to D.C.- a jurisdiction granting substantial rights and protections for gay menfrom states (e.g., New York and Massachusetts) with similar legal regimes.

Despite the limited references to codified discrimination or prejudice in respondents' migration narratives, their moves were influenced by both ongoing understandings of "gay" as a stigmatized identity and experiences of stigma in secondary or intermediate ways. While disclosing a gay identity for most men did not emerge as an imperative to leave - as it still is in many parts of the world — men conceived it as enough of a disruption or burden, to both their own lives and those of friends and families, to require managing the process from afar. Anti-gay stigma, then, is still very much present in North America, but affects coming-out migrations in socially and spatially uneven ways contingent not just on location, but also on individual subjectivities (e.g., as a racial minority or part of an extended family) within those locations. In particular, there is a need for a more nuanced conception of the "informal prejudice" (see Meyer 1995, 2003) through which the values of particular cultural, religious, or ethno-racial communities are 
imagined to constrain, stigmatize, and closet gay men and other queer people. Although there are too few men of colour in the sample to definitively delineate the ways in which race vis-à-vis sexuality might inform a coming-out process, very few described family homes that needed to be fled because they were gay. Instead, they often provided vague allusions to the ways in which historic or prevailing cultural traditions might influence certain family members (e.g., a Christian, African-American grandmother) and affect their relationships with those family members upon disclosure.

Even in these everyday coming-out journeys, the persistent understanding of sexual difference as something that must be disclosed and negotiated creates environments in which men feel constrained — by parents' or families' fears, by potentially changed social relationships, and by the perception that a gay man must exchange one life for another after disclosing his sexuality. Distance and relocation therefore become tools to manage and control a landscape of familial and social networks that is likely to be re-contoured. Relocation, then, is less about an individual identity quest (Knopp 2004) than about the process of defining oneself vis-à-vis networks and communities in different places. This might involve both separating oneself from networks in which they will be rendered different and finding new networks elsewhere that might affirm or clarify their identity. Moving out to come out, then, is a relational journey in which identities and networks are simultaneously redrawn. Continued work on the micro-level experiences of queer people is therefore important to the ongoing project of disentangling the rural-urban and liberal-conservative binaries once perceived to drive queer migration. The following chapter adds an additional layer of analysis by examining the trajectories, or flows, of gay men's migrations during coming-out processes. 


\section{CHAPTER 6}

\section{Remapping Disclosure: Segmented Journeys of Moving Out as Coming Out}

\subsection{One-Way Journeys: Linearity in the Coming-Out Migration Narrative}

Regional, cross-continental, and even international migrations among queer ${ }^{1}$ people have frequently been characterized by linear patterns of relocation, often involving a homophobic or intolerant point of origin, a more welcoming and accepting destination, and roughly simultaneous moving out and coming out processes (Weston 1995; Yue 2008). Despite the growing efforts to de-center the gay and queer places detailed in the previous chapter (see also Phillips et al. 2000), geographers have only begun to suggest ways of reframing the coming-out journey. Work on journeys in general has suggested that they are formative experiences and processes that operate at a variety of scales and locales, rather than a trip between two fixed places (Rose 1993; Pile 1996; Knopp 2001). More recently, work in “emotional geography," has explored the mutual constitution of human emotions such as love, fear, and comfort, and spatial phenomena such as migration (Davidson and Milligan 2004; Bondi et al. 2005).

Geographers of sexualities, in turn have observed that coming-out migrations are complex phenomena that involve multiple types of moves informed by individual emotions and desires (M. Brown 2000; Knopp 2001; Knopp and Brown 2003; Knopp 2004; Gorman-Murray 2007, 2009). A few studies directly challenge the linearity and finality of coming-out migration. Both Gorman-Murray (2007) and N. Lewis (2011) suggest that "out-ness" can be an ephemeral state mediated by routine trips for "gay fixes" in places where one feels comfortable to be openly gay or queer. Others note that queer people who move to places imagined as "emancipatory" (e.g., gay villages) may 
feel excluded by the modes of normative, cosmopolitan gayness they encounter and do not disclose their sexuality until moving to a suburb, the countryside, or a rural area (Valentine and Skelton 2003; Gorman-Murray 2007).

While these interventions have complicated the spatialities of coming out and coming-out migration, few have offered a framework for re-conceiving the coming-out journey. Fortier (2001) and Knopp (2004) offer the key contribution here by reframing the coming-out journey as a wandering or "peripatetic" identity quest that seeks to both affirm a queer identity and find a queer home. While this work provides the conceptual space to imagine the various detours, returns, starts, and stops that are likely to occur within a coming-out journey, it also has limitations. First, it recasts the body (and the emotions and desires within it) as the central driver of migration while the social and spatial contexts in which coming out occurs become peripheral. Second, this work rarely assesses what coming-out migration might entail in material practice or-with a few exceptions (see Waitt and Gorman-Murray 2010, 2011) —what kinds of trips might be included in a coming-out journey. The work in this area therefore remains empirically thin, possibly due to the continued ontological valuation of places over flows in queer and cultural geography (Knopp 2004). As a result, linear, teleological views of the comingout journey persist despite increasingly complex understandings of coming out itself. As Gorman-Murray observes:

Most of the individual migrations described in [existing empirical studies] are uni-directional - "one way," from the country to the city, with no returns or detours or subsequent moves-suggesting a one-off escape from rural constraints to the freedom and the affirmation of the urban queer community. And since these studies assert that the desire for freedom of sexuality figures prominently in the decision to move, this uni-directional rural-to-urban movement intimates a once-and-for-all 
emergence from the rural closet, and the assumption of an already fully formed and fixed urban queer identity. (2007, 109, italics in original)

The following discussion of gay men's migration narratives seeks to address these issues empirically, by fleshing out and thickening the notion of the coming-out journey. By examining various segments of these journeys, and especially the social contexts in which they arise, this analysis moves beyond both assumptions of linearity and the "peripatetic" rejoinder. First, I look at short-term journeys to test one's perceived feasibility of coming out: "scouting" trips to test potential destinations (or even the existence of a place that feels safe and appropriate for coming out). Next, I examine journeys that result in going back into the closet. Third, I discuss migration as a meaningful, often symbolic "test" for the potential for living a heterosexual, heteronormative life or a "trigger" to end that phase of life. Finally, I examine journeys that tend to follow an initial (though not final or complete) disclosure of sexuality: return journeys to places where the respondent had once lived as heterosexual, and moves (often within the city) that mediate the ongoing process of coming out after a destination has been reached.

\subsection{Migrations as 'Scouting' Trips}

For $13 \%$ of the men interviewed (six respondents), short trips in which a potential place to live was assessed or "scouted" were central in their coming-out journeys. Weston (1995) touches on these types of preliminary journeys, highlighting a few cases in which young gay men and lesbians sought out their first experiences of queer city life on weekend trips to usually-nearby metropolitan areas such as Chicago and New York. Indeed, a few men mentioned the role of weekly or monthly trips to nearby cities in discovering the gay scene and building or affirming a gay identity they had 
sometimes begun to disclose to themselves or others. James, who moved to Ottawa from suburban Vancouver in his early thirties, talked about his trips to Toronto and Montreal with the younger, newly out boyfriend he had moved there with: “... We went to Toronto and Montreal all the time ... but again, my boyfriend was just coming out ... [it was] like, 'alright, alright, let's do this again. Are you finished yet? No? Alright, let's go to Toronto again"” (James, 40, white, Anglo-Canadian). For James, the novelty (and sometimes, annoyance) of the routine gay "fix" was a function not only of different points in the life course (between him and his younger boyfriend), but of Ottawa's proximity to Canada's largest cities. On the west coast, he had come out in what he considered to be a relatively small collection of gay spaces on Vancouver's Davie Street. Most men's scouting trips, however, did not involve asserting or testing out a new gay identity; in fact, they tended to take place before the respondent had disclosed his sexuality to himself or others. For many, brief experiences as an intern, visitor, or student in a different province, state, or country were powerful indicators of the possibilities of living life as a gay man.

Mark, who moved to Ottawa from Newfoundland in the 1980s during his late twenties, discussed how two short trips before this more definitive move both aided the process of confirming a gay identity and made him feel more secure about coming out in a challenging spatial and temporal context. Having grown up in a working-class Irish Catholic family that considered being gay a foreign concept and a religious offense, Mark had felt unable to imagine life as a gay man. It was a yearlong trip to Quebec City for a language program that changed this, "opening his eyes" to the potential of such a life:

Quebec was a dramatic shift. I mean it was just so dramatic from St. John's [Newfoundland], you know, in the late '70s, to Quebec City. Uh, it was huge. You know, I just ... the world kind of opened up. And it was, I think, very much the openness of Quebec society that it was such a 
dramatic shift from what I was used to ... The gay group on campus [at Laval University] had an office space on campus at the time. They would have big events like cabarets in the faculty club, and profs [sic] and students would come, you know. That was a major eye opener ... I met couples who had been together for long periods, you know, it was the first time I'd seen that, and was ... so I just got role models all of a sudden - some examples of how you could live a life as a sane gay person and, you know, it could be a very satisfying life. And so that was the first time I had seen that in the flesh, so that was a dramatic shift. So here's a self-esteem, um, confidence, I think, you know, major jump (Mark, 49, white, Anglo-Canadian).

While Quebec City was neither Mark's final destination nor even the place where he claimed to have come out (he identified Ottawa, five years later, as that place), it was clearly a formative — even if unintended — step toward affirming his sexual identity and the feasibility of living a gay life. After two years back in Newfoundland, and what he described as a fairly "closeted" existence, a semester abroad in London, England began the process anew: "That was pretty massive as well in terms of a ... coming-out experience. I mean there was so much going on in London; there were pages of bars and activities ... so that was, that was interesting. It was almost too much, though. It was ... very, you know, over-the-top, in-your-face ...” The experience of this second short journey reinforces earlier observations by Weston (1995), Knopp and Brown (2003) and Gorman-Murray (2007) that the cities considered gay capitals or homelands are not always ultimate destinations — either longitudinally or categorically—-for coming out. In this case, the respondent found the experience of gay London overwhelming, leading him to choose Ottawa as the place where he would finally live as an out gay man.

Terry, who moved to Ottawa from southwestern Ontario at 30, reflected on his first experience in Ottawa as a high-school summer guide at the national Parliament: "And so I remember at the time there was one openly gay guide, and so it ... there was 
just, I mean you actually knew people who [were gay]." While this short-term encounter allowed him to both affirm the feasibility of coming out and the viability of Ottawa as a place to do it (he moved back there and came out later in life) it did not result in disclosure at the time: "I guess just personally I wasn't prepared at that time to seek it out,' he said (Terry, 40, white, Flemish-Canadian). Jason, a Thai man who moved from the west coast of the United States to go to graduate school in D.C. in his mid-twenties, reflected on a similar situation to Terry's: He moved from Bangkok, to Portland, Oregon, for a year-long high school exchange program. The time and space provided by moving allowed him to "explore for the first time, sexually," mostly online (see Munt et al. 2002; Bryson et al. 2006), and to realize that "[being gay was] not that bad, [it was] actually fun" (Jason, 26, Asian, Thai). But similar to Terry, his journey did not include disclosure to those around him: "Even now, my friends in Portland like still have no idea ... except for a couple of them." Jason's story not only highlights some of the ways in which gay men very purposefully test out sexual identities through place, they reinforce that relocation and disclosure rarely overlap in a neat, tidy, complete coming-out process.

\subsection{Moving Out and Going Back In}

As the accounts above suggest, exploring one's sexuality through place does not always result in disclosure, and the accounts of many men show that relocating sometimes results in a choice to re-closet oneself. In contrast to portrayals that correlate successive moves with a progressive advancement toward coming out (Weston 1995; Knopp 2001), a few of the men interviewed had undergone relocations that prompted them to re-closet themselves despite having lived as openly gay elsewhere. This re- 
closeting was not captured as one of the original sub-themes, but was noted after a second careful reading of the sections of narrative related to coming out. Although much of life course research assumes sexuality to remain stable throughout life (Patterson 2000), interventions in queer theory (Sullivan 2003; Giffney 2004) have suggested both that sexuality itself is fluid throughout life and may be performed or practiced differently depending on individual subjectivities and social or historical contexts. This perspective therefore augments newer life course research on how gay men conceive gay identity later in life (see Cohler and Galatzer-Levy 2000; Kertzner 2001; Hostetler and Cohler 2003) because it suggests that even the condition of being out might be affected by both men's conceptions of their own sexuality and the geographic contexts in which they are located at various points in life. Put differently, sexual identity does not remain static after an initial disclosure, but changes depending on geographic and temporal context. For example, Mark, who had spent time exploring and partially affirming a gay identity in Quebec City and London, England, also felt that it was necessary to conceal it upon returning to Newfoundland and entering the professional realm.

But then I went back to Newfoundland ... there were some connections and friends and stuff there ... but you know, it was a fairly closeted-I was a teacher, I was a high school teacher teaching religion and Frenchand it was, you know, I was in a fairly closeted environment ... so I went back to Newfoundland having been, you know, my eyes opened and went back, and my eyes were wide shut. (Mark, 49, white, AngloCanadian)

In this case, economic necessity in the form of a teaching job-particularly one in a Catholic environment that reinforced the same anti-gay norms he had grown up withpartially determined a decision to both move back and go back (in the closet). For others, however, the decision to (re-) conceal being gay was more multi-layered. Peter, an 
African-American man who moved from Texas to Washington, D.C., discussed the ways in which the segmented disclosure of his sexuality was intertwined with his political identity and aspirations for a political career. "Well I knew that I had to go back into the closet when I moved up here," he said, "you know, stepped my toe out of the closet, and then moved up here; I'm like okay, step back in ... um, and I did that for a good 5-10 years ... before I sort of like really came out" (Peter, 39, black, African-American). When asked why he chose to conceal being gay despite moving from what would typically be characterized as a more conservative or repressive environment (Texas) to a more liberal one (D.C.), he explained how his identity was mediated by both his racial identity and his political affiliation:

Well I was trying ... I was trying to advance, advance career-wise ... a new Congress had just taken over ... but it was hard enough being a black Republican, let alone being a gay black Republican ... so I figured, I'll deal with one thing at a time, and it's weird because here in D.C. I often feel that I'm more accepted among Republicans for being gay than among gays for being Republican.

His story reveals that even queer migrations following traditional interior-to-coast, conservative-to-liberal binaries are not necessarily emancipatory, and that other subjectivities, such as a Republican political identity, are likely to mediate one's welcome into the gay community they encounter. Although politically conservative and religious gay men have frequently been described as colluding with an agenda of normalization in the United States and other countries (see Duggan 2002; Nast 2002), politically conservative or religious men frequently find themselves excluded from the communities to which they eventually decide to disclose themselves as gay. Men who moved out and "went back in" therefore did not merely interrupt a pre-determined process of 'opening 
the closet door; they were often negotiating in-between worlds that multiple subjectivities had rendered more complex than imagined or anticipated.

\subsection{Migrations as Coming-Out Tests and Triggers}

This section details how migration itself (or even the potential for migration), rather than the place to which one migrates, can act as a powerful catalyst for coming out. Much like the men who explained how brief trips to unfamiliar places confirmed the feasibility of living securely as an out gay man, several also discussed how relocation or impending relocation revealed dissatisfaction with living out a heterosexual identity. As with the narratives on re-closeting, this theme of migrations as coming-out tests and triggers did not emerge until a second reading of the coming-out data. The narratives featured here also show that some of the most formative portions of coming-out journeys involve trips (or potential trips) to small towns and rural areas. Terry, whose first highschool "scouting trip" to Ottawa is discussed above, described a similar short-term journey to his childhood home in southwestern Ontario to test the possibility of living as a heterosexual man after attending law school in Ottawa.

Um, it was more could I live a straight life? I think [that] was really why I went back. And, um, you know I'd mentioned beforehand when I came back [to Ottawa], that's when I came out. Beforehand it was furtively. But it was going back and saying, okay, do I want to live the life of, you know, um, you know married, blah, blah, blah, and then a few months into the articling thing I realized I couldn't do it. And so, that was my opportunity going back: can I do this or not? And I realized I couldn't, and came back, and the rest is history. (Terry, 40, white, FlemishCanadian)

In other cases, gauging the feasibility of coming out (or in the following case, perceiving the inevitability of coming out) was mediated by several back-and-forth trips 
between a childhood home and a potential gay home. Francis, a French-Canadian from eastern New Brunswick-who noted that his move to Ottawa was typical of rural gay Francophones seeking a bilingual yet accessible stepping stone city_described a coming-out process that bridged both Ottawa and his hometown:

After my first year [in university], I went back to New Brunswick for the summer, and [that was] when ... I was like enough is enough, when I go back to Ottawa; I gotta ... so when I came back, in September I went to the [university] pride center. That's how it ... that's how it all started. I think when, when I went back to New Brunswick for the summer, that's when I realized-I was there for a year, I didn't come out - this has to happen. (Francis, 31, white, French-Canadian)

As a major life course event, migration may also function as a signpost, signal, or opportunity that prompts men to reconsider their sexual identity (Kertzner 2001). For many men, the possibility or imminence of migration itself acted as a trigger for coming out, as opposed to the reverse relationship suggested by Brown $(2000,50)$. Martin, who moved to Washington, D.C., in his mid-thirties, reflected on how an impending move from Madison, Wisconsin, to another town in the state triggered a realization that he no longer wanted to be in a heterosexual relationship:

I had moved [to Madison]... I was living with the woman, we moved there, we were there for about a year, we were getting set to move again [to another town in Wisconsin] and that gave me a lot of anxiety. And then I ... I think it was the thought of that move which made me realize I just couldn't do it ... that it, like, it was over. (Martin, 44, white, European-American)

As Gorman-Murray (2007, 2009) observes, migration decisions frequently stem from comfort, love, and other emotions that queer people attach to particular places and the people (e.g., families or romantic partners) located within them. In Martin's particular case, the possibility of continuing a relationship that had begun to feel uncomfortable in the context of his changing sexual identity triggered an emotional response of anxiety. 
Instead of choosing to quite literally move the (heterosexual) relationship into its next phase, he chose to stay in Madison in order to claim the time and space needed to disclose his sexuality to himself and others. Jerry, a Foreign Service official from British Columbia who moved back and forth between Ottawa and several postings abroad since his twenties, reflected on a similar choice to stay in Ottawa-following a divorce from his wife — instead of going on assignment in Paris: "I very consciously did the opposite [of moving]. I said I don't want to leave here 'till I feel right about myself ... I got feeling better about myself and I don't — it wasn't a question of, you know, being gay, not gay, or whatever - it was just, I was happy, had friends, was over ... the trauma of that relationship ending." During that time, he became involved with another woman and then decided to go to Paris:

And I went ... and it was fantastic. But then, then, did I sort of then, you know, blossom into this big flower? No, in fact, because ... I had started a relationship with a woman here before I left ... it was fine, but it wasn't too serious. And ... but we corresponded and all that, and she was coming to visit after a year, and I was looking forward to that ... and it didn't work out. And um, I don't know, she ... I think we were both looking forward to it and it was a disappointment - more on her side than on my side. And um ... and then after that I met people and then I guess then got into this relationship [with a man] and it was fine. (Jerry, 59, white, AngloCanadian)

In Jerry's case, coming out was an extended, accreted process in which a series of decisions involving partial self-disclosure, choosing not to move, moving, and finally a clarified perspective on a relationship, resulted in the decision to live as a gay man. What is significant in all of these stories is the role of migration or potential migration as a life change or life disruption significant enough to provide an opportunity for reassessment. For the last two men discussed in this section (Martin and Jerry), the possibility of moving — with or without a (heterosexual) partner—signaled a desire to self-interrogate 
their sexuality. For one, the idea of moving itself was enough to advance his ongoing process of coming out. For another, moving away, distancing himself from a relationship, and realizing the possibility of a different life was the final catalyst for choosing to come out as gay.

\subsection{Journeys in the City: Encountering the Imagined 'Community'}

The stories discussed to this point highlight the segmented, often discontinuous journeys that mediate coming out and eventually lead—albeit in unexpected and incomplete ways - to creating a gay life in a particular place. But given the premise that coming out is rarely a once-and-for-all process, it is worth acknowledging some of the coming-out migrations that occur after processes of disclosure have begun. About onefifth of men interviewed (nine respondents) reflected on the intra-city moves they made after moving to new city and beginning to disclose their sexual identity, specifically noting a period of adjustment or transition that occurred after moving out and coming out. As Weston (1995) notes, the central city (which may also contain an urban gay village) is often not the first destination for queer migrants relocating to cities. Some men may move to the suburbs or periphery of a metropolitan area, often with heterosexual friends or roommates, only to realize their coming out experiences there feel insufficient. As others have noted, queer people may define their outness in relation to the queer individuals and communities with which they might interact, sometimes resulting in what GormanMurray $(2009,450)$ calls "gravitational group" migration (see also M. Brown 2000; Valentine and Skelton 2003). Some men felt pressure to embed themselves in the gay neighbourhood in order to attain a truly out identity. Doug, who had moved from 
Colorado to Washington, D.C., to begin university at a school near the city's most established gay neighbourhood, remembered:

Even my therapist, I remember him talking about it, and he was like, 'you need to make gay friends.' He was like, you need to, he was like, you need to start cutting off some of the friends that you have and immerse yourself in the gay community. He's like, you're not gonna [sic] develop an identity until ... yeah; which I thought was kind of strange. But I didn't feel that way. (Doug, 26, white, German-American)

His story highlights the persistent hierarchical valuation of coming-out spaces-even by mental health professionals — despite the diversity of places and trajectories associated with the ongoing processing of coming out (see Knopp and Brown 2003). It is not enough to be out; the ultimate goal should be to be out in an urban, centrally located, and spatially concentrated community. Joseph, who moved from Florida to Alexandria, Virginia (in the Washington, D.C., metro area) in his early thirties, discussed why he eventually moved to downtown D.C. as he began to come out:

So, I waited. I was a late, late bloomer, so in coming [to the D.C. metro area] and seeing the diversity of gay people was kind of what set that off ... and then, I think the juxtaposition between, uh, Virginia-I came out in Virginia - and was living with some roommates that I had moved up with ... when they left, I was like, oh, I wanna go into the city ... like that's where it's at ... I wanna be part of it, so, that's what, yeah, influenced that decision. (Joseph, 38, white, Anglo-American)

Intra-city migrations that prompted first encounters with the gay community elicited feelings of affirmation and comfort, and alternately, fear and exclusion. For a few men, the community they found in Ottawa or D.C. matched the one they had imagined. Daniel, who moved from rural eastern Ontario to downtown Ottawa, remembered the affirmation he received when encountering the city's gay community for the first time: "When I first came out ... everybody wanted to hug you ... and so ... it's very affirming ... have these people be like, they don't know you, they don't know anything about you, and all of a 
sudden, they kind of like you" (Daniel, 28, white, Anglo-Canadian). Yet most encounters were far from universally welcoming or affirming. Joseph, who discussed his move from northern Virginia to central Washington, D.C. (and who also used the trope of the "hug" to describe his encounter with the gay community), recounted his disappointment after moving downtown:

A lot of people think that they, they finally come out, they finally make that move, and it's going to be one big, open, warm hug ... and it's not ... it's maybe a pat on the back ... but there is that sense of belonging. And I mean, there, it still is ... there's a sense of belonging to a group, you finally fit in, you finally belong, but I think there is some, um, disappointment - true disappointment - when you figure out that maybe you don't fit the mold ... and you're not welcomed over here and you're not welcomed over there. (Joseph, 38, white, Anglo-American)

Doug, who had been told by his therapist to locate himself in the community, remembered his fear upon finally encountering the "community within a community" of gay students at a Washington, D.C., university located close to the city's gay village: "I think I was intimidated ... and just being scared of how they would judge me. Would any of them be attracted to me? Would they wanna date me? Would I be the outcast of the group? ... I didn't feel this urgent need to be there" (Doug, 26, white, German-American).

Others perceived the so-called safe haven of the scene to be an uncomfortable or even exploitative place for men beginning to come out. Phillip, an African-American man working in the healthcare industry, contrasted coming out in Washington, D.C., with the experience he imagines in his home town of Philadelphia. For Phillip, the embodied aesthetic of D.C.'s Dupont Circle village on one hand galvanized his coming out; the multitude of professional and "preppy" men that he preferred left him feeling like he "had died and gone to heaven." On the other hand, a scene that he described as "not particularly [racially] integrated" and occasionally "predatory" left him feeling like an 
undervalued outsider, wondering what it would have been like to come out in his hometown of Philadelphia. First, he explained that in a racially diverse city, "you would assume that most of the - at least half of the people in the bar or a third of the people in the bar would be people of colour and that's just not true." Yet he felt that despite not being included in the "scene," he was viewed as a sexual commodity: 'Coming out, in [Washington, D.C.], for me, it was hard even as a young twenty-something, 'cause people are $\ldots$ they're a little more predatory $—$ not predatory in a, in a criminal way - but ... if you were to walk into [a Philadelphia bar] ... [in your forties] with a 22-year-old, people would look at [him] like, as your boyfriend and not as, you know, your entertainment for the evening" (Phillip, 41, black, African-American). His comments were echoed by other men of colour. Kent (27, black, southern African), who moved from Montreal to Ottawa, found that in the city's gay bars, "[patrons] are more attracted to you because it's exotic; they're not looking at you as a human being." Their narratives suggest not only that gay scenes, especially when located in new and unfamiliar cities, can become risky places for young and newly out men (Valentine and Skelton 2003), but that first encounters with scene for men of colour may simultaneously invite disclosure and foreclose meaningful inclusion or participation.

\subsection{Journeys 'Back Home'}

Journeys "home" among queer migrants have been discussed elsewhere, but usually in reference to returning to a childhood or family home later in life (Fortier 2001; Gorman-Murray 2007; Waitt and Gorman-Murray 2010, 2011) or-as discussed in medical and epidemiological literature-after seroconverting to HIV-positive status 
(Cohn et al. 1994; Raimondo 2003). As the previous stories reveal, both the disclosures

of sexuality and the journeys associated with those disclosures are fluid and often discontinuous. Consequently, journeys back home may also act as in-between stopovers that help men to position their changing sexual identity vis-à-vis past "heterosexual" identities, or to confirm plans to come out in a new location. Jack, who grew up in Colorado and went to university in Seattle before moving to Washington, D.C., discussed how a three-month return to Seattle - after coming out to family and friends at home in Colorado - clarified a decision to move permanently to the east coast.

When I was like back in Seattle after graduation-after I was back in Colorado for a while - I met up with some of my friends and I kind of came out to them. And everyone was, they're so liberal, like everyone's cool about [me being out] ... it's still just kind of awkward though, it just never felt very easy. I mean I think it may have just been the timing, 'cause like I moved back out [to Seattle] like a couple weeks after I'd come out [to family and friends in Colorado ... I really feel like I had too long [in Seattle] to kind of like adjust and reflect on it ... kind of assess like how dynamics changed between us. I think it may have been easier for me just to live somewhere else, like start all over. (Jack, 24, white, Anglo-American)

For Jack, revising and renegotiating friendships in a childhood home (Colorado), coupled with the looming task of repeating the process in another place where he had established a heterosexual identity (Seattle), prompted him to "start over" in a place where he felt could initiate meaningful personal relationships as an out gay man (Washington, D.C.).

His story confirms that queer people sometimes seek to essentially replace previous homes with new a new one, rather than "queering" a current home (Fortier 2001, Knopp 2004; Waitt and Gorman-Murray 2010). His decision to move to D.C., however, was not a flat dismissal of his former homes as repressive or homophobic. Instead, he felt that that the identities and networks he had actively created in those places were now at odds with 
a changing sexual identity. Jason's story makes it clear that the flows of coming-out migration are fluid and unpredictable because the places in which they originate and terminate are more socially dynamic they appear in many studies of queer migration. Seattle, an ostensibly liberal city was rendered a difficult place to live because of the distinct set of networks and relationships that Jason had established there earlier in lifeand to some extent — with a different identity. Coming-out migrations are thus better characterized as relational flows rather than linear flights or wandering identity quests.

In other cases, journeys back home where men re-encountered familiar families and cultures redirected the course of coming out. Jordan, a Chinese man born in the Philippines who ultimately moved from Berkeley, California, to D.C. for graduate school, discussed an interim trip home to China after initially coming out in Berkeley. The encounter with a cultural homeland where he felt that his sexuality was recognized and tolerated but almost never discussed openly (see also G. Brown 2008) made him unsure of "how to be gay" in a North American cultural context after he returned:

I'll admit in 2003, I came out, but then I went back to China for a couple years ... so it was like whatever, I was completely out there. When I came back to Berkeley, I didn't really meet that many new people, so it's not like I was coming out ... I mean I think [going back to China] made me inexperienced into how to act, like a completely out gay guy ... so when I came to [D.C.], I actually wasn't sure whether I was gonna [sic] be out or not, so the first one or two weeks, I was wondering, you know, am I gonna tell people, professionally is this something I should say? (Jordan, 26, Asian, Chinese)

In this case, going back to a cultural, but not necessarily lived-in home (China) where his sexuality was neither really hidden nor disclosed left Jordan wondering how to come out again when returning to the United States - a place that he felt demanded him to perform the type of Euro-American normative male gayness that queer of colour scholars 
describe. Like other men's accounts, Jordan's story shows that both coming out and the journeys that mediate it are non-linear, with uneven and discontinuous trajectories.

\subsection{Conclusion: Rethinking 'Moving Out as Coming Out'}

The previous discussion answers calls for further empirical studies of queer migration (Knopp and Brown 2003; Gorman-Murray 2007, 2009; Waitt and GormanMurray 2010) and highlights some variations of coming-out migration (M. Brown 2000). It also challenges the implied linearity and finality of queer coming-out migrations (Fortier 2001; Knopp and Brown 2003; Gorman-Murray 2007, 2009) by elaborating on the relationships between the personal and geographic journeys associated with coming to know oneself as gay. Implicit in this second objective is a renewed focus on the intersectional subjectivities and social contexts associated with coming-out migration-as opposed to "peripatetic" bodies and emotions. For example, younger men—who often moved in the contexts of the Internet age and (sometimes supportive) family homesoften 'scouted' potential destinations online or through language programs and internships in other places (themselves the product of yet another subjectivity, class). In contrast, many older men described not coming out until an imminent move triggered them to do so, with subsequent moves mediating the process even further. Similarly, men of colour frequently experienced conflicted journeys in which their own culture (e.g., a Thai or Chinese background in which being gay was implicitly tolerated but not discussed) met with North American urban environments in which deliberate disclosure was expected. In particular, black men moving to new cities encountered spaces such as 
bars that excluded them from the gay community regardless of their willingness to disclose a gay identity.

This chapter also challenges many common ideas about the geographic trajectory of coming-out migration. First, the narratives suggest that coming-out migrations are rarely forcible displacements or unilateral emancipations. While it has been suggested that disclosing a non-normative sexual identity is "tantamount to spatial displacement" (Puar et al. 2003, 286), few respondents described "escaping" from unsafe or threatening environments or singular journeys in which they emancipated themselves through place. Instead, most men most focused on the ongoing, dialectic manner in which they actively employed mobility to manage relationships and create identities at their own pace. Men such as Mark (from Newfoundland), Jason (from Colorado) and Terry (from southwestern Ontario) began to come out as gay to others only after moving back and forth several times between childhood homes, schools, and potential "queer homes," and after slowly forming assessments of the gay life potentials of one place or the seeming impossibility of coming out in others. Most men never reached an emancipatory moment, at least as it is imagined in most portrayals of the coming-out journey. Men such as Joseph, Peter, and Phillip, who reached D.C.'s Dupont village with the intent to disclose themselves to the community, found that the imagined homeland was, in fact, alternately indifferent, exclusive, and even racist. Coming-out journeys, while employing human agency, thus rarely fall into geographically or temporally tidy stories of emancipation.

Second, this study challenges the assumption of a forward-moving coming-out progression from closeted-ness to openness, one which has been challenged in queer of colour critiques but rarely applied to coming-out migrations in which mobility is 
imagined as an explicit means of precipitating identity formation. Typically, relocationor successive relocations - are assumed to push the migrant-subject closer to full disclosure of a fully formed (homo)sexual identity (Plummer 1995; Weston 1995; Valentine and Skelton 2003; Binnie 2004). In this study, some men's moves resulted in choices to conceal their sexuality (even after being out in other places) or to become more selective about the places and contexts in which they disclosed it. The stories of men such as Peter from Texas and Mark from Newfoundland show that even after journeys involving self-disclosure (or even disclosure to others) have begun, other subjectivities (e.g., a conservative political identity) and circumstances (e.g., career and economic necessities) do not simply disappear in the face of an emerging gay identity. They also show that the formation of a gay identity, while sometimes galvanized by migration, is not always fulfilled by or central to migration.

These two findings, that coming-out migrations are (1) active but not always emancipatory and (2) that they are segmented but not always progressive, reveal a third central theme - that coming-out journeys are relational. This chapter does not refute the findings of Gorman-Murray (2009) and others who observe that coming-out journeys are emotional processes involving searches for love and comfort, but rather reinforces Bondi et al.'s (2005) central thesis that emotions are socio-spatial mediations and not just internalized responses to places and events. Most men's journeys were related to the specific dynamics they had encountered or even created within places—-for example, fear of being rejected by friends that had that come to know the respondent as heterosexual, or anxiety over a heterosexual relationship—rather simply perceiving or imagining places to be homophobic, inclusive, or comforting. As a result, their coming-out journeys are 
understandably discontinuous and segmented, with each successive move emerging as a different step toward "becoming out," as opposed to just coming out.

Fourth and finally, there is a need to revisit the idea of queer migration as a wandering or peripatetic quest, which, to this point, has been the primary framework for re-imagining the coming-out journey. While this study demonstrates that coming out journeys are non-linear and circuitous (i.e., segmented), the term peripatetic, which describes the act of walking or traveling about and frequently acts as a synonym for "itinerant," seems to both downplay both the gravity of coming out and the ways in which men actively use mobility to manage the coming-out process. Although few men felt they had been "displaced," most felt that the process of coming out-one rendered necessary by the persistent characterization of being gay as abnormal or deviant—would fundamentally disrupt the relationships, careers, and lives they had in particular places. "Moving out to come out," then, is not a unilateral quest for sexual fulfillment or identity affirmation, but a relational means of negotiating landscapes_-including homes, workplaces, and social networks - that are rendered (or expected to be rendered) uneven by the disclosure of sexual non-normativity. The ongoing production of homosexuality as deviant category therefore continues to drive coming-out migration, but perhaps in more diffuse and "segmented" ways than originally imagined. Future research must consider therefore consider coming-out journeys not just as linear escapes or embodied quests, but as complex, dialectic interactions in which "knowing oneself as gay" involves multiple moves, places, and (re-)negotiations of the social contexts within them. 


\section{CHAPTER 7}

\section{Embodied Emigrations: Health Experiences and Migration Decision- making}

\subsection{Connecting Queer Migration and Health}

Psychologists, health geographers, and public health specialists have increasingly observed that experiences of health, mental health, and ill-health are mediated by social determinants such as gender, sexuality, social support networks, and access to health services. In addition to emergence of this social determinants of health approach, the transition of medical geography into a broader, more inclusive health geography (see Rosenberg 1998; Kearns and Moon 2002) has opened opportunities to explore the interactions between these determinants and the socially, geographically, and temporally contingent places that people inhabit and move between. Health experiences, and particularly mental and emotional health experiences, among queer people represent one potentially fruitful entrée into research on the mediation of health outcomes by both place and movement between places.

The topic of health and migration among queer people occupies a complex body of literature that includes scientific (yet often highly medicalized and abstract) studies of (homo)sexuality and mental health, embodiment and emotional geographies, and queer migration. The first area of research comprises a longstanding-yet often theoretically and morally fraught — body of studies that, until 1973, had served to characterize nonnormative sexuality itself as a component of ill-health (Bayer 1987). ${ }^{8}$ More recently, the stressors associated with identifying as sexually non-normative (i.e., "minority stress")

\footnotetext{
${ }^{8}$ In 1973, the American Psychiatric Association (APA) removed homosexuality from its manual of disorders. A disease sub-set referred to as ego-dystopic homosexuality (rejection of one's homosexuality) remained in the manual until 1987.
} 
have replaced homosexuality itself as a determinant of poor health and mental health outcomes (Meyer 1995, 2003). A number of population-based studies, usually conducted in metropolitan environments, have validated this theory by finding significant differentials in anxiety, panic, depression, suicide ideation, suicide attempts, and risk for associated physical health outcomes such as HIV exposure and alcoholism (see, for example, Diaz et al. 2001; Mills et al. 2004; Sandfort and de Graaf 2006). Even more recently, health and place researchers have noted that the mental health risk factors or "stressors" such as stigma, anti-gay legislation, and informal prejudice from families, religious groups, and social networks, are all highly place-contingent (Saewyc et al. 2009; N. Lewis 2009).

Geographers and other social scientists, by introducing the concept of emotional embodiment, have complicated the relationship between stress and ill-health by highlighting the diverse ways in which humans experience, internalize, perform, or react to the cultural constructs, relationships, and histories that are embedded in various places and contexts (see, for example, Davidson and Milligan 2004; Hubbard 2005). Stigma and stress, for example, are not just uniform, categorical "risk factors" for ill-health, but contingent factors that might be embodied by gay and queer people in different ways depending on their individuals subjectivities and the places and social contexts in which they are experienced (Williams and Morris 2000; McLaren et al. 2008). Several have also noted that gay and queer people experience a distinctive set of spatialities, whichsimilar to those encountered by low-income families, immigrants, or ethno-racial minorities — might reproduce inequality or vulnerability (Heikkila 2005; Philo 2005; Bailey 2009). 
In an effort to link embodiment and mobility, others have outlined the complex ways in which the embodied and physiological states produced in various places and contexts mediate the movement of individuals and populations (Conradson and McKay 2007; Bailey 2009). Scholars such as Fortier (2001), Knopp and Brown (2003), Knopp (2004), Gorman-Murray (2007, 2009), G. Brown (2008), and Gibson (2008) have extended this premise to studies of queer populations ranging from urban queer youth to self-identified gay men in rural areas. Although the geographic context of these studies varies significantly, they are similar in their use of embodied and emotional responses to place as a means of explaining the complex, varied stories of queer migration that extend beyond the familiar tropes of the urban queer homeland and the intolerance and homophobia of the countryside. Instead, these scholars argue that migrations among queer people are informed by complex, relational, and emotional responses to place, such as attachments to home, finding love, and seeking acceptance in diverse forms of supportive and compassionate communities (Fortier 2001; Law 2003; Gorman-Murray 2007, 2009). Many of these studies, while acknowledging the complexity of embodied queer migrations, frame them as peripatetic or wandering movements often characterized by comfort in movement and placelessness itself (Knopp 2004). In doing so, they also overlook some of the ways in which place that may impact the health of queer individuals. This particular study therefore extends the study of embodiment in queer migration by explaining some of the ways in which the places that queer people inhabit become quite literally embodied in terms of health outcomes and health behaviors.

This chapter is in many ways a follow-up to an earlier article (N. Lewis 2009), which establishes that mental health outcomes among gay men — and particularly the 
disparities between gay and heterosexual men — are significantly mediated by place. In accordance with recent qualitative studies (see Saewyc et al. 2009), this meta-analysis found (1) that queer people across multiple geographies are consistently at higher risk than their heterosexual counterparts for mental health outcomes such as anxiety, depression, and drug and alcohol abuse, and (2) that the particularities of places (e.g., rurality, legal regimes, and health care policies and practices) are likely to influence the geographic variation in health disparities between queer and heterosexual people (see Figure 7.1). The following chapter not only puts a human face on the ways in which stigma, prejudice, and other aspects of place are embodied by people with non-normative sexual identities, but discusses how related health outcomes can both generate migration to a new place or - as the second part of the chapter discusses - result from it.

\section{Figure 7.1. Place-Based Determinants of Minority Stress and Health Outcomes Among Gay Men and Other Sexual Minorities}

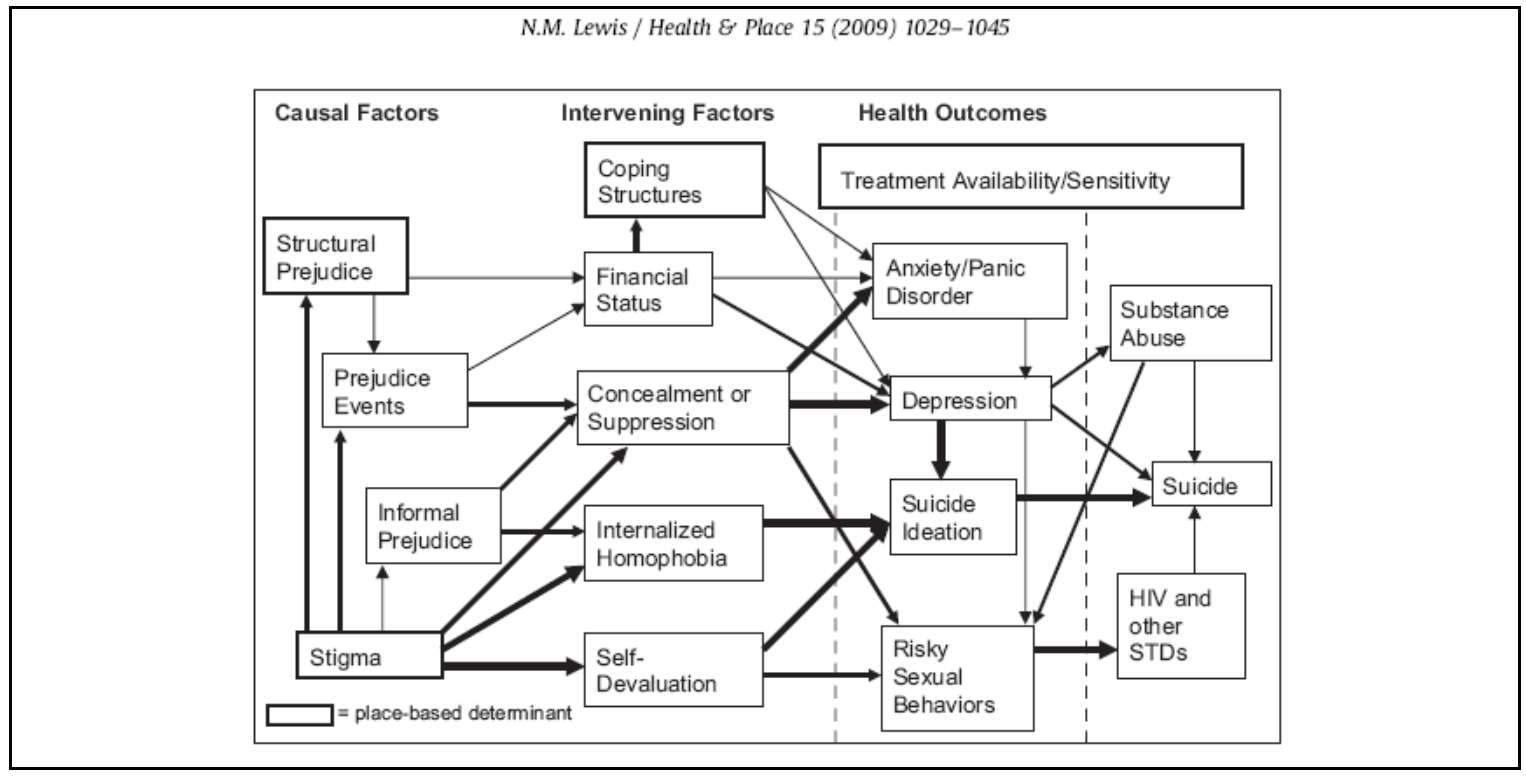

Lewis, N. M. 2009. Mental Health in Sexual Minorities: Indicators, Trends, and their Relationships to Place in North America and Europe. Health \& Place 15, 1029-1045 (p. 1030). Sources: Bagley and Tremblay (2000), Balsam et al. (2005), Botnick et al. (2002), Cochran (2001, 2003, 2007), Diaz et al. (2001), DuRant et al. (1998), Harper and Schneider (2003), Herdt and Kertzner (2006), Mays and Cochran (2001), Paul et al. (2002), Rosario et al. (2006). 
The first part of this chapter highlights experiences of health and ill-health that culminated in or contributed to migration. These stories involve: (1) accounts of how places were embodied in terms of loneliness, internalized homophobia, increased vigilance, and expected or experienced victimization; (2) how these experiences manifested mentally and physically in the form of depression, anxiety, or suicide ideation; and (3) how they precipitated moving to new places. The second part of the discussion examines some of the ways in which gay men may encounter ill-health upon moving to a new place. Here, I assess how the characteristics of new and unfamiliar places are experienced by gay newcomers who find themselves in vulnerable positions as they attempt to adjust to build community in places that are nominally gay-friendly but often complicated and risky for those who are recently out or far removed from friends and family. Although the geographic and temporal contexts of these pre- and postmigration health experiences are different, many of the themes_-including isolation, depression, and substance abuse - are similar.

The material for this chapter was drawn from segments of interviews related to the theme of health experiences. These segments were re-coded into sub-themes including vigilance and concealment of one's sexuality, experiences (or expected experiences) of bodily harm and victimization, and manifestations of stress such as anxiety and depression (see Table 7.1). Due to the breadth of health as a concept, unlike more focused themes such as "coming out," the sub-themes were gleaned exclusively by reading through each interview, as opposed to searching for particular terms. 
Table 7.1. Sub-themes Related to Health Experiences among 48 Self-identified gay male respondents, Ottawa, Ontario, Canada and Washington, D.C., U.S.A.

\begin{tabular}{|l|l|l|l|}
\hline Theme & $\begin{array}{l}\text { No. of } \\
\text { passages }\end{array}$ & $\begin{array}{l}\text { No. of } \\
\text { respondents }\end{array}$ & $\begin{array}{l}\text { \% of } \\
\text { respondents }\end{array}$ \\
\hline Embodiment of stigma or prejudice & 21 & 13 & 27 \\
\hline Vigilance/concealment of sexuality & 12 & 12 & 25 \\
\hline Loneliness or isolation & 15 & 11 & 23 \\
\hline Depression & 10 & 8 & 17 \\
\hline Experiences or threats of bodily harm & 8 & 7 & 15 \\
\hline Anxiety & 6 & 6 & 13 \\
\hline Opportunities to improve physical health through relocating & 7 & 5 & 10 \\
\hline Bullying & 6 & 5 & 10 \\
\hline Drug use/abuse & 6 & 5 & 10 \\
\hline Alcohol use/abuse & 6 & 4 & 8 \\
\hline Health services & 6 & 4 & 8 \\
\hline Physical manifestations of stress & 5 & 4 & 8 \\
\hline Personal growth or redefinition following migration & 5 & 4 & 8 \\
\hline Sexual risk/HIV seroconversion & 3 & 2 & 4 \\
\hline Expectations of non-bodily victimization & 1 & 1 & 2 \\
\hline Suicide ideation or attempts & 1 & 1 & 2 \\
\hline
\end{tabular}

\subsection{Embodied Emigrations: Sexuality 'Out of Place'}

In an effort to highlight some of the ways in which places become embodied by gay men and other queer people, I draw on common embodied experiences in places of emigration, such as empirically experienced stigma or prejudice, loneliness and isolation, and experiences or expectations of harm, and heightened vigilance and the concealment of one's sexuality. Among $27 \%$ of the men interviewed (13 respondents), these experiences emerged from the ways in which they experienced and embodied the places they inhabited. In many accounts, especially those related to coming out, men feeling out of place and ill at ease with their surroundings (Valentine 1993; Cresswell 1996;

Valentine et al. 2003). Shawn, who moved from northern Ontario to Ottawa in his early twenties, explained how experiences in his former hometown had contributed to viewing his sexual identity as deviant: 
There were certain aspects of the local culture, or at least the elements of the culture in which I found myself, which were prone to making one ... feel more vulnerable ... [northern Ontario towns] were definitely places that had a more, uh, backward-looking culture, prizing, you know, the virtues of the past as opposed to looking towards, you know, where society was moving, which was generally seen as threatening ... They were, as small places tend to be-Sudbury, relatively small-um, more bounded in social convention and more apt to view anything that is a deviation from social convention as, well, deviant. (Shawn, 42, white, French-Canadian)

Shawn's narrative reflects the ways in which constructions of homosexuality and understandings of deviance are linked with geographic variations in what he calls "social convention" (Foucault 1979; Halperin 2000; Olund 2010). Shawn's understandings of his own deviance and consequent feelings of vulnerability were rooted not just in sexuality, but in his perceived failure to align with conventions that had diffused through both his family and local institutions such as the Roman Catholic Church. Wally, who had moved from Nova Scotia to Ottawa in the late 1990s, related local culture and the construction of deviant identities in a similar way. Interestingly, he was troubled as much by the attitudes toward difference in general, as he was by any evidence of homophobia.

There's an exclusiveness to the culture, which is ... and in that way it's not inclusive, and for me that was offensive. Um, and I don't just mean about sexuality, I mean about accepting other cultures; accepting other ways of thinking ... you know, for a period of probably five to ten years, there was that ... that overwhelming sense of shame of living and being part of a culture I saw just was not accepting and inviting of other people. (Wally, 43, white, Anglo-Canadian)

Shawn's and Wally's comments not only highlight the emotional nature of men's responses to places, but also suggest that a sense of being "out of place" can be embodied even without direct experiences of exclusion or discrimination. Interestingly, it was not only environments that would normally be conceived as conservative or anti-gay that made respondents feel out of place. Raymond, for example, felt increasingly out of place 
living in Toronto's Church Street gay village, where he felt uncomfortable performing the particular type of gay identity that his friends felt compelled to perform there:

So I think that sense of myself, and knowing myself, and knowing my own identity, I think helped me not necessarily fit in the way that some of my other friends do ... but I also know that they have this very weird, sort of uncomfortable relationship with it, too, because they switch, you can see them switching on and off as they walk, you know, on and off Church Street in Toronto. (Raymond, 31, black, Jamaican-Canadian)

As Raymond's narrative indicates, being uncomfortable stems not from some type of uniform incompatibility between a monolithic gay identity and particular type of places, but from the relationship between gay men's individual subjectivities and the variety of places they inhabit. According to Pete, who moved to Ottawa from southern Quebec after coming out, migration — and the stress that accompanies it—emerges from the ongoing, mutual constitution of individual identity formation and finding a "place" in society: “... when you're trying to find out who you are, there's always ... some like stressful situations ... but you, you always try to find your place in society and stuff, so ... I guess it's been part of the ongoing process" (Pete, 41, white, French-Canadian). Rick, who moved from London, Ontario, explained that while he able to leave a short-term job and move to Ottawa, the limited infrastructure of the gay community and "climate of "homophobia" was perhaps more pressing for residents with more limited mobility:

Yeah, I mean yeah you feel limited when there's only one place to go, and one option for meeting people ... and for me, not meeting people despite doing this job that was quite sort of quite connected to the gay community, and meeting lots of new people, it was a little, certainly, a little depressing and ... a deterrent to wanting to stay, to wanting to stay longer ... but I would get the sense from a lot of people who had lived in longer that there was actually, that the climate of homophobia was much more pressing and present for them, I think because of the history of the city. As someone kind of just popped into London and then dropped out a year later ... I could sense ... that sort of like life-long fear of sort of the people around (Rick, 27, white, Anglo-Canadian). 
For other respondents, the intersectionality of their racial identity and sexuality was central to the ways that they embodied the places they moved from. Randall, for example, felt unable to come out in a place where he already felt marginalized by other signifiers of difference.

And, um, the double whammy — and well of course in Halifax I wasn't out - but the double whammy of being both Aboriginal and black meant that no matter how clever I was, no matter how good my portfolio was, um, how well I presented myself ... um, I was never going to get a break. And that's just simply the fact of life in Nova Scotia ... um, not that I internalized any of that shit, but ... and then when you come, you know, here and I can sort of like be who I know I am, and there isn't that sort of like that, that weighty, heavy wet blanket ... dragging you down ... for those reasons and other reasons, I had just had it, I had done it, and it was over for me. (Randall, 45, black/aboriginal, African-Canadian, Mik'maq)

Shane, who had moved from central Virginia to Washington, D.C., felt similarly about his university experience as a black man in a mostly white university:

... There really wasn't [sic] a lot of people like me. At that time I was going to school, there was no person of colour who identified as gay. I was the only out person on campus, so and I was very visible, so I was like the gay black kid on campus ... and I think I struggled a lot, particularly because my only access to my gay identity was those who I had contact with on campus, online, and magazines, and all of those forms of connection were dominated by white identities. So for me it felt very isolating to, um, be of colour and gay on that campus. (Shane, 27, black, African-American)

Although some men's migrations were influenced by direct or expected experiences of bullying, harm, or victimization, most were more often driven by the gradual accretion of negative feelings toward a place. Doug (26, white, GermanAmerican), for example, said that while he didn't "harbor any ill will" towards his hometown in Colorado, he felt a "general malaise about the whole place." Shane (27, black, African-American), who went to university in Richmond, Virginia, said that "the 
thought of staying in Richmond [made him] want to cry." But as many men indicated, these feelings often generated palpable health effects; that is, they were quite literally embodied. Ashton (47, white, Anglo-Canadian) described it accordingly: "Like when you just don't get that good vibe about a city you feel out of place? Then it starts to take its toll on your mental health ... you start feeling a bit down about being there." Anthony (28, white, Polish-Canadian) described his experience in Saskatoon, Saskatchewan:

“Well, you feel isolated ... you're, you're bored, you know there's —if there's such a thing-you think too much, you're not distracted. It's pretty easy to be negative; it was very easy for me to be negative and I'm a pretty optimistic person.” Men like Ashton and Anthony, who were out before moving, were affected mostly by the tension between their sexual identity and places with little infrastructure to affirm or support it. Men who were not out, however, found themselves isolated by both places with few visible gay men and the metaphorical closet that they occupied (Sedgwick 1990; Brown 2000). As Daniel (28, white, French-Canadian), observed, "There was no way to communicate with [potential partners] without coming out ... there was no way to, uh ... put your feelers out taking any emotional or in some cases even physical risks."

\section{2-1. Bullying and Victimization}

For about $10 \%$ of the men interviewed ( 5 respondents), their feelings of discomfort emerged after they experienced bullying and other forms of victimization. In addition, $15 \%$ (7 respondents) reported experiencing direct threats of violence. As noted by Du Rant et al. (1998), Bontempo and D’Augelli (2002), and several other studies on sexuality, bullying, and mental health, threats of bodily harm and actually-inflicted bodily 
harm produce feelings of fear, powerlessness, and poor health outcomes such as depression and suicide ideation. Several men described experiences of "low-grade" yet damaging harassment or bullying in the places they moved from, usually involving catcalls, slurs, and threats, and usually perpetrated by groups (e.g., "cowardly teenagers") targeting men or couples perceived to be openly gay. Many also mentioned friends and acquaintances that had been "fag-bashed," often with serious injury. A few respondents, however, experienced bullying and harassment directly. Shawn described being targeted for bullying during most of his adolescence in Sudbury, Ontario:

I'm talking about, you know, if you're like everybody else, the you're perceived perhaps as being more, uh, normal, and if you're not then you're perceived as being a good target for, you know, for whatever anybody wants to throw at you (Shawn, 42, white, French-Canadian)

Daniel, who also grew up in a rural region of Ontario, explained how a gradual accrual of harassment led him to feel like an outsider in his own town:

Then as I got older, um, being gay and other kids, some of them I think recognizing it and other ones just using the stigma against other kids ... that gay guy, or fag or queer, and stuff like that, was constantly thrown around ... I mean, I even got chased by a truck down the street once, so I mean, it wasn't, uh, the most positive experience I've had. So, it, um, it was just kind of a low-grade, you're an outsider kind of feeling ... it didn't really encourage me to stay where I was or to find somewhere that was similar ... I mean, we had Jewish kids in our school and black kids in our school and Asian kids in our school but the only insult you heard thrown around was "gay." (Daniel, 28, white, French-Canadian)

For other men, the desire to leave was stemmed not from feelings of displacement, but the expectation that otherwise neutral spaces such as the street or the bar would become dangerous if their sexualities were revealed. Anthony, who moved from Saskatoon to Ottawa recounted: 
In Saskatoon we didn't have-unless you wanted to go and party at the bar-we didn't have a venue where you could go to a, you know, a lounge or coffee shop and feel, uh, safe in your skin, so to speak. You would be integrated with the ... the straight crowd and - which was okay-but at times, you know, kind of rowdy. (Anthony, 28, white, Polish-Canadian)

Many men therefore gravitated to places that they felt would protect or insulate them from stigma (Eisenberg and Resnick 2006; Saewyc et al. 2009). Raymond, for example, described his former home in Toronto's Church Street gay village as a place where he simultaneously felt out of place, yet safe, demonstrating that for queer people, places are often embodied in paradoxical ways (Rose 1993; Valentine and Skelton 2003):

I didn't necessarily want to leave Toronto at the time, um, I was very scared about moving — and it's going to sound like I'm speaking out of both sides of my mouth-but I was very scared of leaving that sort of safety of that village. I knew there wasn't necessarily a very big scene here when I moved here, um, but at the same time, I never felt as if I really belonged to the scene in Toronto, um, so ... coming here and then landing, it made me feel a little bit better, because I felt there were other people like me and in the same sort of mode, and it wasn't necessarily a scene that was very cliquey, so you didn't feel as if you were an outcast to begin with. (Raymond, 31, black, Jamaican-Canadian)

These accounts demonstrate that anti-gay stigma, as well as the geographically uneven ways in which it manifests and diffuses, profoundly affects how gay men embody place, and particularly how they come to see themselves as in or out of place. For some men, feelings of not belonging prompted them to conceal their sexuality.

\section{2-2. Concealing Sexuality}

For the men who framed their migrations as part of a coming-out experience, a sense of being excluded or not belonging rarely resulted in immediately moving to another place. Instead, men frequently attempted to negotiate these experiences by concealing their sexual identity. One-quarter of the men interviewed (12 respondents) 
directly referenced concealing their sexuality in some way prior to, during, or after moving. Embodied behaviors of concealment or suppression tend to emerge not only from the pathologization of non-normative sexuality and the totalizing definitions of homosexuality that emerged from it, but also their association of being gay with a particular set of gender expressions that could be concealed or altered (Sullivan 2003). Many of the respondents discussed their perceived need to maintain a front or façade while living in particular places. Mark, who had lived in western Newfoundland before moving to Ottawa, said there was a constant worry that neighbors, friends, and coworkers would "discover the fraud that [he] was" (49, white, Anglo-Canadian).

In many cases, men's decisions to conceal sexual identity were responses to auditory and visual cues from the environments around them. These cues included "the tone" with which people in school or work environments talked about sexuality, ridicule of openly gay or lesbian people in the community, or the covert gossip about men believed to be gay. As mentioned elsewhere, the frequency of these cues was often related to the perceived smallness of the places in which men were located. While this smallness often corresponded to population size of places, it was also related to the density of the networks in which the respondent was located. Men who were located in close proximity to extended families or family friends, for example, were concerned about their inability to control the diffusion of the news that they were gay.

People talked about it and loved gossiping about it, and it was just a big deal, and I just did not, I did not want that to happen to me." (Doug, 26, white, German-American)

[In a] smaller town also ... more people know what you're up to, so the gossip factor is like ... you're more self-conscious about what you're doing socially in a place where more people know you. (Sebastian, 42, Métis, French-Canadian, Mik'maq) 
Just rumors of somebody being gay there, like the whole city knew, and they were gossiping about it. There's no way I would have lived there ... like I'm, I don't have a thick skin enough to handle that. (Francis, 30, white, French-Canadian)

Other respondents observed that concealing their sexuality required them to be constantly vigilant about altering their bodily behaviors in workplaces or public space. Anthony (28, white, Polish-Canadian) remembered his experience in Saskatchewan: "I worked a lot, not with the general public, but I worked with external clients that weren't colleagues, and I have to admit I had to, um, not tone it down, but ... I had to be prudent and, and careful with how I presented myself ... um, yeah, so I would say like I'd have to 'watch it."' Ashton had made similar modifications to avoid being targeted for his sexuality on the streets of London, Ontario:

So I was sort of nervous in certain neighbourhoods and, you know, avoided them, and certainly avoided them late at night, and they weren't even like rough neighbourhoods per se ... I just wasn't really comfortable there. And part of it was because I was as a gay person, you know ... you know that whole like, you know; you got to walk a little bit "butcher" when you go through a tough neighbourhood? You're afraid of getting targeted. (Ashton, 47, white, Anglo-Canadian)

Several men invoked the act of holding hands as a baseline for whether a particular place required them to conceal their sexuality. Rick, who had also moved from London, said, "If I was going to walk down the street holding hands with another dude, I would feel nervous for very specific reasons in London, and less in Ottawa" (Rick, 27, white, AngloCanadian).

The threat of exposure had profound implications for the health of many men. As previous research suggests, the perceived need to remain vigilant about modifying one's behaviors has been connected to health outcomes such as anxiety and depression 
(Cochran 2001; Meyer 2003). Francis, who moved to Ottawa from eastern New

Brunswick, discussed the impact of concealing his sexuality before and after moving.

I would say [my well-being] improved [after moving], 'cause when I was in New Brunswick, especially at the end, I was living a life that wasn't who I was. It did affect me, but I didn't really know at the time. I said, when I move to a big city, I'll be myself ... [in Ottawa] I mean I was in the closet. I wouldn't fit in, find new friends ... I was also here with a lot of friends from New Brunswick ... I didn't come out right away (Francis, 30, white, French-Canadian).

Francis' account shows not only the persistence of pressure to conceal one's sexuality, but also that moving away — while perhaps precipitated by the fatigue resulting from concealment—does not always eliminate the pressure to continue concealment.

Decisions to conceal being gay may also prevent men from seeking the help of a health professional where they live (Cant 2005). As Doug explained, "My home town wasn't like a rural place or anything; we're 20 minutes from Boulder [Colorado] so it was pretty liberal there. If I wanted to, I could have went to a liberal doctor in Boulder ... but I, I think even there I would have had a fear that the doctor would have judged me, which I think is terrible (Doug, 26, white, German-American). Luke, who had moved to Ottawa from southwestern Ontario, was similarly skeptical about the abilities of health professionals to serve gay men, noting a pervasive "presumption of heterosexuality" (Epstein and Johnson 1994). He remembered, "[There was] assumed heterosexuality in a context where- 'cause it was like in a medical clinic and I'd gone there with a friend of mine who was female —um, and they just assumed that we were having sex ..." (Luke, 24, white, French-Canadian). In contexts of assumed heterosexuality, men often felt that finding a supportive counselor was a stroke of luck, rather than the norm.

So [my parents] sent me to see [a psychologist]. After about 6 months, he wrote a report to them, basically saying your son is very well-adjusted 
young kid, but if you guys need some help in dealing with who he is, you are free to come see me. He basically told them they were the ones who needed [help]. I was lucky to get someone like that there, because they could have just as easily tried to beat it out of me. You know there are people trained in classical psychotherapy who still believe you can convert people, and [my town] would have been a great place to practice if you had that kind of attitude. (Sebastian, 42, Métis, French-Canadian, Mik'maq)

While Sebastian was fortunate to encounter a gay-affirmative counselor, his trepidationwhich may have also stemmed from his parents' decision to send him to counseling in the first place - is indicative of many gay men's perceptions of health services in particular places. As Cant (2005), observes, ongoing understandings of health care facilities as heteronormative - unless otherwise specified - may cause some men to avoid treatment for mental or even physical health issues.

\section{2-3. Embodying Stress: Victimization, Anxiety and Depression}

For many men, the stressors of stigma, prejudice and being perpetually vigilant about their sexual identity resulted in physically manifested health outcomes such as anxiety and depression. Several studies have reported substantially higher rates of both anxiety/panic disorders and depression among gay men when compared with their heterosexual counterparts (see N. Lewis 2009), usually attributing the difference to minority stress experienced as the result of stigma and prejudice (Meyer 2003). In this study, about $11 \%$ of men interviewed (5 respondents) reported experiences of anxiety, while another $17 \%$ (8 respondents) reported experiences of depression-figures very similar to those reported for gay men in national-level population health surveys $(\mathrm{N}$. Lewis 2009). The significance of these experiences is borne out in individual migration narratives. For Shawn, his childhood and adolescence in northern Ontario had caused him 
to embody stigma and stress in a cumulative manner, creating an expectation of

victimization that — as with Francis - continued even after he moved to Ottawa at age 20.

And to a certain extent, you learn to adopt certain behavior patterns that paint you as a target for the next, for the next one that comes along. Um, so ... and to a certain extent you even come to see yourself as you are being described to yourself by others sort of like victimizing yourself after a while. But so, um, and when that all of a sudden disappears-I mean I'd suspect I spent the better part of my twenties getting over my teens. (Shawn, 42, white, French-Canadian)

In other cases, however, anxieties over "getting out" came from secondary circumstances arising from decisions to conceal being gay or to live a heterosexual life, rather than direct experiences of victimization. For at least two men, anxieties came from being in heterosexual relationships and decisions about whether to continue those relationships.

Um, I wasn't out in Halifax [Nova Scotia]; I was in a really bad relationship with a woman in Halifax. I was not making any-nor could I, and I realized this only after moving to Ottawa - nor could I make any progress in my professional life ... [I had] anxiety disorder ... a walking wound ... so Halifax was an awful, awful, awful period of my life. (Randall, 45, Black/Aboriginal, African-Canadian, Mik'maq)

I had moved [to a town in Wisconsin] ... I was living with the woman, we moved [to Madison, Wisconsin], we were there for about a year, we were getting set to move again and that gave me a lot of anxiety. And then I, I think it was the thought of that move which made me realize I just couldn't do it ... that it, like, it was over. (Martin, 46, white, European-American)

For some men, anxiety arose from more subtle feelings that they were out of

place, rather than acts of victimization or the pressures of concealing their sexuality. For Jeffrey (42, Asian, Chinese), getting out became more urgent after deciding that rural Pennsylvania — where he had recently landed a one-year professor position-was not his “type of place." As an Asian gay man living in an area with few Asians or gay men, he felt that he was perpetually being slotted into particular identity categories. He was told 
during his interview that his university was nicknamed "Dyke U.," in a manner that both aimed to allay his taken-for-granted trepidation about the place and assumed some sort of commonality between him and the lesbian students that ostensibly went there. In the supermarket, he was frequently asked by other shoppers to describe products that looked unfamiliar or exotic. Ironically, these attempts by others to slot him "into place" made him increasingly anxious about being out of place. "I think partly because when I was in [Pennsylvania] I wanted to get out. I feel like I'm stuck and I don't know when and if I can get out ... it's just not my type of place; small, um, too, too white, uh, just too rural." Important to note is that Jeffrey's anxieties about being out of place emerged from ongoing events, rather than the pre-formed, categorical definitions of the place that university administrators almost expected him to have. For some men, the desire to move or potential to move was not just a source of anxiety (e.g., worries over the possibility of remaining "stuck"), but also as a potential valve for anxiety. For Anthony (28, white, Polish-Canadian), realizing that he no longer wanted to live in Saskatchewan created anxiety, while moving to Ottawa ameliorated it: "Um, well, I was nervous because I wanted to leave and I was nervous that I was going to miss an opportunity to leave, so I was anxious to get out - anxious might be the better word - and I'm not anxious now because I'm where I want to be; I'm enjoying where I am and what I do.”

Several other men agreed that moving out had lessened their anxiety. For Luke, who had grown up in both a religious home (Jehovah's Witness) and homophobic school environment where his sexuality was rejected, moving to Ottawa-where he was able to access to other forms of social support such as a gay youth group — significantly reduced his anxiety. "In Welland [Ontario], I had panic attacks on occasion. I've had like one or 
two since I've moved here, so ... I definitely ... anxiety's gone down," he said (Luke, 24, white, French-Canadian). As Chapters 5 and 6 indicate, a few men were able to decrease their anxiety by moving elsewhere specifically to come out (Fortier 2001; Knopp 2004) as an openly gay man in another place. For Jack, the ability to start over in a new city (Washington, D.C.), where his sexuality could be disclosed early on in his interpersonal relationships, lessened the anxiety that had affected him in Seattle: “... I think like living in D.C. and ... kind of like break into the gay community here, like having friends who know about me ... I'd say that sort of, um, anxiety I had back in Seattle is really gone ... I was, like always kind of ruminating about it" (Jack, 24, white, European-American). Jack's experience again shows that mental and emotional health outcomes among gay men are mediated not just by aspects of place, but by the ways in which they mediate life circumstances and subjectivities. While Jack had lived in a city (Seattle) that many might consider equally or more open and accepting than Washington, D.C., reducing his anxiety required geographically separating from networks in which he had established a presumptively heterosexual identity.

Experiences of depression mediated many men's migration histories. Most of the men who reported becoming depressed prior to moving felt associated it with a lack of opportunity to build friendships and romantic relationships. In places where there was little visible presence of other gay men, many men reported feeling that the space they occupied had been narrowed or constrained. Ashton, for example, said that both his depression and his eventual move to Ottawa were influenced by the depression of living in a large city that seemed to have been rendered much smaller by his sexuality.

I was very, very happy to leave [London]. It was to me, it was 400,000 people that felt like 100,000 ... I think it was affecting my moods, I think 
I was probably ... I've never been prone to, like, deep depression, but I think it was like, low-grade ... London was never a city I felt comfortable in ... it wasn't a city where they had organized groups, eh? So, you couldn't go to an outlet like that and meet nice people and, and get acclimatized. (Ashton, 47, white, Anglo-Canadian)

For Anthony, who had left Saskatchewan six months prior to being interviewed, said that getting depressed was the product of a lack of social infrastructure, and consequently, "too much time to think."

Where I was, I was bored a lot of the time, I didn't have a social network, I didn't have things to do, didn't have events to go to, and therefore you would come home and there-I guess there was some underlying, not depression as in, as in the, the medical sense of depression, but you, you were bored-you had too much time to think maybe. (Anthony, 28, white, Polish-Canadian)

Men's depressive feelings tended to worsen when they began to disinvest in the places they lived. Processes of both social and personal disinvestment occurred once men began to feel that their identities might become incompatible with a place. While this disinvestment occasionally occurred in anticipation of moving elsewhere, the lag time was often substantial. Anthony, for example, described disengaging from Saskatchewan long before having the opportunity to move to Ottawa. "[it was] not having people that I enjoyed being around; not developing relationships, and, and part of it was that I chose not to develop relationships." Joseph (38, white, European-American), who was living in the Florida panhandle prior to moving to Washington, D.C., felt that both his decision to stay closeted and the seemingly limited opportunities for gay relationships where he lived had caused a decline in his self-care and a large weight gain: "I think it might have been [depression]. I think it was also from the standpoint of, like, I don't care, like I really just didn't have I didn't have any options anyway, so it just wasn't really worth that much effort." Joseph was not the only respondent to emphasize the palpable physical effects of 
the stressors they experienced. Luke, who moved to Ottawa from a small Ontario town in his teens, described some of the health effects he suffered by being bullied at school:

In high school, because there was a lot-it was a very kind of narrowminded, homophobic high school-I ... I developed ulcers, um, I got, um ... like I got really, really bad migraines, and just a lot of kind of stressrelated health issues that were kind of having a really, really big impact on me ... so, uh, once I kind of left the area, I felt a lot better. (Luke, 24, white, French-Canadian)

For Randall, a bi-racial (black, Aboriginal) man living in Nova Scotia, a series of events_-including persistent employment discrimination, a faltering relationship with a woman, and an unexpected pregnancy_affected his mental health to the extent that he had considered suicide. He remembered:

I had walked to the crest of the MacDonald Bridge and I stood there for-or was it the MacKay? I don't remember which, it doesn't really matter, they're both high and they're both over the harbor-and I stood there - it was rush hour — and I stood there until it got dark — waiting for myself to throw myself over. And I knew if I stayed in Halifax, one day I would throw myself over. So I had to get out, I had to leave. (Randall, 45, black/Aboriginal, African-Canadian, Mik'maq)

Randall's story not only reflects the implications of "double discrimination" (Diaz et al. 2001) for the mental health of gay men of colour, it highlights how the individual ways of coping with a stigmatized sexual identity (e.g., choosing to engage in a heterosexual relationship) can intensify negative place-health relationships among gay men.

Some men also turned to alcohol and other drugs as coping devices when faced with the stressors of coming out, discrimination, or potential rejection from friends and families. In previous studies, substance abuse has been connected to worsening anxiety and depression, as well as risky sexual behavior (Diaz et al. 2001; Botnick et al. 2002; Paul et al. 2002; Mills et al. 2004). While a substantial proportion of the interviewees used drugs or alcohol in general, fewer reported using them as a way to cope with some 
variation of minority stress. Eight percent of men interviewed (four respondents) reported using drugs in this fashion and another $8 \%$ (not necessarily the same $8 \%$ ) reported using alcohol. Anthony, for example, found that in an environment with low social connectivity for gay men and few places where he felt "safe in his own skin," he frequently turned to binge drinking as a way to have fun. “Um, I find I don't binge drink as much [in Ottawa]," he said. “... I don't have a need to do it or a desire to do it. With that being said, I - because I socialize and have a larger social network-I do drink more frequently, but I drink less ... [before, it was] the, the need to, um, have a good time ... I was bored so, I wanted to ... yeah, wanted to do something at the time" (Anthony, 28, white, PolishCanadian). Similarly, Jack described using drugs as a form of self-medication to negotiate social situations where he was not comfortable to "be himself:"

When I was in school—when I was still in Seattle-I used to use like ... I'd use marijuana and like some prescriptions drugs and alcohol and tobacco to kind of self-medicate. Um ... and I realized those things were making me just more and more unhappy ... I think like they released stress; they were like a social ... like a social crutch, so when I went out I felt more relaxed around groups of people if I was smoking. (Jack, 24, white, European-American)

As the accounts in this first section of the chapter demonstrate, gay men's experiences of mental and emotional health are intimately linked to both place and individual subjectivities such as race and relationship status. They also provide a more qualitative understanding of how minority stress (Meyer 1995; 2003) is experienced in daily lives. Finally, they suggest some ways in which mobility itself is linked with mental and emotional health for gay men. In a North American context where anti-gay stigma is geographically variable — both across and within places—gay men's health experiences are intimately bound up with their mobility. This is evident, for example, in men's 
negotiations of city space that involve being more vigilant or walking in a more masculine way in particular areas. Moving itself also becomes a way to negotiate space that has been rendered narrower or more constrained by sexual non-normativity.

Before moving elsewhere, many men had begun to feel that places deemed ordinary or normal for others (e.g., mid-sized cities) were constraining environments with limited social support, infrastructure, or opportunity. Finally, the act of moving itself is linked with health issues such as depression and anxiety. Many men grew anxious over the perceived need to locate themselves in what they deemed to be healthier, safer places (sometimes before coming out), or alternately, the possibility of moving elsewhere and still not coming out. In addition, moving elsewhere frequently mitigated some of the negative health outcomes related to minority stress. While men did not always move purposely to address a health issue, they sometimes found that anxiety, depression, and stressors such as isolation and bullying they had experienced in other places decreased significantly upon moving. Moving out, however, should not be deemed a panacea for the minority stress that gay men and other queer people encounter. In fact, the act of moving and settling elsewhere often poses its own set of health-related issues.

\subsection{Health after Migration: Encountering ‘The Scene,' Encountering Risk}

Reinforcing earlier findings that moving out rarely results in a once-and-for-all “emancipation" from the social stress of being gay (Fortier 2001; Knopp 2004; GormanMurray 2007), the men's narrative discussed in the second part of this chapter highlight some risks and challenges that might be encountered by gay men moving to new places. Health risks that respondents mention in the first portion of the chapter, such as substance 
abuse and HIV risk, were discussed even more frequently in relation to post-migration experiences and encountering new and unfamiliar spaces and scenes. Their observations echo Valentine and Skelton's (2003) finding that the gay scene, particularly for young and newly out men and women, is both a place to "find oneself" and "lose oneself." While only some men's moves to Ottawa or Washington, D.C., aligned with a comingout process or a move from a place without a scene to a larger, more visible gay community, many of the respondents' narratives reflect the exclusion, isolation, and risk that gay men may face when encountering new places.

Occasionally, men described the types of emancipatory experiences sometimes imagined to coincide with queer migrations (see, for example, Weston 1995; Maddison 2002). For example, $8 \%$ of the men interviewed (four respondents) felt that moving had allowed for personal development and improved wellness. For Jack, moving to Washington, D.C., was a "fresh start" that coincided with coming out and a general improvement in health. "When I was in Seattle, like, all throughout college I had ... I felt like pretty unhappy a lot of the time and might be depressed, and then, like after I came out, I moved out here for an internship and then I was ... it was the first time I was like living openly with a fresh start" (Jack, 24, white, European-American). Jack's experience, however, was not exemplary. Despite the assumed existence of "queer homelands" into which one can easily insert themselves without having set foot there before (Fortier 2001), few men found resettling to be a straightforward process. Loneliness and isolation, for example, were mentioned as frequently with reference to post-migration experiences as they were to pre-migration ones. 
After moving, many men experienced conflicted feelings about having abandoned family or friends in one place and sometimes setting out to construct a more complete queer life in a new place. The loneliness and isolation discussed by $23 \%$ of the men interviewed (11 respondents), for example, occurred just as frequently after moving as it had before). Mark discussed some of the emotional challenges of leaving Newfoundland for Ottawa in his late twenties:

Yeah, there were compensating factors, though ... that was the, that was the difficulty of it because, you know, family was very close, and it's always a big, emotional thing to sort of, you know, people when you leave the island ... it's not a happy situation, you know, but it happens all the time. But you know, it's an emotional wrenching, and for the families left behind, particularly. (Mark, 49, white, Anglo-Canadian)

Often, men tacked back and forth between the place they had left and the one they moved to as they attempted to break into the networks of a new city. Raymond (31, black, Jamaican-Canadian), remembered encountering "submerged" social networks in Ottawa and his consequent reluctance to fully invest in his new city. "Although I quickly made a few friends who I went out with and did things with ... [I was] lonely, not feeling like I had that network — my sort of friends in Toronto — a lot, I went home a lot, often ... I think it was, yeah, just 'cause the ... everyone's so submerged, right?"

As Mark and Raymond observe, moving to a new city is a rarely a seamless process, and men may encounter a number of emotional challenges along the way. For men who were not yet out, encountering a visible gay scene for the first time created feelings of insecurity and fear as often as feelings of comfort of welcome. While some men who came out after moving expressed relief about the opportunity to begin new relationships with a disclosure of their sexuality (i.e., "having friends who know"), many were fearful about finally coming out despite having placed themselves in environments 
that were ostensibly more supportive. Doug remembered going through a period of depression after moving to Washington, D.C., for university and facing "the reality" of coming out on a campus (and in a city) where gay identities were more visible.

Like my freshman year, I was ... I didn't really suffer from any depression at all. That kind of manifested itself sophomore year ... [During first year] I was very pleased and happy and I just felt like I had started a new life, you know, I just felt like I had started living. I think maybe it was becoming more reality that I was gay and I was gonna [sic] have to deal with it and there was a fear there of how people would react to it ... I was still ... struggling with that, coming to terms with that, I think that was a big part of it. (Doug, 26, white, German-American)

For Doug and others, moving out and coming out was not a seamless transition but an emotionally fraught experience in which facing the possibility of coming out—rather than the coming-out process itself-created fear and depression.

Other men found that the process of breaking in to be the most difficult part of relocation. Jeffrey, who had moved to Washington, D.C., from rural Pennsylvania hoping to find a community that was more sexually and racially diverse, found that he felt equally "out of place" in Dupont Circle. "I went to [name of bar] and I felt like I'm so out of place, you know ... I think you have to be more outgoing, more, um, almost like more assertive ... to make the first connection ... I always just assumed that if I'm white, it would be easier ... I don't have to be as assertive about certain things (Jeffrey, 42, Asian, Chinese). Joseph echoed his feelings, remembering how he felt that he had failed to fit into the young, athletic, professional image that he felt represented they gay community in D.C. "I think there is some, um, disappointment—-true disappointment—when you figure out that maybe you don't fit the mold and you're not welcomed over here and you're not welcomed over there ... there's just as much, but different prejudice with the community and then that's a hard lesson to learn, you know?" (Joseph, 38, white, 
European-American). The perceived failure to fit in can have physical implications as well as emotional ones. Joseph added, “... When I first came out [in D.C.], I dropped 60 pounds, I was running 21 miles a week, uh, you know, got myself into shape ... just coming screaming out of the closet, and just being like, if I'm gonna, you know, here I am ... if I'm gonna do this, then I'm gonna be ... the best that I can be." Arthur (30, white, European-American) had a similar experience when he moved to Washington, D.C. "Since I moved here I have gotten in shape," he said, "um, I'm a lot more conscious, you know, about what I eat ... I think I've gotten in shape maybe not for the right reasons ... maybe for like ... you know, gay culture body image reasons as opposed to like for my own internal reasons, or at least that's why I did at first." Joseph and Arthur's accounts suggest a need to question emancipatory notions of relocating to urban gay communities, and especially moving out to come out. Encountering the community, as these men indicate does not necessarily result in emplacement and can even bring on anxiety, depression, and changes in various health behaviors.

New cities and new scenes were also places where men encountered drug and alcohol use and sexual risks. Many of the respondents, particularly those who had moved to D.C., found that encountering an unfamiliar scene that seemed to revolve around alcohol—coupled with wanting to fit in —led to an excessive use of alcohol. In fact, about $75 \%$ of the respondents (including almost all who had moved to Washington) reported drinking more frequently than they did before moving (in the accompanying health selfassessment), even though only $8 \%$ directly referenced alcohol use in their migration narrative. Jack, who commented that his drinking had "skyrocketed" since moving to Washington, said, "uh, just the lifestyle in D.C.-particularly in the gay community-is 
like very heavy about drinking and my friends are very heavy drinkers" (Jeffrey, 42, Asian, Chinese). Jack added, 'It's always in excess. It's never ... people never go out for a couple glasses of wine or a beer, it's always like people drink to get really drunk" (Jack, 24, white, Anglo-American).

About $20 \%$ of men interviewed (nine respondents) also reported beginning to use drugs or using drugs more frequently after relocating. Usually, the initiation of or increase in drug use was the result of increased availability, the instability generated by relocating, or a combination of both. For Joseph, using drugs like ecstasy for the first time stemmed from encountering an unfamiliar scene where drugs were widely used: "I think just everybody ... it was, you know, it was early 2000s and it just kind of ... everywhere you go ... it was just kind of, you know, there" (Joseph, 38, white, AngloAmerican). While Joseph's drug use was casual, Max described his move to Washington, D.C., as the cause of his self-described "lowest point" in an long-term phase of drug use he had begun in Arizona and continued in Hawaii: "When I first got to Washington, I sort of kept ... all of the elements of the lifestyle except for the physical fitness ... I, I sort of like experienced the, you know, debilitating paranoia of drug problems coupled with a degrading physical appearance ... and so, initially, I would say, for probably the first year I was here, I actually had a worse time interacting with people” (Max, 31, white, European-American). While had planned to distance himself from the transient, ephemeral party culture he had been part of in Honolulu after moving to D.C., the process of uprooting and then encountering a new scene caused him to continue relying on drugs. Sam, who moved from Montreal to Ottawa for a government job following an unfinished degree, the loss of a parent, and a failed relationship described a similar battle 
with drugs. "Um, you know, I lost my spirit city—Montreal—I lost my, um, father, I lost my health, I lost my boyfriend, um, I didn't finish the Ph.D. and had to process that ... so then I, I started using more than I'd ever explored in Montreal ... cocaine and meth ... so I had to at one point sort of say to my family doctor I need some help" (Sam, 44, white, European-Canadian). Max and Sam's accounts both show that individual life eventsand the ways they precipitate or otherwise mediate migration — are as important as the scene itself in contributing to gay men's drug use.

Some men observed that newly encountered communities and scenes could be sexually liberating, but also risky. A few respondents saw moving to a larger city as an opportunity to improve their sexual health by gaining access to information. Shane (27, black, African-American) commented, "I think that maybe that awareness was in part a result of living in a place like D.C. as opposed to Richmond [Virginia]... I'm sure I could have accessed information, but maybe not as significantly as I did here." Many, however, observed that the size of the community and the increase in potential sexual partners were themselves a factor in sexual risk. One respondent contrasted Washington, D.C., with the gay community he experienced at a small liberal arts college in New England.

Uh, having to come here and sort of contend with these, like, big places and not really being sure how to navigate it, not sure how to feel safe at the beginning ... I used to joke with my friends at [name of college] that it was like, it was not a big deal to hook up with someone you just met at [name of college], because they had already been vetted by the admissions committee, I mean, they've been through, they've been very carefully selected. It's not true when you go into a big city, you know? Who is this person? I don't fucking know. They're not my age range; they didn't go to like ... so, you have no idea. (Brian, 27, white, JewishAmerican) 
For others, their accounts of sexual risk in a new place were informed by direct experiences of HIV seroconversion. Joseph described contracting HIV in Washington, D.C., as he tried to understand where he fit into the gay community he encountered there:

No, I kind of do [know when I contracted HIV] ... I think there's probably some self-esteem issues there ... I think that trying to fit in thing that we talked about ... I think that always plays into things ... I think trying to, just trying to fit in ... you may not [use protection during sex] because you don't want to be rejected ... so you would just conform or just not say anything 'cause, you know ... (Joseph, 38, white, AngloAmerican)

For Sam (44, white, European-Canadian), discovering his HIV status in Ottawa raised new questions about whether he needed to move from Ottawa back to Montreal to seek care in a more supportive environment. "When I first was diagnosed, I actually wanted to get treatment in Montreal just because of the stigma aspect of it ... I've been more conscious of it than if I was in a big city such as Montreal where you can sort of disappear into the village or into, you know, your neighbourhood." At the same time, he stayed in Ottawa because of the social support and health services that the city provided. "It's sort of a big small town, so in terms of the intimate support networks that you need at that point in your life to get you through that period I think that's an advantage. But it also has the advantage, um, of having big-city hospital facilities. So the quality of care that I get at the Ottawa General is ... second to-none. HIV, then, is not just a potential risk associated with negotiating new scenes but — as other studies have observed - a reason for return migration (see Cohn et al. 1994; Raimondo 2003).

\subsection{Minority Stress and Migration: The Qualitative Perspective}

The respondents' experiences of health both preceding and following migration provide considerable qualitative evidence for the minority stress model in which social 
stigma, discrimination, and other determinants ultimately create experiences of ill health, including anxiety, depression, and suicide ideation. The fact that these experiences contribute to gay men's migration decisions not only reinforces the severity of the stigma they encounter, but also that stigma itself — and the networks and services that mediate it-is geographically variable. Although the decision to migrate in light of negative mental and emotional health effects is often as related to individual identities and circumstances (e.g., a failing relationship or double discrimination as a racialized gay man) as it is on the particular place lived in, the findings highlight some important potential linkages between place and the health of sexual minorities.

Granted that changes in health after moving were reported retrospectively, sometimes long after the move had occurred (and thus creating a potentially more optimistic portrayal of past migration decisions), some changes were reported with great consistency. Almost $90 \%$ of respondents reported being happier after moving and about $80 \%$ reported improved overall health. Most men also reported having higher self-esteem and less sadness after moving. These findings, however, do not necessarily indicate that respondents simply exchanged locations that were homophobic, repressive, or stigmaladen for ones that were more supportive or otherwise healthier. As the previous narratives suggest, the health behaviors and outcomes that men experienced prior to-and sometimes after-moving are also extensions of their individual life course trajectories. Although poor mental and emotional health among gay men is sometimes a response to direct threats of stigma, discrimination, harm, or exclusion, it may also be a response to a perception that their environment cannot provide the support, or infrastructure, or opportunities that they see as appropriate for their stage in life. 
The specific experiences of ill-health that men experienced tended to be bound up with expectations about their individual development in the places they lived. Some men experienced anxiety and depression because they were concealing or repressing their sexual identities in order to advance professionally. For others, symptoms of anxiety were connected to the anticipation of migration itself, specifically the expectation that their lives would not move forward if they remained geographically rooted in place. Similarly, a lack of social support or meaningful relationships was more often related to individual men's choices to limit or constrain their social lives in settings that they felt were not conducive to living life as an out gay man. Similarly, men's expectations that they needed to embrace "the scene" and establish a new, often unfamiliar, network of gay friends and acquaintances after moving led to its own set of health issues. As several narratives indicate, the desire to create a new "identity in place" can also lead to excessive drinking, drug use, or risky sexual behavior.

The previous accounts show that health service infrastructures rooted in places may also contribute to gay men's migrations. Men may avoid seeking support from counselors or mental health professionals if they expect either a low likelihood of affirmation or the possibility of non-confidentiality (Epstein and Johnson 1994; Cant 2005). Consequently, men may move elsewhere to seek professional assistance with coming out or other sexuality-related health issues rather than doing so where they currently live — and where families and friends also live. Similarly, access to gay-positive physicians and sexual health clinics was an important factor in the overall well-being of many gay men, even if not necessarily primary determinants of their migration decisions. 
For men who had seroconverted, finding a supportive environment for HIV treatment was also an important consideration.

Interestingly, there was a marked difference between the Ottawa and Washington, D.C., samples. The Ottawa group reported consistent improvements in a variety of health indicators following migration, particularly relationships with families, numbers of friends and relationships with friends (indicators of social support), energy level, and level of comfort around other people. Respondents in Washington, D.C., in contrast, were more mixed in their assessments of health following migration. As noted in earlier chapters, many of the men in the Ottawa sample reported negative experiences in homes, schools and communities they came from. Although the diversity of narratives and places of origin highlighted in this chapter and previous chapters no doubt overcome the simple binaries of gay metropolis and homophobic countryside, the stories of Canadian men migrating from smaller and more remote places such as northern Ontario, Nova Scotia, and Newfoundland tend to reinforce the link between rurality, heteronormativity, and experiences of ill health among gay men observed by other researchers (Flowers and Buston 2001; Saewyc et al. 2009; Barton 2010).

Finally, the findings here both advance the idea of queer migration as an embodied phenomenon and introduce the idea of migration as a mode of self-care for sexual minorities. Adding to both the general work of emotional geographers (Davidson and Milligan 2004; Bondi et al. 2005) and to specific studies of queer migration as an embodied phenomenon (Knopp 2004; Gorman-Murray 2007), the previous narratives show that queer migration is not just emotional in nature, but quite literally embodied in terms of health behaviors and outcomes. Men's accounts of mental and emotional health 
prior to moving and the observed changes in health after moving indicate that processes of relocation are often mediated by emotions such as fear, isolation, or "out-of-placeness," as well as experiences of bullying, victimization, anxiety, depression, and other forms of ill-health such as substance abuse.

Despite the high rates of reported improvements in health following relocation noted here, this chapter does not seek to suggest that gay men's health outcomes are automatically improved by moving to urban environments. First, men can encounter new sets of risks associated with adapting to new cities, "communities," and "scenes" (Valentine et al. 2003; Carrillo 2004; Bianchi et al. 2007). Second, reported changes in health may be influenced more by the life events and transitions informed by changes in environments rather than by a change of location itself. Many men noted, for example, that improvements in self-esteem were related to individual maturation, greater life experience, and caring less what others thought of them. In this sense, the life course and migration simultaneously inform the health of gay men. Men's decisions to move to specific sites, or even the act of moving itself, can facilitate the life course transitions so important to health and well-being. By moving from places where families, social networks, or work environments had rendered it more difficult to form romantic relationships or community identities, men mitigated the constraints of place on their individual development and overall health.

This chapter also advances a notion of migration as self-care. This idea had previously only been used to describe migrants, usually refugees, who had usually experienced both physical threat from violence, poverty or disease, and post-resettlement mental and emotional health issues such as post-traumatic stress disorder (Momartin et al. 
2003). In the specific case of gay men, most interventions into health and migration addressed only a narrow, highly medicalized interpretation of migration as either a vector for HIV/AIDS transmission or a concern for service providers in areas to which infected men were returning (Cohn et al. 1994; M. Brown 1995). The findings here offer evidence for a much broader interpretation of migration as a vehicle for self-care throughout the life courses of gay men. Men's narratives highlight multiple variations on this theme: migration as a way to mitigate perceived threats of physical and emotional harm, as a means of accessing health or counseling support in a gay-positive environment, as a way to access new networks of social support ("families of choice"), or as a tool to reduce the anxieties or depression associated with concealing sexuality in an environment of particularly tight or dense familial and social networks. Consequently, I reassert here the findings of previous work noting that migration is central in the lives of gay men and other queer people (Knopp and Brown 2003; Knopp 2004; Gorman-Murray 2007), but challenge the idea that their relocations are most frequently the product of identity quests. Instead, they are often the truly embodied consequences (i.e., literally moving the body elsewhere) of the ways in which uneven landscapes of rights, support, and stigma are embodied in the health behaviors and outcomes of gay men. 


\section{CHAPTER 8}

\section{Migration as Security: Capital Cities as New Homelands?}

\subsection{Introduction}

Historic and geographic studies of gay men's lives have typically focused on large cities. Collectively, they show that gay identities do not merely exist in cities but also something bound up in the evolution of cities as industrial complexes, global crossroads, and sites where culture and counterculture are produced (D'Emilio 1983; Chauncey 1994; Aldrich 2004). With some notable exceptions (see Osborne and Spurlin 1996; Phillips et al. 2000; Knopp and Brown 2003), most of these accounts have focused not just on large cities, but on a particular set of cities that — because of their historical significance as centers of gay politics (San Francisco, New York) or a more commodified set of cultural amenities (Sydney, Manchester)—have become concretized as types of capitals or homelands that ostensibly attract gay men from across the countries in which they are located (Weston 1995; Black et al. 2002; Markwell 2002; Binnie and Skeggs 2004). Although these places are significant sites in the Western imaginary of gay politics and culture, they represent demographically only a fraction of men who identify as gay. Consequently, they are now arguably less dominant sites of gay identity formation than they were during the previous century.

The recent work on queer migrations as an embodied and emotional phenomena (see Knopp 2004; Gorman-Murray 2007), while usefully highlighting the ways in which migration is mediated by individual circumstances (e.g., coming out and identity formation), does not necessarily dispute the centrality of sexual identity itself in the queer migration discourse. As the introduction notes, assumptions remain that men will then 
gravitate to places that have a large community of gay men or hold some cultural or political significance as gay homelands (Fortier 2001). Less has been done, however, to examine how men form gay identities, broadly conceived—not just sexual identities, but also workplace, political, and community identities. This chapter demonstrates that these broader identities are formed in relation to the particular institutions located in places, and how desires to form such identities might influence their migrations. Recent studies have noted that migrations that appear to be undertaken for purely economic or educational reasons are still influenced by sexual subjectivities (Gorman-Murray 2007; Waitt and Gorman-Murray 2010). This chapter builds on these studies not just by asserting that there is a linkage between sexuality and economic or career-based migration, but to examine the specific ways in which gay men's migrations are linked with the institutions and institutional cultures of places.

With some exceptions (G. Brown 2009), most of the literature to date that has examined the relationship between gay men's migrations and the political and economic aspects of cities tends to reify a consumer-centric model of attraction that equates gay identity with high spending power and deference to global cosmopolitanism (Puar 2002; Binnie and Skeggs 2004). Many of these studies are econometric, generated in part by the availability of same-sex couple data in the recent U.S. Censuses (see Black et al. 2002, 2007; Florida 2002, 2005; Walther and Poston 2004; Cooke and Rapino 2007). Because of their econometric methodological approach, most of these studies unsurprisingly identify economic variables (e.g., employment, housing prices, and the availability of certain goods) as the primary driver of locational patterns among gay male couples. Their elaboration of the ways in which sexuality non-normativity might inform migration to 
particular places—-for example, the desire to seek out safe and inclusive work environments - is limited. Instead, these studies argue that locational patterns among same-sex couples, used as a rough proxy for people who identify as gay or lesbian, are based on economic decisions aimed at maximizing consumption. Since gay male couples are assumed to value so-called "non-child amenities" (e.g., arts, nightlife, rental housing) over child-oriented amenities (e.g., schools, parks, low crime), they will ostensibly sort to cities with an abundance of the former (Black et al. 2002; Black et al. 2007; Cooke and Rapino 2007). Political attitudes and gay rights protections, in contrast, are often dismissed as noisy or lacking in explanatory power.

Much like these recent attempts to quantify the locational choices of same-sex couples, discursive trends in urban, political and economic geography have reinforced associations between gay men, spending power, and metropolitan environments. Some claim that Richard Florida's creative class theory (Florida 2002, 2005) positions queer people — particularly gay men — as commodified "tracking molecules" for the vibrancy and attractiveness of urban economies (Storper and Scott 2009). Despite the instrumental conceptions of sexual difference that these theories employ, jurisdictions such as Singapore have turned their attention to the recruitment, attraction and retention of gay and lesbian workers, particularly civil servants (Fujita 2007; Yue 2008; Phillip 2008). Similarly, the "pink dollar" (Puar 2002) used to represent the spending power of gay men and lesbians has shaped ideas about gay economies (Bell and Binnie 2004; Bassi 2006), "market segments" (Branchik 2002) and "brand relationships" (Kates 2000), but does little to explain the ways in sexuality informs the day-to-day economic lives (including economic migrations) of queer people. 
The literature surrounding the politics of queer migration is similarly fixed, but more so in the scale of analysis than in the ideas presented. Most recent studies address the role of the state (particularly the national state) in the formation of immigration policies that define the family — and therefore family reunification — as a heteronormative institution (Lubhéid 2005, 2008; Lubhéid and Cantù 2005; Manalansan 2006; Yue 2008). Similarly, the state is often posited as the primary container of policies and practices aimed at regulating gay men's lives through tools such as public health campaigns, marriage laws, and the criminalization of homosexuality (Smith 2005a; Cooper 2006; Oswin and Olund 2010; Olund 2010). Less has been done, however, to examine how the inherently uneven landscape of rights, regulations, and institutions that queer people encounter within Canada and the United States might influence their migrations. Given that the laws and policies of both states are multiscalar in nature, it is also useful to consider how political and economic institutions operating at the local level might add to the complexity of gay lives and create imperatives or opportunities for migration.

Cities therefore continue to be important drivers of queer migration, but perhaps in different ways than previously catalogued. First, cities are significant to queer migrants in ways that extend beyond both their real and imagined queer cultural significance (Weston 1995; Fortier 2001; Aldrich 2004) and their more recent portrayal as containers of creativity and cosmopolitanism (Florida 2002, 2005). Second, as life course theory suggests, cities are not just sites where gay men form sexual identities, but places where particular sets of policies, practices, and institutions convene to shape the development of gay men's professional and community identities. These two observations indicate that there is perhaps room to consider how places like Ottawa and Washington, D.C.- cities 
that are neither queer cultural homelands (Fortier 2001) nor cosmopolitan centers-have come to attract gay men through their particular economic and institutional configurations. Heeding recent calls to avoid abstraction and to assess queer population patterns more qualitatively and critically (see Knopp 2004; Brown and Knopp 2006; Gorman-Murray 2007), this chapter critically interrogates notions of "locational choice" among gay men. In doing so, it further builds on a life course approach to queer migration, based on the networks, institutions, and life histories, and challenges dominant visions of the gay economy that have typically focused on nightlife, consumer outlets, and social services (Bassi 2006; G. Brown 2009). It also suggests that the economic and institutional configurations of the capital city, and particularly the opportunities they provide for gay men to create identities beyond the sexual realm, are both motivators and products of gay men's migrations.

The evidence gleaned from interviews suggests that the search for a secure livelihood (economic and otherwise) is central to most gay men's migrations. The most common themes related to "economic migration" (see Table 8.1) were the draw of politically relevant work, the presence of queer organizations and networks comprising a local gay economy, the security of government jobs, and negative experiences or perceptions of other economic sectors in places previously lived. Seeking out employment in the government sector was both the most common theme related to economic migration as well as the factor most frequently cited as the most important overall reason for relocating to either city (see Tables 8.2 and 8.3). Almost half of the men interviewed said that they had moved primarily for purposes of work, employment, or career, with their specific reasons ranging from receiving a specific job offer to 
looking for work in the sectors of politics, development, and advocacy that dominate

Ottawa and Washington, D.C. In addition, about half were employed by the Canadian and

U.S. federal governments as public servants, and most worked in foreign and

international affairs, health, energy, and national defense.

Table 8.1. Sub-themes Related to Economic Migration among 48 Self-identified Gay Men, Ottawa, Ontario, Canada and Washington, D.C., U.S.A.

\begin{tabular}{|l|l|l|l|}
\hline Sub-Theme & $\begin{array}{l}\text { No. of } \\
\text { passages }\end{array}$ & $\begin{array}{l}\text { No. of } \\
\text { respondents }\end{array}$ & $\begin{array}{l}\text { \% of } \\
\text { respondents }\end{array}$ \\
\hline Queer organizations and economies & 30 & 24 & 50 \\
\hline Security of federal government jobs & 29 & 19 & 40 \\
\hline Coming out in the workplace & 21 & 16 & 33 \\
\hline Queering government work & 20 & 17 & 35 \\
\hline Workplace conducts and disciplining & 17 & 14 & 29 \\
\hline Draw of a political environment and institutions & 17 & 13 & 27 \\
\hline Negative experiences in other sectors & 16 & 10 & 21 \\
\hline Networking/socializing & 12 & 10 & 21 \\
\hline Transience & 12 & 9 & 19 \\
\hline Connection between white-collarness/education and acceptance & 8 & 8 & 17 \\
\hline Financial difficulties and expectations & 6 & 6 & 13 \\
\hline Tradeoff between lifestyle and security & 4 & 3 & 6 \\
\hline Pulling gay men into "appropriate" government positions & 3 & 2 & 4 \\
\hline Disadvantages of living in a capital city & 2 & 1 & 2 \\
\hline Federal government conservatism & 1 & 1 & 2 \\
\hline Housing & 2 & 1 & 2 \\
\hline
\end{tabular}


Table 8.2. Most Important Reasons for Moving, Occupations, and Incomes Sample of Self-identified Gay Men (N=24), Ottawa, Ontario, Canada

\begin{tabular}{|c|c|c|c|c|}
\hline Pseudonym & City & $\begin{array}{l}\text { Most important } \\
\text { reason for moving }\end{array}$ & Occupation (sector) & $\begin{array}{l}\text { Annual } \\
\text { Income* } \\
(\$ 000 \mathrm{CDN})\end{array}$ \\
\hline Steve & Ottawa & work/employment & Professor (academia) & 115 \\
\hline Raymond & Ottawa & education & civil servant (heritage) & 70 \\
\hline Pete & Ottawa & work/employment & product consultant (food/beverage) & 65 \\
\hline Anthony & Ottawa & quality of life & civil servant (foreign affairs) & 70 \\
\hline Sebastian & Ottawa & coming out & civil servant (health policy) & 85 \\
\hline Luke & Ottawa & coming out & $\begin{array}{l}\text { community developer (gay } \\
\text { advocacy) }\end{array}$ & 24 \\
\hline Derek & Ottawa & work/employment & civil servant (foreign affairs) & 75 \\
\hline David & Ottawa & work/employment & civil servant (industry, retired) & 115 \\
\hline Terry & Ottawa & education & civil servant (lawyer, justice) & 80 \\
\hline Chad & Ottawa & work/employment & civil servant (education) & 100 \\
\hline Adrian & Ottawa & work/employment & civil servant (national defense) & 80 \\
\hline Ashton & Ottawa & work/employment & civil servant (skills development) & 80 \\
\hline Jerry & Ottawa & work/employment & civil servant (foreign affairs, retired) & 80 \\
\hline Shawn & Ottawa & work/employment & civil servant (national defense) & 90 \\
\hline David & Ottawa & work/employment & researcher (queer health) & 40 \\
\hline Randall & Ottawa & education & civil servant (natural resources) & 60 \\
\hline Wally & Ottawa & work/employment & $\begin{array}{l}\text { consultant (information } \\
\text { management) }\end{array}$ & 115 \\
\hline Rick & Ottawa & work/employment & civil servant (legislature) & 55 \\
\hline James & Ottawa & relationship & manager, non-profit (health) & 55 \\
\hline Mark & Ottawa & coming out & civil servant (services) & 90 \\
\hline Smith & Ottawa & relationship & lobbyist (health) & 100 \\
\hline Francis & Ottawa & education & $\begin{array}{l}\text { civil servant } \\
\text { (media/communications) }\end{array}$ & 75 \\
\hline Sam & Ottawa & work/employment & civil servant (strategic review) & 100 \\
\hline Daniel & Ottawa & education & coordinator (housing cooperative) & 30 \\
\hline
\end{tabular}

* For respondents in households with two incomes, the reported household income was divided by two. 
Table 8.3. Most Important Reasons for Moving, Occupations, and Incomes, Sample of Self-Identified Gay Men (N=24), Washington, D.C., U.S.A.

\begin{tabular}{|c|c|c|c|c|}
\hline Pseudonym & City & $\begin{array}{l}\text { Most important reason for } \\
\text { moving }\end{array}$ & Occupation (sector) & $\begin{array}{l}\text { Annual Income* } \\
\text { (\$000 US) }\end{array}$ \\
\hline Marshall & $\overline{\mathrm{DC}}$ & education & civil servant (foreign affairs) & 75 \\
\hline Jesse & $\mathrm{DC}$ & work/employment & professor/artistic director (dance) & 155 \\
\hline Ian & DC & work/employment & consulting (energy) and student & 15 \\
\hline Max & $\mathrm{DC}$ & personal & civil servant (justice) & 55 \\
\hline Jason & $\mathrm{DC}$ & education & research assistant (foreign affairs) & 60 \\
\hline Tim & $\mathrm{DC}$ & education & scientist (energy) & 70 \\
\hline Green & $\mathrm{DC}$ & work/employment & civil servant (meteorology) & 50 \\
\hline Michael & $\mathrm{DC}$ & work/employment & $\begin{array}{l}\text { biologist (environmental } \\
\text { conversation) }\end{array}$ & 70 \\
\hline Joseph & $\mathrm{DC}$ & work/employment & $\begin{array}{l}\text { advertising director } \\
\text { (communications) }\end{array}$ & 60 \\
\hline Doug & $\mathrm{DC}$ & education & executive assistant (academia) & 35 \\
\hline Adam & $\mathrm{DC}$ & work/employment & civil servant (national defense) & 100 \\
\hline Arthur & $\mathrm{DC}$ & work/employment & civil servant (foreign affairs) & 80 \\
\hline Marshall & $\mathrm{DC}$ & social networks & civil servant (foreign affairs) & 100 \\
\hline Martin & $\mathrm{DC}$ & relationship & civil servant (Census) & 70 \\
\hline George & $\mathrm{DC}$ & education & $\begin{array}{l}\text { journalist (communications) and } \\
\text { student }\end{array}$ & 65 \\
\hline Jordan & $\mathrm{DC}$ & education & research associate (economics) & 68 \\
\hline Jake & $\mathrm{DC}$ & locational choice & executive director (queer advocacy) & 80 \\
\hline Jack & $\mathrm{DC}$ & work/employment & intern (foreign affairs) & 35 \\
\hline Peter & $\mathrm{DC}$ & politics & consultant (federal government) & 70 \\
\hline Owen & $\mathrm{DC}$ & work/employment & $\begin{array}{l}\text { bureau chief (international } \\
\text { development) }\end{array}$ & 200 \\
\hline Brian & $\mathrm{DC}$ & politics & $\begin{array}{l}\text { project manager (international } \\
\text { development) }\end{array}$ & 66 \\
\hline Jeffrey & $\mathrm{DC}$ & work/employment & research scientist (health) & 120 \\
\hline Shane & $\mathrm{DC}$ & work/employment & research manager (health) & 60 \\
\hline Phillip & DC & relationship & writer (health communications) & 105 \\
\hline
\end{tabular}

* For respondents in households with two incomes, the reported household income was divided by two. 
The capital city has thus emerged as a desirable destination for gay men, perhaps not in spite of the government sector but because of it. There is no easy explanation for this trend. One on hand, the finding that capital cities such as Ottawa and D.C. are also "gay cities" is not new. Studies of Ottawa by Kinsman (1995) and Robinson and Kimmel (1994) and studies of Washington, D.C., by Rimmerman (2002), Dean (2003), and Johnson (2004) have revealed that gay men have long held government positions and established their own communities in these cities. In 1940s, 1950s and 1960s, Ottawa and Washington, D.C., became viable alternatives for men seeking to avoid the gendernormative workplaces of more heavily industrial and corporate environments. As Shane (27, black, African-American) observed, “Apparently, Capitol Hill has always been run by gay men.” At the same time, Ottawa and Washington, D.C., are not known for visibly gay spaces or identities as they might be conceived in a gay cultural homeland. The advent of the capital city as a new type of homeland, then, is due to political and economic "pushes" from a variegated landscape of rights and inclusion for gay men, as well as a number of discursive and more pragmatic pulls of a "queered" capital city.

\subsection{Precarious Positions: Migration as the Negotiation of Uneven Landscapes}

In contrast to aforementioned studies that position gay men's locational choices as a matter of maximizing already-privileged lives, this chapter frames their migrations as negotiations of uneven landscapes of rights, stigma, and social norms. In particular, it attributes gay men's locational choices to multiple forms of precariousness: codified denials of rights, informal forms of stigma and discrimination in workplaces and other settings, and resultant variations in the life course that may render otherwise 
economically "logical" locational decisions more difficult. Recent interventions into the role of rights in queer migration tend to focus on national regimes of immigration rights and regulations that prioritize heteronormative configurations of family and partnership (Lubhéid 2005, 2008; Manalansan 2006). These studies tend to focus on the scale of the country, with less attention to both the codified ways and less visible ways that anti-gay stigma within countries influence the day-to-day lives and relocation decisions of gay men and other queer people. Regimes of gay rights in Canada and the United States have recently been cast as oppositional systems, with Canadian policies based on a premise of rights affirmation through the 1982 Charter of Rights and Freedoms and U.S. policies operating from a premise of rights denial, marked by the Defense of Marriage Act since 1996 and state anti-sodomy laws that were not overruled until 2003 (Lind 2004; Smith 2005). These generalizations, however, mask the more nuanced ways in which anti-gay policies and practices diffuse through both countries in spatially uneven ways. Adrian, for example, noted that even the numerous protections afforded by the Canadian federal government were still subject to fissures and ruptures.

...There are so many legal protection mechanisms within the federal government to protect you, um, given the fact that within our own, you know, constitution, uh, sexual identity, orientation is protected. Uh, the grounds under the Human Rights Act include sexual orientation. You certainly might and will encounter specific areas-be it geographic or certain managers or whatever - who might, uh, react negatively, but it's up to you as a gay person to stand up and say, okay, challenging you, and take it out into the open. It will be dealt with very quickly. (Adrian, 56, black, African-Canadian)

In the United States, in contrast, men observed a baseline of rights denial, under which even careful decisions about where to work could not provide sufficient security. Max, for example, explained that his stable civil service job 
and the advent of new protections of gay rights in D.C. since he had moved there (e.g., gay marriage in 2010) provided, at best, incomplete security amidst an unruly patchwork of policies and practices.

Well as far as I know, there's no federal protection of, um, employment discrimination for, uh, gays and lesbians ... one of the sort of things that I'm personally coming to grips with now is, is the, uh, sort of the patchwork nature of a lot of the gay marriage legislation ... because [partner's name] and I live in D.C., where we are legally married, I work for the federal government, which may or may not recognize it - the jury's still out - and (partner's name) works in Virginia, which explicitly doesn't recognize it. (Max, 31, white, European-American)

Shane, who was contemplating moving from D.C. to New York City for law school at the time he was interviewed (May 2009), explained that similarly the relative absence of rights protections in that state compared to D.C. would have been a major detractor to moving there. He decided to stay in D.C. rather than relocating.

Why would I give up having more or less full rights - as much as D.C. can give us - to a place that the governor is, doesn't feel that gay people should be protected within the government ... I mean, I like my rights, so ... I applied to law school, law school this fall ... it was hard because if I moved to New York I would give up my right to marry in New York if I moved to New York. Um, and some of my friends were like, oh it doesn't matter, it's just law school, but like for me, no it's important. It's very for important for me to know that where I'm living that I'm being fully re, um, respected as, as in individual within that, um, place ... I refuse to move to a place where someone can literally fire me for being gay. I mean, what type of job security is that? (Shane, 27, black, AfricanAmerican)

Given the geographically complex and variable nature of inclusion for queer people, in terms of both official, jurisdictional proscriptions of rights (United States) and more everyday, informal practices of inclusion (both the United States and Canada), men tended to privilege the environment of the individual city as the primary determinant of their security. Martin, for example, explained that when he and his partner relocated to 
D.C., they considered not only which places would have the highest density of job opportunities in his partner's relatively narrow field (geology), but also whether they were likely to have multiple workplaces that were respective and supportive of sexual difference: "So I mean, if the kinds of organizations — of which in D.C. there are manythat [partner's name] could conceivably work for, um, if they were all located in Topeka, Kansas, you know ... the gay issue would have been much larger ... but it was, certainly reassuring knowing that we could move here, and that just really was unlikely to be an issue" (Martin, 46, white, European-American).

As Martin observes, the particular configurations of institutions, organizations, and social and cultural norms in individual cities are seen as providing both security in a fundamentally insecure landscape and the factors necessary for establishing what they believe to be meaningful professional lives and community identities as their life courses progress (Cohler and Galatzer-Levy 2000; Kertzner 2001). At the same time, men's ongoing attention to the importance of economic security and protective environments reflect the internalization of neoliberal imperatives to find ways to preserve themselves in the context of living in nations that provide only partial security and welfare for queer people (Gibson-Graham 1996; Peck and Tickell 2002). The following sections describe in greater detail the dual processes of men's security-seeking migration decisions and the transformation of national capitals into new types of homelands centered on highly professionalized and institutionalized models of the "gay community. In particular, I examine the role of work in men's migration decisions, the discursive construction of capital cities as economically secure places for gay men, and the ways in which the 
capital city has become queered by the increasing visibility of gay men and lesbians in the civil service and its associated sectors.

\subsection{Precarious Positions, Part Two: Conceiving Risk at Work}

Men's decisions to move to Ottawa or Washington were often informed by negative employment experiences in other places, demonstrating that gay men's feelings of being out of place are often mediated through experiences of work (Cresswell 1996; Badgett 1996; Griffith and Hebl 2002; Willis 2009, forthcoming). Their experiences of fear, harassment, or other difficulties in workplaces point to the economic insecurity associated with sexual non-normativity. According to Willis (2009), the workplace is often problematic and socially divided site for queer people, with symbolically and sometimes materially discriminatory practices used to define the boundaries of sexual normalcy. As a result, queer workers may stay in the workplace closet, a place that simultaneously isolates and protects them as they decide if and how to make their sexual identities visible or public in the workplace (Willis 2009, forthcoming). The following analysis suggests that these behaviors not only mediate experiences within the workplace, but also decisions about where to work (e.g., which firm) and about which place might provide the greatest selection of desirable workplaces.

Among the men interviewed, 17\% (eight respondents) reported negative experiences in previous jobs because of their sexuality. Several had realized early in life, often in places with relatively narrow agricultural and manufacturing economies, that the geographically proximate or otherwise appropriate job opportunities were rendered precarious by their sexuality. Some were concerned, for example, about the ways in 
which their sexuality might be expressed in gender-normative work environments, what Shane (27, black, African-American) described as "knowing I come off as gay." For Luke (24, white, French-Canadian), those fears were realized during some of his first jobs in a southwestern Ontario city: "And once I did try to work in a stock room, and I ... all the other guys that were working there just made fun of me non-stop. Uh, finally I got a job in a restaurant [and I was] the only guy working there. He went on further to describe the gender-normative nature of the city's economy as a whole:

It almost kind of reminds me of what I hear small towns in Alberta are like where it's like ... it's a mill town. It's a mill town where there's you know, the little French sector and then there's the mills and everything, and everybody, all the men are like, "Grr" and all the women are taking care of the house. And, um ... I didn't fit into that, so ... it was just really kind of odd to be surrounded by that kind of environment, where those are really your only two options. (Luke, 24, white, FrenchCanadian)

Terry (40, white, Flemish-Canadian), who had also moved to Ottawa from southwestern Ontario, discussed how a similar experience of summer employment shaped his decision not to return there after school: "I mean there were of course times when I was an undergrad where I went back home to work in the summer and, um, on one occasion I worked in a factory, and you know ... it was very sexist, it was very, um, homophobic, it was, um, you know it was all of those things." Luke and Terry's narratives demonstrate the workplace is not just where a job is carried out, but yet another site where the gay life potentials of places are assessed.

In other cases, men decided to move because they felt unable to come out in the jobs they held. In fact, $33 \%$ of men interviewed (16 respondents) identified issues of coming out at work as somehow related to their migration decisions. As Griffith and Hebl (2002) observe, the decision to stay closeted at work not only increases anxieties 
associated with concealing one's sexuality and "managing" a workplace identity, but also decreases satisfaction with particular jobs and workplaces_often leading to "attrition" and ultimately relocation. Mark, who was teaching high school in western Newfoundland before moving to Ottawa, felt that his employment was dependent on staying closeted. His involvement in a profession already highly subject to public purview was rendered even more precarious by a recent child sexual abuse scandal in St. John's and the "unfortunate connections" he would expect the community to make if his own sexuality was ever revealed.

Um, well as a teacher, uh, I felt a little bit exposed. I met people from time to time and I would have people visit my apartment-I was actually living in a small town outside of Corner Brook, um, for a while, and you know I was feeling, that oh okay, this could blow up in my face at some point. And I just felt a little bit vulnerable ... I couldn't be, couldn't have been out at work, and you know, socially there was a real stigma, I think. And I mean in Newfoundland, of course, the whole scandal with the Mount Cashel orphanage and the Catholic Church and everything did have a chill over, I think, gay issues generally. People, you know, made the connections and ... the unfortunate connections. (Mark, 49, white, Anglo-Canadian)

Mark's position at work, coupled with the smallness of the community in which he was located, prevented him from coming out in any context. With few options available, he decided to go back to school in order to qualify for civil service positions in Ottawa. Pete described a similar fear of "connections" or assumptions based on his sexuality, but in the context of his volunteer work in an eastern Quebec town.

Um, the only issue that I had [in Quebec] is like-um, because I've been playing baseball for many years, I was like coaching some, um young players as well ... and then I was afraid eventually that like something would come out, so that's ... that's one thing I had to do and I quit ... so I kind of like, stopped [volunteering] again around young people because of that. Um, with all the crazy stuff that goes around, like I would not, um say, play with fire; just in case I would like get burned bad ... people can 
make some very easy assumptions, like you're still guilty in the eyes of the public. (Pete, 41, white, French-Canadian)

Both Pete's and Mark's comments describe the self-policing and insecurity associated with work environments rendered precarious by sexual non-normativity. They also reinforce the perceived impossibility of coming out when ostensibly straight identities are intertwined with economic livelihoods or community positions. Rather than risking the rupture of those livelihoods, both men chose not to disclose their sexuality in work or community contexts until moving to Ottawa. As observed in other aspects of gay men's life courses, experiences of work prior to and after relocation were consistently mediated by intersectional subjectivities, such as age and race. Randall, who moved to Ottawa from Halifax, described his experience looking for work in a city he perceived to be discriminatory toward both racial and sexual minorities:

And, um, the double whammy - and well of course in Halifax I wasn't out - but the double whammy of being both Aboriginal and black meant that no matter how clever I was, no matter how good my portfolio was, um, how well I presented myself ... um, I was never going to get a break. And that's just simply the fact of life in Nova Scotia ... but you know, if I had been out, I mean the triple whammy would have been devastating. (Randall, 45, black/Aboriginal, African-Canadian, Mik'maq)

In Randall's case, being openly gay was less a potential threat to any position he already occupied than it was another signifier of difference that would have made entering the job market even more difficult. His experience indicates that gay men may perceive a threshold of acceptable difference in workplace and institutional environments, either in the visibility of sexuality alone (i.e., outness) or in its accumulation with other signifiers of difference. Like Mark, he moved to Ottawa to both continue his education and improve his access to work environments that he expected might be more inclusive. 
In some scenarios, men felt compelled to move because of the nature of the work in which they were engaged. Rick, for example, discussed the challenge of doing HIV/AIDS advocacy work in a city dominated by economic and class configurations that left little space for work related to the health and well-being of minority groups. In particular, he perceived a connection between London, Ontario's industrial economy, its social conservatism, and the difficulty of doing advocacy work:

There's still the 3M, London Life [magazine], moneyed sort of blueblood conservatives ... the reality, practically speaking, is doing social justice work or any kind of advocacy or activism is difficult in London. There was support - but not broad support for the work-for the work we were doing in the community; there was a lot of fracturing in the community. I mean London has a serious history with, um, homophobia beingcoming - from the municipality, particularly in the nineties under one particular mayor, and so that has rendered a city with very little sense of community-LGBT community. (Rick, 27, white, Anglo-Canadian)

Collectively, these narratives suggest not only a desire for workplaces that are safe, secure, and supportive toward non-normative sexualities, but a desire to live in places with a diversity of sectors that are inclusive of multiple gender and sexual identities. Although the largest metropolitan areas in North America, such as Toronto and New York, might seem the most likely destinations for gay men seeking economic security and inclusion, the following case studies of Ottawa and Washington, D.C., reveal that the economies of capital cities — and particularly the presence of a large public sector-have acted as powerful attractors for gay men and other queer people.

\subsection{Seeking Security: Discursive Constructions of the Capital City}

While men's reasons for leaving the various employment and community positions they occupied — and the places in which they were located — were relatively 
straightforward, their decisions to come to the capital city are less intuitive. Why, when the dominant assumptions about gay men's locational decisions are related to city size and a variety of cosmopolitan amenities, would they choose to come to two mid-sized cities (about 600-700,000 residents in each, metropolitan area not included) that are more known for histories of conservatism and regulation (Johnson 2004; Andrew 2007; Paris and Anderson 2007; N. Lewis 2011) than for their culture or inclusivity?

It seems that the capital city has emerged as a site in which gay men can secure their livelihoods in the midst of an otherwise insecure and uneven landscape of policies and practices aimed at regulating or suppressing sexual non-normativity. For some men, security was conceived in purely economic terms, such as higher, steadier incomes, clear pathways for training and promotion, and guaranteed pensions. Some men's migrations were motivated by inter-regional disparities in employment opportunities, such as those between Ottawa and the contracting economies of Newfoundland and Nova Scotia or between Washington, D.C. and declining hi-tech clusters such as Seattle following the dot-com bust. In some cases, long-term relocation to the capital city was based more happenstance than pre-planned decision; one- or two-year stints in the government sometime became permanent arrangements — what some men called being shackled by “the golden handcuffs.” More frequently, however, men's motivators for seeking employment in the government sector were intertwined with their sexuality.

Forty percent of the men interviewed (20 respondents) attributed their migration decisions to a desire to work in the government sector, making it one of the most common themes in the entire study. For a few, moving for a government job was based on economic concerns they associated with gay men's life courses. Sam (44, white, 
Anglo-Canadian), who moved to Ottawa from Montreal, felt that a high-paying, stable government job was a means to meeting life goals such as home ownership in the context of unlikely marriage and living on a single income. For most, however, the security of the capital city was framed in a number of discursive ways. Among men who had moved to Ottawa, the civil service was frequently described as an institutional reflection of Canada's nationally articulated position on gay rights. They acknowledged that while the inclusion and acceptance of sexual non-normativity in Canada was perhaps more socially and spatially uneven in practice than in terms of law, Ottawa and the civil service represented places where the federal vision of gay rights would be most likely to be carried out. According to Mark, moving to Ottawa in the 1990s to work in the federal civil service was a way of assuring access to some of the rights and protections that Canada had recently granted to gay men, lesbians, and same-sex couples.

So I think generally the federal government is ... is progressive. You know, a number of health benefits came in, oh I don't know, ten, twelve years ago probably ... so my partner's been getting benefits - dental and health benefits-for a long time. And, so, that came about without any real issues. You know, I think that there was a Supreme Court-it did, it, was court-mandated at one point—but, you know, nobody really raised any hackles as it were. (Mark, 49, white, Anglo-Canadian)

And the government in the end has been accepting whereas private companies-even though they are accepting in smaller towns, obviously - are ... you'd be the weirdo where in [Ottawa] you're sort of the mainstream. (David, 55, white Anglo-Canadian)

Men who had moved to Washington, D.C., in contrast, referenced the importance of institutional atmosphere and general "way of doing things" in the capital city itself, rather than to the official policies of U.S. government agencies, which—as previously noted-are more "patchwork" in their protections of gay rights. Adam, who had moved from Ohio to Washington, D.C., for a civil service job transfer, explained that while the 
federal government had afforded rights and benefits to gay men in both places, the social and cultural contexts of Washington, D.C. were important to his everyday inclusion within a federal system that was "not standardized" geographically:

I don't think [being gay] hinders advancement at all in this city—I think it might in other cities-I think federal service is much more tied to where you're living and where you're working than people think; it's not standardized across the country, necessarily, but in D.C. there, there's a flavor of that, that it's very comfortable to have gays working without any issues in just about every federal agency, I think ... but I didn't get a sense of that in Ohio. (Adam, 34, white, German-American)

Nick (26, white, Eastern European-American) had considered similar factors when looking for a job with the National Weather Service. "The idea that if I got that [North Dakota] job, my god ... I mean, there's no gay people up there ... like I went on [the social networking site] gay.com just to see if there was any gay people and there was one other gay person ... I'm going keep in mind that I want maybe something more affordable but also something that is gay accepting." Nick's narrative demonstrates not only that gay men use the perceived "presence" of a gay community to gauge the cultures of potential workplaces, but also that the perceived absence of other gay men can overturn migration decisions that would be otherwise logical in terms of finances and career trajectories.

Men assessed the potential inclusivity of Ottawa and Washington, D.C., in various ways, including their discursive construction as white-collar cities and as sites of political protest and the negotiation of identity. For example, 17\% of men interviewed ( 8 respondents) drew a connection between the high education levels of the capital city, the dominance of its professional (i.e., white collar) sector, and the presumable social acceptance of sexual non-normativity. Just as some men used friends' experiences to gauge the social potentials of places, others employed historic and demographic 
descriptors to assess whether Ottawa and D.C. were cities that could provide secure, long-term economic futures. Connecting high education and income levels to social awareness, many men reasoned that Ottawa and Washington, D.C., were places in which they could build careers and develop community identities. "People [in Ottawa] are more educated," said Sebastian (42, white, Métis, French-Canadian, Mik'maq). "Like, it’s definitely a middle-class, educated, cultural city for its size. I would guess there's [sic] a high percentage of university-educated people here.”

For some, the high education levels and incomes of Ottawa and Washington, D.C., were simply “qualities of place," that Florida $(2002,2005)$ and others have positioned as attractors for a variety of workers, irrespective of their sexual identity. Drawing a comparison between Ottawa and D.C., David observed, "[Ottawa is] distinct, yes - parallels to Washington - where you have the seat of government, where you have a population that's clearly white-collared and highly educated for starters, and a very secure work force that has a constant income base ... and you have institutions of that government or the country that are national cultural icons ... you're going to have an attractive, fascinating labour force" (David, 55, white, Anglo-Canadian). Adam even invoked the link between sexual non-normativity and the "creative economy" that has recently, and problematically, become concretized in urban development literature (Lewis and Donald 2010):

I just think that, that gay men tend to be attracted more toward, um, jobs in politics, in law, in, um, I don't know, academic institutions, which we have a lot of here, um, I guess government, too, perhaps. Um, but there's ... no like industrial feel to the city at all, there's no manufacturing at all, there's no, any of that, so I think that might have something to do with it, too. I think gay men tend to be attracted more toward like the, um, the creative kinds of jobs. (Adam, 34, white, German-American) 
Although Adam's comment suggests that sexual non-normativity is perhaps more accepted in service-based than industrial sectors, this is more likely related to the more flexible gender norms of these sectors (see McDowell 1999) than to some inherent link between sexual non-normativity and creativity. If anything, it suggests that gay men employ popular discourse — and even academic discourse — as referents for their decisions about where to live.

Other men provided somewhat more nuanced explanations of the relationships they perceived between education, class, place, and their individual security. Mark (49, white, Anglo-Canadian) described the education and awareness as antidotes to the perceptions of threat that might generate anti-gay discrimination in other places: "I felt that people [in Ottawa] were educated and aware enough that they're not going to be threatened." Terry, however, offered a more complex interpretation of the capital city, acknowledging that even a place with an assumed baseline of social acceptance was still susceptible to ruptures of homophobia: "I mean it's not to say that Ottawa is not homophobic, but ... there's just a lot of it in a blue-collar city ... whereas, you know when you're in a whitecollar city people are more educated" (Terry, 40, white, Flemish-Canadian). Although these explanations are fuzzy, and may even reflect an internalized liberal discourse of education and tolerance, they acknowledge the ways in which mundane qualities of place (as opposed to, say, gay cultural significance) can define certain cities as gay-positive.

For many men, it was the capital-city status of Ottawa and Washington, D.C. that had rendered them desirable destinations. Among the $27 \%$ of men (13 respondents) who discussed how political institutions affected their decisions to come to Ottawa or Washington, D.C., several felt that the influence was discursive rather than job-related. 
Much like the "white-collar city," the notion of the political and socially conscious capital was invoked by drawing a connection between political enlightenment and a gaypositive environment. Chad (35, white, Anglo-Canadian) observed, "I would assume a lot of, uh, gay men and women probably gravitate to Ottawa just because of the social aspect, the social consciousness of Ottawa. Like I think it's ... I don't know if I'm here by accident or [on purpose]. Echoing the findings of other chapters, Chad, unsure of whether he is in Ottawa by accident or on purpose, indicates that gay men's locational decisions are sometimes based on fuzzy, instinctive perceptions of places than on careful cost-benefit analyses.

In yet another type of discursive construction, men imagined the capital city as a site where struggles over identity and inclusion were waged. In this way, the capital city was understood as a place where minority groups like gay men could actively influence their inclusion at the national level. Shane (27, black, African-American), for example, observed that gay men's moves to Washington might be driven by a sustained "awareness" of the government and a desire to participate in it: "I think that when you're a minority, your relationship to government and advocacy, I think, is a very complicated but, it's a very_-I think you're very conscious of it ... I mean, if you are not—if you don't have your full rights - you're aware of the government and how it can have an impact on you, and so I think that being in a place like D.C. is going to draw gay people 'cause I think it's a very important part of, uh, our experience." Although the narratives of Shane and others usefully demonstrate the various ways in which a "capital city imaginary" has been constructed among gay men, they do not address some of the more practical ways in which the reconfigured North American capital city might be attracting increasing 
numbers of gay men and other queer people. The following sections discuss how Ottawa and Washington, D.C. - and particularly the government sectors within them- have been "queered" through (1) changes in legislation and workplace practice and (2) the accretion of tertiary and auxiliary gay organizations, (3) synergies of the government and advocacy sectors, and (4) social dynamics that have embedded gay men and other queer people in the institutional frameworks of these cities.

\subsection{Queering the Capital City Economy}

The intersections of (homo)sexualities and urban economies beyond gentrification and land markets have only recently been investigated by geographers. Landmark studies such as those by Binnie and Skeggs (2004) and Bassi (2006), however, tend to focus on the collection of restaurants, retail outlets, nightlife spots, and associated services that have generally come to be understood as the gay economy (G. Brown 2009). The following narratives show that the economies of Ottawa and Washington, D.C., and particularly the public service and non-profit sectors have become queered in ways that suggest a gay economy extending beyond the ways in which it is typically conceived (see G. Brown 2008, 2009) ${ }^{9}$. Given the fraught relationship between federal governments, public service work, and the regulation of sexual minorities in the post-World War II era (see Chapter 9), the growing visibility of queer people in the Canadian and U.S. federal governments is somewhat surprising. During the 1950s and 1960s, when McCarthyist principles of "national security" dovetailed seamlessly with the regulation of sexual minorities and other threatening sub-populations, gay men (and men believed to be gay)

\footnotetext{
${ }^{9}$ Here, the term queering is used as a verb to denote the process through which historically or presumptively heteronormative spaces such as the civil service have been complicated by the acknowledgement of sexually non-normative identities.
} 
were routinely expelled from government agencies in both cities (D'Emilio 1983;

Robinson and Kimmel 1994; Kinsman 1995). Homosexuality was not only conflated with other "fringe" and "deviant" categories (see Olund 2010), such as "Communist," but recast as grounds for denying security clearances - usually on the premise that gay men were either morally bankrupt or likely to be blackmailed as public servants (N. Lewis 2011). The following narratives suggest not only that government work is now less precarious for gay men, but also that a new type of gay economy has coalesced around the civil service, its auxiliary gay and lesbian organizations, and the related clusters of advocacy organizations in both cities. As a result, Ottawa and Washington, D.C., have emerged as new sorts of gay homelands marked by political visibility, career development opportunities, and the formation of community identities later in life.

\section{5-1. Legislative and Policy Changes}

The reconfiguration of the civil service as a gay-inclusive sector in Canada and the United States has been galvanized by legislative changes in both countries. In Canada, recognition of sexual difference the public service has typically come in the form of topdown policies at the federal level. The Government of Canada has determined in federal court cases (see Smith 2005a) that sexual orientation is an immutable characteristic under which equal rights must be granted (Egan v. Canada 1995) and that partner benefits must be afforded to gay and lesbian people in both the public and private sectors (Rosenberg v. Canada 1998). In general, men who had come to Ottawa to work for the federal government were attracted by the safeguards against anti-gay discrimination in that sector. As Adrian (56, black, African-Canadian) observed, "The various support 
mechanisms ... within the [Canadian] government ... are all there.” Chad (35, white, Anglo-Canadian) agreed, “... in the workplace we have a series of —at least in the federal workplace — we have a series of rules that dictate [non-discrimination] ... and I think the other big issue that really is ... is that people understand what the rules are, and people know what their rights are." While the actual experiences of Canada's "baseline" of inclusion are geographically variable, these men expected that in Ottawa-and particularly in the government sector-this baseline would be upheld.

In the United States, where equal rights for queer people have historically been negotiated from a baseline of rights denial (e.g., state anti-sodomy laws and the Defense of Marriage Act), rights for queer employees have rarely been universal (Lind 2004). The Foreign Service, however, was one of the first sectors in which same-sex partner benefits received federal recognition. Arthur, who moved from Virginia to Washington, D.C. for a job with the Department of State, discussed the transformation of the Foreign Service from a site of numerous expulsions of gay men during the McCarthy era to a far more gay-inclusive agency:

We've come - particularly under [Secretary of State Hillary] Clinton-a long way since [the 1950s and 1960s]. Um, we just had a major ... um, Obama's executive order about, you know, [travel and relocation] benefits and so on, which really didn't do anything for most of the federal workforce, but it did a lot for the Foreign Service. Because we're constantly relocating and whatever else, for the first time, partners have diplomatic passports and can get diplomatic visas and status and interviews from the host government, which they couldn't before. They can now travel with us on official orders and have their airfare paid for and be medically evacuated if there's a problem, and they're considered actually dependents now whereas they weren't before. So, for your average Foreign Service officer, per like reassignment, that's probably five to ten thousand dollars, right? (Arthur, 30, white, EuropeanAmerican) 
At the same time, Arthur noted the absence of this type of recognition in other government agencies and observed that his agency's policies, while progressive, are tenuous and subject to change: "The Department [of State] does have a policy of nondiscrimination but it's not rooted in law." Although the forthcoming narratives here and in Chapter 9 show that the U.S. and Canadian federal governments are by no means unequivocally inclusive, the narratives of Adrian, Chad, and Arthur highlight some of the significant legislative and policy changes made in the past two decades. Yet, they also highlight geographic differences in how security is conceived. In Ottawa, working for the federal government is a means of locating oneself in a place where ostensibly universal federal legislation is most likely to be implemented in practice. In Washington, D.C., government work is deemed less an assurance of security because there is no baseline of inclusion in either the U.S. federal government or the United States itself. In both cities, and especially Washington, D.C., the informal ways in which a gay economy has been established are perhaps more important in the attraction of gay men to these cities and their day-to-day experiences of inclusion.

\section{4-2. The Emergence of Gay Workplace Organizations}

Given the sometimes uneven nature of official workplace policies and practices in Ottawa and Washington, D.C., many men attributed more value to the informal ways in which the capital-city economy has become more gay-inclusive. The emergence of auxiliary and tertiary organizations within government (and non-governmental) agencies that serve as modes of organizing and socializing for gay employees have been central in this transition. The fact that many men in Ottawa referred to Public Service Pride (PSP) 
network as both the most important workplace-based gay group and the largest, most influential gay organization in the city, suggests an increasing confluence of governmentsector work and the social and political livelihoods of gay men. Rick (27, white, AngloCanadian) described the PSP's monthly social event: "It's like the largest gay event in Ottawa is when the gay public servants have their monthly thing and they get ... like 200 people or 250 people out ... for that to be a very specific event, and also a very specific regular event, to have the regular attendance in the hundreds in Ottawa is like, you know you just don't see it at any other event, you know, except for the public servants."

Washington, D.C. lacks a similar umbrella organization for civil servants, but many of the men interviewed participate in gay organizations within the Department of State, World Bank, International Monetary Fund, several universities, and a host of other workplaces. These groups, they observed, have not only solidified the visibility of queer people in the public service, but have also acted as advocates and watchdogs for gay rights. Max explained that the gay and lesbian group he participates in at the U.S. Department of Justice (DOJ) regularly intervenes in the practices of the department, despite an ongoing need for the group to "decide what it is" since the limitation of its functions during the Bush administration.

Well, it's social, but it also, whenever like the DOJ does something nasty ... like I mean there was an [issued public opinion opposing gay marriage] so we wrote a sort of letter of concern to the Attorney General about that; and in some ways, I think the, the group at DOJ is still deciding what it is, because ... a lot of its functions were banned under the Bush administration, they were not allowed to meet on government property during the Bush administration. (Max, 31, white, EuropeanAmerican)

Even while sometimes operating in an ad hoc fashion, these informal organizations have been central in helping gay men to navigate positions in which 
expected protocols and practices are unclear. Due to the U.S. government's frequent silence on the issue of sexual non-normativity, men are often left to their own to determine the boundaries of "out-ness" in contexts that may be hostile to sexual nonnormativity. John described how gay and lesbians foreign servants in Washington, D.C., employ the Gays and Lesbians in Foreign Affairs Agencies (GLIFAA) organization in Washington, D.C., as an information-sharing network:

Basically, the way it works is that we all recognize life is not easy. Therefore, the gay Foreign Service officers have an informal network to help each other out. They identify jobs that are open that have gayfriendly bosses or even try to help people get positions in the nicer locales (i.e., Europe, certain areas of Asia or South America). You see the way the Foreign Service works is the reputation that you have. Because of GLIFAA, there is a network to help you. As long as you aren't a jerk, the other officers will watch out for you ... if you take a position in a hardship post (i.e. Baghdad, Kabul, etc.), the GLIFAA members form a small community. I mean, how could you not? It's not friendly place for openly gay males ... lots of repression from the soldiers who get annoyed even if you look at them funny. So it becomes natural that a lot of the gay men hang out together for solace, companionship, and sanity. (John, 33, white, Italian-American, personal communication)

While groups like GLIFAA on one hand represent the "queering" of a sector that historically has repressed sexual non-normativity, they also represent an ad hoc addenda to agencies that have not fundamentally changed in their day-to-day practices of including sexual difference. In Washington, D.C., in particular, public-sector and nonprofit gay workplace organizations appear to facilitate the work of openly gay public servants, but do not always succeed in—or even aim to—effect political change.

\section{5-3. Synergies of the Government and Advocacy Sectors}

The capital-city gay economy includes not just the public service and its auxiliary gay professional organizations, but also non-governmental gay service and advocacy 
organizations and their various interdependencies with the government. The main national gay rights organizations in North America, Human Rights Campaign and Egale (now located in Toronto) have long been fixtures in the protests, court cases and lobbying activities that take place in Ottawa and Washington, D.C. Consequently, they were central in recasting national capitals as the centers of national gay rights-seeking agendas (N. Lewis 2011). As Jake (35, white, Jewish-American) observed, "Certainly when the D.C. marriage fight came up, it was a lot more convenient for all these groups to be involved 'cause it was their backyard." In some cases, men had moved to Ottawa or Washington, D.C., specifically to work in gay rights organizations. Jake, for example, moved to D.C. for a long-term career in advocacy:

I was sort of non-profit, advocacy-minded and wanted to be in a place that would be supportive of that ... the first job was working for. ... Results, the non-profit grassroots citizen's advocacy organization working to create the public and political will to end hunger and the worst aspects of poverty. ... And then I worked for the Human Rights Campaign for a couple years. ... And then I worked for Equality Maryland for five years, starting as the sole employee and then working my way into like a six-person organization with multiple consultants and lobbyists. (Jake, 35, white, Jewish-American)

While Jake benefited from the diversity of advocacy organizations found in Washington, D.C., Rick chose to work in Ottawa specifically because of the linkages between the advocacy and policy sectors. "And certainly when I was coming here, that's what I was thinking ... a great opportunity to be in an activist organization in a very political city ... it is a good city to sort of see how change happens, how shifts in thinking kind of work their way through the different levels of government, so I think, yeah, it provides that opportunity" (Rick, 27, white, Anglo-Canadian). Incidentally, at the time of his interview 
Rick had transitioned from working in a gay health and advocacy non-profit to working as a legislative assistant on Ottawa's Parliament Hill.

Other men participated in service and advocacy groups on a volunteer basis, sometimes employing the skills that they used routinely in government-sector positions. "I volunteer a lot," said Randall (56, black/Aboriginal, African-Canadian, Mik'maq), who worked as a graphic designer for a federal environmental agency. The advocacy group, Egale ... I did some pro bono design work for them, two years running. Then, um, there is the, uh, [gay health and counseling organization] Pink Triangle Services, and I did some pro bono design work for them two years running." For Marshall, the volunteer sector in Washington, D.C., provided ample opportunity to apply skills he had developed while working in various health organizations.

I always like go in and out of them whenever I'm in the different work environments. I worked in HIV prevention for two years, so I worked both on an HIV group at work, but then also I volunteered at WhitmanWalker [HIV/AIDS clinic], that was relevant ... I worked at the Red Cross, and then I have also volunteered as disaster action volunteer ... and I've worked at like the Capitol Food Bank, and so I've done a couple of like one-off kind of projects, and sometimes they're gay organized, but they're not necessarily ... even gay organizations. (Marshall, 29, white, Italian-American)

As Marshall suggests, the interactions between the government and advocacy sectors in Ottawa and Washington, D.C., create entrées into the gay community for many men. For Sam (44, white, Anglo-Canadian), who moved from Montreal to Ottawa in his early thirties, volunteering was how he decided to make connections within the community after realizing that Ottawa's gay life was not centered around the same sort of nightlife-oriented, village-based configurations he had experienced in Montreal. In addition, he felt that it was an important part of establishing a community identity at an 
age when frequent nights out on the town no longer felt sustainable or appropriate. "I had started to volunteer in the community," he said, “... was on the steering committee for an HIV/AIDS study, was working with the local chapter of Egale Canada, and so realized that, through that work even, there were a lot of connections to be made." These accounts reflect not just the density of federal and local gay organizations in these two cities, but the ways in which gay men's identities and interests have led them to opportunities that cross-cut the public service, non-governmental and volunteer sectors.

\section{5-4. The Network Effect: Social Dynamics of the Capital-City Gay Economy}

While policy changes, the creation of gay workplace organizations, and the growth of government-advocacy synergies have all contributed to the emergence of a type of alternative gay economy in Ottawa and Washington, D.C., gay men's lives in these cities are perhaps more affected by the collective social impact of these changes than by any single development. In these "government towns," respondents found not just a relative assurance of economic security in a precarious landscape, but also a social and cultural life driven by institutional configurations.

Twenty-one percent of men interviewed (ten respondents) indicated that networking and socializing was an important consideration in where to live and a central part of their daily lives. They described the large number of gay men in the government sector, coupled with the corollary set of gay institutions as a "professional network" (Anthony, Chad), but also a "club" (James), and the basis for a "built-in social life" (David). It was this network, many said, that provided the greatest assurance of successful career development. Invoking a common social capital argument, many men 
argued that the relative advancement of gay men in the government sector, coupled with professional and social linkages, serve to concretize their integration into the civil service. In this way, sexual non-normative identities became "beneficial" rather than precarious. Wally (43, white, Anglo-Canadian) observed that he not only had several gay managers, but mentors who guided him through work environments that were less gaypositive when he began his career in the Canadian government 10 years prior: "The reality ... no, when I look back on it ... Just like I don't believe being gay is holding myself [sic] back here. If anything, my career has demonstrated that it's actually turned out to be a benefit." Anthony felt similarly about his career in Ottawa:

Even in terms of work, I find that being gay ... you meet people, you have a larger professional network, and I think that it's an advantage to be gay in many regards, you know, in a career work setting ... I didn't have that advantage in a smaller center, um, I didn't have other gay colleagues. And I wouldn't say that having gay colleagues, I was favored to any great extent but at the same time you have a natural connection to those people and therefore they pay more attention to your work style, your work ethic, your reputation and, I mean ... it's all about who you know, right, in addition to what you know. (Anthony, 29, PolishCanadian)

These types of networks not only serve to solidify gay men's position in the civil service, but may also have positive spillovers into other segments of the so-called gay economy. Arthur (30, white, European-American) observes, "I mean [gay professionals in Washington] ... it's like a network, a professional network basically, and I do think people here are much more likely to support other gay-owned businesses or restaurants or what have you, or realtors."

The fundraiser, which has become a fixture of social life among gay men in both Ottawa and Washington, D.C., is another example of this type of community reinvestment. Adam (34, white, German-American), "There are so many, uh, 
organizations that people work for that require [fundraisers], so, you know, all these NGOs that are out there and, um, charities, things that are based in D.C. You know, I, I probably have 25 or $30 \%$ of my friends [who] work in that field. So they're always having fundraisers ... so it's just part of the culture in D.C., I think-more so in D.C. than anywhere else I've seen.” Jake agreed, “... it benefits the local community to have [gay organizations] here partially because there's a never-ending array of fundraisers to go to - which is either a benefit or a curse depending on how you look at it — but certainly, there are community-building things that these community organizations will do locally." In this way, the geographic placement of national gay and lesbian organizations such as the Human Rights Campaign and Egale Canada has led to the formation of a distinctly national-cum-local set of networks and economies that offer opportunities for community-building and diverse (albeit institutionally defined) means of reinvesting in local and national gay interests.

\subsection{New Migrations, New Homelands}

The narratives discussed in this chapter challenge a number of dominant portrayals of both queer migration trajectories and the related idea of the "queer homeland." First, the centrality of political and economic security in men's migration narratives suggests that ultimately, often later in life, the influence of sexuality on migration becomes less about the formation of a gay identity and more about the advancement and sustainability of professional, family, and community life potentials. In this sense, relocation for gay men is less a wandering identity quest than it is the search for security in an inherently precarious landscape of policies and practices affecting gay 
livelihoods. Despite different national contexts of rights in Canada and the United States, respondents consistently pointed to the capital city as somewhere that workplaces (e.g., federal agencies) are more likely to offer protection from discrimination and where clear opportunities for community participation are offered. This was due not only to discursive understandings of educated and white-collar cities as gay-positive places, but also the ways in which the government sector itself is understood as a gay environment. As Jason (26, Asian, Thai) observed, "I think [D.C.] has really come to terms that the city is pretty much run by a lot of gays ... we're pretty competent at what we do ... so if you take gays out of D.C. it would be a weird place, you know."

Second, the findings here complicate both the concept of economic migration and the separation of economic migration and queer or "sexual" migration. The narratives show that among gay men, even moves that might otherwise be termed "economic" (i.e., responses to pushes and pulls such as unemployment or job opportunities) are still mediated by sexuality. For some men, the professional positions they had held in one location were rendered insecure because they felt compelled to stay closeted in their workplaces and communities. For others, moving to Ottawa or Washington, D.C., to work in federal government agencies provided greater career security than where they had worked previously, particularly because of the transformation of policies and practices in those institutions during the past two decades. This is not intended to imply that sexual identity was always central in men's economic relocations- they may not even have identified as gay or been out at the point at which they moved — but to acknowledge that non-normative sexual subjectivities still influence migrations that might not typically be termed queer migration. The objective, then, has not been to read 
sexuality into the migration narrative, but to productively uncover some of the ways in migration might be used to negotiate unevenness and inconsistency in the landscape of professional and economic opportunities for gay men.

Similarly, this chapter complicates concepts of the "gay economy" predicated on nightlife, cultural amenities and social services. In showing how government work in North America has (1) been formally and informally transformed in ways that acknowledge and include sexual difference and (2) coalesced with related sets of institutions and organizations, this chapter suggests that gay economies are fluid assemblages with "diverse" practices and institutions, profoundly shaped by the cities in which they are located. More specifically, Ottawa and Washington, D.C., represent variants of the traditional government-military complex in which sexual non-normativity is now frequently acknowledged rather than repressed. Both cities have emerged as sites where gay men and lesbians have waged campaigns for political equality and created meaningful and increasingly public day-to-day economic and professional identities in institutions once considered hostile to sexual non-normativity. This is due not only to internal changes in the civil service, but to the emergence of corollary institutions that have aided and sustained the career trajectories and professional networks of gay men.

The particular type of gay economy found in Ottawa and Washington - and the ongoing migrations that have contributed to it and been generated by it —also suggests the emergence of a new type of queer homeland that extends beyond the definitions that have typically been offered. During the past century, queer homelands, almost always large metropolitan areas, have been rooted in historical particularities that helped create urban queer communities (e.g., the Industrial Revolution), struggles for gay rights (e.g., 
The Stonewall Riot) or more general countercultural movements (Chauncey 1994; Weston 1995; Aldrich 2004). Consequently, San Francisco, New York, and other cities concretized as homelands are significant yet perhaps antique representations of queer communities in North America. Notions of homeland based on consumption are equally problematic. In the 1980s and 1990s, increasing visibilities of queer (usually gay and lesbian) identities and branding tools (e.g., villages, parades, and festivals) use to market them, created a new breed of homelands rooted in capturing the pink dollar (Puar 2002; Binnie and Skeggs 2004). Ottawa and Washington, D.C., mid-sized cities with limited histories of grassroots activism and relatively little branding of gay venues or neighbourhoods, do not fit neatly into either of these categories. Yet they also defy assumptions that cities without overtly gay or queer identities are inherently heteronormative. Both Ottawa and Washington, D.C., have emerged as a third type of homeland anchored in institutions rather than historical events or commercial venues.

The obvious gaps in this discussion are the dual processes of privilege and exclusion that operate in this new type of homeland. The institutions and organizations discussed here — as well as most of the respondents whose narratives are sharedrepresent an educated and economically secure vision of gay migrations and economies. Access to professional positions in the civil service, international organizations, nongovernmental organizations, and advocacy and fundraising organizations typically require university degrees. Both cities are known for their high cost of living, and particularly for high rental rates. Similarly, the networks through which professional advancement occurs are not unequivocal sources of liberation or community-building, but also loci of power through which certain identities (e.g., responsible civil servant) are 
promoted while some men are excluded based on education, class, or professional position. The following chapter provides this much-needed rejoinder by analyzing how configurations of institutions in these cities have also acted as disciplining, regulatory bodies. To some extent, they have created gay communities that, while substantial, are markedly different from the politically progressive, visible communities associated with the queer homeland as it has traditionally been conceived. This final substantive chapter shifts away from the nexus of migration itself to focus on the everyday experiences of gay men who have moved to and live in these "government towns." 


\section{CHAPTER 9}

Gay in a Government Town: Experiences of Relocation and Regulation

\subsection{Introduction}

Capital cities, traditionally seen as legislative hubs and military command posts, are also places that impart day-to-day ways of being influenced by the routines, procedures, and decorum associated with the government sector. These modes of conduct have both a strong and a unique effect on gay- and queer-identified individuals and communities. Much of the recent work in queer geography (Markwell 2002; Binnie and Skeggs 2004; Nash 2005; Prior 2008) highlights the city as an important site of identity formation, political opportunity, and social organization for queer people, and frequently studies places with highly visible, established, and historically rich queer communities such as Sydney, New York, and Toronto. Many have complicated this narrative by examining how these traditional gay centers — and even the gay villages within them — are often "paradoxically" comforting yet isolating or even oppressive for the queer people who live in or near them (Rose 1993; Valentine and Skelton 2003; Ray 2004).

Increasingly, geographers are turning their attention to de-centering sexualities (see Phillips et al. 2000) by examining the lives and experiences of gay men who live outside of the largest urban centers (Waitt and Gorman-Murray 2007; Visser 2008; G. Brown 2009). This chapter further answers calls to expand the range of gay spaces studied by geographers (G. Brown 2008) by assessing the formation and evolution of gay communities and spaces in two mid-sized, non-primate capital cities enmeshed in state institutions and characterized by complex — often competing — scales of policy, identity, and belonging. In an exploratory, comparative case study of Ottawa, Ontario, Canada, 
and Washington, D.C., U.S.A., this chapter explores how "the discursive contours" of states and their capital cities attempt to control intimacy, rate and assess particular sexualities, and contribute to the formation (or fragmentation) of gay communities (Howell 2007, 292-294; see also Cooper 2006; Oswin 2010; Olund 2010). The tropes of the "government town," and particularly the national capital, often attract gay men through an appeal to security in the form of high-paying work, non-discrimination mandates, and their status as centers of advocacy activities, such as right-seeking court cases (Ottawa) and fundraisers and protests led by the Human Rights Campaign (Washington, D.C.). Yet the government town also disciplines gay men to approach their inclusion as sexual citizens in a normalized, compartmentalized, often non-public, nonactive way (Cooper 2006).

I ascribe this finding to two mutually constitutive factors. First, the densely packed government institutions in both cities are historical and current focal points of disciplinary power and regulatory mechanisms (i.e., governmentality) that have often targeted gay men. Second, the distinctly national and usually rights-based mode of organizing - as opposed to transgressive or radical forms of grassroots, collective action - that have centered on Ottawa and Washington since the 1980s encourage gay men to present themselves as responsible, disciplined, and as similar as possible to their heterosexual counterparts. Consequently, there is a tension between rights and opportunities articulated by the Canadian federal government (and to a lesser extent, the United States and D.C. governments) and the on-the-ground disciplining and regulating (or self-disciplining/-regulating) of gay men working both inside and outside of the federal government. These tensions are more pronounced in Ottawa and Washington, 
D.C., than in larger, more economically diverse cities such as New York City, Toronto, and Montreal. By examining the direct role of these cities' institutions in social organization, community formation and day-to-day conduct among gay men, this chapter adds an additional layer of analysis to important work linking the normalization of queer activism and sexual citizenship to intermediate forces such as neoliberalism (Duggan 2002; Smith 2005). As such, this case study is an answer to recent calls (see Lemke 2007, 56) to re-investigate the state itself as an integral instrument and effect of governmentality practices—not just a foundation of them.

In a project focused on migration decisions and journeys, the particularities of life for gay men in "government towns" were not originally anticipated as key thematic concerns. Ottawa and Washington, D.C., had been chosen as destination study sites mostly because of their lack of attention in the broader literature on queer migrations and livelihoods and the author's lived experience in both cities. After the interviews in Ottawa were conducted, however, it was clear that the dominance of government in these cities had not only had a palpable effect on men's migration decisions - as discussed in the previous chapter-but also on their daily lives. About $60 \%$ of the respondents were working or had worked in the federal government, and their interviews have provided much of the qualitative evidence used here. Although the interviews had originally been coded for both "economic migration" and "rights and regulations," it was discovered after coding for sub-themes that the same economic and political factors that drew gay men to capital cities had also regulated their lives and communities in particular ways. A more natural thematic divide, then emerged between the attraction of the capital city (Chapter 8) and its disciplining and normalizing effects (this chapter). Key sub-themes informing 
this chapter were the legacies of surveillance in capital cities, the disciplining effects of government workplaces, the normalization of gay activism, and the limited visibility of the gay community (see Table 9.1).

Table 9.1. Sub-themes related to Rights and Regulations, Sample of Self-identified Gay Men (N=48), Ottawa, Ontario, Canada and Washington, D.C., U.S.A.

\begin{tabular}{|l|l|l|l|}
\hline Sub-theme & $\begin{array}{l}\text { No. of } \\
\text { passages }\end{array}$ & $\begin{array}{l}\text { No. of } \\
\text { respondents }\end{array}$ & $\begin{array}{l}\text { \% of } \\
\text { respondents }\end{array}$ \\
\hline Legacy of oppression, ongoing self-discipline & 21 & 18 & 33 \\
\hline Normalization and mainstreaming & 16 & 13 & 27 \\
\hline Security associated with gay public life and public figures & 7 & 7 & 15 \\
\hline Economic, gender, and racial exclusion & 11 & 8 & 17 \\
\hline Activism as community identity & 11 & 6 & 13 \\
\hline Activist fatigue & 9 & 6 & 13 \\
\hline Limited visibility & 6 & 6 & 13 \\
\hline Performing homosexuality elsewhere & 6 & 5 & 10 \\
\hline Subsuming local queer politics into national agendas & 6 & 5 & 10 \\
\hline Lack of a village & 5 & 5 & 10 \\
\hline Immigration and marriage rights & 7 & 5 & 10 \\
\hline Connection between politics and non-normative sexuality & 5 & 4 & 8 \\
\hline Transience and disinvestment & 3 & 3 & 6 \\
\hline historic governmentalities & 3 & 3 & 6 \\
\hline Retentive effect of the capital city and public service & 2 & 2 & 4 \\
\hline Community fragmentation & 2 & 2 & 4 \\
\hline Countercurrents or undercurrents to normalization & 2 & 2 & 4 \\
\hline Co-opting gay identities & 2 & 2 & 4 \\
\hline Regional geographic variations & 2 & 2 & 4 \\
\hline
\end{tabular}

This chapter is designed to capture both the macro-level aspects of governmentality in Ottawa and the more individual ways in which gay men have experienced the mechanisms through which governmentality is achieved or leveraged. After briefly explaining some of geographic, historic, and political particularities of both cities, I look at the ways in which they have historically regulated gay men, often through the imposition of technologies or force on individual men's bodies. Next, I explain how ostensibly "liberal" and "progressive" environments - themselves the products of legislative and regulatory reinventions - have attracted gay men to Ottawa while 
continuing to regulate them through the less obvious but routine privileging of certain identities and certain modes of activism. I turn to the micro-level experiences of individual respondents in order to express how these modes of regulation are experienced on a day-to-day basis - a relatively new approach that broadens understandings of the relationships between governmentality and conduct. Interview material related to governmentality and regulation was organized into basic categories of analysis: historic stances and actions of federal governments toward gay men, professional and office environments, the role of government in the social lives of gay men, and perceptions of gay community formation and infrastructure. These comments indicate that regulation has contributed to a fragmented community in which gay men often embrace government-ascribed practices and identities, consume gay culture outside the city limits to resist these practices, and lack visible geographic and social focal points.

\subsection{Situating and Contextualizing Ottawa and Washington, D.C.}

As centrally planned, non-primate capital cities rooted in various forms of political compromise (i.e., between northern and southern U.S. states and between English and French Canada), Ottawa and Washington, D.C. are smaller, "second-tier" cities that function mainly as government centers. At the same time, the gay and lesbian populations in both cities - at least as measured by the prevalence of same-sex couplesare substantial (see Tables 3.1 and 3.2 in Chapter 3). While the percentage of same-sex couples in Ottawa is similar to that in Toronto and Montreal, Washington, D.C., is similar to Atlanta, New York, and most other large metropolitan areas in the United States, with only San Francisco standing apart from other cities. The percentages of recorded same- 
sex couples, however, are higher in Canada due to less ambiguity in the legality of samesex partnerships (marriage was legalized in 2005) and the ease with which common-law relationships can be reported.

Despite the presence of large gay populations in both Ottawa and Washington, D.C., the communities and contexts in which they are located are markedly different from most cities considered gay or queer homelands. As observed by Dascher (2000), residents of national capitals may hold more political sway, the protests that take place there may have more power, and the tax cuts and subsidies sometimes afforded by the federal government often come first in the capital city. In addition, federally funded public goods, such as museums and arts centers, create locally experienced positive externalities, and information on important policy changes or reforms often circulates through the capital city before other cities (Dascher 2000). The presence of the federal government in both cities, however, is often observed to impede grassroots social movements and local development (Stanfield 1997; N. Lewis 2010, 2011). Since the federal and municipal governments play a role in dictating what the images of both cities should be, image should be, local interests are often muddled by quasi-federal bodies such as the National Capital Commission in Ottawa and the National Capital Planning Commission in Washington (Andrew 2007; NCPC 2011). The marketing, branding, and development efforts that have lent visibility (although in a commodified manner) to ethnic and other "diverse" communities in other cities are therefore more limited in Ottawa and Washington, D.C.

Both cities, due in part to their emergence as sites of national compromise among diverse regional identities, are geographically situated in way that complicates 
understandings of the liberal gay metropolis. Ottawa, located outside the WindsorQuebec corridor that typifies urban Canada, is located in close proximity to much smaller, often politically and religiously conservative communities in both Ontario and Quebec (Moore and Rennie 2006; Andrew 2007). Since 1998, many of these communities have been amalgamated into the city of Ottawa, leading to a fractured political environment in which the development of the downtown core is partially determined by residents who live up to 100 kilometres away. Many respondents also expressed a palpable discomfort with the close proximity of communities whose residents have perpetrated attacks on gay men in Ottawa or led counter-protests during events such as Ottawa Pride (Moore and Rennie 2006).

Washington, D.C., is similarly positioned at the historic division between North and South—diverse regions in and of themselves but marked by dominant cultural characterizations. The northeastern states have typically been cast as urban, Democrat, and industrial/post-industrial, and secular, while the Southern states are often described as Protestant or Evangelical, Republican, and rural. The city is marked by a confluence of these identities - in terms of both the elected representatives and other "transplants" living and working there — and to a certain extent, competition between these identities. As in Ottawa, there is also an ethno-cultural disjuncture within the city, but between highly educated, high-income and usually white newcomers and a more historically rooted African-American population that is largely Christian (e.g., Baptist, Pentecostal, Adventist) and often poor. Over $16 \%$ of families, most of them African-American, live below the poverty line even though D.C.'s median family income of $\$ 62,000$ is well above the national median (U.S. Census Bureau 2000). Pointing out these tensions is not 
intended to cast particular group or identities as inherently anti-gay — many gay men in both cities live in the surrounding suburbs, are partnered, and see themselves as having "typical" households or families — but to highlight the implications of such politically and culturally complex cities for the development of an active, complete sense of sexual citizenship among gay men in both cities.

\subsection{Historic Governmentalities in Ottawa and Washington, D.C.}

Gay men, as residents of a capital cities dominated by government institutions, are perhaps more frequently and directly exposed to their respective states' various modes of governing than those in other frequently studied cities, such as New York, San Francisco, Toronto, and Montreal. The ways in which governments impart a particular type of power or influence through means other than force, law, or individual-level surveillance have been categorized as both governance and governmentality. Governance is a concept emerging from the urban-economic tradition that explains the ways in which states govern not just through legislation and policy, but also through the non-governmental organizations, foundations, businesses, and charitable interests comprising a given jurisdiction (see Isin 2000). Governmentality, on the other hand, is a Foucauldian concept that comprises the modes or tropes through which governments impart a way of being upon their citizens.

Governmentality is leveraged not only through various institutions, but also more importantly through particular apparatuses or dispositifs, such as town planning, vaccination campaigns, and other devices ostensibly intended to promote safety or security (Foucault 1979; Brown and Knopp 2006; Elden 2007, 29-30; Prior 2008; Hutta 
2009). Governmentality is also manifested in particular "inscription devices," such as graphs, schedules, and timetables, which act as powerful depictions of truths or rationalities (Lemke 2007; Huxley 2008). Legg (2005) organizes these modes of regulation into five typologies: (1) episteme, or distinctive and privileged ways of thinking, knowing and expressing truth; (2) ethos, or the distribution and execution of tasks according to the morals or principles of the government; (3) visibilities, or the ways of seeing and representing reality; (4) identities, or the ascription of attributes to a population that render it more governable and connect it to a desired mode of conduct; and (5) techne, or the mechanisms and tools used for regulatory interventions (see also Brown and Knopp 2008; Brown and Knopp 2006). These last three modes, and the last two in particular, have been central in the regulation of gay men in Ottawa and Washington, D.C.

By creating categories and reinforcing them through various tools, the state exercises a bio-political power (as opposed to sovereign, territorial power) over a citizenry that has been reconceptualized as a governable population, or set of subpopulations, rather than a collection of individuals (Schlosser 2008; M. Brown 2009). This bio-power is often enacted in institutions such as clinics, prisons, courts, universities, and police departments, before being re-absorbed and reproduced by society and its conventions, behaviors, comportments and subjectivities (Howell 2007, 304; Huxley 2008). In other words, governmentality is a dispersed form of power-seeking where the ways in which governments think about their citizens ultimately influence how citizens think about and conduct themselves (Huxley 2008; M. Brown 2009). In this way, certain behaviors or actions are recast as "normal" (and thus conducive to the 
preservation of state security), while others are abnormal or deviant. Capital cities, it has been suggested, are not just dominated by the sovereign power of territory, but also highly exposed to the mundane, day-to-day processes of governmentality (see, for example, Stephen Legg's 2007 study of governmentality in colonial Delhi, India).

Queer individuals have long been the target of governments' efforts to recast multiple, unwieldy non-normative identities into definable, readily governable subpopulations (Foucault 1978; Halperin 2000). The concept of homosexuality, which first appeared around 1870, not only collapsed the historically accreted psychological, erotic, and practical (i.e., physical) aspects of sexual identity — and the various types of interpersonal relationships associated with these aspects - it formed a clear divide between a safe, normative, heterosexual population, and a more threatening homosexual population in urgent need of regulation (Halperin 2000; Howe 2004; Oswin and Olund 2010). Although North Americans were subjected to the governing of intimacy in the form of anti-prostitution and public health campaigns for much of the $20^{\text {th }}$ century (see Olund 2010), the Cold War era marked an apex in the moral panic over politically, socially, and sexually non-normative groups. In Canada, Ottawa became central to the government's concerns over internal security, and its spaces and institutions became prime sites to for the expression of control over ostensibly threatening groups of people.

Through discourse, textual constructions, and specific techne such as advertising campaigns, both the Canadian and U.S. governments used the trope of "national security" to forward a broader agenda of moral and social regulation intended to prioritize the nuclear family and domestic tranquility, stamp out deviance, and define what constituted a proper citizen (see D’Emilio 1983; Robinson and Kimmel 1994; Kinsman 1995, 1996, 
2000, 2001; G. Lewis 1997; Gentile 2000; Johnson 2004). Cementing gender identities was central to this agenda. In both countries, national security and effective foreign policy were predicated on the primacy of realist, non-idealistic, and presumably "masculine" thought in the federal government, with women playing supporting roles in the home and workplace (Gentile 2000; Johnson 2004). For example, the Miss Civil Service pageants conducted at various government branches in Ottawa were not only a means of selecting recruiters for a female work force, but also a way to create a professional, attractive female counterpart to the strong responsible, masculine "government men" and "fighting men" serving their country in bureaucratic and military endeavors (Gentile 2000). In both cities, individuals who did not conform to these norms or demonstrated other indicators of "gender inversion" were considered incompatible with the security agenda, and — in the case of gay men — were even considered inherently criminal (D’Emilio 1983; Kinsman 1995, 2000; Johnson 2004). In both Canada and the United States, the capital cities emerged as the primary sites where the resultant wars were waged against populations of gay men perceived as threatening.

In Ottawa during the Cold War years, the Royal Canadian Mounted Police (RCMP) and a non-public national security panel investigated and subsequently fired numerous presumed homosexuals from the civil service in the 1950s and 1960s. The purge operated under the premises that (closeted) gay men — whose sexual practices were already deemed criminal—were easier to blackmail, generally of "weak character," and inherently connected to other peripheral or radical social movements such as Communism. By the late 1960s, the RCMP had collected over 9,000 files on presumed homosexuals, mostly living in the Ottawa area. In their efforts, the police created a map 
of Ottawa - a particular visibility of the bio-power exercised at the time - that designated supposed (and highly numerous) sites of homosexual activity. The RCMP also deemed particular branches of the civil service, the Department of External Affairs and its embassies in particular, to be "cesspools" of homosexuality (Kinsman 1995, 142). The RCMP officers who conducted the investigations were often untrained in security matters but deployed many so-called identifying techniques to identify homosexuals. These included public opinion analysis, i.e., hearsay, interrogating terminated civil servants and other ostensibly known homosexuals, and more "scientific" methods such as measuring the pupil dilation and movement in response to various semi-pornographic images. The latter technology, also known as the "fruit machine," was developed at Ottawa's Carleton University and deployed in Canada until the late 1960s — at least five years longer than in the United States (Robinson and Kimmel 1994; Kinsman 1995).

In Washington, D.C., a strikingly similar war against the "menace" of homosexuality was waged in the 1950s and 1960s (D'Emilio 1983; G. Lewis 1997; Johnson 2004). Much like the RCMP in Ottawa, the Federal Bureau of Investigation (FBI) was the primary body responsible for investigating presumed homosexuals in the civil service. The FBI's efforts were funded by the Civil Service Commission, an organization ostensibly founded with the intent of routing out threats of Communism from within the civil service but that became preoccupied with the security-related and especially "moral" threats of homosexuality. Consequently, the Commission spent as much as $\$ 12$ million each year not just initiating the expulsions of thousands of gay men from the government, but investigating and cataloguing countless details of their sexual lives, often relying on accounts or perceptions of co-workers (G. Lewis 1997). 
Much of this security campaign was performed under the moniker of the Hoey Investigation (named for the North Carolinian senator chairing the effort) and executed by the so-called "D.C. morals squad" founded by Senators Kenneth Wherry and Lister Hill (G. Lewis 1997; Dean 2003; Johnson 2004). As in Ottawa, the investigation identified both particular workplaces and public spaces where the threat was the strongest. The Department of State (equivalent to Ottawa's Department of Foreign Affairs) was identified as housing a secret inner circle of gay men who controlled foreign policy, while Lafayette Park, adjacent to the White House, was presumed to be the primary site of gay cruising activities (G. Lewis 1997). In Washington, D.C., the parameters for expulsion were fuzzier (and remained so until the 1970s), with the offense of merely "embarrassing" an agency considered equal to an actual breach of security through blackmail or other means. By 1950, the U.S. Navy had identified a list of 1,740 gay male employees living in the D.C. area, while the U.S. Army had identified 5,000. Civil service expulsions during the 1950s occurred at a rate of several hundred per yearabout 1,500 occurred between 1954 and 1955. While they continued well into the 1960s and 1970s, the U.S. government refused to respond to public inquiries on the figures (G. Lewis 1997).

\subsection{Ottawa and Washington, D.C., in National Struggles for LGBT Advancement}

Although the Canadian and U.S. governments both moved away from the more deliberate anatamo-politics that characterized the Cold War era, both have still leveraged a less intrusive bio-political power partially by explicitly or implicitly defining the terms of the LGBT movement since the 1980s. The ways in which this process has transpired, 
however, are markedly different in the two countries. In Canada, where the LGBT politics have been largely national in scale, Ottawa has emerged as the natural center of an agenda focused on "petitioning" for rights through the federal court system. The United States, in contrast, represents a more uneven patchwork of LGBT rights and activisms, with laws advancing LGBT rights emerging as often at the state scale (e.g., marriage rights in six states and D.C.) or even the local scale (e.g., municipal ordinances banning LGBT workplace discrimination) as at the national. The particular mode of LGBT politics in D.C., however, is frequently characterized by the replacement of localized grassroots or radical agendas with more normalized and restrained activisms that target the relatively immobile national scale of rights-granting measures.

While Canada is notable for having some of the most advanced LGBT (lesbian, gay, bisexual, transgendered) protections in the world as of 2010, these advances have come through a particularly "legalized" politics (i.e., one that both focuses on law and operates well within the bounds of the law). With some exceptions (e.g., the official decriminalization of homosexuality in 1968), the most notable LGBT advancements in Canada have been underscored by individuals seeking rights under the 1982 Charter of Rights and Freedoms. Although the entrenchment of the Charter into the Canadian Constitution formed an overarching federal baseline of equal rights recognition (Lind 2004), it was also an important moment in the establishment of regulatory power (though not necessarily purposeful regulation) over Ottawa's gay community because it defined both an ethos for LGBT advancement and the identities associated with the process. The creation of the Charter established a "right" way to achieve advancement (i.e., privileging individual legal expertise and official channels of rights-seeking) and 
recast Ottawa as the center of the national LGBT agenda. This is not to say that Ottawa has not witnessed moments of grassroots negotiation of sexual citizenship; the first Canadian demonstration for gay rights, for example, took place on Parliament Hill in 1971 (Smith 2005a). Most policy changes, however, have been achieved through court cases in which individuals and legal professionals challenged the state in a controlled, ordered environment. In the 1995 landmark case of Egan v. Canada, the Supreme Court deemed sexual orientation one of the immutable characteristics under which equal rights must be granted. Subsequent cases (see Smith 2005a) have granted LGBT citizens publicand private-sector employment benefits for same-sex partners (Rosenberg v. Canada, 1998), the right to disseminate and publish material depicting same-sex relationships (Chamberlain v. Surrey School Board 2002), and marriage rights (Halpern et al. v. Canada 2003). Ottawa's gay community has been central in this process of seeking rights and re-positioning formerly exclusive institutions such as marriage as new ideals. Egale, the principal national gay rights organization in Canada - and the litigator or intervener in most of the cases mentioned above — started in 1986 as a small, informal Ottawa-based group of lawyers, trade activists, and public servants who could employ their expertise, education, and government connections to secure the equality of freedoms that could be realized under Section 15 of the Charter (Smith 2004; Smith 2005b).

Washington, D.C., is located within a much different national context of LGBT politics. In Canada, the LGBT movements at both the "center" of the state (i.e., Ottawa) and in other major cities such as Toronto emerged at roughly the same time-mostly in the 1960 s and 1970 s — and coalesced into a broader national agenda by the 1980s. In contrast, the most powerful U.S. movements emerged earlier (in the 1940s and 1950s) at 
the geographic and political periphery, in places like New York and San Francisco, and due to the largely fractured nature of LGBT rights in the United States, have remained rooted in those places (Chauncey 1994; Weston 1995). In Washington, D.C., perhaps due to lasting effects of the Lavender Scare and the ongoing treatment of the district as federal domain rather than a self-governing city, never truly gained a localized LGBT political agenda — despite being "a very gay city" in informal ways (e.g., underground bar and cruising scenes) from the beginning of the $20^{\text {th }}$ century (Johnson 2004).

Although there is a great deal of work on LGBT politics in the United States, often comparing "assimilationist" and "radical" approaches (see Rimmerman 2002), the spatialities of these politics are often overlooked. In fact, the actors thought to be central to the historic and present-day animation of LGBT politics in the U.S., such as the Human Rights Campaign (HRC), Parents and Friends of Lesbians and Gays (PFLAG), the Gay Liberation Front, and the "Christian Right," are frequently described in nonspatial terms. Where the actors originated, moved to, or are most densely located, then, is cast as inconsequential to the modes of activism or the interests of gay and lesbian communities in particular places and at particular points in history. The history of Washington, D.C.'s, gay rights movement, however, is in many ways different from that of San Francisco, New York, and other well-known case studies.

Like Ottawa, Washington, D.C. has, at very specific moments in time, witnessed instances of grassroots LGBT mobilization. A 1965 Pennsylvania Avenue protest of civil servants - many of whom were connected with the San Francisco-based Mattachine Society promoting LGBT workplace rights — is generally thought to be one of the first public demonstrations of the U.S. gay rights movement (G. Lewis 1997; Rimmerman 
2002). In addition, Washington, D.C. eventually became one of the U.S. cities with its own chapter of the Gay Liberation Front, although the organization started in New York City. Even so, the city has spawned few, if any, of its own LGBT movements or organizations. Instead, the gay politics of the city are dominated by the Human Rights Campaign (HRC), a group that began as the Gay Rights National Lobby—an organization intended to "lobby Congress and organize a national network of lobbyists at the local level" (Rimmerman 2002, 29). In other words, HRC is both an organization with a primarily national (and some would argue assimilationist) agenda and one which the city acquired by virtue of its geography (i.e., proximity to federal government institutions) than any organic social movement.

Although the process of rights-seeking at the national level is neither exclusive of nor completely antithetical to broader strategies of queer liberation, the identities employed have tended to be different. While gender-bending, pro-sex rhetoric, bathhouse events and other strategies intended "rock the boat" often achieved greater visibility through their incorporation of "fringe" identities such as drag queens, bull dykes, and leather daddies (Warner 1995; Nash 2005; Nash and Bain 2007), the rights-seeking agenda in both Canada and the United States has relied on the white, middle-class, responsible, disciplined, and openly gay citizen for testimony, legal expertise, and media leverage (Smith 2005a, 2005b). Egale, for example, was originally comprised mostly of visible, middle-class and "out" white gay men, and tended to eschew any countercultural or difference-seeking agenda (Smith 2005b, 84). The result was an ideological framing of the local LGBT movement around sameness and responsibility, imparted largely by Ottawa's gay legal community and reflected back onto the city's other gay residents by 
the federal government and its associated institutions. Similarly, HRC is a highly centralized, hierarchical organization that-while pursuing agendas relevant to communities in other parts of the country-is staffed and supported (e.g., through fundraisers) in large part by Washington, D.C. residents. The city's gay men, then, are co-opted as "poster children" for a centrist agenda focused mostly on marriage rights and generally non-divisive events such as National Coming Out Day.

During the past twenty years, the highly structured, often top-down mode of LGBT organizing in these cities has persisted and even intensified for two reasons. First, since gay men in both capitals are physically and professionally proximate to the federal institutions (e.g., Canadian Parliament, U.S. Congress and Senate) that grant rights, they have continued to be co-opted into a national rights-seeking agenda-perhaps in lieu of pursuing more localized liberation efforts (see Nash 2005; Nash and Bain 2007). Even though Egale, for example, ultimately became institutionalized as a national organization, $44 \%$ of its membership was Ottawa-based even in 1995. The coterie of federal LGBT groups in Ottawa grew further with the addition of the Lesbian and Gay Immigration Task Force (LEGIT) in 1991 (Smith 2004). Other institutional decisions, such as the addition of an LGBT liaison and hate crime unit to the Ottawa police force in 1989 (following the assault and murder of a local man perceived to be gay), entrenched the importance of using official channels of representation and engagement in Ottawa's LGBT rights-seeking agenda (Moore and Rennie 2006). Washington, D.C., like Ottawa, also eventually became the site of other national-level groups, such as the National Gay and Lesbian Task Force (NGLTF) in 1986. While NGLTF has pursued a more leftist agenda than $\mathrm{HRC}$, often focusing on anti-violence and other causes aimed at protecting 
queer people outside the middle class, it is still typically hierarchical organizations with limited connection to the local community.

Second, Ottawa and Washington, D.C., like most North American and Western European cities, were increasingly exposed in the 1980s and 1990s to forces of economic contraction and governments intent on transferring welfare responsibilities to individual citizens and eschewing programs aimed to enfranchise "minority" groups (see Peck and Tickell 1994, 2002). In the late 1980s and early 1990s, as gay issues lost political representation due to increasing conservatism and downsizing, the responsibilities fell to individual "activists" (often public servants and other professionals) interested in volunteering to help LGBT causes (Smith 2005a, 2005b; Cooper 2006). In addition, lesbian and gay work was recast as "controversial," "unpopular," or "risky" unless it could be connected with national agendas such as HIV/AIDS education or youth wellbeing (Smith 2005b; Cooper 2006). The gay communities of both cities, where national LGBT agendas are generally privileged, have since struggled to resist these neoliberal forces and engage in collective activism.

The scalar and ideological specificities of Ottawa and Washington, D.C., have also affected the structure and cohesion of gay communities in those cities. In contrast to the many LGBT groups in Toronto, New York, and San Francisco that have "flown under the radar" of neoliberal government institutions by fulfilling a needs-based rather than rights-based mandate (Smith 2005b), the groups defining the federal-cum-local LGBT movements in Ottawa and Washington have typically rewarded a regulated, official "meeting-table" version of sexual citizenship rather than an active sexual citizenship that involves modifying the rules of the game, creating collective rights and responsibilities, 
or furthering a political or normative agenda (Cooper 2006; Smith 2005b). In addition, the national-level agendas that have dominated LGBT movements in Ottawa and Washington have only sometimes been taken up by less educated, less privileged, or less knowledgeable members of the gay community, unlike local, collective-action projects that often have shorter organizing times and more immediate effects (Rimmerman 2002; Smith 2004).

Indeed, the consistent discourse of equality, coupled with a routine conflation of federal and local LGBT rights agendas in both cities, may have corresponded with a decline in political engagement among the gay community and the "stamping out" of a "more challenging sexual politics" (Cooper 2006, 923). The privileging of individual legal expertise, litigation, and minimizing difference over collective action in capital-city LGBT movements, then, has also created an internalization and reproduction of neoliberal ideals, characterized by gay men seeking to portray the ideal sexual citizenupwardly mobile, responsible, and conservative (Smith 2004). It has also rewarded those versions of sexuality (e.g., coupled and monogamous) that allow queer people to edge closer to the margins of acceptability (Prior 2008; Oswin 2010). The routine elevation of certain types of sexual identities over others has been identified by some as a "new homonormativity" anchored in consumption and domesticity (Duggan 2002, 1816).

In the following section, I show that both governmentality and this particular version of homonormativity, while pervasive in the individual, micro-level experiences of the gay men who live in these cities, are not totalizing. The following analysis shows that regulatory power over gay men in Ottawa, while dense, can sometimes be ruptured, resisted, or re-interpreted (G. Brown 2008, 2009; Hutta 2009; Brown and Knopp 2008). 
More specifically, I build on the observations of respondents to explain how the entrenchment of the federal government and its institutions in the lives of gay men in these cities has led to (1) the continued self-disciplining of gay men to fulfill the expected identities of public servant, (2) an exclusivity in gay social circles based on class and job level/ranking, (3) the choice to consume "gay culture" outside the city of Ottawa, and (4) the lack of formation of a gay village or other central hub for socializing, organizing, and providing services.

\subsection{Government Cultures and the Fragmentation of Gay Communities}

As noted in the previous chapter, absorption into the civil service provides many gay men in both cities with a sense of security, success, and protection from discrimination. At the same time, widespread ascription to the norms of federal government agencies among both direct and contract employees appears to have created a highly fragmented gay community in the city. In particular, the intention of many gay men to fit into the identity of an ideal government employee figures prominently into the lack of "outness" and public engagement among the gay community. According to Cooper (2006), Western government cultures since the 1990s have been characterized by both limited "speakability" (i.e., reduced urge and capacity to speak, the reduced extent to which certain topics or fields renders themselves utterable, and greater restrictions on what can be legitimately said) and a "deportment" characterized by poise, manners, style, and political centrism. Although homosexuality technically no longer qualifies as taboo in the Canadian government environment, the remnants of its illegality and outright repression (see also Prior 2008) continue to define discourses about propriety, discretion, 
and career advancement. In fact, 33\% of the men interviewed (16 respondents) discussed the ongoing legacies of gay oppression in the government town, making it one of the most common themes in the study. Several men observed the routine privileging of particular gay agendas and identities in Ottawa:

There's a [politically correct] tolerance for mainstream homosexuality ... there's [also] a palpable uncomfortability [sic] with what you, someone might term more fringe issues in ... the package of gay activism that could be going on in any city at a given time. So I would say Ottawa skews a little better on some of the mainstream things; like you would probably find if you did a survey of the city-I'm not sure how gay marriage is viewed, I haven't heard any polls lately-but say during when same-sex marriage was being debated, I would have said Ottawa ... would appear better off on that sort of an issue. But if you started to look at like, um, taking serious steps to deal with homophobia in schools, I would say you would see a reverse reaction to that ... there would be much more of a resistance to the sort of giving practical value to rights versus just a, you know, verbal kind of recognition. (Rick, 27, white, Anglo-Canadian)

Respondents in Washington, D.C. observed the same trend, especially the

dominance of what several referred to as "black-tie activism" over a broader

range of social movements focused on local LGBT issues.

So there is no big overall kind of thing except for the HRC, which I find them to be kind of annoying. I just think they're excruciating! ... I don't think they do enough in promoting causes like ... like they just seem to be going to parties all the time and they're raising money for AIDS research. Great, but what about like sex, you know, education, sexual health, what about the gay elderly, what about gay teens who are getting harassed in high schools, that kind of thing? So it's all, I think they're all very much political, and I don't think they really care about the like issues, the big issues. Yeah, look how much money we raised this year, you know? (Tim, 27, white, Italian-American)

Others discussed how the neoliberal nature of LGBT organizing in the capital city, coupled with the economic privilege of many in the community, has created to some extent an internalized, "roll-with-it" neoliberalism (Keil 2009) 
among the gay men living there and a disconnect with political and social realities

of the LGBT community at large.

And I also wonder if it's the community, 'cause I think they feel like they don't necessarily need these services because they have, you know, the benefits and the ... and the sort of incomes to be able to just sort of do things on their own and get help wherever they need it and when they need it ... so sort of very individualized in that sense, too. (Raymond, 31, black, Jamaican-Canadian)

Max attributed this disconnect to the distinct way in which gay men in capital cities

become politicized (i.e., vis-à-vis the national state).

Um, [D.C.] is a political town, and the gay community here is a political entity as much as it is a social entity, and I think that's one of the big differences between like the, the community here and the community in most other towns is that, you know, it sees itself in those term ... to some extent, I mean, a group creates an identity by, you know, excluding ... but I, I think you're seeing that taken to a pretty large extreme here ... you have, uh, this, this group concentrating together, glomming together ... to sort of like ... secure political power, essentially. (Max, 31, white, European-American)

The historic governmentalities of both cities are also seen as central in the de-

politicization of the cities' gay communities. Several men in both cities noted the government's past interventions into its employees' lives, particularly through the techne of the security clearance process.

They would hold it over you from a security point of view or your security clearance, obtaining it, and if you didn't have a security clearance, you couldn't have certain jobs, per se. You couldn't-you certainly couldn't - work for a cabinet minister if you didn't have security clearance, you know, so the RCMP would - to give you the clearance - they would have everything on your life so to speak. (David, 55, white, Anglo-Canadian)

The U.S. civil service was observed to operate similarly: 
It was ... it was occurring ... across the board; it was not always consistently applied. It was not a specific "check this box and you're out," um, but I think, uh, it was ... it was commonplace in most Federal agencies in terms of granting security clearance to ask the question, and if the question was answered yes, it was considered sufficient grounds. (Arthur, 30, white, European-American)

In Ottawa, men felt that these past applications of governmentality had far-reaching

effects on the present-day culture of the public service:

With the federal government as well-there's been a very sort of, um, conservative culture imposed upon the gay culture in the city and the, you know, where you quickly realize the long history of some of the persecutions dating back to the forties and fifties by the RCMP and whatnot and the federal government. And so, I think that has carried forward even until present time with some of the older civil servants being very discreet and anyone from sort of a Director-General and above not being openly gay or lesbian in their workplace. I mean, it's changing rapidly and I'm a part of that change and that shift, um, still I think it's different from Montreal where most-more-of the employment would be in more open gay-friendly. (Sam, 44, white, European-Canadian)

Uh, and really when I became a public servant, I wasn't entirely sure on where [anti-gay] policy stood at that point. It became clearer to me as time went on, so, um ... and I recall when I came out to one of my bosses; he asked me as part of this interview ... "why did you wait so long?" And I explained to him this concept of this [policy] was threatening, and he said, "oh well you know the department has come a long way." And I responded to this, "uh, commander, you know ... sir you will not be without recognizing that up until about ten years ago, homophobia was an official policy of this department." And so he said, "yes, but we've come ... one of the departments that have come the longest way." And I said, "That's because you had longer to come than the rest of them." (Shawn, 42, white, French-Canadian)

For men in D.C., fears about security clearances and the potential for expulsion,

were even more variable across government agencies, likely due to the lack of clear,

universal anti-discrimination law for U.S. government employees. Arthur (30, white,

European-American), who applied for and received a position with the Department of

State in 2001, was aware that the Clinton administration had recently mandated sexual 
non-discrimination in the civil service but still expected to be rejected for the position because he was gay. Adam, who worked at the Central Intelligence agency in Washington, D.C., explained that gay men and lesbians working at that agency were also unclear about anti-gay discrimination protocols - and therefore uneasy about the prospect of being out at work.

Psychological stability is more of an issue: if you're a gay man and you're totally unhappy with ... that could be a problem. But if you're an established person that's very stable, then it's not gonna matter. I mean there's, there's weird politics in any organization ... I know people that, that refused to acknowledge that they're gay at work ... um, I'm kind of in the middle of that ... I mean, I, I'm out to people at work but I don't, I don't bring it up very often, we don't tend to be very ... we don't converse a lot about our personal lives, so, um, even people I work with closely, we just don't, you know, talk about that stuff very much. (Adam, 34, white, German-American)

While the campaigns against suspected homosexuals are perhaps the most obvious examples of the Canadian and U.S. governments targeting a (sub-) population perceived as threatening, this type of activity has continued in more subtle ways. In general, both cities are dominated by long-term government workers, many of whom are seeking incrementally to increase their rank or position through various tests, designations, and promotions. For gay men, this requires alternately acting as a disciplined, unassuming, and impartial representative of the government (government workers typically do not participate in highly public political activities) or as an "informant," "resource," or "specialist" on issues pertinent to the "gay community" (Cooper 2006; Pryce 2001, 15). Sebastian, for example, explained how his sexuality rendered him an automatic expert on gay men's health issues at the public health agency he worked at in Ottawa: 
I'm working in public health, and you know, we do a lot of population health and determinants of health ... if anything, I think that my life experience as a gay person is seen as an advantage where I work because, uh, you know, when you're devising strategies about infectious disease prevention, uh ... if you've seen a bath house, you know, more than once in your life, like you know anything about the lifestyle of single gay men. (Sebastian, 42, Métis, French-Canadian, Mik’maq)

Even without using force, the federal government culture creates particular types of privileged and visible gay identities such as advisors or specialists on health or youth interests, while closeting those that might be considered more politically risky (Brown and Knopp 2006; Cooper 2006). In many cases, any reference to one's sexuality was defined as something that needed to be kept outside of the office environment in order to achieve the desired civil servant identity:

I guess it's through interactions with people I've met over the years at different parties and stuff like that, you know ... comments like, "I would never come out at the office," or "I would never talk about what I did over the weekend at the office," so maybe those things where you keep your private life a little more separate ... you get the sense that if you were straight and talking about your wife and kids going off to, you know, a party, or a Montreal weekend, you'd feel much more comfortable talking about that in the office than you would if you were going off to a Black and Blue [circuit party] weekend, right? ... Um, those types of things, I think, you know, that type of sensitivity to what you can and can't say, so maybe that is sort of the way that people sort of, um, you know, change their behavior, modify, to talk about what they would do. (Raymond, 31, black, Jamaican-Canadian)

Yeah, I mean no one should act [at work] like they act at a bar ... but when you're gay you have a different ... um, fun is different ... you have a different kind of fun, and so you really have to watch it, yeah. (Anthony, 29, white, Polish-Canadian)

The pressures to closet oneself that men frequently observed in Ottawa and Washington,

D.C., were not confined to the workplace. Ian (31, Hispanic, Nicaraguan-American)

recounted his experience of joining a gay running group in D.C. after moving from

Seattle. Although the group was just another chapter of the same group he had joined in 
Seattle, the dynamics of the group were different: "[Usually during introductions] everybody says their name, but they don't do that in D.C. ... they don't wanna, you know, whatever, be publicly at a gay event ... this is the way it was explained to me ... ‘cause I was like, why do these people not say their names?" While Ian was puzzled by the lack of public introductions at the running group, several men in both cities attributed this type of "self-monitoring" (see Huxley 2002) as a means of avoiding any hindrances to career advancement:

Like, it's ... it's, you know, the history of Ottawa is very much one-like I mentioned earlier - one of repression, of, of sort of, um constant surveillance. Um, and I think there's still a very real sense-and this might be talking out of turn - that it still can have a negative impact on a career as a civil servant. (Raymond, 31, black, Jamaican-Canadian)

And the man who I was talking to said, "Um, well you know, there ... there is this perception of a ... of a pink ceiling in the federal government, and therefore you really don't want to be terribly out otherwise you'll hit the pink ceiling." (Ashton, 47, white, AngloCanadian)

George recounted the way in which D.C.'s own "pink ceiling" was described to him during a career day event for his graduate program's gay student group.

I remember, you know, [a panelist] just talking, like, well, you know I haven't come out to people in my office ... in my work ... but yeah, you might not feel like you want to come out for professional reasons and that's fine and I'm just sitting here thinking to myself that I'm at a job event sponsored by [the school's] gay organization ... telling me that you might consider that it could be a good idea not to be open about yourself for professional reasons. And my head was just exploding and I'm thinking, why am I here? (George, 39, white, Jewish-American)

As these narratives suggest, the self-regulation of sexuality is perhaps not just a perceived requirement of the civil service, but a mode of behavior that diffuses through the capital city more generally: 
[Conservatism is], um ... a characteristic of being the capital [of Canada]. That said, the downside is there, is that there's an implied expectation that there's a code of life that operates just below the surface, as opposed to the very outré or the flamboyant, because it's a function of the nature of the city. You may be in a group of people, and you may never know that this one's a diplomat from another country where your lifestyle would be entirely suspect or in question, and this one is, uh, the Commissioner of the RCMP. You know, I mean you just don't know who you're operation with until parameters and definitions are made or understood. (David, 55, white, Anglo-Canadian)

You know how we were talking about [the government] attracting gay men [to Washington D.C.]; it probably detracts gay men from coming here, too. I mean, you know I always thought when I first moved here, I thought, oh, it's this big city, it's so liberal, it's so open, but the longer you're here, the more you realize that, um ... I don't wanna say it's conservative ... certainly is not as open and, um, liberal as I would say, you know, New York, or San Francisco, or Los Angeles. (Joseph, 38, European-American)

Despite the continuously ambivalent relationship between many gay civil servants and their government employers, the federal government continues to dominate political organizing and even social life among gay men in both cities. As the previous chapter discussed, the emergence of a new type of gay economy surrounding the public service and advocacy sectors in both cities has made them more inclusive of gay men and lesbians than ever before. At the same time, the dominance of this configuration has limited the modes of political and social organizing employed by the community. According to Rick (27, white, Anglo-Canadian), "The bureaucracy—or the liberal traditions of the bureaucracy — probably aided the [LGBT] movement in Canada, or at the same time hindered in a lot of ways, you know, social development. So in Ottawa I think that's part of the problem. It's like the largest gay event in Ottawa is when the gay public servants have their monthly thing." In addition, the entrenchment of the government in 
the gay communities of both cities often encourages the self-segregation of men based on income, employment sector, or even on government ranking.

It's a weirdness about any kind of gathering of gay men in Ottawa, where you're comparing what your status is within the federal civil service. Uh, if you're, you know, an engineer, are you a 4 or are you a 5? If you're an $\mathrm{EX}$, are you a 2 or are you a 3? Um, do you work for the deputy administrator or are you just a policy analyst? It's always this like really goofy bullshit one-upmanship. (Randall, 45, black/Aboriginal, AfricanCanadian, Mik'maq)

Yeah, when it comes to like gays, I, I just feel like I'm not comfortable ... like I go out to these events, you know whatever, to try to meet people, go like a bar, happy hour night, whatever ... and you have all the lawyers like clumped together talking about, oh, well I was in law school and I did this in court - oh, you're not a lawyer? And then you've got, you know, the military people who are all sitting there with like stony looks on their face, talking about, you know, oh yeah, well I used to know that when I was in the military. (George, 39, white, JewishAmerican)

The emergent divisions within the gay communities of both cities are not just

professional, but also class-based and racial. Many men described the emphasis on

education, income, and professional positions in both cities as fostering an exclusive type of homonormativity (see Duggan 2002; Nast 2002) in which particular ways of "being gay" were privileged over others. Their narratives reveal that the selective integration of gay visibilities and identities into the civil service, while reframing the government sector as a site for securing gay livelihoods, has also encouraged the tacit equation of being gay with conformist and exclusive practices of upward mobility.

I think my sense was that if you had a small apartment on the Plateau [in Montreal], and had a boyfriend, could sort of manage to get by, and go out to the Village, and go on a vacation ... then you were living a good life. It wouldn't be quite the same definition here [in Ottawa], where the expectations would be much more around the house in the suburbs with, you know, a kickass vacation, and, uh, some more material possessions ... and you know, some equity, and you know, a vision of a retirement. (Sam, 44, white, European-Canadian) 
[Washington, D.C.] is a city generally of high-profile individuals ... you know, it's funny 'cause they run in clumps and they all sort of kind of look alike, and they all kind of dress alike ... and it sort of bleeds into the people who don't even fit in there who are wearing the same kind of clothes and, and it's just kind of like - sort of, but and again, that's also sort of styles, and, and things that are sold by, made by the mainstream. (Max, 31, white, European-American)

In D.C., the emergence of a professionalized and normalized class of gay men as the dominant face of the gay community also has tended to reinforce racial cleavages in an already-segregated city. One on hand, these cleavages are longstanding: the city's black Christian and gay communities have long been cast as oppositional. Black Christians in D.C. have frequently been censured by local gay organizations for both their opposition to local gay agendas (e.g., the right to marry in D.C.) and for the rejection of young gay men in black families. Black men in D.C. have consequently been caught between communities. While several bars and nightlife previously filled this gap by catering to mostly black men (and in mostly black areas of the city), the emergence of professional, out, and usually white civil servants as the dominant group in the community seems to have suppressed some of this diversity. Mostly white areas such as Dupont Circle and adjoining, now-gentrifying U Street have become the so-called "gaybourhood," while black venues on the eastern side of the city (e.g., in the Navy Yard area) have closed. Black men therefore tend to feel disenfranchised in this new iteration of "the gay community." Men like Phillip (41, black, African-American), were unfamiliar with this dynamic when they first moved to Washington, D.C.: "You would assume that most of the - at least half of the people in the bar or a third of the people in the bar would be people of colour and that's just not true and there's a reason for that." 
Although these observations allude to a totalizing definition of homonormativity as the gradual assimilation of gay and queer people into heteronormative, conformist, and racially and economically exclusive practices and lifestyles, several men—particularly in Ottawa - pointed to the fact that men leading ostensibly homonormative lives were actually “queering” heterosexual spaces (see also Visser 2008).

Umm ... neighbors across the street, I find that's a good example. I think they're ... you know, they're tolerant people, they're lovely people ... but their first reference to us was, "oh we had ...," what she said to me, "Oh we had your friend over when you were away "cause he, you know, he's probably a bit lonely ... had him over for a meal" ... So, you know, there's a little bit of ... they didn't know - because I don't think they had really dealt with gay people before-didn't know how to address us or how to deal with us ... They want to feel progressive or open-minded, but they don't know how to carry it off. (Ashton, 47, white, Anglo-Canadian)

Uh, friends of mine actually put it very nicely in that they bought - they built this giant house out in [suburban Ottawa] and you know, they dug up, and big lawn, and ... at the end of the day, nobody really cared if they were two fags ... they were more upset about the fact their lawn wasn't perfect ... And once they fixed their lawn, they were nice neighbors again. (James, 40, white, Anglo-Canadian)

Such examples show that in mundane and everyday spaces, home and workplace lives among gay men that might be considered homonormative can both transcend the imagined binary of heterosexual/homophobic vs. safe/gay space and create relationships that are unexpected and enlightening, even if not necessarily transformative (G. Brown 2008; Visser 2008; Luzia 2010).

In other cases, gay men resist the normative aspects of the capital city altogether by leaving to consume gay culture elsewhere. Many have observed that the "cosmopolitan self" and consumption practices promoted in various media have led to the construction of a hyper-mobile, affluent, global gay (Puar 2002; Binnie and Skeggs 2004, 43). In Washington, D.C., these portrayals resonated among the respondents, who noted 
the frequency with which gay men seem to travel abroad and particularly to gay resort destinations in the northeastern United States, such as Provincetown, Massachusetts and Rehoboth Beach, Delaware. In Ottawa, however, these constructions did not capture the regularity or the routine nature of travels to nearby metropolitan areas. Geographically situated between two larger cities (Toronto and Montreal) that are traditionally understood to be gay centers, Ottawa's own scene-while viable in terms of potential consumers - is persistently (some say increasingly) hampered by monthly or weekly consumption of gay culture outside the city limits. Such activities represent the spatial codes into which heterosexism is inscribed, not just between closeted workplace and open home, but also between more restrained day-to-day city life and places to "let loose," such as other cities or carefully circumscribed and ephemeral events such as Pride parades (Howell 2007, 304).

I see enough Ottawa faces in Montreal to support another bar or two here if they all stayed ... So when I really do-you know whether it's two or three months or whatever-I want to let loose, a bunch of us will go to Montreal. (Sebastian, 42, Métis, French-Canadian, Mik’maq)

There's a sense of decorum, maybe that people have to, have to live up to yeah, I think a lot of people have a lot of high-profile jobs, and you know, you just have to maintain yourself. I mean the only time you see [public displays] are at the Gay Pride Parade where people feel more free to express themselves, and that's, and that's one time where it's encouraged and expected, I think, in [D.C.]. (Doug, 26, white, GermanAmerican)

Yet again, the idea that gay social lives can be lived through travel or during specified yearly events elides the degree to which such practices exclude certain men based on the class or social positions they occupy. While some men were simply unable to afford to participate in these activities, others avoided them because they seemed socially exclusive. 
And that's once again the common discourse here, or the common attitude is that you go to Montreal or Toronto on the weekends ... Um, I don't have evidence to back it up; I think there's a huge population who can't afford to do that ... who, um, you know don't have a weekend place, can't afford to travel, stay at hotels, so I think anecdotally, you hear of everyone, right? But I think it's, um, a lot of, um, "well I wish I could go" as opposed to them actually making the shift and doing that. (Sam, 44, white, European-Canadian)

One of the things that I think I see a lot is just that, um, the people in D.C. like to travel a lot and if you don't, you know, make enough money, that makes it harder to be a part of that. (Max, 31, white, EuropeanAmerican)

I've, you know, never ended up ... um, in fact I think I've only been to one, no, only a couple, a couple pride events ... it's kind of hesitance because it's like, oh, you know, is it like, you know just the bar crowd out in the streets. (John, 33, white, Italian-American)

The recasting of leisure spaces and festivals as places to escape regulation (see Puar 2002), coupled with many men's decisions to attempt to live their gay lives outside the public purview, has materially affected the social infrastructure of both cities. In Ottawa, this has been exemplified in a long terms struggle to launch the city's gay village, which was finally recognized by the municipal government. After being bypassed by both the municipal government (McKinnon 2005) and the Bank Street business improvement area (Deschamps 2008) in more thoroughly planned revitalization projects, Ottawa's would-be village was left to engage in "bottom-up" branding of the area that most gay businesses and services call home. The scenario of apparently benign neglect was emblematic not only of the "hearing without doing" that Cooper (2006) describes as entrenched in highly regulated places, but also the Foucauldian tendency for controversial groups to be rendered less visible.

In numerous other Canadian cities, municipal governments and business associations have frequently branded their gay communities in an effort to attract tourists 
and compete with other would-be cosmopolitan cities (see, for example, the Montreal case in Podmore 2001 and Ray 2004). Such projects have been criticized for desexualizing or "purifying" space in order to promote a gay village as a motif for urban regeneration — safe and usable, yet different enough to be interesting (Bell and Binnie 2004). In addition, they can overshadow the disadvantage and homophobia present in a place (Markwell 2002) or render the gay community subject to surveillance and containment (England 1994). Yet the village also offers a type of "compact visibility" that may be particularly meaningful to newcomers, recently "out" individuals and those without the money or social capital needed to access the less visible or less proximate aspects of gay life (Binnie and Skeggs 2004, 48). In Ottawa, which did not designate a gay village until November 2011, some men there saw the absence of a village as evidence of the city's conservatism and a gay population whose most visible groups may not to rely on gay urban spaces ${ }^{10}$ :

... There's been a movement to try and create a gay village for about a decade, and while advances have probably been made over that time, we still don't have a gay village ... there's still groups and there's movements to try and create that. But I mean, they exist in Montreal, they exist in Toronto, they exist in Vancouver, they exist in Calgary for crying out loud. (Wally, 43, white, Anglo-Canadian)

The absence of a defined gay village was something respondents found odd given the presence of advanced rights, liberal political norms and a large queer-identified population in Ottawa. Steve, who had incidentally lived in Washington, D.C., before moving to Ottawa, felt that D.C.'s Dupont Circle-despite the limitations to its diversity

\footnotetext{
${ }^{10}$ Six blocks of Ottawa's Bank Street was designated by the City of Ottawa as Le/The Village in November 2011. At the time respondents were interviewed, this was a hotly contested issue, reflecting Ottawa's much different attitudes toward marked, visible gay space, compared to Toronto or Montreal While the village designation has allowed for signage featuring both a city logo and a "village" one, it is yet to be seen how the recent designation might actually change the business mix of the area or benefit the community.
} 
and inclusivity—had provided an "everyday" space of social encounter that was sorely missing in Ottawa.

Um, it's ironic in Washington, unlike Ottawa, you know you don't really have strong legal rights, but there was a very strong sense of gay community that was very out, very vocal, very dynamic. Whereas here in Ottawa, you have full legal rights, and the community at least in my opinion is much more, um ... cloistered, almost. In Washington on daily basis, we might well meet people - other gay men and lesbians who we knew - and, you know, it was very much that you felt like you were part of a community. And in that sense, it was part of an everyday experience. Whereas here, it's much less likely that I'll meet gays and lesbians who I know in the course of my everyday life (Steve, 47, white, AngloCanadian).

With no designated village, Ottawa was seen as having few visible, identifiable spaces where gay men with limited knowledge of the city (or limited ability to travel elsewhere) could access services. Raymond (31, black, Jamaican-Canadian) observed, like definitely the services aren't very visible or available. They've tried but they've hard a very hard time. Um, the queer community here, too, is very transient as well so more often they'll go out to Ottawa or Toronto or Montreal than stay here." Since there is no centralization of services - and therefore few opportunities to target and attract diverse groups of men — many assume that most services are geared to the same groups of men that are already the most visible in Ottawa. David, originally from southern Africa, commented on the relative invisibility of services in Ottawa, particularly for gay men who identify as non-white.

But we don't have any group, like ... so we can build something in Ottawa for us, especially in our community ... yeah, from the minority. Because most of the services, it's so like ... most of the services are directed towards, like, white people ... even the advertisements and everything you see. So, it's so hard to tell people from out in likeespecially minorities - that it's normal to be gay, 'cause they don't identify to any ...Y You know like, people from my country, they're like, 
"oh you're gay ... oh that's a white thing. (Kent, 27, black, southern African)

In Washington, D.C., the fragmentation of the gay community has been

characterized more by the contraction of identifiably gay spaces and the diffusion of areas where it is merely "okay" to be gay. While Dupont Circle fills the role of D.C.'s "gay village," the visibility and performance of sexuality in that space is arguably restrained than in well-known gay neighbourhoods like San Francisco's Castro. Doug remembered his first encounter with Dupont Circle after moving there from Colorado:

..I guess it wasn't as gay as I thought it was, especially going to Dupont Circle ... 'cause you hear about the stories and ... just seemed like a normal part of the town to me ... there weren't like rainbow flags everywhere; there were some but it wasn't like, it wasn't like you see on television ... San Francisco, guys walking down the street in leather chaps, it wasn't like that at all. (Doug, 26, white, German-American)

Many observed that while Dupont Circle remains a commercial and nightlife space geared to gay men, the gay cultural institutions located within it have declined during the past few years. Max (31, white, European-American) said, "And you've seen a lot of the old, sort of, um, like centers of gay culture here dissolve. I mean, Lambda Rising [bookstore] closed. The Blade closed. Those were two, I think, huge, like, I mean, sort of psychic artifacts of the, like, in the minds of the gay media here." In addition, Dupont Circle has to some extent been replaced by a group of sexually indistinct neighbourhoods (e.g., Columbia Heights, Shaw) as the residential hub for gay men.

I don't know, D.C.'s different; it's changed a lot in the last ... well since I moved here ... you know, most people lived in Dupont. Now Logan got big and now Columbia Heights. I mean most, most of the gays probably live in the Logan/Dupont sort of area but now it's spreading out to like Columbia Heights and Shaw ... now D.C. isn't as centric as it was five or six years ago ... but I mean, ideally, I think most people would probably want to live in Dupont, but it's just not affordable. (Nick, 26, white, Eastern-European American) 
Although these observations reflect the general trend toward gentrification and consumerled growth in most gay villages (Markwell 2002; Binnie and Skeggs 2004), they also reflect a concurrent disinvestment in more organic and more visible queer social spaces (see Andrucki and Elder 2007). Although many men felt that the decline of the village and the outward diffusion of gay spaces were indicators of decreasing stigma, improving rights, and a generational shift in the community (the "it gets better" phenomena), the transition also represents an exchange of visible community spaces for unmarked, privatized spaces. It is also emblematic of the particular visibilities lent to groups or identities seen as controversial or problematic, especially in cities that are highly regulatory and institutionally dense (Legg 2005, 2007). Although Gorman-Murray and Waitt (2008), Visser (2008) and others note these can be places of "queering" as much as they are normalization, the particular combination of historic regulation, privileging of wealth and professionalism over community, and transience seem to suggest gradual (though often undetectable) processes of de-gaying as much as they do queering.

It's the culture of the city ... it's a, it's a transitory place ... I think that level of investment ... I think in general there's sort of this idea that, well, I mean you know I'm not gonna be here that long anyways ... and it's a very interesting thing that there's this idea that, you know, somebody - the people in DC - are interested in what they can get out of you and while I, I didn't really find this to be the case exactly, it's, it's a very strong myth that perpetuates strongly in this city (Ian, 31, Hispanic, Nicaraguan-American).

This final comment also brings to light the impact of the capital city's present-day position as a transient government-military complex, one which—despite increasingly gay-positive workplaces and a fading history of deliberate regulation toward gay mencontinues to shape impact gay men's lives and communities in unexpected ways. The 
continued disinvestment in the gay communities of both cities suggests that present-day "government towns," while providing more secure livelihoods for individual gay men than other places, do not seem to foster collective identities or mobilizations.

\subsection{The Continued Entrenchment of Government in Gay Men's Everyday Lives}

The narratives of men in both cities suggest not only that governments encourage a particular affect, or way of being, among their employees, but that they profoundly shape gay life in capital cities. The insinuation of the government into the lives and identities of gay residents, through both historical campaigns and perpetually reproduced ways of organizing, living, and behaving, have created places in which the gay community remains less visible and in many ways closeted compared with those in other large North American cities. In some ways, these government towns appear to be between worlds: they lack the highly public gay life seen in the villages of Toronto, Montreal, San Francisco, New York, Chicago, and other large North American cities and seem to eschew many of the definitive assertions of gay identity and community, such as marking gay spaces, using private homes as political and organizational focal points, often observed in small towns (see, for example, Gorman-Murray et al. 2008). As Sebastian observed:

I think that the cookie-cutter type of person feels more comfortable [in Ottawa] ... Like the kind of job I have, what I get to do every day, the kind of money I make, the kind of pension I've got. ... So people move here, I think, and end up getting sucked into the vortex and just become like what they see around them after a while. I think that's what happens. (Sebastian, 42, Métis, French-Canadian, Mik'maq)

Although the analysis suggests that the institutions of capital cities have in many ways maintained, privileged, and reproduced a homonormative way of life (per Duggan's 
2002 definition), there are also ruptures and fissures in the normalization processes that men in these two cities encounter. The AIDS Coalition of Ottawa and the new GayZone weekly drop-in program, for example, engage in considerable outreach work to bring health services and youth networking opportunities to the less visible and less privileged cohorts of the queer-identified community (Wright 2003; Deeprose and Bouchard 2010). The queer-positive Abiwin housing cooperative and 2010 Promdemonium event geared toward uniting and supporting the city's queer communities (Abiwin 2010; Promdemonium 2010), are just two of what Brown (2009) calls "alternative gay enterprises" that operate in a socially responsible manner and are committed to mutuality and horizontality (1504). Similarly, Washington, D.C. in the past few years has spawned a number of distinctly "queer" organizations and media outlets, such as the Queer Crafter Collective and the Queer D.C. Poetry Project.

The emergence of events, groups, and other outlets in both cities in the past few years indicates that capital cities are embarking on the non-mainstream, non-village, nonconsumptive queer social life that Nash (2010) has observed in Toronto's Parkdale neighbourhood. The key difference, however, is that queer identities were never truly consolidated or made public in the same way that they were in Toronto or places like San Francisco and New York city. The comments of the respondents also show that gay men's life-worlds are generally complex and often incorporate elements of adaptation and resistance, such as living differently at home and work, consuming gay culture elsewhere, in what might otherwise be considered homonormative lifestyles (Waitt and GormanMurray 2007; Visser 2008). 
The capital city, however, is still a fundamentally contradictory space in which the city and its gay citizens are simultaneously promoted as arbiters of distinctly national visions of LGBT rights and freedoms, yet regulated by the institutions that are positioned to confer them. As the previous chapter argues, these cities offer the potential to live as an out gay man with sufficient opportunities for career advancement and more generally for self-actualization, it may also be an environment in which men become saturated in the disciplinary narratives of the federal government (Pryce 2001). Although many have claimed that high LGBT visibility—as seen in more organized and active communities such as Toronto and Sydney—can be used promote certain types of queer identities or conceal repression and homophobia (see Markwell 2002), it seems that the general lack of collective activity through non-government channels in capital cities have had a similar effect. Although both Ottawa and Washington, D.C., have ostensibly large gay populations, many men have embraced and reproduced many of the disciplinary and neoliberal ideals of the federal government, including secure lifetime employment, a conservative, apolitical deportment, and a wealth-based notion of self-sufficiency (e.g., frequently traveling elsewhere to live more openly) rather than community investment.

This comparative case study also prompts us to think more closely about the role that geographic proximity to state institutions plays in the emergence of LGBT movements and the structure (or lack thereof) of queer communities in various cities. Gorman-Murray, Waitt, and Gibson (2008) note that even a small, ostensibly queerfriendly "country town," can become a site of regulation and heteronormativity imposed under the monikers of "national culture" and "national belonging." The previous analysis shows that the potential for such interventions is perhaps even greater in places that act as 
centers of their respective states. Although cities such as Toronto (Nash 2005) and Sydney (Markwell 2002) might also be considered state-suffused places that are ripe for regulation, the presence of other economies and institutions (e.g., arts, entertainment, and business) in those places seems to foster discourses of community development and political resistance as much as they do normalization.

Ottawa and Washington, D.C., on the other hand, resonate more closely with Visser's (2008) work on South Africa's judicial capital of Bloemfontein, where classbased fragmentation and disinvestment in LGBT community institutions co-exist with the quiet, apolitical integration of gay men and lesbians into ostensibly heterosexual spaces. The fragmentation and de-politicization of gay communities in Ottawa and Washington are at least partially attributable to the historic and current role of those cities as their respective countries' front lines — and even testing grounds - for many of the mechanisms through which governmentality is inscribed upon non-heterosexual people. Many respondents' comments tellingly point not only to normalization and de-politicization, but also to a heightened awareness of the technologies (security clearances and "fruit machines"), identities (the ideal civil servant, the married gay couple), and (in)visibilities (refusal to delineate a gay village) that federal and local institutions use or have used to regulate them. Consequently, these cases also suggest that sexual citizenship in a federal capital is perhaps defined more in relation to the national state than other jurisdictions (e.g., the city or the neighbourhood).

Finally, the evidence put forth here suggests a need to re-interrogate the role of government itself in the formation and conduct of LGBT communities; i.e. the "nittygritty" and often "messy" relationships between sovereign power and biopolitical power 
(Schlosser 2008). This directive does not necessarily oppose recent literature suggesting that neoliberal forces, such as the privatization and institutionalization of queer space (see Markwell 2002; Bell and Binnie 2004; Andrucki and Elder 2007), play a highly visible role in the construction of the "ideal" LGBT community and the desirability (or undesirability) of certain sexual identities. It does ask, however, that researchers look carefully at how the state's regulatory role and influence in cities like Ottawa and Washington, D.C., may also cause "bunkering-in" where the less assimilated queers are "driven underground" or closeted (Bell and Binnie 2004; Brown and Knopp 2006). Given the breadth of these questions, practitioners of sexuality and space studies must continuously work to challenge notions of "metropolitan," "progressive," and "liberal" to look at the ways in which the state unexpectedly shapes the ways and places in which sexuality is understood and negotiated. In particular, the cases of Ottawa and Washington, D.C. definitively challenge the idea of cities as emancipatory places for gay men. In these particular cases, they are as much sites of ongoing regulation as they are places of freedom or opportunity. As the interviewees' narratives demonstrated, even places increasingly (and more publicly) deemed to be centers of the political and professional advancement among gay men, are also sites dominated by specters of historical regulation and ongoing modes of self-discipline. 


\section{CHAPTER 10}

\section{Conclusions}

\subsection{Introduction}

This study scales in the queer migration discourse by providing an empirical examination of gay men's migrations. It is one of the few empirical examinations of queer migration in North America, and the only one involving a Canadian case study. In applying a life course perspective, this research not only challenges the presumed teleological and ontological finality of migration in gay men's lives (i.e., moving out to come out, once and for all), but also highlights the various points at which migration might intersect the life course for sexually non-normative individuals. By demonstrating how gay men employ migration to negotiate the individual circumstances and experiences they encounter during the life course, including changes in health, entering the labour market, establishing community identities and livelihoods, and ongoing processes of coming out, this work fundamentally extends and challenges a number of bodies of literature. It also offers a novel application of life course theory, and makes several new arguments about the dynamics of queer migration and geographies of sexualities more broadly.

\subsection{Revisiting the Literature}

First, by adopting the individual migration narrative as the unit of analysis, this study un-fixes the body of queer migration literature that reifies the nation-state as the primary moderator of migration among sexually non-normative individuals (Lubhéid 2005, 2008; Manalansan 2006). While the policies of states that outlaw homosexuality or 
privilege the heteronormative family in reunification policies no doubt generate certain migrations and prevent others, they do not necessarily capture the more ordinary migrations that gay men and other queer people undertake across regions, between cities, or-as shown in Chapter 6-within cities. The everyday nature of these journeys indicates that despite improving (yet still geographically uneven) landscapes of gay rights and regulatory policies in North America, migration still involves the challenging negotiation of networks (e.g., families, friends) and institutions (e.g., schools, workplaces). The frequency with which sexuality intersects with gay men's migrations shows that being gay—regardless of the policies regulating it—continues to be understood by men as something that needs to be alternately concealed, disclosed, negotiated, and managed. Even in situations where disclosing the possibility of being gay to oneself or to others was not perceived to pose an imminent threat (e.g., familial disownment, physical harm), it was still seen as something that needed to be carefully managed. Changing one's environment by moving was central in these processes, showing that disclosing or negotiating a non-normative sexual identity—while not "tantamount to displacement" (Puar et al. 2003)—is still often mediated by relocation.

Second, this study extends the small body of literature that already focuses on queer migration as an embodied phenomenon. While usefully scaling-in the concept of queer migration as something more related to individual experiences than national policies and practices, much of the literature tends to fixate on the individual identity quest—particularly the need to define oneself as gay vis-à-vis an imagined gay community that is located elsewhere or to try on different gay identities in different places (Knopp 2004; Gorman-Murray 2007). These journeys are often described as 
wandering or peripatetic, terms that capture the fluidity of migration in queer people's lives but cast migration as the product of individual desires and elide the geographically uneven forces (e.g., policies, practices, networks and institutions seen as incompatible with sexual non-normativity) that continue to drive gay men's migrations.

Coming out and the associated processes of moving, however, are not just individual processes of gay identity creation, but social and cultural phenomena that depend on place, intersectional identities such as age and race, and structures such as families and social networks. Studying queer migration at the scale of the body avoids essentializing a diverse population and provides an important entrée into research on how migration pushes, pulls, and processes affect the queer body. At the same time, however, “embodied" emigrations must be understood as relational phenomena; that is, one in which embodied and emotional aspects of migration can be seen as the product of policies, practices, and social dynamics located within sending and receiving places. While individual interests such as sexual desire and pursuing or negotiating romantic relationships undoubtedly play a role in many queer migrations, they are not the primary or singular concern. This study shows that many men's migrations are informed by concerns such as employment that in one sense fall outside the scope of sexuality, but are rendered more difficult or complicated by the way in which sexual difference is acknowledged and included across places. Queer migrations are therefore both embodied and relational phenomena.

Third, this study challenges the work of demographers, economists, and economic geographers that posits gay men's locational choices as the product of purely economic decision-making based on cost-benefit analyses of a location's housing costs and 
amenities (Black et al. 2002, 2007; Walther and Poston 2004; Cooke and Rapino 2007). The ongoing linkage between sexual non-normativity and economic growth, referenced in studies of the "creative city" (Florida 2002, 2005) that position gay men as "tracking molecules" (Storper and Scott 2009) rather than "sexual citizens" (Bell and Binnie 2004), threatens to reify gay men as either consumers or a consumable identity. In contrast, this study not only highlights how men's “diverse economic practices” (G. Brown 2009) as workers and community members might inform their migrations, it also shows that the policies and practices of places — and not just the amenities contained within them - are fundamental to their relocation decisions.

Most men had moved not in search of amenities, but in search of work, particularly in government sectors that offered job security and had become increasingly inclusive of gay employees (albeit in carefully circumscribed ways). Put differently, gay men who migrated were not looking for coffee shops, yoga studios, bars, or clubs; rather, they were moving in response to the ways in which places were perceived to include or exclude sexual non-normativity. Their motives for migration was evident not only in their stated reasons for moving (e.g., the desire to not be relegated to peripheral or substandard spaces in cities), but also in their evaluation of the environments they had chosen to live in. Many men saw the lack of gay space in Ottawa and Washington, D.C., to be indicative not of reduced "need" for concentrated (albeit branded and commercialized) space, but of an ongoing failure of their respective cities to lend visibility to their gay populations. 


\subsection{The Value of a Life Course Approach}

Adopting a life course approach has offered several opportunities for new understandings of queer migration that extend beyond the productive, but often siloed ways in which it has been framed to this point. The study of where gay men are locatedand where they choose to locate- has moved from the use of vehicles such as HIV/AIDS (Cohn et al. 1994; M. Brown 1995) and gentrification (Knopp and Lauria 1985; Knopp $1990,1992)$ to a more direct focus on gay men's day-to-day lives. At the same time, much of the migration literature remains focused on particular segments of the life course. Coming out has frequently been given primacy in the discourse, with migration approximating an early-in-life escape from the closet (Weston 1995; M. Brown 2000). Other strands of literature concerned with migration rights and regulations often focus on marriage, partnership, and family (Lubhéid 2005, 2008; Manalansan 2006), implicitly (though not exclusively) focus on men usually later in life who are engaged in established relationships and interested in marriage or adoption. The life course approach instead establishes that sexual non-normativity mediates migration continuously throughout life, offering evidence to Knopp's (2004) assertion that migration is central to queer people's lives. Yet it also challenges the idea that these migrations are rooted in an affinity for placelessness or liminal space themselves, demonstrating instead that queer people employ migration to negotiate major life events in an uneven landscape of rights, regulations, and social acceptance.

The life course approach also reveals the importance of life stage, historical contingencies, and intersectional identities in the migration decisions of gay men. Put differently, both gay men's lives and the places they move to and from are dynamic. 
Typically, men moved for different sets of reasons at different points in life. The migrations that men undertook earlier in life typically involved an element of "moving out to come out." In these situations, men typically sought to negotiate complex and sometimes threatening networks and institutions at home while seeking out a community against which they could define themselves. Although these coming-out migrations typically took place between ages 18 and 30, for some men they occurred later in life, particularly among men who had previously been engaged in a heterosexual relationship. In general, the coming out narrative aligned with Weston's (1995) portrayal of gay migration in the United States as a rural-to-urban journey among young men and women, though the narratives employed here nuance the role of place. Although many men had moved to Ottawa and Washington, D.C. from other cities, those who moved as part of an early-in-life, but also continuous, segmented, and relational coming-out process had frequently come from smaller and geographically peripheral cities such as Halifax (Nova Scotia), Sudbury (Ontario), Columbus (Ohio), and Richmond (Virginia).

The archetype of rural-to-urban coming-out migration was less common among men later in life. Many had moved for careers, seeking out both job security and a local economy that they felt would be more inclusive of their sexual identity and their professional interests (e.g., a career in politics, advocacy, or education). Men also found opportunities to create community identities in ways that they had felt unable to where they moved from; not only through work, but through socializing, networking, and volunteering. While older men were more likely to stay in Ottawa or Washington, D.C.often due to the career security they had already achieved there-men under 40 typically intended to move within the next five years. This trend suggests that a large, spatially 
concentrated gay community not only becomes decreasingly important to gay men later in life (Cohler and Galatzer-Levy 2000; Kertzner 2001), but that they are less likely to undertake relocation as part of identity formation (i.e., creating a gay identity through place). On one hand, the trend of moving down the urban hierarchy later in life aligns with the general population (Plane et al. 2005). On the other, gay men's reasons for decreasing interest in large cities over the life course are likely different. Most men over 40 were less interested in positioning themselves vis-à-vis a (city-centered) gay community and were more reliant on their individual networks of partners, colleagues, and friends. Consequently, many planned to move to previous homes (i.e., closer to family), or purchase new or second homes based on the perceived suitability of a placeregardless of its size of the perceived size of its gay community.

Historical contingencies figured prominently in many men's migration narratives, particularly among those who had moved in the 1980s or 1990s. The key theme in these narratives was not—as might be expected—moving from places that were especially hostile or intolerant, but the process of moving to cities where there was opportunity to participate in the movements that were defining gay communities at that time (see also Weston 1995). For men who moved to Ottawa or Washington, D.C., during this period in history, early gay rights movements or campaigns for HIV/AIDS awareness provided a ready source of identity-building activities, even if they were less visible or smaller in scale compared to other cities. Put differently, individual processes of relocation and identity formation at this point in history appeared to be more bound up in the collective political and social movements of the time. This is not to imply that men moved explicitly to participate in city-centered social movements, but rather that Ottawa and 
Washington, D.C., were embedded in their imaginations as places where these movements were being waged, and that relocating would allow them to experience and participate in phenomena that were ostensibly relevant to their lives.

The particular status of Ottawa and Washington, D.C. as government centers also made them attractive to many respondents, particularly those who were interested in influencing their respective countries' gay rights movements in a top-down fashion, either through political careers or participation in "national" events, such as court cases, lobbying activities, and demonstrations. Many men discussed the satisfaction they experienced having participated in or witnessed historical moments such as the achievement of marriage equality in Canada (2005) and Washington, D.C. (2010). Having noted their belief that politics were an inherent part of a "minority" identity, some respondents suggested that these capital cities had in some ways become new homelands for gay men interested in participating in the highly "legalized" politics that had emerged there - and had perhaps become the more dominant mode of queer politics in North America. These findings suggest that there has been both a historically contingent hierarchy of homelands, with the twin coastal centers of San Francisco and New York ultimately being replaced by multiple nodes. They may also suggest a change in the types of homelands sought by gay men. While the "big cities" that Weston (1995) describes as destinations for queer Americans were in fact centers of queer politics, they were also culturally significant sites with their own queer cultures produced by the accretion of other historical events (e.g., New York's Industrial Revolution, San Francisco's role as a point of return for men who fought in the World War II's Pacific Theatre). While Ottawa and D.C., had local (although admittedly less visible) queer cultures of their own, their 
emergence as migration destinations for gay men is due more to the particular set of government institutions located there, rather than a simultaneous emergence of the (grassroots) political and cultural (or the political as cultural).

As life course theory suggests, life trajectories including migrations do not stem from a predetermined, uniform human developmental path, but from individual circumstances and subjectivities. Consequently, gay men's migration decisions and processes are not based on a set pathway of coming out, gay identity formation, and partnership, but also other identities bound up with sexuality. Ethno-racial identity, for example, was prominent in the narratives of many non-white respondents. In some cases, men felt that the visible difference created by their racialization and the limited the space in which they could shape a comparatively less visible sexual identity. An Asian man living in small-town Pennsylvania, for example, felt that his Asian-ness had already rendered him so much of a curiosity that asserting a gay identity as well felt overwhelming and resulted in a desire to leave.

Others, particularly black men, felt that asserting their sexual identity would make them even more susceptible to the discrimination that they already encountered because of their race. In places with longstanding histories of segregation and discrimination (e.g., Halifax, Richmond, Philadelphia), many black men felt their lives would be dominated by a "double whammy" of racial and sexual discrimination. For these men, relocating was sometimes a means of overcoming a seemingly impossible set of life circumstances, including empirically experienced discrimination (e.g., at job interviews or social venues). In other cases, moving was a means of circumvention perceived - though not necessarily confirmed — expectations that their relatives or communities might embody 
historically accrued, culturally specific stances on homosexuality. Interestingly, men of colour - even those moving from places (e.g., Nova Scotia, Pennsylvania, Virginia) that would normally be considered less diverse than the places they moved to- - found that Ottawa and Washington, D.C., were dominated by institutionalized class- and race-based hierarchies and exhibited a degree of segregation they had never seen before. Likewise, many white respondents acknowledged the role of their privilege in both their migration decisions and day-to-day lives, responding — when prompted — that being white made it "easier" to move and resettle.

The life course approach thus offers ways to think about both how migrations may change throughout individual men's lives and how gay migration - at least in a North American context—has changed during the past several decades. For each individual, migration emerges at the confluence of age, life stage, historical contingencies, institutions, and relationships. Queer migrations, then, are not limited to early-in-life flights from threatening environments or the negotiation of geographically uneven equalities landscapes by established couples seeking to marry or adopt children. They are also more mundane movements across cities and regions that, while not driven by sexual identity, usually (and necessarily) take sexual non-normativity into consideration. In this sense, the more general migration trajectories of gay men and other queer people are also likely to have changed over time. The ideas of fear, flight, and escape to the city that have shaped much of the queer migration discourse to date were likely more relevant thirty or forty years ago than they are today — even though they were probably always in need of nuancing. As the narratives of respondents who moved in the 1980s and 1990s suggest, limited legal recognition, limited social acceptance, and the ubiquity of the closet in many 
areas - coupled with the ongoing politicization of the gay rights movement in cities like New York, Toronto, and San Francisco_-affirm the centrality of metropolitan emancipation in queer migrations and imaginaries of that era. While these types of migrations are not obsolete, there is now a more pressing need to examine the multiplicity of queer migrations in an increasingly variegated landscape of rights and acceptance.

\subsection{Limitations: Those Who Cannot Migrate and Those Who Must}

Before moving on to a number of more specific conclusions, two limitations of this study must be acknowledged: (1) a focus on more general mobility and migration rather than immigration; and (2) the elision of gay men in Ottawa and Washington, D.C., who have not moved from other places. Since the purpose of this project was to capture a broad range of gay men's migrations in North America, the previous chapters purposefully focus on men's more loosely governed cross-regional and inter-city migrations rather than immigration issues dictated by federal (and often heteronormative) laws. The focus on day-to-day forms of power and oppression, as opposed to the more concretized rights and regulations governing gay lives, elides the unevenness of gay rights across and within countries - particularly in the United States. As scholars like Silvey (2004), Manalansan (2006), and Lubhéid (2005, 2008) have observed, the heterosexism of marriage and immigration rights across places have profound effects on the lives and mobilities of queer people. A few of the men interviewed-especially those at later points in the life course-were more constrained by the legality of their partnerships and mobilities across jurisdictions than they were by the particularities of day-to-day life in a capital city. For partnerships in which both partners were U.S. 
citizens, this was usually reflected in decisions to stay within jurisdictions such as D.C.,

where partner or marriage rights are granted. For bi-national couples, the laws in the

United States had profound effects. Steve described his inability to gain resident status in

the United States and his decision to move back to Canada with his partner:

I was working in Washington and I was there on a [North American Free Trade Agreement Nonimmigrant Professional] TN visa, and the TN Visa basically ties you to your employer, in that you have basically very limited job mobility because the visa is associated with your ... um, my partner, um, was working for the American government, wasn't particularly happy in his job, wanted to make a move, and he had already had permanent resident status in Canada, so he could basically go anywhere, whereas I was tied to my employer in Washington ... and so, that also played a role in ... in deciding to come back here, because there was the fact that I was tied to my employer, um, didn't have my mobility. (Steve, 47, white, Anglo-Canadian)

Martin shared the details of an even more complex scenario in which his foreign partner

was immobilized by both their inability to marry in an internationally recognized way and

the visa-granting rules of the Latin American country that he had left:

Until [partner's name]'s immigration situation is not dependent on a work visa which leaves him at the mercy of CIS ... we're definitely keeping things at arm's length ... there would be issues with him going to see an immigration officer at $a$, at the embassy or the consulate down in Paraguay, and if they had some sense that he was forming lasting relationships here when he's not supposed to 'cause he's on a work visa, like they could, someone could conceivably deny him a visa ... you can get married [in D.C.], it just wouldn't—other than filing D.C. taxes jointly - I don't know what exactly it would do ... [If gay marriage were legal] we'd have gotten married five years ago and he would have gotten his green card immediately ... but now he's entirely dependent on his work ... for his ability to stay. So if ... they went through layoffs... if he couldn't find someone else to pick him up and sponsor him for, for work he would have been on a plane, whereas we know people that, you know, are in similar situations, heterosexual couples and they just get married and it just becomes a non-issue. (Martin, 46, white, European-American). 
For men engaged in same-sex coupled relationships in the United States, immigration policies articulated at the federal level continue to have a profound impact on both mobilities and livelihoods.

Second, the analysis put forth here does not address the life circumstances of men living in Ottawa and Washington, D.C., who have not moved to those cities from other places. As Chapter 7 noted, there is consequently a selection bias in the study that paints migration as a positive and integral component of the gay life course. In fact, not all gay men have the opportunity to migrate and the life experiences of men who have grown up in Ottawa and Washington, D.C., and not left tend to be quite different from those of the mobile, often middle-class gay men who move to them. While this study cannot presume to speak for those men who never left (e.g., those who came out "in place"), some interviews suggest that they might experience particular segments of the life course differently. Chapter 7, for example, demonstrates that some men experience significant distress prior to moving, a finding that also suggests that some men may become depressed or otherwise ill to the extent that they become immobilized.

The study's emphasis on migration itself also privileges to some extent the experiences of men who occupy certain class and racial subjectivities. Shane, for example, suggested that the idea of Washington, D.C. (and particularly Northwest D.C.) as a destination for gay migrants was likely perpetuated by privileged, and usually white gay men, rather than black men from who had grown up in peripheral neighborhoods such as Anacostia and Congress Heights in Southeast D.C. Their perceptions of Washington, D.C., as a locus of close family ties, poverty, but also poverty and 
discrimination, might lead them (if means allowed) to leave the city entirely rather than simply taking the Metro to Dupont Circle—itself seen as a bastion of gay white privilege.

Um, so we may be getting like a skewed perspective about [homophobia in D.C.] ... I do also know that young people get a lot of harassment in the communities, and a lot of people come from low-income areas, andyou know sometimes I think about-I think, if you're from the city, if you're from lower-income communities, the city's a place you escape and if you come, if you're outside of that, the city's a place you go to for refuge. And so it depends on who you are, the city and its sense of safety and, and comfort, I think, may change based on where you come from. (Shane, 27, black, African-American)

Similarly, the Ottawa metropolitan area includes several working-class communities that — while not destinations for the gay men who come from across Canada to go to university or work in the federal government — typify everyday life for many of the gay men already living there. Some men have grown up in and continue to live and work in poor neighbourhoods within the core of the city (e.g., Vanier) or in agricultural communities surrounding the city. For certain men living in Ottawa, mobility may be limited by educational attainment, income, skills, and - in the case of French-speaking communities—language. The result is a "tale of two cities" (see Wright et al. 2003) similar to that in D.C. As Sam observed in his interview:

I mean the last Community Foundation report, you know, spins a tale of two Ottawas ... there is a definite divide between those who have fulltime benefits and salary and, um, the technology sector has taken a hit in the past several ... so I think there's a very stable employment-real estate-housing base here that speaks to an advantage and, uh, privilege and comfort. (Sam, 44, white, European-Canadian)

Sam's comments reveal that alongside the narrative of rights and regulations in gay men's lives - and the ways in which gay men use space and mobility to navigate themthere is an equally important story of how race and class might render certain groups of gay men and other queer people less able to negotiate the uneven contours of stigma and 
exclusion they encounter in North America. For these men, the myth of the mobile, highincome "creative worker" or "global gay" (Florida 2002; Puar 2002) becomes even more problematic. In a city like Ottawa, marked by the longstanding absence of a gay village and general disinvestment in the infrastructure of the gay community, where do younger men come out, and where are they able to access the resources they need? Similarly, how do gay men who fall outside the normative expectations of high education and high income form meaningful community identities in cities with gay networks characterized by black-tie activism and frequent travel outside the city limits? While not addressed here, these observations suggest a need for continued interventions that investigating the role of class and privilege in the formation of gay identities.

\subsection{The Role of Scale and Urban Hierarchy in Gay Men's Migrations}

This study has focused more on individual gay men's lives and the dynamics of the particular places traversed, rather than potential national typologies of gay migration. On one level, the two case studies represent similar scenarios of gay men seeking social space and economic security in two capital-city beacons or destinations. While the design of the study gives primacy to the city as a scale of analysis, it is also important to consider how different scales of belonging might mediate men's migrations — and how those scales might fit together. It is therefore useful to think of sexual citizenship (Bell and Binnie 2004), or the ways in which sexuality influences how individuals conceive themselves vis-à-vis the state (and vice versa), as multi-scaled. Under the circumstances in which many men's migrations originated, lower spatial scales such as the body, the school, and the home seemed to take precedence over those of the city or the nation. Yet 
the ways in which men came to understand their identities as stigmatized - and the ways in which they anticipated this to affect their relationships or disrupt their lives - are very much products of long-term efforts by the Canadian and U.S. governments to cast gay men as a non-normative population in need of regulation (Halperin 2000; Olund 2010). In many ways, this remains the baseline for how society understands sexual non-normativity and how gay men might come to understand themselves. There are, however, differences, in the ways these understandings diffuse through or are mitigated by place. The very recent efforts in gay and lesbian inclusion articulated at the scale of the state or the nation diffuse quickly to the regions, towns, homes, and even individuals that are the most privileged by the state and its institutions (e.g., urban regions, middle-class families, government employees, or university-educated individuals). Yet the diffusion of these ideas, in addition to being recent, is also uneven. Gay men's migrations therefore originate in a complex patchwork of homes, families, social networks and institutions in which their sexuality may be alternately affirmed and excluded.

When a destination is considered, men also contemplate forms of sexual citizenship that are more concretely articulated at the scale of the state or the nation. Here, a clearer divide emerges between gay-affirming places that constitute suitable destinations and those left behind. This divide is not delineated by the imagined cultural significance of particular cities, but by the very tangible ways in which certain places have meaningfully included gay men and other queer people in their structures and institutions. While this can be articulated at higher scales (e.g., marriage rights in Canada most northeastern U.S. states, and Washington, D.C.), it seems that the ad hoc formation of different types of urban economies in specific cities - and sometimes their 
relationships to the state-holds more sway in determining the suitability of potential destinations. For example, cities with a preponderance of sectors traditionally open to sexual non-normativity (e.g., education, arts and design, government) or with more institutions expected to uphold state articulations of non-discrimination (e.g., the civil service) are also seen as more inclusive of gay men. On one hand, this suggests that there are now places beyond New York and San Francisco where gay men can pursue a more complete form of sexual citizenship, facilitated not just by an extensive network of social venues and grassroots advocacy organizations, but by institutions that very much engage with the state. In this way, state-suffused cities like Ottawa and Washington, D.C., may be the new beacons for an emergent, formalized (and possibly normalized) type of sexual citizenship. Consequently, the patterns of gay migration at the national scale are perhaps more diffuse than the mid-century journeys to San Francisco, Chicago, and New York by Kath Weston in 1995. Smaller cities with a strong state presence such as Quebec City, Quebec, and Albany, New York, might therefore emerge as reasonable alternative destinations. At the same time, these types of destinations might privilege some gay identities (e.g., middle-class, professional, and white) while excluding others.

Throughout the chapters, there are also several Canadian-U.S. differences in men's migration decisions and trajectories. First, a difference is evident in the samples garnered for Ottawa (the Canadian case study) and Washington, D.C. (the U.S. case study). While most of the men interviewed in Washington, D.C., had usually moved from other cities, and from diverse parts of the country, respondents in Ottawa had tended to follow a more regional, urban-to-rural pattern of relocation, with most moving from the Atlantic Provinces, Quebec, or within Ontario. Although there was potential geographical 
bias in both groups due to convenience sampling, many men confirmed that the demographic trends observed in each sample were externally valid. As this trend emerged, interviewees were asked whether Ottawa was a common destination for gay men from regions such as northern Ontario and the Maritime provinces. Ottawa, most agreed, was an accessible, geographically proximate regional "stepping stone" to other metropolitan areas in Canada. Washington, D.C., however, functioned more as a distinctly national destination, with migrations seemingly driven more by educational and employment opportunities — and the distinct set of institutions providing them - than by its proximity to communities of origin or its position in the urban hierarchy.

The differences between Ottawa and Washington, D.C., suggest that individual motivations, desires, and life trajectories, as well as the urban hierarchies of particular countries might influence gay men's migration trajectories (see also Plane et al. 2005). In Canada, where there were fewer cities, more distance between them, and marked divisions — both quantitatively and discursively_ between first-tier, second-tier, and third-tier cities, men more frequently alluded to the types of cities available to them and the potentials of each type. Ottawa, for example, was acceptable as a stepping stone for men who were early in life, coming out, or from rural areas, but ultimately considered inferior to one of the three main metropolitan areas of Vancouver, Toronto, and Montreal—with the latter two cities often used for routine, temporary trips that "hedged" gay lives in Ottawa. Washington, D.C., in contrast, was seen to be "just another city" in a multi-nodal hierarchy of multiple potential destinations. Migrations to D.C. were therefore more associated with the particularities of educations and careers than with the city's relative location or its potential to serve as a stepping stone from surrounding rural 
areas. Interestingly, respondents in Ottawa were more likely to anticipate moving down the urban hierarchy later in life than respondents in Washington, D.C. This suggests, perhaps, that both the actual and perceived baseline of rights and acceptance for gay men in Canada - regardless of city size — is in fact higher in Canada than in the United States.

\subsection{Between Body and Place: The Relational Nature of Queer Migration}

A key thread throughout this study has been the juxtaposition of embodied experiences (e.g., coming out, health, self-discipline) and the structures (e.g., places, networks, institutions) that mediate them. While a turn to the body has shed light on the highly contingent and subjective nature of queer migration, it tends to elide the role of the places from which queer migration emerges and the flows through which it travels. Consequently, the places and trajectories in various queer migrations continue to be conceived rather simplistically, both in academia and in popular discourses. Movement between abstract types of places (e.g., urban and rural, liberal and conservative) takes precedence by default, and queer journeys are usually imagined as unilateral, often final escapes from threatening or harmful environments. In addition, the continued emphasis on the body creates an assumption that most queer migrations are based on an individual's identity quest or their development as a sexual being.

A renewed focus on pushes, pulls, and flows in queer migration —in some ways a revisitation of Ravenstein's (1885) theory of human migration, albeit a more nuanced and complex one - helps to work toward establishing some of the trends and variations in the journeys of sexually non-normative individuals. The imagined push of an intolerant environment, for example, is recast in Chapter 5 as the simultaneous management of 
place-embedded social and familial relationships and an ongoing coming-out process. The escape or displacement referenced by many geographers studying gay migration in the 1990s and early 2000s (Weston 1995; Puar et al. 2003; Binnie 2004) is similarly redrawn in Chapter 6 as an extended, circuitous journey in which men test out and try out different places and identities throughout life. The attraction of various destinations, particularly cities, is also complicated and reconfigured in this analysis. The cities of Ottawa and Washington, D.C.- discussed at length in Chapters 8 and 9-were rarely deemed to be sites of emancipation, and were never deemed to be merely because of their city-ness. Instead, they emerged as places that provided a unique set of career- and community-based opportunities for gay men, particularly later in life and especially once careers were established. With an increasingly institutionalized gay economy that departs markedly from the consumption-based forms present in many cities, these two capital cities have become destinations that are both highly attractive and highly regulatory.

These findings suggest a more relational conception of queer migration, one in which migrations emerge at the intersection of the social dynamics of places (including the networks, institutions, and relationships established within places), the felt impact of these dynamics on the individual body, and individual subjectivities such as class, race, age, and life stage. The body, then, is not a deterministic end from which desires and quests for movement emerge. Instead, the queer body—itself dynamic and changing throughout the life course - responds to the pushes and pulls of real and imagined networks, institutions, and relationships in a variety of sending and receiving places. This conception establishes queer migrations as neither displacements nor wanderings, but as 
active, ongoing, and often carefully managed journeys that negotiate an uneven landscape of rights and acceptance throughout the life course.

\subsection{Ongoing Experiences: Coming Out and the Regulation of Sexuality}

This study reinforces emerging understandings of coming out as a continuous, ongoing process that emerges in different forms and iterations throughout the life course. The first experience of disclosing a changing sexual identity may occur in a family home, before any migrations occur (Valentine et al. 2003). Men may then be faced with coming out again after moving, either to a specific gay community or scene or simply to an entirely new group of friends. Coming out in the workplace often involves assessing the suitability of the environment, the potential for formal or informal repercussions, and the degree to which sexual non-normativity can be acknowledged or displayed (Willis 2009, forthcoming). Although most men note the decreasingly centrality of a gay identity as their own lives progress, they are still continuously prompted to disclose something conceived as non-normative as they move through different places. The continued importance of coming out in gay men's lives affirms that being gay continues to be conceived by society and by men themselves as deviant—not necessarily immoral but not normal either. Regardless of changes in laws concerning marriage or adoption, the perception of being gay as problematic or abnormal — emanating from society and internalized by gay men themselves — continues to mediate gay men's lives in more mundane ways, including their migration decisions.

The continued conception of "gay" as a problematic or deviant identity in need of regulation, while emerging in different and spatially uneven forms, is also suffused 
through a wide range of places. In family homes, men reported being regulated by parents who feared that exploration of sexual identity would expose their sons to danger. In schools and in public places (e.g., streets), some men experienced regulation in the more direct forms of verbal harassment. In yet other settings, men employed self-regulation of their deportment, relationships, and location (e.g., walking "butcher" in certain neighbourhoods and living the more visibly gay aspects of life in other cities). In the cases of Ottawa and Washington, D.C., many men found upon moving that they were exposed to new regimes of regulation based on professionalism, class status, and historic legacies of repression and discrimination. Consequently, migration for most men-while certainly helping them to negotiate important life events — rarely results in any sort of final emancipation from societal regulation or self-regulation. Instead, it simply changes the context and scale of regulation. Rather than being regulated by families or communities in which being gay was cast as problematic, men who moved to Ottawa and Washington, D.C., encountered dense configurations of government and city institutions that, while nominally inclusive of gay men and other queer people, encouraged normalized and conservative ways of being in more subtle and diffuse ways. Therefore, the regulation of sexual non-normativity is often negotiated through movement, but never truly avoided, escaped, or overcome.

\subsection{Questioning 'The New Homornormativity'}

During the past decade, many geographers have taken up the debate surrounding "homonormativity," or the assimilation of queer lives into ostensibly heteronormative practices, such as marriage, domesticity, and the purchase of property and amenities 
(Duggan 2002; Nast 2002; Sothern 2004; Oswin 2005). These practices are seen as encouraged by both the state itself (e.g., through the granting of marriage rights) and in the fuzzier, more diffuse trends of neoliberalism, such as a disinvestment in collective, radical queer politics. Middle-class, coupled, and usually white gays and lesbians are typically highlighted as the key subjects of the new homonormativity. These subjects are positioned as those who have the resources to participate in homonormative practices and lifestyles, and who are ostensibly upheld as the representatives that allow queer people to edge closer to the margins of acceptability. The homonormative trend has been alternately critiqued as eliding the racism and discrimination affecting queer people of colour, flattening the diversity and fluidity of queer identities, and dulling the radicalism and transgression that once characterized queer politics.

In this discourse, activities considered the most radical, transgressive, or "queer"— despite the seemingly steady decline of activities categorized as such—are upheld as the ideal, while other practices are dismissed as homonormative. This distinction establishes almost a type of "queer normativity" in which the most assertive and radical expressions of non-normativity (e.g., gender-bending, sexual liberation politics) are valued as the practices most representative of a queer identity. On one hand, then, men featured in this study might be characterized as homonormative subjects. Most are educated and middle-class, and many are coupled. They have also moved to two cities in which the forces of social and sexual normalization are arguably stronger than they are in other North American cities.

To flatly dismiss these men's lives as homonormative, however, would also ignore the ways in which their life courses have been altered and negotiated by virtue of 
being gay. Even men coming from supportive, middle-class homes in politically liberal areas still undertake relocation as part of coming out. Similarly, middle-class gay men working in government bureaus may still "push back" against normative environments in various ways. One might serve as a "watchdog" for workplace homophobia and discrimination through their bureau's auxiliary LGBT organization. Another might travel on a weekly basis to Montreal or New York to participate in the types of gay events (e.g., parties and parades) that he feels would be socially unacceptable or professionally dangerous in Ottawa or Washington, D.C. In addition, many men's migrations to Ottawa and Washington, D.C.— - and within these cities_ — could be seen as complicating the assumed heteronormativity of these cities' most normalized spaces, including the civil service and the outlying suburbs. This reflexivity, which Visser (2008) refers to as homonormalization, problematizes the notion of homonormativity as a one-way process. In both cities, discourses of empowerment emerged alongside discourses of regulation. Just as many men alluded to the regulatory forces of "the government town" upon sexually non-normative bodies, several also claimed that the influx of gay men into these two cities, and particularly into the Canadian and U.S. civil services, had rendered the capital city a place where "you have to be okay with gay people."

\subsection{Toward Holistic and Contingent Concepts of Queer Migration}

The central goal of this thesis has been to unfix the reified scales, binaries, and concepts used in the past to understand queer migration. Queer migration studies during the past decade have focused mostly on two scales of analysis, the nation-state and the body. Both are useful frameworks for studying the relationships between sexuality and 
mobility. The literature on state policies and practices reveals the privileging of the heteronormative family in national immigration policies and the quiet suppression of transnational mobility for queer people. Similarly the focus on the body, typified by studies of intra-national queer migration, usefully highlights mobility as an identityforming tool and an expression of embodied emotions and desires. These two scales of queer migration, however, are only occasionally discussed in conjunction (i.e., the embodied experience of being regulated). Relying on these two frameworks obscures the variety of forces shaping queer migration at various social and spatial scales, including the home, the family, the social network, the community, and the region. This thesis suggests that most migrations emerge from both life transitions at the level of the body and the social dynamics of places in which the body is located during those transitions. This suggests that more careful attention must be paid to the interrelationships of queer bodies and the breadth of places they encounter and traverse over the life course.

Second, this thesis disrupts many of the binaries assumed to drive the migrations of sexually non-normative individuals. Spatial binaries, including in the closet/out of the closet, rural/urban, countryside/metropolis, liberal/conservative, developed/developing and even East/West have characterized much of the queer migration discourse during the past two decades (Weston 1995; Cant 1997; Parker 1999; M. Brown 2000; Puar 2002, 2007; Binnie 2004). The narratives discussed here allow for a conception of queer migration that moves beyond binary places to the dynamics within places; that is, the families, networks, relationships, and institutions in which queer people are embedded as they move through space. Certainly, the cultures, policies, and practices of various places influence these dynamics, but often in more nuanced and diffuse ways than might be 
expected based on more typical readings of the queer migration narrative. Cities such as Seattle (Washington), Austin (Texas), and Toronto (Ontario), places typically characterized as homelands or havens to which queer people might move, became points of departure for men who- because of their life circumstances (e.g., beginning a comingout process or leaving a relationship) or subjectivities (e.g., as a person of colour)— rendered those places difficult to live in. Similarly, Ottawa and Washington, D.C., two cities that have never been embedded in the queer imaginary, became important destinations for men seeking to create community and professional identities in sectors that have transformed to include them publicly and formally — albeit in ways that are sometimes carefully circumscribed and highly regulated ways.

Lastly, this study challenges teleologically and ontologically final conceptions of queer migrations. Queer migrations are rarely one-time events; instead, they are continuous, circuitous journeys undertaken throughout life — with moves often occurring when one's sexuality renders a particular life transition difficult or in need of (spatial) negotiation. The narratives reveal two reasons for the ongoing nature of queer migration. First, the "events" typically thought to influence the migrations of queer people (e.g., coming out, seeking same-sex partnership) are actually ongoing processes that emerge and re-emerge at various points in the life course. Coming out, for example, often involves traversing several different places and may involve closeting oneself in one place and disclosing in another, or doing both in the same place - contingent on the social and spatial context. It also continues throughout the life course, as new workplaces, neighbourhoods, and social networks are encountered. Romantic relationships, similarly, are often more frequently informal, interrupted, and short-term than they are concretized 
in the form of same-sex marriage. Consequently, queer migrations, even when informed by factors deemed common-sense, are still more complex than typically imagined. Sexual non-normativity, coupled with the uneven landscape of rights and acceptance that accompany it, is therefore likely to influence migration and mobility throughout life, in both direct forms such as immigration policy and in more diffuse forms related to the ongoing characterization of gay, queer, and other identities as problematic or in need of regulation and negotiation.

Given the vast array of factors influencing queer migrations, it can also be argued that gay men's migrations are likely to be temporally and historically contingent. The discourses that have until recently have become concretized in queer migration literature (e.g., rural-to-urban flight) have historical points of origin: the Industrial Revolution established the city as the place in which single men and women were less constrained by hetero-normative boundaries and where identifiable "gay cultures" were created. For much of the twentieth century, homosexuality was both classified as mental illness and illegal in practice; this was the norm for North America and most of the West. Later in the century, cities such as New York and San Francisco were established as the key sites where a truly radical queer politics — assumed to be a siren call for young queer people throughout the country - had emerged. Consequently, the idea that most queer migrations in North America originated in hostile, usually rural environments and landed in the metropolis was a reasonable one, although most queer migrations had still probably been complex in nature. Indeed, some of the migrations of the 1940s, 1950s, 1960s, and 1970s that Weston (1995) chronicles in "Get thee to a big city" are likely to have followed a rural-to-urban trajectory and - in the context of more limited general population mobility 
at that time - have been singular in nature. Many journeys undertaken by queer people today undoubtedly have an element of this traditional narrative but are likely to be more diverse in nature, signalling the need for the more careful analysis of queer migration undertaken here.

As the landscape of queer rights and queer politics continues to change, the narratives of queer migration must also change. Rights to marry and adopt have been established in several federal and local jurisdictions, and even individual cities and workplaces have adopted anti-discrimination ordinances and policies. The advent of the Internet and the growing presence of queer lives and identities in the mass media have further diffused landscapes of inclusion and acceptance that have always been decentered but often characterized in binary ways. Similarly, the grassroots and radical queer politics of the 1960s and 1970s — existing in many forms and places but usually thought to emerge in a small set of cities — now sits alongside a highly legalized politics that affects spatially diffuse groups but is perhaps most densely concentrated in centers of power such as Ottawa and Washington, D.C. Consequently, new narratives must be developed that consider the evolution of both individual queer lives and the places in which those lives are embedded. Continued research in this area promises not only to understand the "everyday" nature of queer migration, but a broader understanding of how both places and journeys shape queer lives. 
Aldrich, R. 2004. Homosexuality and the City: An Historical Overview. Urban Studies 41, 9: 1719-1737.

Andrew, C. 2007. Trying to be World-Class: Ottawa and the Presentation of Self. In T.A. Gibson and M.D. Lowes (eds.), Urban Communication: production, text, context. Lanham, MD: Rowman \& Littlefield, pp. 127-141.

Andrucki, M.J., and G.S. Elder. 2007. Locating the state in queer space: GLBT non-profit organizations in Vermont, USA. Social \& Cultural Geography 8: 89-104.

Arora, K. 2006. The Mythology of Female Sexuality: Alternative Narratives of Belonging. Women: A Cultural Review 17: 220-250.

Badgett, M.V.L. 1996. Employment and sexual orientation: Disclosure and discrimination in the workplace. In A.L. Ellis and D.B. Riggle (eds.), Sexual identity on the job: Issues and services. New York: Haworth Press.

Bailey, A. 2009. Population Geography: Lifecourse Matters. Progress in Human Geography 33, 3: 407-418.

Balsam, K.F., Beauchaine, T.P., Mickey, R.M., and E.D. Rothblum. 2005. Mental Health of Lesbian, Gay, Bisexual, and Heterosexual Siblings: Effects of Gender, Sexual Orientation, and Family. Journal of Abnormal Psychology 114, 3: 471-476.

Barker, J.C., G. Herdt, and B. de Vries. 2006. Social support in the lives of lesbians and gay men midlife and later. Sexuality Research \& Social Policy 3, 2: 1-23.

Barton, B. 2010. 'Abomination'-Life as a Bible Belt Gay. Journal of Homosexuality 57, 4: 465-484.

Bassi, C. 2006. Riding the dialectical waves of gay political economy: a story from Birmingham's commercial gay scene. Antipode 38: 213-235.

Baxter, J., and J. Eyles. 1997. Evaluating Qualitative Research in Social Geography: Establishing 'Rigour' in Interview Analysis. Transactions of the Institute of British Geographers 22, 4: 505-525.

Bayer, R. 1987. Homosexuality and American Psychiatry. Princeton, NJ: Princeton University Press.

Bell, D. 1991. Insignificant Others: Lesbian and Gay Geographies. Area 23, 4: 323-329.

Bell, D., J. Binnie, J. Cream, and G. Valentine. 1994. All hyped up and no place to go. Gender, Place and Culture 1: 34-47. 
Bell, D. and J. Binnie. 2004. Authenticating queer space: citizenship, urbanism and governance. Urban Studies 41, 9: 1807-1820.

- 2000. The sexual citizen: queer politics and beyond. Cambridge, UK: Polity Press.

Bell, D., and G. Valentine (eds.). 1995. Mapping Desire: Geographies of Sexualities. London: Routledge.

Bianchi, F.T., C.A. Reisen, M.C. Zea, P.J. Poppen, M.G. Shedlin, and M.M. Penha. 2007. The sexual experiences of Latino men who have sex with men who migrated to a gay epicenter in the USA. Culture, Health \& Sexuality 9, 5: 505-518.

Binnie, J. 2007. Sexuality, the Erotic, and Geography: Epistemology, Methodology, and Pedagogy, in K. Browne, J. Lim, and G. Brown (eds.). Geographies of Sexualities: Theory, Practices, and Politics. Burlington, VT: Ashgate, pp. 29-38.

- 2004. The Globalization of Sexuality. London: Sage.

- 1995. Trading places: consumption, sexuality, and the production of queer space. In D. Bell and G. Valentine (eds.), Mapping Desires: Geographies of Sexualities. London: Routledge, pp. 182-199.

Binnie, J. and B. Skeggs. 2004. Cosmopolitan knowledge and the production and consumption of sexualized space: Manchester's gay village. The Sociological Review 52: 39-61.

Black, D.A., S.G. Sanders, and L.J. Taylor. 2007. The Economics of Gay and Lesbian families. Journal of Economic Perspectives 21: 53-70.

- 2002. Why Do Gay Men Live in San Francisco? Journal of Urban Economics 51: $54-76$.

Bondi, L., J. Davidson, and M. Smith. 2005. Introduction: Geography's "emotional turn," in J. Davidson, L. Bondi, and M. Smith (eds.), Emotional Geographies. Aldershot, UK: Ashgate, pp. 1-16.

Bontempo, D. E., and A. D'Augelli. 2002. Effects of At-School Victimization and Sexual Orientation on Lesbian, Gay, or Bisexual Youths' Health Risk Behavior. Journal of Adolescent Medicine 30: 364-374.

Botnick, M.R., K.V. Heath, P.G.A. Cornelisse, S.A. Strathdee, S.L. Martindale, and R.S. Hogg. 2002. Correlates of Suicide Attempts in an Open Cohort of Young Men Who Have Sex with Men. Canadian Journal of Public Health 93, 1: 59-62. 
Boysen, G.A., D.L. Vogel, S. Madon, and S.R. Wester. 2006. Mental Health Stereotypes About Gay Men. Sex Roles 54: 69-82.

Branchik, B.J. 2002. Out in the Market: A History of the Gay Market Segment in the United States. Journal of Macromarketing 22, 1: 86-97.

Brown, G. 2009. Thinking beyond homonormativity: performative explorations of diverse gay economies. Environment and Planning A 41: 1496-1510.

- 2008. Urban (Homo)Sexualities: Ordinary Cities and Ordinary Sexualities. Geography Compass 2/4: 1215-1231.

Brown, G. K. Browne, R. Elmhirst, and S. Hutta. 2010. Sexualities in/of the Global South. Geography Compass 4, 10: 1567-1579.

Brown, M. 2009. 2008 Urban Geography Plenary Lecture-Public Health as Urban Politics, Urban Geography: Venereal Biopower in Seattle, 1943-1983. Urban Geography 30, 1: 1-29.

- 2006. Sexual citizenship, political obligation, and disease ecology in gay Seattle. Political Geography 25: 874-898.

- 2000. Closet Space: Geographies of Metaphor from the Body to the Globe. London: Routledge.

- 1997. Replacing Citizenship: AIDS and Radical Activism. New York: Guilford.

- 1995. Ironies of distance: An ongoing critique of the geographies of AIDS. Environment and Planning D: Society and Space 13: 159-183.

Brown, M., and L. Knopp. 2008. Queering the Map: The Productive Tensions of Colliding Epistemologies. Annals of the Association of American Geographers 98, 1: 40-58.

- 2006. Places or Polygons? Governmentality, Scale, and the Census in The Gay and Lesbian Atlas. Population, Space and Place 12: 223-242.

Browne, K. 2006. Challenging Queer Geographies. Antipode 38, 5: 885-893.

Browning, F. 1998. A Queer Geography: Journeys toward a Sexual Self. New York: Crown.

Bryson, M., L. MacIntosh, S. Jordan, and H. Lin. 2006. Virtually Queer? Homing Devices, Mobility, and Un/Belongings. Canadian Journal of Communication 31: 791-814. 
Cant, B. 2005. Exploring the implications for health professionals of men coming out as gay in healthcare settings. Health and Social Care in the Community 14, 1: 9-16.

Cant, B. (ed.) 1997. Invented Identities? Lesbians and Gays Talk About Migration. London: Cassel.

Cantú, L. 1999. Border crossings: Mexican men and the sexuality of migration. Unpublished doctoral dissertation, University of California, Irvine.

Carrillo, H. 2004. Sexual migration, cross-cultural sexual encounters and sexual health. Sexuality Research and Social Policy 1: 58-70.

Carpenter, C. 2007. Revisiting the Income Penalty for Behaviorally Gay Men: Evidence from NHANES III. Labour Economics 14: 25-34.

Carpenter, C, and G.J. Gates. 2008. Gay and Lesbian Partnership: Evidence from California. Demography 45: 573-590.

Cass, V.C. 1979. Sexual orientation identity formation: A theoretical model. Journal of Homosexuality 4: 219-235.

Castells, M. 1983. The City and the Grassroots. Berkeley, CA: University of California Press.

Castles, S., and M.J. Miller. 1998. The Age of Migration: International Population Movements in the Modern World. New York: The Guilford Press.

Chang, H.V. 2008. Autoethnography as method: Developing qualitative inquiry. Walnut Creek, CA: Left Coast Press.

Chauncey, G. 1994. Gay New York: Gender, Urban Culture, and the Making of the Gay Male World, 1890-1940. London: Flamingo.

Clifford, J. 1988. The Predicament of Culture. Berkeley: University of California Press.

Cochran, S.D. 2001. Emerging issues in research on lesbians' and gay men's mental health: does sexual orientation really matter? American Psychologist 56, 11: 931947.

Cochran, S.D., and V.M. Mays. 2002. Relation between psychiatric syndromes and behaviorally defined sexual orientation in a sample of the U.S. population. American Journal of Epidemiology 151: 516-523.

- 2000. Lifetime Prevalence of Suicide Symptoms and Affective Disorders among Men Reporting Same-Sex Sexual Partners: Results from NHANES III. American Journal of Public Health 90, 4: 573-578. 
Cochran, S.D., V.M. Mays, M. Alegria. A.N. Ortega., and D. Takeuchi. 2007. Mental Health and Substance Use Disorders among Latino and Asian American Lesbian, Gay, and Bisexual Adults. Journal of Consulting and Clinical Psychology 75, 5: 785-794.

Cochran, S.D., V.M. Mays, and J.G. Sullivan. 2003. Prevalence of Mental Disorders, Psychological Distress, and Mental Health Services Use among Lesbian, Gay, and Bisexual Adults in the United States. Journal of Consulting and Clinical Psychology 71, 1: 53-61.

Cohler, B.J., and A. Hostetler. 2003. Linking Life Course and Life Story: Social Change and the Narrative Study of Lives over Time. In J.T. Mortimer and M. J. Shanahan (eds.), Handbook of the Life Course. New York: Kluwer, pp. 555-576.

Cohler, B.J., and R.M. Galatzer-Levy, R.M. 2000. The course of gay and lesbian lives: Social and psychoanalytic perspectives. Chicago: University of Chicago Press.

Cohn, S.E., J.D. Klein, J.E. Mohr, C.M. van der Horst, and D.J. Weber. 1994. The Geography of AIDS: Patterns of Urban and Rural Migration. Southern Medical Journal 87, 6: 599-606.

Colgan, F. 1999. Recognising the lesbian and gay constituency in UK trade unions: moving forward in UNISON. Industrial Relations Journal 30, 5: 444-463.

Conradson, D., and D. McKay. 2007. Translocal subjectivities: mobility, connection, and emotion. Mobilities 2: 167-174.

Cooke, T.J. 2003. Family migration and the relative earnings of husbands and wives. Annals of the Association of American Geographers 93, 338-349.

Cooke, T.J., and M.A. Rapino. 2007. The Migration of Partnered Gays and Lesbians between 1995 and 2000. The Professional Geographer 59: 285-297.

Cooper, D. 2006. Active citizenship and the governmentality of local lesbian and gay politics. Political Geography 25: 921-943.

Cornwell, J. 1988. A case study approach to lay health beliefs: reconsidering the research process. In J. Eyles and D.M. Smith (eds.), Interpreting the Geographical World: Qualitative Approaches in Geographical Research. Oxford, UK: Basil Blackwell, pp. 219-232.

Cowan, S. 2005. Gender is No Substitute for Sex: A Comparative Human Rights Analysis of the Legal Regulation of Sexual Identity. Feminist Legal Studies 13: 67-96.

Cresswell, T. 1996. In placelout of place. London: University of Minnesota Press. 
Daniel, C. 1997. Diminishing Returns from Statistical Analysis: Discrimination in Public Employment. Public Administration Review 57, 3: 264-266.

Dascher, K. 2000. Are politics and geography related?: Evidence from a cross-section of capital cities. Public Choice 105: 373-392.

Davidson, J., and C. Milligan. 2004. Embodying emotion, sensing space: introducing emotional geographies. Social \& Cultural Geography 5: 523-532.

Dean, R. 2003. Imperial brotherhood: gender and the making of Cold War foreign policy. Boston: University of Massachusetts Press.

Deeprose, B., and C. Bouchard. 2010. Gayzone. Workshop presented at the Rainbow Health Ontario Conference, March 25-27, Toronto, Canada.

DeGraaf, R., Sandfort, T.G.M, and M. ten Have. 2006. Suicidality and Sexual Orientation: Differences between Men and Women in a General Population-Based Sample from the Netherlands. Archives of Sexual Behavior 35, 3: 253-262.

Deschamps, M.J. 2008. Bank St. BIA says no to village proposal. Capital Xtra, August 1. http://www.xtra.ca/public/printStory.aspx?AFF_TYPE=2\&STORY_ID=5218.

D’Emilio, J. 1989. Gay politics and community in San Francisco since World War II. In M. Duberman, M. Vicinus and G. Chauncey (eds.), Hidden from History: Reclaiming the Gay and Lesbian Past. New York: Penguin, pp. 456-473.

- 1988. Intimate matters. New York: Harper and Row.

- 1983. Sexual identities, sexual communities. Chicago: University of Chicago Press.

Diaz, R.M., G. Ayala, E. Bein, J. Henne, and B.V. Marin. 2001. The impact of homophobia, poverty and racism on the mental health of gay and bisexual Latino men: Findings from 3 U.S. cities. American Journal of Public Health 91: 927932.

Duggan, L. 2002. The new homonormativity: the sexual politics of neoliberalism. In R. Castronovo and D. Nelson (eds.), Materialising democracy: towards a revitalized cultural politics. Durham, NC: Duke University Press, pp. 175-194.

Duke University Medical Center. 2005. Duke Health Profile (The Duke). http://healthmeasures.mc.duke.edu/images/DukeForm.pdf.

Dykstra, P. and L. van Wissen. 1999. Introduction. In L. van Wisent and P. Dykstra (eds.), Population issues: an interdisciplinary focus. New York: Kluwer, pp. 122. 
Eisenberg, M., and M. Resnick. 2006. Suicidality among Gay, Lesbian and Bisexual Youth: The Role of Protective Factors. Journal of Adolescent Health 39, 5: 662668.

Elden, S. 2007. Rethinking governmentality. Political Geography 26: 29-33.

Elder, G. 1998. Life Course as Developmental Theory. Child Development 69, 1: 1-12.

- (ed.) 1985. Life course dynamics. Ithaca, NY: Cornell University Press.

Eng, D. 1997. Out here and over there: queerness and diaspora in Asian American Studies. Social Text 52/53: 31-52.

England, K.V. L. 1994. Getting Personal: Reflexivity, Positionality, and Feminist Research. The Professional Geographer 46, 1: 80-89.

Epstein, S. 2003. Sexualizing governance and medicalizing identities: The emergence of 'state-centered' LGBT health politics in the United States. Sexualities 6, 2: 131171.

Erikson, E.H. 1963. Children and Society. New York: W.W. Norton \& Co.

Fawcett, J.T. 1989. Networks, Linkages, and Migration Systems. International Migration Review 23: 671-680.

Fellows, W. 1998. Farm Boys: Lives of Gay Men from the Rural Midwest. Madison, WI: University of Wisconsin Press.

Ferguson, R. 2004. Aberrations in black: toward a queer of colour critique. Minneapolis: University of Minnesota Press.

Finney, N. 2011. Understanding ethnic differences in the migration of young adults within Britain from a lifecourse perspective. Transactions of the Institute of British Geographers, DOI: 10.1111/j.1475-5661.2011.00426.x.

Florida, R. 2005. Cities and the Creative Class. New York: Routledge.

- 2002. The Rise of the Creative Class: And How It's Transforming Work, Leisure, Community and Everyday Life. New York: Basic Books.

Flowers, P. and K. Buston. 2001. I was terrified of being different: exploring gay men's accounts of growing-up in a heterosexist society. Journal of Adolescence 24: 5165.

Floyd, F.J., and R. Bakeman. 2006. Coming-Out across the Life Course: Implications of Age and Historical Context. Archives of Sexual Behavior 35, 3: 287-296. 
Forest, B. 1995. West Hollywood as Symbol: the significance of place in the construction of a gay identity. Environment and Planning D: Society and Space 13, 2: 133157.

Fortier, A.-M. 2001. Coming home: queer migration and multiple evocations of home. European Journal of Cultural Studies 4: 405-424.

Forrester, J. 1996. If p, then what? Thinking in cases. History of the Human Sciences 9, 3: $1-25$.

Foucault, M. 1979. On Governmentality. Ideology and Consciousness 6, 5-21.

- 1978. The History of Sexuality: An Introduction. New York: Vintage.

Frank, O., and T. Snijders. 1994. Estimating hidden populations using snowball sampling. Journal of Official Statistics 10: 53-67.

Gates, G.J., and J. Ost. 2004. The Gay and Lesbian Atlas. Washington, D.C.: Urban Institute Press.

Gatrell, C., and A. Flowerdew. 2005. Choosing a Topic. In R. Flowerdew and D. Martin (eds.), Methods in Human Geography: A Guide for Students Doing a Research Project. Harlow: Pearson/Prentice Hall, pp. 38-45.

Gay, Lesbian, and Straight Education Network (GLSEN). 2011. The Trevor Project. http://www.thetrevorproject.org/content/glsen.

Gentile, P. 2000. 'Government Girls' and 'Ottawa Men': Cold War Management of Gender Relations in the Civil Service. In G. Kinsman, D.K. Buse, and M. Steedman (eds.), Whose National Security? Canadian State and the Creation of Enemies. Toronto: Between the Lines, pp. 131-142.

Gibson, C. and N. Argent. 2008. Getting On, Getting Up and Getting Out? Broadening Perspectives on Rural Youth Migration. Geographical Research 46, 2: 135-138.

Gibson-Graham, J.K. 1996. Queer(y)ing Capitalist Organisation. Organization 3: 541545.

Giffney, N. 2004. Denormatizing queer theory: more than simply lesbian and gay studies. Feminist Theory 5: 173-178.

Gopinath, G. 1997. Nostalgia, desire, diaspora: South Asian sexualities in motion. Positions Asia Critique 5, 2: 467-489. 
Gorman-Murray, A. 2009. Intimate mobilities: emotional embodiment and queer migration. Social \& Cultural Geography 10, 4: 441-460.

- 2008. Queering the family home: narratives from gay, lesbian, and bisexual youth coming out in supportive family homes in Australia. Gender, Place and Culture 15: $31-44$.

- 2007. Rethinking queer migration through the body. Social \& Cultural Geography 8, 1: 105-121.

Gorman-Murray, A., G. Waitt, and C. Gibson. 2008. A Queer Country? A case study of the politics of gay/lesbian belonging in an Australian country town. Australian Geographer 39, 2: 171-191.

Green, A.I. 2002. Gay but not queer: toward a post-queer study of sexuality, Theory and Society 31: 521-545.

Griffith, K., and M. Hebl. 2002. The Disclosure Dilemma for Gay Men and Lesbians: 'Coming Out at Work.' Journal of Applied Psychology 87, 6: 1191-1199.

Halberstam, J. 2005. In a queer time and place: transgender bodies, subcultural lives. New York: New York University Press.

Hall, P. 1986. National Capital World Cities and the new division of labour. In: H.J. Ewers, J.B Goddard and H. Matzerath (eds.), The Future of the Metropolis; Berlin, London, Paris, New York: Economic Aspects. New York and Berlin: Walter de Gruyter \& Co., pp. 135-145.

Halperin, D.M. 2000. How to do the history of male homosexuality. GLQ: A Journal of Gay and Lesbian Studies 6, 1:87-124.

Hannah, M.G. 2005. Representation/Reality. In N. Castree, A. Rogers, and D. Sherman (eds.), Questioning Geography. London: Blackwell, pp. 151-166.

Haritaworn, J. 2008. Shifting Positionalities: Empirical Reflections on a Queer/Trans of Colour Methodology, Sociological Research Online 13: no pages.

Harper, G.W., and M. Schneider. 2003. Oppression and Discrimination among Lesbian, Gay, Bisexual, and Transgendered People and Communities: A Challenge for Community Psychology. American Journal of Community Psychology 31, 3/4: 243-252.

Heikkila, E. 2005. Mobile vulnerabilities: perspectives on the vulnerabilities of immigrants in the Finnish labour market. Population, Space and Place 11: 485497. 
Heinz, W., and H. Krüger. 2001. Life Course: Innovations and Challenges for Social Research. Current Sociology 49, 2: 29-45.

Herdt, G. and R. Kertzner. 2006. I do, but I can't: The impact of marriage denial on the mental health and sexual citizenship of lesbians and gay men in the United States. Sexuality Research and Social Policy 3, 1: 33-49.

Herdt, G., J. Beeler, and T. Rawls. 1997. Life course diversity among older lesbians and gay men: A study in Chicago. Journal of Gay, Lesbian, and Bisexual Identities 2: 231-247.

Hopkins, P., and R. Pain. 2007. Geographies of age: thinking relationally. Area 39: 287294.

Hockey, J., and A. James. 2003. Social identities across the life course. Basingstoke, UK: Palgrave MacMillan.

Howe, C. 2007. Sexual Borderlands: Lesbian and Gay Migration, Human Rights, and the Metropolitan Community Church. Sexuality Research \& Social Policy 4, 2: 88107.

Hubbard, P. 2005. The Geographies of 'Going Out': Emotion and Embodiment in the Evening Economy. In J. Davidson, L. Bondi, and M. Smith (eds.), Emotional Geographies. Aldershot, UK: Ashgate, pp. 117-134.

Human Rights Campaign. 2011 (a). Marriage Equality \& Other Relationship Recognition Laws. http://www.hrc.org/files/assets/resources/ Relationship_Recognition_Laws_Map(1).pdf.

- 2011 (b). Parenting Laws: Joint Adoption. http://www.hrc.org/files/assets/resources/parenting_laws_maps(1).pdf.

Humphrey, J.C. 1999. Organizing Sexualities, Organized Inequalities: Lesbians and Gay Men in Public Service Occupations. Gender, Work and Organization 6, 3: 134 150 .

Howell, P. 2007. Foucault, Sexuality, Geography. In J.W. Crampton and S. Elden (eds.), Space, Knowledge, and Power: Foucault and Geography. Aldershot, UK: Ashgate, pp. 291-316.

Hostetler, A., and B. Cohler. 1997. Partnership, Singlehood, and the Lesbian and Gay Life Course: A Research Agenda. Journal of Gay, Lesbian, and Bisexual Identity 2, 3/4: 199-230. 
Hurewitz, D. 2002. Sexuality Scholarship as a Foundation for Change: Lawrence v. Texas and the Impact of the Historians' Brief. Health and Human Rights 7, 2: 205-216.

Hutta, J. S. 2009. Geographies of Geborgenheit: beyond feelings of safety and the fear of crime. Environment and Planning D: Society and Space 27: 251-273.

Huxley, M. 2008. Space and Government: Governmentality and Geography. Geography Compass 2, 5: 1635-1658.

- 2002. Governmentality, Gender and Planning: A Foucauldian perspective. In P. Allmendinger and M. Twedwr-Jones (eds.), Planning futures: new directions for planning theory. London: Routledge, pp. 136-154.

Icard, L. 1986. Black Gay Men and Conflicting Social Identities: Sexual Orientation versus Racial Identity. Social Work Practice in Sexual Problems 49, 1/2: 83-93.

Isin, E. 2000. Governing Cities without Government. In E. Isin (ed.) Democracy, Citizenship and the Global City. London: Routledge, pp. 148-168.

Jackson, P.A. 2001. Pre-gay, post-queer: Thai perspectives on proliferating gender/sex diversity in Asia. Journal of Homosexuality 40: 1-25.

Jadotte, H. Haitian Immigration to Québec. 1977. Journal of Black Studies 7, 4: 485-500.

Jivraj, S., and A. de Jong. 2011. The Dutch Homo-Emancipation Policy and Its Silencing Effects on Queer Muslims, Feminist Legal Studies, DOI: 10.1007/s10691-0119182-5.

Johnson, D.K. 2004. The Lavender Scare: The Cold War Persecution of Gays and Lesbians in the Federal Government. Chicago: University of Chicago Press.

Johnston, L. 2007. Mobilizing pride/shame: lesbians, tourism and parades. Social \& Cultural Geography 8, 1: 29-45.

Kates, S.M. 2000. Out of the Closet and Out on the Street!: Gay Men and Their Brand Relationships. Psychology \& Marketing 17, 6: 493-513.

Kearns, R., and G. Moon. 2002. From medical to health geography: novelty, place, and theory after a decade of change. Progress in Human Geography 26, 5: 605-625.

Keil, R. 2009. The urban politics of roll-with-it neoliberalization. City 13, 2-3: 230-245.

Kertzner, R. 2001. The adult life course and homosexual identity. Annual Review of Sex Resarch 12: 75-92. 
Kimmel, D. and B. Sang. 1995. Lesbians and gay men in midlife. In A.R. D'Augelli and C. Patterson (eds.), Gay and Lesbian Aging and Human Development. New York: Oxford University Press, pp. 517-534.

King, M., E. McKeown, J. Warner, A. Ramsay, K. Johnson, C. Cort, L. Wright, R. Blizard, and O. Davidson. 2003. Mental health and quality of life of gay men and lesbians in England and Wales. British Journal of Psychiatry 183, 552-558.

Kinsman, G.W. 2001. Challenging Canadian and Queer Nationalism. In T. Goldie (ed.), In a Queer Country: Gay and Lesbian Studies in a Queer Context. Vancouver: Arsenal Pump.

- 2000. Constructing Gay Men and Lesbians as Security Risks, 1950-70. In Whose National Security? Canadian State and the Creation of Enemies, ed. G. Kinsman, D. K. Buse and M. Steedman, 143-153. Toronto: Between the Lines.

- 1996. The Regulation of Desire: homo and hetero sexualities. Montreal: Black Rose Books.

- 1995. 'Character Weakness' and 'Fruit Machines': Towards an Analysis of the Anti-homosexual Security Campaigns in the Canadian Civil Service. Labour 35: $131-161$.

Klitzman, R.L., J.D. Greenberg, L.M. Pollack, L.M., and C. Dolezal. 2002. MDMA ('ecstasy') use, and its association with high risk behaviors, mental health, and other factors among gay/bisexual men in New York City. Drug and Alcohol Dependence 66: 115-126.

Knopp L. 2007. On the Relationship between Queer and Feminist Geographies. The Professional Geographer 59: 47-55.

- 2004. Ontologies of Place, Placelessness, and Movement: queer quests for identity and their impacts on contemporary geographic thought. Gender, Place and Culture 11: 122-134.

- 2001. A Queer Journey to Queer Geography, in Moss, P. (ed.), Placing Autobiography in Geography. Syracuse, NY: Syracuse University Press, pp. 7898.

- 1992. Sexuality and the spatial dynamics of capitalism. Environment and Planning D: Society and Space 10: 651-659.

- 1990. Some theoretical implications of gay involvement in an urban land market. Political Geography Quarterly 9, 4: 337-352. 
Knopp, L., and M. Brown. 2003. Queer diffusions. Environment and Planning D: Society and Space 21: 409-424.

Kobayashi, A., and V. Preston. 2007. Transnationalism through the lifecourse: Hong Kong immigrants in Canada. Asia Pacific Viewpoint 48: 151-167.

Kobayashi. A., and B. Ray. 2005. Placing American Emigration to Canada in Context. The Migration Source, January.

Lamble, S. 2009. Unknowable Bodies, Unthinkable Sexualities: Lesbian and Transgender Legal Invisibility in the Toronto Women's Bathhouse Raid. Social \& Legal Studies 18: 111-130.

Lauria, M., and L. Knopp. 1985. Toward an analysis of the role of gay communities in the urban renaissance. Urban Geography 6, 2: 152-169.

LaViolette, N. 2003. Coming Out of Canada: The Immigration of Same-Sex Couples under the Immigration and Refugee Protection Act. Mc Gill Law Journal 49, 4: 969-1003.

Law, R. 2003. Communities, citizens, and the perceived importance of AIDS-related services in West Hollywood, California. Health \& Place 9: 7-22.

Legg, S. 2007. Spaces of Colonialism: Delhi's Urban Governmentalities. Oxford, UK: Blackwell.

- 2005. Foucault's population geographies: classifications, biopolitics and governmental spaces. Population, Space and Place 11, no. 3: 137-156.

Lemke, T. 2007. An Indigestible Meal? Foucault, Governmentality, and State Theory. Distinktion: Scandinavian Journal of Social Theory 15: 43-66.

Lena, S.M., T. Wiebe, S. Ingram, and M. Jabbour. 2002. Pediatricians' knowledge, perceptions, and attitudes toward providing health care for lesbian, gay, and bisexual adolescents. Annals of the Royal College of Physicians and Surgeons 35, 7: 406-410.

Levinson, D.J., with C. Darrow, E. Klein, and M. Levinson. 1978. Seasons of a Man's Life. New York: Random House.

Lewis, Nathaniel M. 2012 (forthcoming). Remapping Disclosure: Gay Men's Segmented Journeys of Moving Out and Coming Out. Social \& Cultural Geography 13, 4: pages forthcoming. 
- Gay in a 'government town': the settlement and regulation of gay-identified men in Ottawa, Canada, Gender, Place and Culture, DOI:

10.1080/0966369X.2011.624590.

- Lewis, N. 2009. Mental health in sexual minorities: Recent indicators, trends, and their relationships to place in North America and Europe. Health \& Place 15: 1029-1045.

- Lewis, N. (forthcoming). Beyond Binary Places: The Social and Spatial Dynamics of Moving Out and Coming Out in Canada, ACME: An International E-Journal of Critical Geographies (special issue on sexualities in Canada), submitted 10-32011.

Lewis N, and B. Donald. 2010. A New Rubric for "Creative City" Potential in Canada's Smaller Communities. Urban Studies 47, 3: 29-54.

Lind, A. 2004. Legislating the Family: Heterosexist Bias in Social Welfare Policy Frameworks. Journal of Sociology \& Welfare 31, 4: 21-34.

Lubhéid, E. 2008. Queer/Migration: An Unruly Body of Scholarship. GLQ: A Journal of Gay and Lesbian Studies 14: 2-3.

Lubhéid, E. and Cantù, L. (eds.) (2005) Queer Migrations: Sexuality, U.S. Citizenship, and Border Crossings. Minneapolis, MN: University of Minnesota Press.

Luzia, K. 2010. Travelling in your backyard: the unfamiliar places of parenting. Social \& Cultural Geography 11, 4: 359-375.

- 2008. Day Care as Battleground: using moral panic to locate the front lines. Australian Geographer 39, 3: 315-326.

Maddison, S. 2002. Small towns, boys, and ivory towers: a naked academic, in Campbell, J. and Harbord, J. (eds.), Temporalities, Autobiography and Everyday Life.

Manchester: Manchester University Press, pp. 111-127.

Manalansan, M. 2006. Queer Intersections: Sexuality and Gender in Migration Studies, International Migration Review 40: 224-249.

- 1995. In the Shadows of Stonewall: Examining Gay Transnational Politics and the Diasporic Dilemma. GLQ: A Journal of Gay and Lesbian Studies 2: 425-438.

Markwell, K. 2002. Mardi Gras Tourism and the Construction of Sydney as an International Gay and Lesbian City. GLQ: A Gay and Lesbian Studies 8, 1-2: 8199. 
Mays, V.M., and S.D. Cochran. 2001. Mental Health Correlates of Perceived Discrimination among Lesbian, Gay, and Bisexual Adults in the United States. American Journal of Public Health 91, 11: 1869-1876.

McChesney, C. 2005. Cultural Displacement: Is the GLBT Community Gentrifying African-American Neighborhoods in Washington, D.C.? The Modern American Spring.

McHugh, K. 2000. Inside, outside, upside down, backward, forward, round and round: the case for ethnographic studies in migration. Progress in Human Geography 24, 1: 171-189.

McKendrick, J. 1999. Multi-Method Research: An Introduction to its Application in Population Geography. Professional Geographer 51, 1, 40-50.

McKenzie, K., and R. Whitley. 2002. Social capital and mental health. The British Journal of Psychiatry 181, 4: 280-283.

McKinnon, N. 2005. What about the gaybourhood? Capital Xtra, November 3. http://www.xtra.ca/public/printStory.aspx?AFF_TYPE=2\&STORY_ID=1089.

McLaren, B. Jude, and A. McLachlan. 2008. Sense of Belonging to the General and Gay Communities as Predictors of Depression among Australian Gay Men. International Journal of Men's Health 7, 1: 90-99.

Meyer, I.H. 2003. Prejudice, Social Stress, and Mental Health in Lesbian, Gay, and Bisexual Populations: Conceptual Issues and Research Evidence. Psychological Bulletin 129, 5, 674-697.

- 1995. Minority Stress and mental health in gay men. Journal of Health and Social Behavior 36, 338-367.

Miller, V. 2005. Intertextuality, the referential illusion and the production of a gay ghetto. Social \& Cultural Geography 6, 1: 61-79.

Mills, T.C., J. Paul, R. Stall, L. Pollack, J. Canchola., Y.J. Chang, J.T. Moskowitz, and J.T., Catania, J.A. 2004. Distress and Depression in Men Who Have Sex with Men: The Urban Men's Health Study. American Journal of Psychiatry 161, 2: 278-285.

Mitchell, J.C. 1983. Case and Situation Analysis. Sociological Review 31, 3: 186-211.

Moore, D., and A.M. Rennie. 2006. Hated Identities: Queers and Canadian Anti-Hate Legislation. Canadian Journal of Criminology and Criminal Justice 48, 5: 823836. 
Mountz, A. 2010. Seeking Asylum: Human Smuggling and Bureaucracy at the Border. Minneapolis: University of Minnesota Press.

Munt, S. 1998. Heroic Desire: Lesbian Identity and Cultural Space. London: Cassell.

Munt, S., E. Bassett, and K. O’Riordan. 2002. Virtually belonging: Risky connectivity and coming out online. International Journal of Sexuality and Gender Studies 7, 2: $125-137$.

Nash, C.J. 2010. Queering Parkdale: queer space and Toronto's gay village. Association of American Geographers Annual Meeting, April 14.

- 2006. Toronto's gay village (1969-1982): Plotting the politics of gay identity. The Canadian Geographer 50: 1-16.

- 2005. Contesting Identity: Politics of Gays and Lesbians in Toronto in the 1970s. Gender, Place and Culture 12, 1: 113-135.

Nash, C.J., and A. Bain. 2007. 'Reclaiming Raunch?' Spatializing queer identities at Toronto women's bathhouse events. Social \& Cultural Geography 8, 1: 47-62.

Nast, H. J. 2002. Queer patriarchies, queer racisms, international. Antipode 34, 5: 877909.

Nawyn, S. 2010. Gender and migration: Integrating feminist theory into Migration Studies. Sociology Compass 4, 9: 749-765.

Olund, E. 2010. 'Disreputable life': race, sex, and intimacy. Environment and Planning D: Society and Space 28: 142-157.

Osborne, K.L. and W.J. Spurlin (eds.). 1996. Reclaiming the Heartland: lesbian and gay voices from the Midwest. Minneapolis: University of Minnesota Press.

Oswin, N. 2005. Towards Radical Geographies of Complicit Queer Futures. ACME: An International E-Journal for Critical Geographies 3, 2: 79-86.

Oswin, N., and E. Olund. 2010. Guest editorial: governing intimacy. Environment and Planning D: Society and Space 28: 60-67.

Palmore, E. 1978. When can age, period, and cohort be separated? Social Forces 57, 282 $-295$.

Parker, R. G. 1999. Beneath the Equator: Cultures of Desire, Male Homosexuality and Emerging Gay Communities in Brazil. New York: Routledge. 
Patterson, J.L. 2002 Capital Drag: Kinging in Washington, D.C. Journal of Homosexuality 43, 3/4: 93-123.

Paris, J.W. and R.E. Anderson. 2007. Faith-based Queer Space in Washington, D.C.: the Metropolitan Community Church-DC and Mount Vernon Square. Gender, Place and Culture 8, 2: 149-168.

Paul, J., J. Catania, L. Pollack, J. Moskowitz, J. Canchola, and T. Mills. 2002. Suicide attempts among gay and bisexual men: Lifetime prevalence and antecedents. American Journal of Public Health 92, 1338-1345.

Parker, R. 1999. Beneath the Equator: Cultures of Desire, Male Homosexuality and Emerging Gay Communities in Brazil. New York: Routledge.

Peck, J., and A. Tickell. 2002. Neoliberalizing Space. Antipode 34, no. 3: 380-404.

Phillips, R., Watt, D., and D. Shuttleton (eds). 2000. De-centring Sexualities: Politics and Representation beyond the Metropolis. London: Routledge.

Philo, C. 2005. The geographies that wound. Population, Space, and Place 11, 441-454.

- 1996. Coming Out: Staying in? Invited comments on 'Coming out: exposing social theory in medical geography.' Health \& Place 2, 1: 35-40.

Pile, S. 1996. The Body and the City: Psychoanalysis, subjectivity and space. London: Routledge.

Plane, D.A., C.J. Henrie, and M.J. Perry. 2005. Migration up and down the urban hierarchy and across the life course. PNAS 102, 43: 15313-15318.

Plummer, K. Telling Sexual Stories: Power, Change, and Social Worlds. London: Routledge.

Podmore, J. 2001. Lesbians in the Crowd: Gender, Sexuality and Visibility along Montreal's Boul. St. Laurent. Gender, Place and Culture 8, 4: 333-355.

Poon, C.S., and E.M. Saewyc. Out Yonder: Sexual-Minority Adolescents in Rural Communities in British Columbia. American Journal of Public Health 99, 1: 1-7 (advance release).

Portes, A. 1997. Immigration Theory for a New Century: Some Problems and Opportunities. International Migration Review 31, 4: 799-825.

Pratt, G. 1999. From Registered Nurse to Registered Nanny: Discursive Geographies of Filipina Domestic Workers in Vancouver, BC. Economic Geography 75, 3: 215226. 
Price, M., I. Cheung, S. Friedman, and A. Singer. 2005. The World Settles in: Washington, D.C., as an Immigrant Gateway. Urban Geography 261, 1: 61-75.

Prior, J. 2008. Planning for Sex in the City: urban governance, planning and the placement of sex industry premises in inner Sydney. Australian Geographer 39, 3: 339-352.

Promdemonium. 2010. Home page. http://www.promdemonium.ca.

Puar, J. 2010. In the Wake of It Gets Better. The Guardian, November 16.

- 2007. Terrorist Assemblages: Homonationalism in Queer Times. Durham, NC: Duke University Press.

- 2002. Circuits of Queer Mobility: Tourism, Travel, and Globalization. GLQ: A Journal of Gay and Lesbian Studies 8, 1-2: 103-137.

Pryce, Anthony. 2001. 'Some people live out their own snuff movie': knowledge, 'safer' sex and managing desire in the city. Sexual and Relationship Therapy 16, 1: 1534.

Puar, J., D. Rushbrook, and L. Schein. 2003. Sexuality and space: queering geographies of globalization. Environment and Planning D: Society and Space 21, 4: 383-387.

Ravenstein, E. The Laws of Migration. Journal of the Statistical Society of London 48, 2: $167-235$.

Ray, B. 2004. A diversity paradox: Montréal's gay village. Our Diverse Cities 1: 72-75.

Richards, L. 2002. Using NVIVO in Qualitative Research, Version 2.0. Thousand Oaks, CA: Sage Publications/Scalar.

Richardson, D. 2005. Desiring Sameness? The Rise of a Neoliberal Politics of Normalisation. Antipode 37, 3: 515-535.

Rimmerman, C.A. 2002. From Identity to Politics: Lesbian and Gay Movements in the United States. Philadelphia: Temple University Press.

Robinson, D.J., and D. Kimmel. 1994. The Queer Career of Homosexual Security Vetting in Cold War Canada. The Canadian Historical Review 75, 3: 319-345.

Rosario, M., Scrimshaw, E.W., and J. Hunter. 2006. A Model of Sexual Risk Behaviors among Young Gay and Bisexual Men: Longitudinal Associations of Mental Health, Substance Abuse, Sexual Abuse, and the Coming-Out Process. AIDS Education and Prevention 18, 5: 444-460. 
Rose, G. 1993. Feminism and geography: the limits of geographical knowledge. Minneapolis: University of Minnesota Press.

Rumbaut, R. 1997. Introduction: Immigration and Incorporation. Sociological Perspectives 40, 3: 333-338.

Rushbrook, D. 2002. Cities, queer space, and the cosmopolitan tourist. Gay and Lesbian Quarterly 8, 1-2: 183-206.

Saewyc, E.M., Y. Homma, C.L. Skay, L.H. Bearinger, M.D. Resnick, and E. Reis. 2009. Protective Factors in the Lives of Bisexual Adolescents in North America. American Journal of Public Health 99, 1: 1-7.

Sandfort, T.M., R. de Graaf, R.V. Bijl and P. Schnabel. 2001. Same-sex behavior and psychiatric disorders. Archives of General Psychiatry 58: 85-91.

Savin-Williams, R. 2001. Suicide Attempts among Sexual Minority Youths: Population and Measurement Issues. Journal of Consulting and Clinical Psychology 69, 6: 983-991.

Schlosser, K. 2008. Biopolitical Geographies. Geography Compass 2, 5: 1621-1634.

Schwanen, T. 2006. On 'arriving on time,' but what is 'on time'? Geoforum 37: 882-894.

Schwiter, K. 2010. Anticipating the transition to parenthood: the contribution of Foucaultian discourse analysis to understanding life-course patterns. Area, DOI: 10.1111/j.1475-4762.2010.00975.x.

Sedgwick, E.K. 1990. Epistemology of the Closet. Berkeley, CA: University of California Press.

Sibalis, M. 2004. Urban Space and Homosexuality: the Example of the Marais, Paris' Gay Ghetto. Urban Studies 41: 1739-1758.

Silvey, R. 2004. Power, difference and mobility: feminist advances in migration studies. Progress in Human Geography 28, 4: 490-506.

Silvey, R., and V. Lawson. 1999. Placing the Migrant. Annals of the Association of American Geographers

Simon, W., and J.H. Gagnon. 1986. Sexual scripts: Permanence and change. Archives of Sexual Behavior 15, 2: 97-120.

Sinfield, A. 2000. Diaspora and hybridity: queer identities and the ethnicity model. In N. Mirzoeff (ed.), Diaspora and Visual Culture: Representing Africans and Jews. London: Routledge, pp. 95-114. 
Smith, M. 2008. Political Institutions and Lesbian and Gay Rights in the United States and Canada. New York: Routledge.

- 2005 (a). Social Movements and Judicial Empowerment: Courts, Public Policy, and Lesbian and Gay Organizing in Canada. Politics \& Society 33, 2: 327-353.

- 2005 (b). Resisting and reinforcing neoliberalism: lesbian and gay organizing at the federal and local levels in Canada. Policy \& Politics 33, 1: 75-94.

- 2004. Segmented networks: Linguistic practices in Canadian lesbian and gay rights organizing. Ethnicities 4, 1: 99-124.

- Smith, M. 1998. Social Movements and Equality Seeking: The Case of Gay Liberation in Canada. Canadian Journal of Political Science 31, 2: 285-309.

Social Planning Council of Ottawa. 2003. Ottawa's Families and Households: A Profile, 1996-2001.

Sothern, M. 2004. (Un)Queer Patriarchies: Or, What We Think When We Fuck. Antipode 36, 2: 183-190.

Sparke, M. 1996. Displacing the field in fieldwork, masculinity, metaphor and space. In Nancy Duncan (ed.), Bodyspace: Destabilizing Geographies of Gender and Sexuality. London: Routledge, pp. 212-233.

Statistics Canada. 2010. Population of Census Metropolitan Areas (2006 Census Boundaries). http://www40.statcan.ca/01/cst01/demo05-aeng.htm.

- 2006. Census of Canada. Special tabulation of partnered same-sex households in Canada and citizenship of partners, by Canada, Ottawa-Gatineau, Toronto, Montreal, and Vancouver Census Metropolitan Areas. Received from: Brian Ray, Department of Geography, University of Ottawa.

Stough, R.R. 2000. The Greater Washington Region: A Global Gateway Region, in Andersson, E. and Andersson, D.E. (eds.), Global Gateway Regions: Gateways to the Global Economy. Chelthenham, UK: Edward Elgar, pp. 105-123.

Strauss, A. 1990. Qualitative Analysis for social scientists. Cambridge, UK: Cambridge University Press.

Strauss, A., and J. Corbin. 1990. Basics of qualitative research: Grounded theory procedures and techniques. Newbury Park, CA: Sage.

Supreme Court of Canada. 1995. Judgments of the Supreme Court of Canada. Egan v. Canada, 2 S.C.R. 513. http://scc.lexum.umontreal.ca/en/1995/1995scr-2513/1995scr2-513.html. 
- 1991. Judgments of the Supreme Court of Canada. Osborne v. Canada (Treasury Board), 2 S.C.R. 69. http://scc.lexum.umontreal.ca/en/1991/1991scr269/1991scr2-69.html.

Sullivan, N. 2003. A Critical Introduction to Queer Theory. Armadale: Melbourne Publishing.

Taylor-Vaisey, N. 2009. Does Ottawa suffer from gay brain drain? Capital Xtra, May 27. http://www.xtra.ca/public/printStory.aspx?AFF_TYPE=2\&STORY_ID=6832.

Thomas, W.I., and F. Znaniecki. 1981-1920. The Polish Peasant in Europe and America. New York: Octagon Books.

Troiden, R.R. 1989. The formation of homosexual identities. Journal of Homosexuality $17,43-73$.

Turner, H.A., R.B. Hays, and T.J. Coates. 1993. Determinants of Social Support among Gay Men: The Context of AIDS. Journal of Health and Social Behavior 34, 1: 37 -53 .

U.S. Census Bureau. 2000. Census 2000 Summary File 2 (SF 2) 100-Percent Data. http://factfinder.census.gov/servlet/ DCGeoSelectServlet?ds_name=DEC_2000_SF2_U.

Valentine, G. 2007. Theorizing and Researching Intersectionality: A Challenge for Feminist Geography. The Professional Geographer 59: 10-21.

- 2005. Tell me about ... using interviews as a research methodology. In R. Flowerdew and D. Martin (eds.), Methods in Human Geography: A Guide for Students Doing a Research Project, $2^{\text {nd }}$ edition. Edinburgh Gate: Addison Wesley Longman, pp. 110-127.

- 2000 (ed.). From Nowhere to Everywhere: Lesbian Geographies. Binghamton, NY: Huntington Park Press.

Valentine, G., and T. Skelton. 2003. Finding Oneself, Losing Oneself: The Lesbian and Gay 'Scene' as a Paradoxical Space. International Journal of Urban and Regional Research 27, 4: 849-866.

Valentine, G., T. Skelton, and R. Butler. 2003. Coming out and outcomes: negotiating lesbian and gay identities with, and in, the family. Environment and Planning D: Society and Space 21: 479-499.

Van Damme, M. 2004. Mothers in two types of lesbian families: Stigma experiences, supports, and burdens. Journal of Family Nursing 10: 454-484. 
Vanderbeck, R.M. 2007. Intergenerational geographies: age relations, segregation, and re-engagements. Geography Compass 1/2: 200-221.

Visser, G. 2008. The homonormalisation of white heterosexual leisure spaces in Bloemfontein, South Africa. Geoforum 39: 1344-1358.

Wachter, M.L. 1980. The Labor Market and Illegal Immigration: The Outlook for the 1980s. Industrial and Labor Relations Review 33, 3: 342-354.

Waitt, G. 2006. Boundaries of Desire: Becoming Sexual through the Spaces of Sydney's 2002 Gay Games. Annals of the Association of American Geographers 96, 4: 773 -787 .

Waitt, G., and Gorman-Murray, A. 2011. 'It's about Time You Came Out:' Sexualities, Mobility, and Home. Antipode. DOI: DOI: 10.1111/j.1467-8330.2011.00876.x

- 2010. Journeys and Returns: Home, Life Narratives, and Remapping Sexuality in a Regional City. International Journal of Urban and Regional Research. DOI: $10.1111 / \mathrm{j} .1468-2427.2010 .01006 . x$.

- 2007. Homemaking and Mature Age Gay Men 'Down-Under': Paradox, intimacy, subjectivities, spatialities, and scale. Gender, Place and Culture 14, 5: 569-584.

Walton, G. 2004. Bullying and Homophobia in Canadian Schools: The Politics of Policies, Programs, and Educational Leadership. Journal of Gay \& Lesbian Issues in Education 1, 4: 23-36.

Walther, C.S., and D.L. Poston. 2004. Patterns of gay and lesbian partnering in the larger metropolitan areas of the United States. Journal of Sex Research 41: 201-214.

Warner, T. 1995. Never Going Back: A History of Queer Activism in Canada. Toronto: University of Toronto Press.

Weeks, J. 2007. The world we have won. London: Routledge.

- $\quad$ 1977. Coming Out: Homosexual Politics in Britain from the nineteenth century to the present. London: Quartet Books.

Weeks, J., B. Heaphy, and C. Donovan. 2001. Same Sex Intimacies: Families of Choice and Other Life Experiences. London: Routledge.

Weston, K. 1995. Get thee to a big city: sexual imaginary and the great gay migration. GLQ: A Journal of Lesbian and Gay Studies 2: 253-277. 
- 1991. Families we choose: Lesbians, gays, and kinship. New York: Columbia University Press.

Widmer, E., and G. Ritschard. 2009. The de-standardization of the life course: Are men and women equal? Advances in Life Course Research 14, 1-2: 28-39.

Williams, R., and R. Williams-Morris. 2000. Racism and Mental Health: The African American Experience. Ethnicity \& Health 5, 3-4: 243-268.

Willis, P. Forthcoming. Labouring in silence: Young lesbian, gay, bisexual and queeridentifying workers' negotiations of the workplace closet in Australian organisations. Youth and Society.

- 2009. It really is water off our backs: Young LGBQ people's strategies for resisting and refuting homonegative practices in Australian workplaces. Gay and Lesbian Issues and Psychology Review 5, 3: 134-145.

Wilton, R. D. 1999. Qualitative Health Research: Negotiating Life with HIV/AIDS. Professional Geographer 51, 2: 254-264.

- 1996. Diminished Worlds: the geography of everyday life with HIV/AIDS. Health \& Place 2: 69-83.

Worth, N. 2009. Understanding youth transition as "becoming": Identity, time, and futurity. Geoforum 40, 6: 1050-1060.

Wright, A. 2003. From Sprint to Marathon: A Strategic Plan for Getting in Shape for a New Era of HIV/AIDS in Ottawa. Ottawa: Ottawa-Carleton Council on AIDS. http://www.aco-cso.ca/SprintToMarathon_Eng.pdf.

Yin, R. K. 2003. Case study research, design and methods, $3^{\text {rd }}$ edition. Newbury Park: Sage Publications.

Yue, A. 2008. Same-Sex Migration in Australia: from Interdependency to Intimacy. GLQ: A Journal of Lesbian and Gay Studies 14, 2-3: 239-262.

- 2007. Creative Queer Singapore: The Illiberal Pragmatics of Cultural Production. Gay \& Lesbian Issues and Psychology Review 3, 3: 149-160. 


\section{APPENDICES}

\section{Appendix A. Ethics Approval}

July 13, 2009

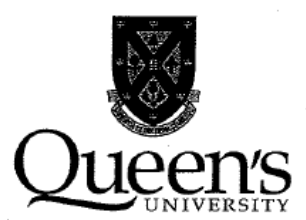

OFFICE OF RESEARCH SERVICES

Mr. Nathaniel Lewis

Fleming Hall, Jemmett Wing, Room 301

Q⿱乛龰een's University

Kingston, Ontario, Canada

$\mathrm{PhD}$ Candidate

Tel $613533-6081$

Fax $613533-6806$

Queen's University

ors@queensu.ca

GREB Ref \#: GGEO-095-09

www.queensu.ca/vpr/

Title: 'Moving 'Out,' Moving On: The Role of Mental and Emotional Health Concerns in the Migration Decisions of Gay Men Living in Ottawa and Washington, D.C."

Dear Mr. Lewis:

The General Research Ethics Board (GREB), by means of a delegated board review, has cleared your proposal entitled "Moving 'Out,' Moving On: The Role of Mental and Emotional Health Concerns in the Migration Decisions of Gay Men Living in Ottawa and Washington, D.C." for ethical compliance with the Tri-Council Guidelines (TCPS) and Queen's ethics policies. In accordance with the Tri-Council Guidelines (article D.1.6) and Senate Terms of Reference (article G), your project has been cleared for one year. At the end of each year, the GREB will ask if your project has been completed and if not, what changes have occurred or will occur in the next year.

You are reminded of your obligation to advise the GREB, with a copy to your unit REB; of any adverse event(s) that occur during this one year period (details available on webpage www.queensu.ca/vpr/greb/addforms.htm\#Adverse ). An adverse event includes, but is not limited to, a complaint, a change or unexpected event that alters the level of risk for the researcher or participants or situation that requires a substantial change in approach to a participant(s). You are also advised that any adverse events must be reported to the GREB within 48 hours.

You are also reminded that all changes that might affect human participants must be cleared by the GREB. For example you must report changes in study procedures or implementations of new aspects into the study procedures on the Ethics Change Form that can be found at

http://www.queensu.ca/vpr/greb/addforms.htm\#Change. These changes must be sent to Linda Frid at the Office of Research Services or FRIDL@queensu.ca prior to implementation. Ms. Frid will forward your request for protocol changes to the appropriate GREB reviewers and / or the GREB Chair.

On behalf of the General Research Ethics Board, I wish you continued success in your research.

Yours sincerely,

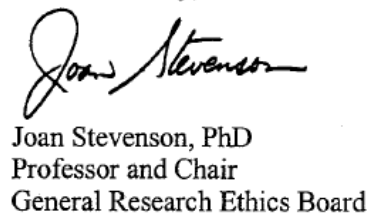

c.c.: Dr. Audrey Kobayashi, Faculty Supervisor

Dr. Beverley Mullings / Dr. Mark Rosenberg, Co-Chairs, Unit REB

Joan Knox, Dept. Admin.

$\mathrm{JS} / \mathrm{gi}$

SHIPPED SEP 122009 


\section{Appendix B. Recruitment Notice}

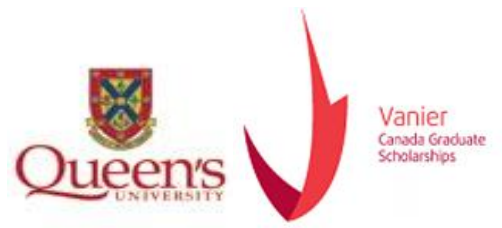

Project Name: "Moving Out, Moving On: The Role of Emotional Health and Well-Being in the Migration Decisions of Gay Men Living in Ottawa, ON and Washington, DC."

\section{Is this research for you?}

These 45- to 60-minute interviews are part of a dissertation project in the Geography Department at Queen's University (Kingston, Ontario, Canada), sponsored by a Queen's Dissertation Grant and a Social Science and Humanities Research Council Vanier Canada Graduate Scholarship. The purpose of the project is to examine how health and well-being affect gay men's decisions to relocate. The researcher is Nathaniel Lewis, a PhD candidate in the Queen's University Geography Department. These interviews, along with a short questionnaire, are a way to find out more (beyond Census data and single-city studies) about how individual gay men and couples in the United States and Canada make their relocation decisions.

\section{Considering participating or want to find out more about this research?}

Contact: Nathaniel Lewis, PhD Candidate, Queen's University Geography

Phone: 202-641-3786

E-mail:6nl12@queensu.ca

\section{Purpose of the study:}

To better understand how places-through community-building, legislation, service availability, and other characteristics - contribute to the emotional health and well-being of gay men and in turn influence their migration and settlement decisions.

\section{What are the benefits of participating in this study?}

You may benefit from sharing your experiences and learning about those of others once the research is complete. The dissertation and any publications produced from it will be made available to all participants in the study. The research findings will also inform future studies on under-researched areas of gay men's health (mental/emotional health, migration decisions).

\section{Compensation:}

None offered, but the researcher will gladly buy coffee/tea/food for the interview.

\section{Consent to Participate?}

Participation in this research is entirely voluntary. Participants may withdraw at any time; in which case their materials will be destroyed. All information is confidential and will be kept in a safe file.

\section{What does the study involve?}

1. Completion of a brief demographic and health questionnaire requiring 5 minutes.

2. Responding to about 10 interview questions during the course of $45-60$ minutes.

When: April-May 2010.

Where: Washington, D.C., locations TBD by researcher and participant. 


\section{Appendix C. Letter of Information and Letter of Consent for Interviews with Self-identified Gay Men}

My name is Nathaniel Lewis and my research project is about the role of mental and emotional health in the migration decisions of gay men. Studies of HIV/AIDS and "gay ghettos" currently dominate health and social geography work on the movement of gay men. My project is to gather the perspectives of individual gay men, health practitioners, activists, and political figures in Ottawa and Washington on how health figures into men's decisions to relocate to certain places. I want to learn how health-related factors such as stigma, human rights legislation, and access to social services may attract gay men to some places and deter them from others. Your oral account and those of other respondents will be used as a central component of my $\mathrm{PhD}$ thesis and will help create one of the first systematic studies of how gay male individuals/couples go about making locational and migration decisions. Interviewees are full participants in the creation of this study. Any work published from this research will be sent (via PDF) to individuals and organizations participating in the study. This research is funded by a Social Science and Humanities Research Council Vanier award, the Queen's University Graduate Dean's Doctoral Field Travel Grant, and an Association of American Geographers Dissertation Research Grant.

Depending on the extent of your migration experience and what you would like to share, this interview could last 45 minutes to one hour. It can also be longer or shorter if you wish. I'll propose a neutral interview location (e.g., a coffee shop), but the interview can be done wherever is convenient for you. If I have follow-up questions, I may contact you for an additional interview. You may also contact me at any time to add to, correct, or remove information your file. Also, if you know anyone else who has similar experiences of relocating to and settling in Ottawa or Washington, and you would like to share their name, I would like to know about them. I will not disclose your referral if you wish. If the interview process creates distress, I can refer you to an appropriate service such as counseling/social support network. Your participation is voluntary. If you opt to withdraw, please notify me of this decision by e-mail. All records of this interview will be destroyed if you withdraw. You can also decide to bypass particular interview questions and/or propose additional questions.

Interviewees will give relevant details of their age, occupation, recent and past relocation, and self-assessed mental and emotional health status. Once transcribed, the interviews will be stored in both a "safe" file (i.e., on flash drive or CD only) as well as a "working" file format that will attach a randomly selected alternate surname to each interview. Alternate surnames will also be used in any publications produced from the study.

Interviews will be digitally recorded. At the bottom of the form please indicate whether I have permission to record your account. If you do not want your account or story to be recorded, I can take notes. My research will result in a $\mathrm{PhD}$ thesis as well as shorter publications (academic papers, books, book chapters) and presentations open to the general public. My completed thesis will have digital and transcribed copies of all interviews in its appendix unless it is clear that you do not wish your interview to be included. Following the completion of the study, all digital recording files will be destroyed and electronic transcription (Word) files will be deleted.

If you have any questions, concerns or complaints about the research procedures, you can contact the researcher, Nathaniel Lewis, the researcher's supervisors in the Queen's Geography Department, Audrey Kobayashi, or the Chair of General Research Ethics Board at Queen's University, Joan Stevenson.

Nathaniel Lewis, Ph.D. Candidate in Geography

Queen’s University, Kingston, Ontario, 6n112@queensu.ca, 613-533-6000 


\section{Additional contacts:}

Audrey Kobayashi

Professor and Graduate Chair

Queen's University, Kingston, Ontario

kobayasi@queensu.ca 613.533.3035
Dr. Joan Stevenson

Chair, General Research Ethics Board

Queen's University, Kingston, Ontario

joan.stevenson@queensu.ca 613.533.6288

Letter of Consent for the research project titled: Moving "Out," Moving On: Well-Being and Migration Decisions among Gay Men Living in Ottawa and Washington, D.C.

$\mathrm{I}$, have read the Letter of Information and all my questions have been answered satisfactorily. I am aware of the research project's goals, and I understand that my oral account will be digitally recorded. I am aware that I can contact the researcher, Nathaniel Lewis, the researcher's academic supervisor, Audrey Kobayashi at Queen's University, or Dr. Joan Stevenson, the Chair of the General Research Ethics Board at Queen's University, with complaints, comments, questions or concerns. I am aware that my participation is completely voluntary and that I am free to withdraw at any time. I am also aware that the researcher will take all precautions to ensure confidentiality.

Please sign and date this form. You will be given a copy of this letter for your records.

Name:

Date:

Signature:

By initialling this statement below:

I am granting permission for the researcher to use a digital recorder.

I would prefer that the researcher take notes only.

I hereby give consent to the researcher to use my identity in this research.

I prohibit the researcher from using my identity in this research.

I am granting permission for the researcher to attribute my name to facts or quotes. 


\section{Appendix D: Letter of Information and Letter of Consent for Interviews with Key Informants}

Letter of Information for the research project titled: Moving “Out," Moving On: Well-Being and Migration Decisions among Gay Men Living in Ottawa and Washington, D.C.

My name is Nathaniel Lewis and my research project is about the role of mental and emotional health in the migration decisions of gay men. Currently, studies of HIV/AIDS and individual "gay ghettos" tend to dominate health and social geography work on the movement of gay men. My project is to gather the perspectives of individual gay men, as well as health practitioners, activists, and political figures in Ottawa and Washington on how health figures into men's decisions to relocate to certain places. I want to learn how health-related factors such as stigma, human rights legislation, and access to social services may attract gay men to some places and deter them from others. Your oral account and those of other respondents will be used as a central component of my $\mathrm{PhD}$ thesis and will help create one of the first systematic, publishable studies of how gay male individuals and couples go about making their locational and migration decisions. Interviewees are full participants in the creation of this study. Any work published from this research will be sent (via PDF) to individuals and organizations participating in the study. This research is funded by a Social Science and Humanities Research Council Vanier award, the Graduate Dean's Doctoral Field Travel Grant at Queen's University and an Association of American Geographers Dissertation Research Grant.

Depending on the nature of your work and what you are able to share, this interview could last 45 minutes to one hour. It can also be longer or shorter if you wish. I can conduct the interview wherever is most convenient for you. If I have follow-up questions, I may contact you for an additional interview. You may also contact me at any time to add to, correct, or remove information from your file. Also, if you know anyone else involved with gay politics, health care, activism, or social life in Ottawa or Washington, and you would like to share their name, I would like to know about them. I will not disclose your referral if you wish. Your participation is voluntary. If you opt to withdraw, please notify me of this decision by e-mail. All records of this interview will be destroyed if you withdraw. You can also decide to bypass particular interview questions and/or propose additional questions.

Key informants will give relevant details of the work or services that they perform (or that their organization performs) and of the health and social benefits and/or challenges that gay men experience while living in Ottawa or Washington. Once transcribed, the interviews will be stored in a "safe" file (i.e., on flash drive or CD only).

Interviews will be digitally recorded. At the bottom of the form please indicate whether I have permission to record your account. If you do not want your account to be recorded, I can take notes. My research will result in a $\mathrm{PhD}$ thesis as well as shorter publications (academic papers, books, book chapters) and presentations open to the general public. My completed thesis will have digital and transcribed copies of all interviews in its appendix unless it is clear that you do not wish your interview to be included. Following the completion of the study, all digital recording files will be destroyed and electronic transcription (Word) files will be deleted.

If you have any questions, concerns or complaints about the research procedures, you can contact the researcher, Nathaniel Lewis, the researcher's supervisors in the Queen's Geography Department, Audrey Kobayashi, or the Chair of General Research Ethics Board at Queen's University, Joan Stevenson. 
Nathaniel Lewis

$\mathrm{PhD}$ Candidate in Geography

Queen's University, Kingston, Ontario

6nl12@queensu.ca 613.533.6000

\section{Additional contacts:}

Audrey Kobayashi

Professor and Graduate Chair

Queen's University, Kingston, Ontario

kobayasi@queensu.ca 613.533.3035
Dr. Joan Stevenson

Chair, General Research Ethics Board

Queen's University, Kingston, Ontario

joan.stevenson@queensu.ca 613.533.6288

Letter of Consent for the research project titled: Moving "Out," Moving On: Well-Being and Migration Decisions among Gay Men Living in Ottawa and Washington, D.C.

$\mathrm{I}$, , have read the Letter of Information and all my questions have been answered satisfactorily. I am aware of the research project's goals, and I understand that my oral account will be digitally recorded. I am aware that I can contact the researcher, Nathaniel Lewis, the researcher's academic supervisor, Audrey Kobayashi at Queen's University, or Dr. Joan Stevenson, the Chair of the General Research Ethics Board at Queen's University, with complaints, comments, questions or concerns. I am aware that my participation is completely voluntary and that I am free to withdraw at any time. I am also aware that the researcher will take all precautions to ensure confidentiality.

Please sign and date this form. You will be given a copy of this letter for your records.

Name:

Date:

Signature:

By initialling this statement below:

I am granting permission for the researcher to use a digital recorder.

I would prefer that the researcher take notes only.

I hereby give consent to the researcher to use my identity in this research.

I prohibit the researcher from using my identity in this research.

I am granting permission for the researcher to attribute my name to facts or quotes.

I am granting permission for the researcher to attribute the name of my organization to facts or quotes. 


\section{Appendix E. Pilot Study Interview Schedule for Self-identified Gay Respondents}

Age Race/Ethnicity

Current city of residence

Other places lived

Health and Wellness Self-Assessment

1. I like who I am

2. I am not an easy person to get along with

3. I am basically a healthy person

4. I give up too easily

5. I have difficulty concentrating

6. I am happy with my family relationships

7. I am comfortable being around people

How much trouble did you have with:

8. Sleeping

9. Getting tired easily

10. Feeling depressed or sad

11. Nervousness

How often did/do you:

12. Socialize with other people

13. Take part in weekly social or recreation activities
Occupation

Last place lived

Time passed since last migration

Please respond to each statement with 2 check marks, one under the BM column for your assessment "before moving" and a second under AM for "after moving."

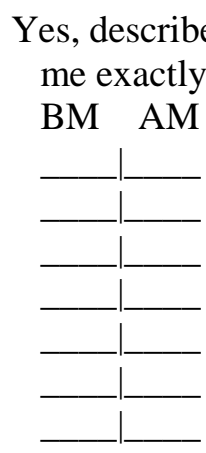

Somewhat

No, doesn't describes me describe me BM AM
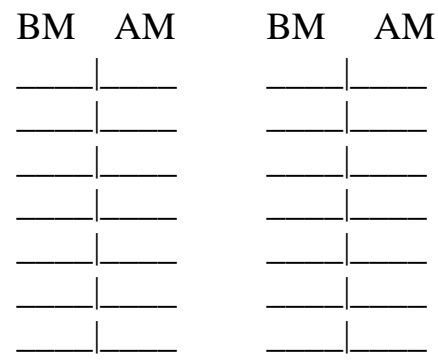

\section{None}
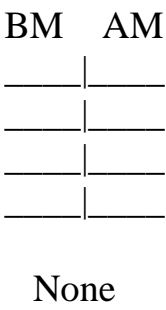

BM AM

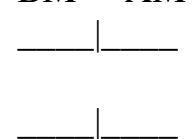

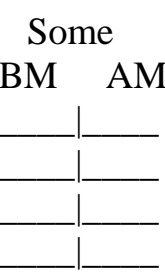

Some

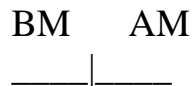

A Lot

BM AM

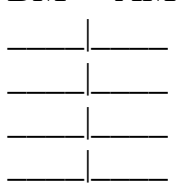

A Lot

BM AM

Rank the following reasons (1-7) for moving here:

1. Employment

2. Culture/Nightlife

3. Improved social life

4. Finding a partner

5. More liberal/open norms

6. Interest in politics/activism

7. Other (please specify) 
Migration Decisions

1. What attracted you to this city?

2. What caused you to leave your previous place of residence?

3. Did your mental health or wellness factor into your decision to move here? If so, what types of problems or challenges were you encountering back at home?

4. Did "coming out" or identity formation play a role in your decision to move here?

5. Do you feel that this place is a final destination for you? If so, why? If not, why and where might you move to in the future?

\section{Gauging Social and Health Infrastructure of the Gay Community}

6. How does the "gay community" here facilitate or hinder your wellbeing?

7. What aspects of the city (outside of the "community") make it easy (or difficult) to be gay here?

8. What kinds of activities do you take part in here?

9. Are there certain institutions (social life, activism, sports, health care, etc.) that play a role in your life here? How do these differ from what was available to you in the last place you lived or other places you lived before that?

\section{Gauging Stigma and Discrimination}

10. How would you characterize perceptions of homosexuality in this city? How do these compare with places that you have lived in the past?

11. Do you feel that other gay men view the city similarly, or are there certain individual characteristics (age, race, etc.) that influence the experiences of yourself and others?

12. Have you experienced particular incidents here that made you feel anxious or unwelcome?

13. Are there elements of stigma or discrimination here that would cause you to move elsewhere in the future? 


\section{Appendix F. Pilot and Final Interview Schedule for Key Informants}

Role of Organization or Service Provider

1. What role do you (or does your organization) play in facilitating the health and well-being of the gay community in this city?

2. What are the particular services you provide?

3. What other groups or organizations do you work with?

Migration Decisions of Gay Men and their Relationships to Health

4. In your opinion, where do gay men who have moved here typically come from and why do they choose this city as their destination?

5. What are some of the challenges (social, economic) that gay men typically face when they move to this community?

6. Are there particular health-related issues that gay men may face that drive them to resettle here?

7. Are there certain health-related concerns that gay men experience in relation to migrating and resettling in general?

Gauging Social and Health Infrastructure of the Gay Community

8. What are some of the emotional difficulties that men who are either using your services or involved with your organization typically report?

9. Are there service gaps in this city that have not yet been filled? How do these gaps compare with those in other cities that gay men may move to?

10. Are there intersecting characteristics of gay men (age, race, socioeconomic status) that might affect the types of services they use and the frequency with which they use them?

\section{Gauging Stigma and Discrimination}

11. How would you characterize perceptions of homosexuality in this city?

12. If there is stigma or discrimination against gay men, how do they typically manifest in the experiences of gay men who live here?

13. Are there adequate coping structures here for gay men to mitigate some of the stigma or stress they experience? 


\section{Appendix G. Final Interview Schedule for Self-identified Gay Respondents}

How old are you?

How would you identify yourself in terms of race or ethnicity?

Next, I'm going to compile a short migration history, so I want you to tell me the last few places that you lived and the dates that you lived in each one.

\begin{tabular}{|l|l|}
\hline City & $\begin{array}{l}\text { Dates lived there (mo./year-mo./year, min. 6 } \\
\text { mos.) }\end{array}$ \\
\hline & \\
\hline & \\
\hline & \\
\hline & \\
\hline
\end{tabular}

And where were you born?

Next, I'm going to ask how you would assess several different aspects of life before versus after moving to Ottawa. First, I will give you an area of life, and you can give me one of these responses: "improved" "declined" "stayed the same," or "not applicable." I may ask you why a certain aspect of life got better or worse after leaving and moving to Ottawa.

I'll start with the most general questions:

\begin{tabular}{|l|l|l|l|l|}
\hline & Improved & Declined & $\begin{array}{l}\text { Stayed } \\
\text { the } \\
\text { same }\end{array}$ & $\begin{array}{l}\text { Not } \\
\text { applicable }\end{array}$ \\
\hline $\begin{array}{l}\text { How would you rate your overall } \\
\text { happiness since moving here? }\end{array}$ & & & & \\
\hline $\begin{array}{l}\text { How would you rate your overall } \\
\text { health since moving here? }\end{array}$ & & & & \\
\hline
\end{tabular}

Now I want to ask about a number of more specific factors:

\begin{tabular}{|l|l|l|l|l|}
\hline & Improved & Declined & $\begin{array}{l}\text { Stayed } \\
\text { the } \\
\text { same }\end{array}$ & $\begin{array}{l}\text { Not } \\
\text { applicable }\end{array}$ \\
\hline Self-esteem? (Why?) & & & & \\
\hline Relationships with friends? (Why?) & & & & \\
\hline Relationships with family? (Why?) & & & & \\
\hline Ability to complete tasks? (Why?) & & & & \\
\hline Concentration? (Why?) & & & & \\
\hline $\begin{array}{l}\text { Level of comfort around other people? } \\
\text { (Why?) }\end{array}$ & & & & \\
\hline
\end{tabular}


For these factors, I want you to tell me if the following factors "increased," "decreased," "stayed the same" or were "Not Applicable."

\begin{tabular}{|l|l|l|l|l|}
\hline & Increased & Decreased & $\begin{array}{l}\text { Stayed } \\
\text { the same }\end{array}$ & $\begin{array}{l}\text { Not } \\
\text { applicable }\end{array}$ \\
\hline Amount of sleep? (Why?) & & & & \\
\hline Quality of sleep? (Why?) & & & & \\
\hline Energy level? (Why?) & & & & \\
\hline Frequency of feeling sad? (Why?) & & & & \\
\hline $\begin{array}{l}\text { Frequency of feeling depressed? } \\
\text { (Why?) }\end{array}$ & & & & \\
\hline Frequency of feeling nervous? & & & & \\
\hline $\begin{array}{l}\text { Frequency of feeling anxious or } \\
\text { panicked? (Why?) }\end{array}$ & & & & \\
\hline Frequency of using alcohol? (Why?) & & & & \\
\hline Frequency of using tobacco? (Why?) & & & & \\
\hline $\begin{array}{l}\text { Frequency of using other substances? } \\
\text { (Why?) }\end{array}$ & & & & \\
\hline $\begin{array}{l}\text { Frequency of socializing with other } \\
\text { people? (Why?) }\end{array}$ & & & & \\
\hline $\begin{array}{l}\text { Frequency of taking part in weekly } \\
\text { social or recreation activities? (Why?) }\end{array}$ & & & & \\
\hline
\end{tabular}

Have you experienced significant changes in any of these areas of life during or after any of your previous migration experiences?

Now, we'll move on to the open-ended questions. Just try to answer in as much detail as possible.

\section{Migration Decisions}

1. What was your most important reason for moving to Ottawa? Can you expand on this? What were the other major reasons that you moved here? What was your thought process in determining that you were going to move here?

2. Why did you leave to come to Ottawa?

3. How did this (event, experience, feeling, etc.) affect you?

4. Were there other ways that being gay was constraining your opportunities in that place? 
Gauging Social and Health Infrastructure in the Gay Community

5. What do you remember experiencing or feeling when you first settled here? Were there any difficulties that you faced in adjusting?

6. What role does the gay community here play in your everyday life?

7. What aspects of Ottawa apart from the gay community make it easy or difficult to be gay here?

8. Are there certain institutions, such as religious or political organizations, that play a role in your life here? How do these differ from what was available to you in the last place you lived or other places you lived before that?

\section{Gauging Stigma}

9. What are the attitudes toward homosexuality in Ottawa? How does this compare with places that you lived in before?

10. Have you experienced incidents or events here that made you feel anxious or unwelcome?

11. Do you think that there are other factors, like age or (given ethnicity/race) that play a role in these experiences?

\section{The Future/Additional Demographic Information}

12. Looking forward five years from now, do you still see yourself in Ottawa or do you see yourself somewhere else?

13. Do you feel that this place is a final destination for you? If so, why? If not, why and where might you move to in the future?

14. What is your occupation? And what is the highest degree you've achieved? If you have a partner, what is his occupation? What's your approximate (family) income? 


\section{Appendix H. Example of Coding Process Step 1}

JB: I take better care of myself. I, um, have much more of a routine ... like I have a much stronger routine.

NL: Mm-hmm, mm-hmm.

JB: Um, I just ... I'm not as bogged down by the stress that was involved in living in that—in Welland.

NL: Yeah.

JB: So I'm able to kind of focus on other things.

NL: Yeah. What was stressful about living in Welland?

JB: Just the general, um, population ... that made it very hard for me to comfortable being out. \#

NL: Yeah. And were you out at that point?

JB: Um, not really.

NL: Yeah.

JB: Kind of, but not, you know to the same capacity as I am here.

NL: Mm-hmm, mm-hmm.

JB: Yeah.

NL: I mean so how did that make you feel? I don't know. How did you notice that like manifesting itself in day-to-day life?

JB: Um, well in ... in high school, because there was a lot-it was a very kind of narrowminded, homophobic high school-I ... I developed ulcers, um, I got, um ... like I got really, really bad migraines, and just a lot of kind of stress-related health issues. @

NL: Yeah.

JB: That were kind of having a really, really big impact on me ... (NL: Mm-hmm ...) ... so, uh, once I kind of left the area, I felt a lot better. \# 


\section{Appendix I. Example of Coding Process Step 2}

\section{THEME 1: COMING OUT (\#)}

Terms searched: coming out, come out, came out, coming-out, followed by general scan.

CO1: Large city, critical mass, density, gravitational

CO2: Anonymity, distance from previous identity

CO3: Feeling of stasis, inability to advance, stunting of relationships

CO4: Out of place, discriminated against

CO5: Reintegration

CO6: Brief trips for clarity, self-discovery

CO7: Fear of rejection

CO8: Role of parents

CO9: Distance from family

CO10: The opposite - not leaving until coming out (migration as a marker of stages)

CO11: Avoiding burdening people

CO12: Research processes for determining new location

CO13: Subconscious awareness

CO14: Transition after coming out

DF: In that it's okay for a lot of clubs to do that. I mean, when I was coming out, like you were gay, that was on the edge ... (NL: Right.) ... and even then it was barely on the edge ... (NL: Mm-hmm, mm-hmm.) ... you know?

DF: But where I grew up, you know, we were surrounded by the Bible Belt, so all I had to do was drive 20 minutes, and all of a sudden I could get yelled at. \# (James) CO4

RB: Um, I was able to come out gradually to the family, uh, being away, and I was, yes, I think being away actually helped, that I felt able to do it eventually.

RB: Um it took, took a while, I would, you know, I told sisters first and then, and then ... but feeling grounded, more grounded that I was confident enough to have that - those conversations, and knew they wouldn't be devastating to me.

RB: I think ... I don't know if I would have thought about it in rational terms like that, but I think that's kind of the way it worked, that I was able to ...

RB: But it, I did, yeah, get it figured out, get an identity that I was comfortable with and that felt confident in, and then felt empowered ... (NL: Right.) ... to be strong enough to tell my parents when I knew it was going to be a difficult conversation.

RB: Uh, but, and it went reasonably well. It was difficult to begin with but it's gotten better since. \# (Mark) CO9 